\title{
Not-In-Kind Technologies for Residential and Commercial Unitary Equipment
}

February 2000

\author{
Steve Fischer \\ Solomon Labinov
}

Oak Ridge National Laboratory

Oak Ridge, Tennessee

Prepared by the OAK RIDGE NATIONAL LABORATORY

Oak Ridge, Tennessee 37831

managed by

LOCKHEED MARTIN ENERGY RESEARCH CORP.

for the

U.S. DEPARTMENT OF ENERGY

under contract number DE-AC05-96OR22464 



\section{ACKNOWLEDGEMENTS}

The authors gratefully acknowledge the assistance and support they received from many individuals and organizations. This project would not have been possible without the funding provided by the Department of Energy and the individual efforts of Esher Kweller and John Ryan of DOE. Mr. Kweller, Van Baxter and Phil Fairchild of ORNL, and Karim Amrane of the Air Conditioning and Refrigeration Institute (ARI) provided the advice and direction necessary for a useful evaluation of alternative cycles and concise presentation of operating principles, advantages, disadvantages, and economic feasibility of each technology. Members of the ARI Research and Technology committee and ARTI 21-CR Alternative Cycles subcommittee were instrumental in encouraging DOE to undertake this effort and provided valuable information to the project. Steve Garrett at Penn State University, Carl Zimm at Astronautics of America, Jim Braun at Purdue University, Greg Swift at Los Alamos National Laboratory, Rick Murphy and Robert DeVault of Oak Ridge National Laboratory, and many others provided detailed information about their own research on heat pumping technologies. 


\begin{abstract}
This project was initiated by the Department of Energy in response to a request from the HVAC industry for consolidated information about alternative heating and cooling cycles and for objective comparisons of those cycles in space conditioning applications. Twenty-seven different heat pumping technologies are compared on energy use and operating costs using consistent operating conditions and assumptions about component efficiencies for all of them. This report provides a concise summary of the underlying principals of each technology, its advantages and disadvantages, obstacles to commercial development, and economic feasibility. Both positive and negative results in this study are valuable; the fact that many of the cycles investigated are not attractive for space conditioning avoids any additional investment of time or resources in evaluating them for this application. In other cases, negative results in terms of the cost of materials or in cycle efficiencies identify where significant progress needs to be made in order for a cycle to become commercially attractive.

Specific conclusions are listed for many of the technologies being promoted as alternatives to electrically-driven vapor compression heat pumps using fluorocarbon refrigerants. Although reverse Rankine cycle heat pumps using hydrocarbons have similar energy use to conventional electric-driven heat pumps, there are no significant energy savings due to the minor differences in estimated steadystate performance; higher costs would be required to accommodate the use of a flammable refrigerant. Magnetic and compressor-driven metal hydride heat pumps may be able to achieve efficiencies comparable to reverse Rankine cycle heat pumps, but they are likely to have much higher life cycle costs because of high costs for materials and peripheral equipment. Both thermoacoustic and thermionic heat pumps could have lower life cycle costs than conventional electric heat pumps because of reduced equipment and maintenance costs although energy use would be higher.

There are strong opportunities for gas-fired heat pumps to reduce both energy use and operating costs outside of the high cooling climates in the southeast, south central states, and the southwest. Diesel and IC (Otto) engine-driven heat pumps are commercially available and should be able to increase their market share relative to gas furnaces on a life cycle cost basis; the cost premiums associated with these products, however, make it difficult to achieve three or five year paybacks which adversely affects their use in the U.S. Stirling engine-driven and duplex Stirling heat pumps have been investigated in the past as potential gas-fired appliances that would have longer lives and lower maintenance costs than diesel and IC engine-driven heat pumps at slightly lower efficiencies. These potential advantages have not been demonstrated and there has been a low level of interest in Stirling engine-driven heat pumps since the late 1980's. GAX absorption heat pumps have high heating efficiencies relative to conventional gas furnaces and are viable alternatives to furnace/air conditioner combinations in all parts of the country outside of the southeast, south central states, and desert southwest. Adsorption heat pumps may be competitive with the GAX absorption system at a higher degree of mechanical complexity; insufficient information is available to be more precise in that assessment.
\end{abstract}




\section{TABLE OF CONTENTS}

LIST OF TABLES $\ldots \ldots \ldots \ldots \ldots \ldots \ldots \ldots \ldots \ldots \ldots \ldots \ldots \ldots \ldots \ldots \ldots \ldots \ldots \ldots \ldots$

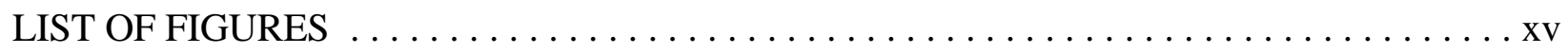

EXECUTIVE SUMMARY $\ldots \ldots \ldots \ldots \ldots \ldots \ldots \ldots \ldots \ldots \ldots \ldots \ldots \ldots \ldots \ldots$ xii

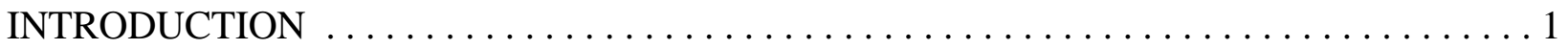

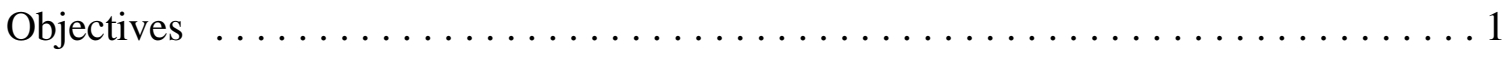

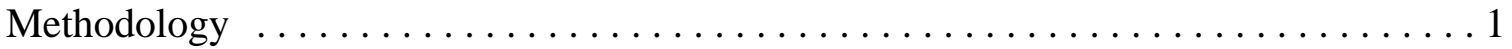

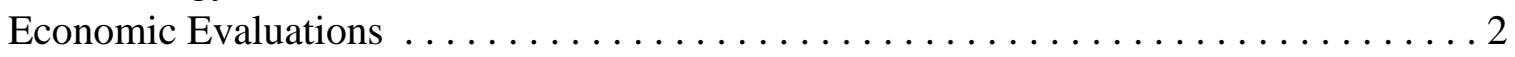

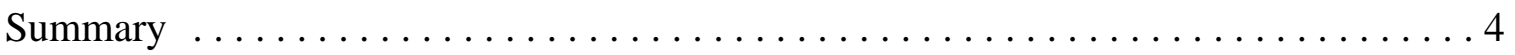

REVERSED RANKINE CYCLE HEAT PUMPS $\ldots \ldots \ldots \ldots \ldots \ldots \ldots \ldots \ldots \ldots \ldots \ldots 7$

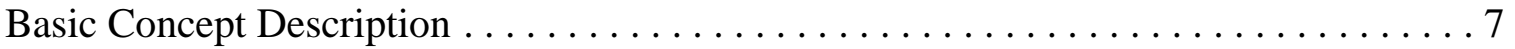

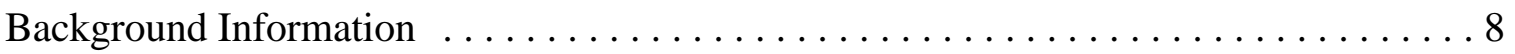

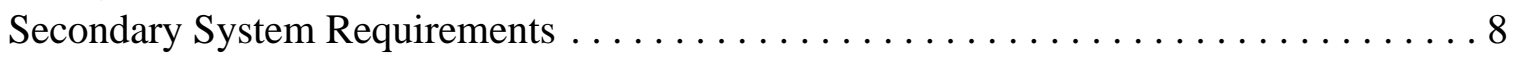

Efficiency Data . . . . . . . . . . . . . . . . . . . . . 9

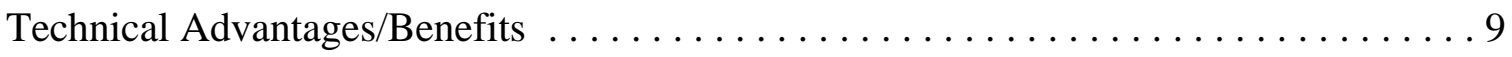

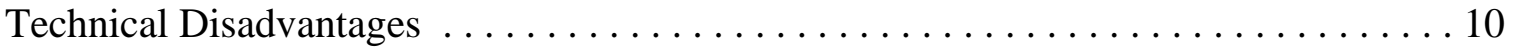

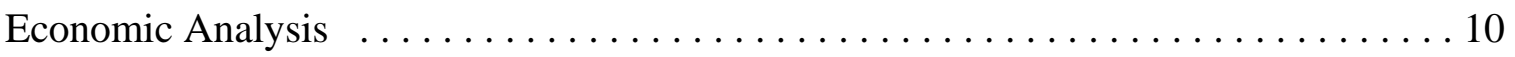

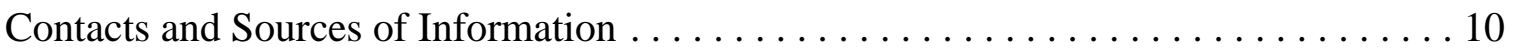

Obvious Holes in Knowledge, Understanding, Information . . . . . . . . . . . . 10

RANKINE CYCLE: HYDROCARBONS $\ldots \ldots \ldots \ldots \ldots \ldots \ldots \ldots \ldots \ldots \ldots \ldots \ldots \ldots$

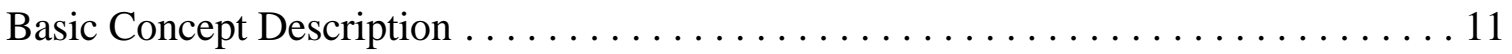

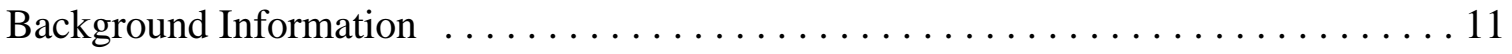

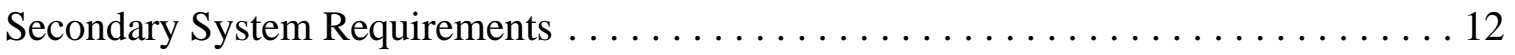

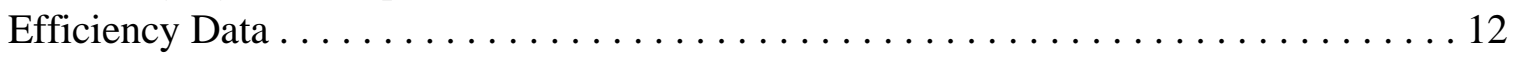

Technical Advantages/Benefits . . . . . . . . . . . . . . . . . . . . 12

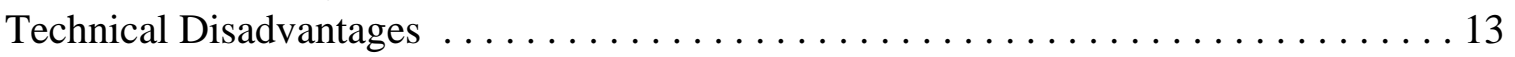

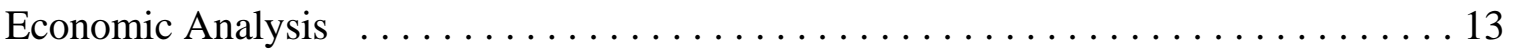

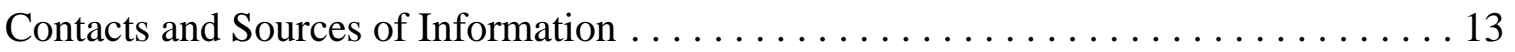

Obvious Holes in Knowledge, Understanding, Information $\ldots \ldots \ldots \ldots \ldots \ldots \ldots$

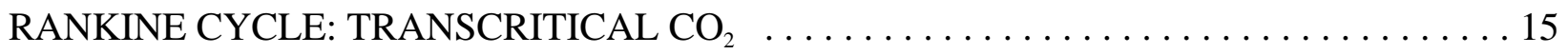

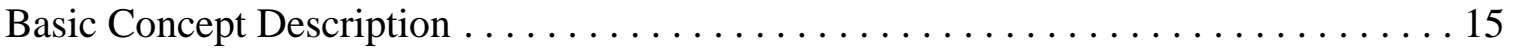

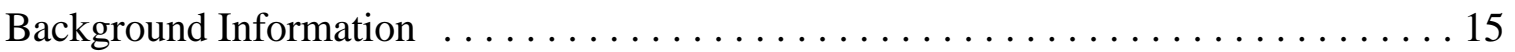

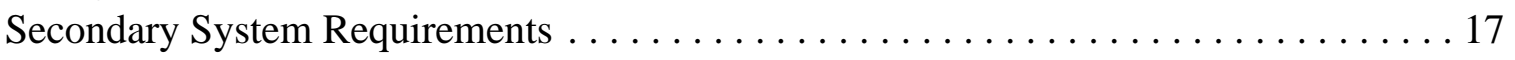

Efficiency Data . . . . . . . . . . . . . . . . . . . . . . . 17 


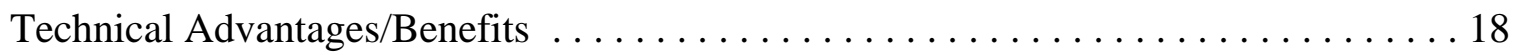

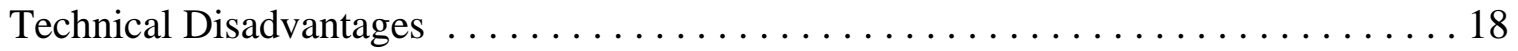

Economic Analysis . ..................................... 19

Contacts and Sources of Information . . . . . . . . . . . . . . . . . . . 19

Obvious Holes in Knowledge, Understanding, Information .............. 20

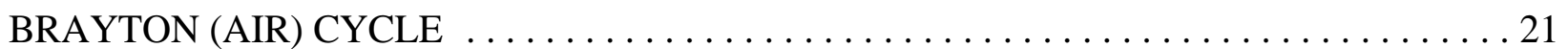

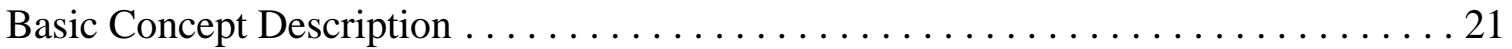

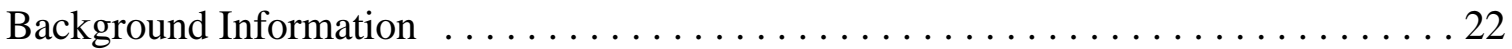

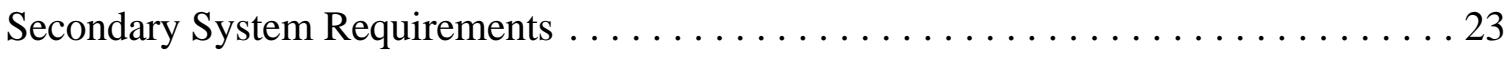

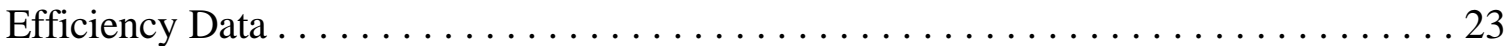

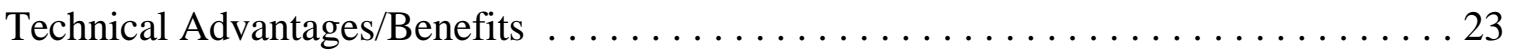

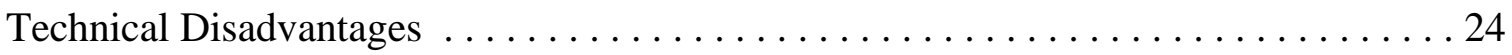

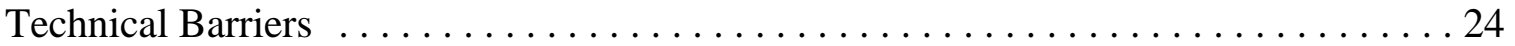

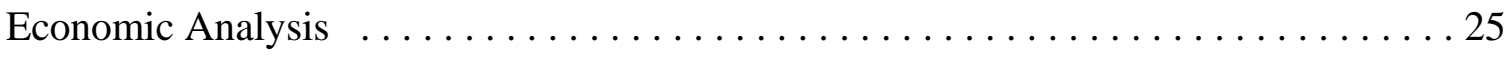

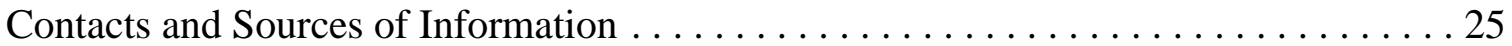

Obvious Holes in Knowledge, Understanding, Information . . . . . . . . . . 25

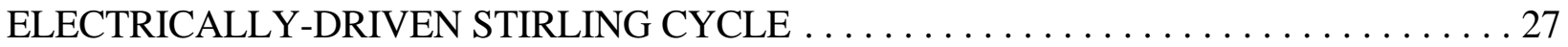

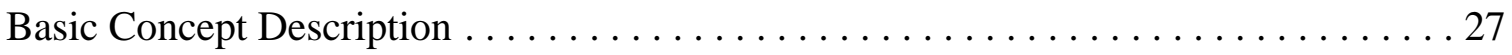

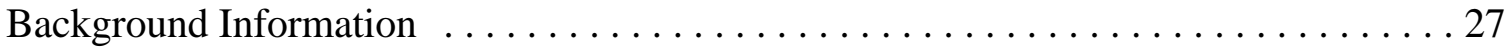

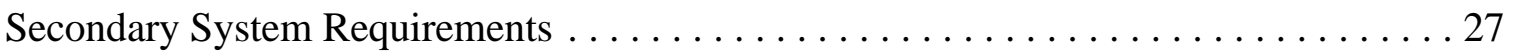

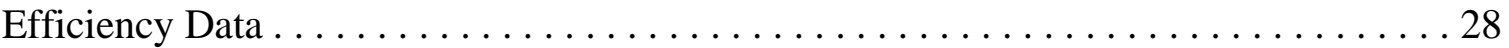

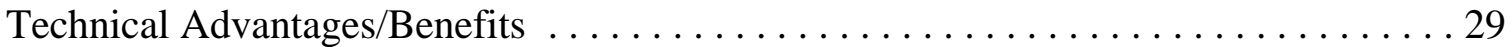

Technical Disadvantages . . . . . . . . . . . . . . . . . . . . . . 29

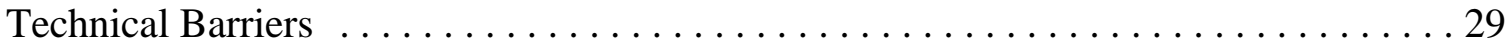

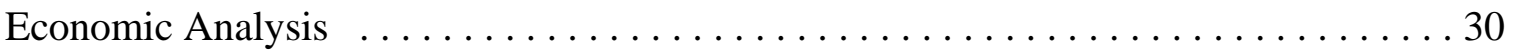

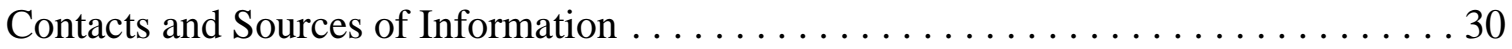

Obvious Holes in Knowledge, Understanding, Information $\ldots \ldots \ldots \ldots \ldots \ldots$

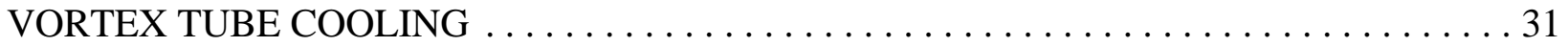

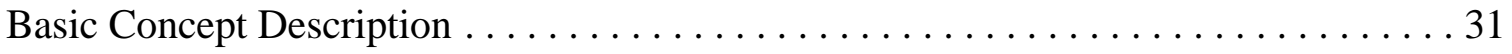

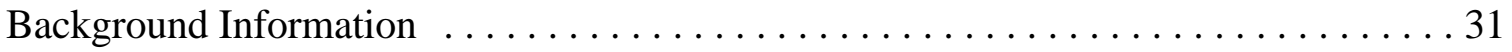

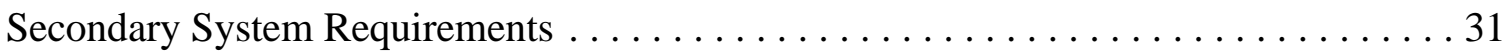

Efficiency Data . . . . . . . . . . . . . . . . . . . . . . . . . . 31

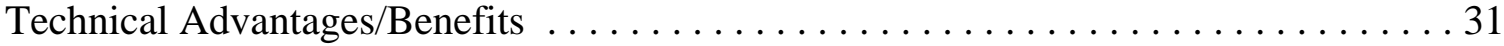

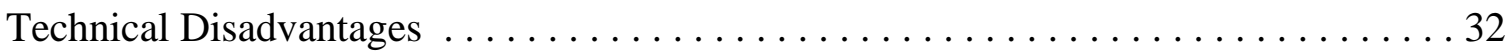

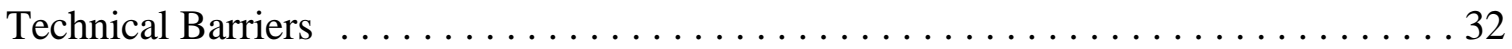

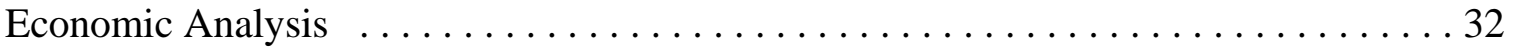

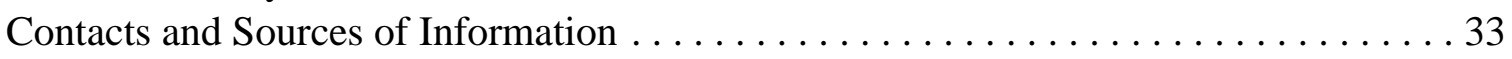

Obvious Holes in Knowledge, Understanding, Information $\ldots \ldots \ldots \ldots \ldots \ldots \ldots$ 
THERMOELECTRIC COOLING . . . . . . . . . . . . . . . . . . . . . . . . . 35

Basic Concept Description .................................. 35

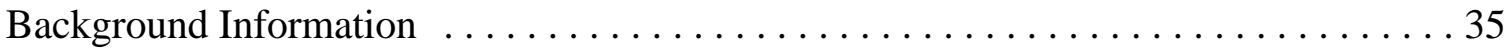

Secondary System Requirements . . . . . . . . . . . . . . . . . . . . . 38

Efficiency Data ........................................... 39

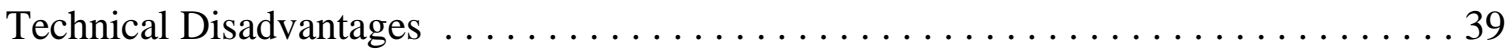

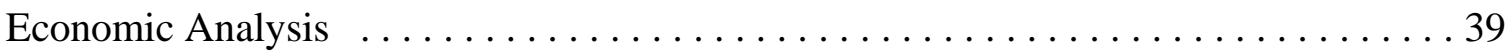

Contacts and Sources of Information $\ldots \ldots \ldots \ldots \ldots \ldots \ldots \ldots \ldots \ldots \ldots \ldots . \ldots \ldots$

Obvious Holes in Knowledge, Understanding, Information ............... 40

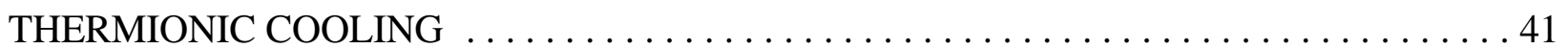

Basic Concept Description ................................. 41

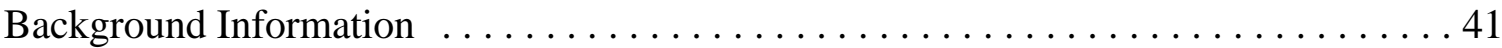

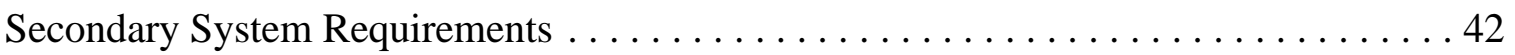

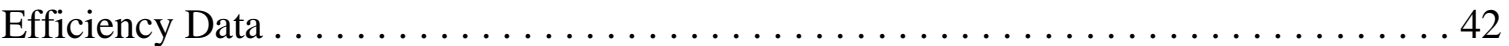

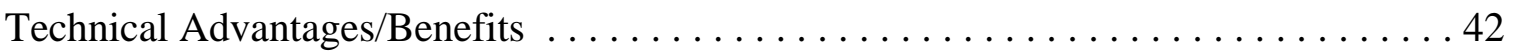

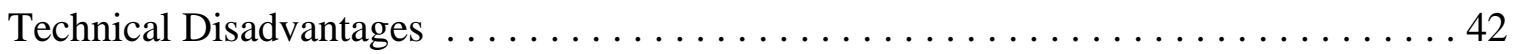

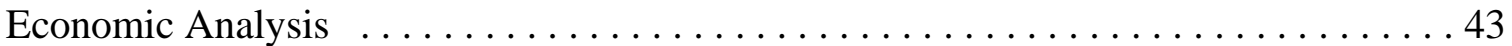

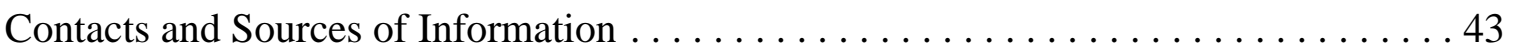

Obvious Holes in Knowledge, Understanding, Information ............... 44

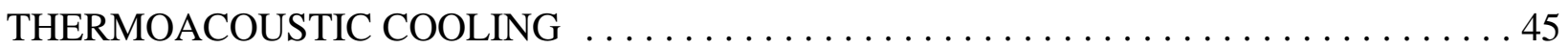

Basic Concept Description ................................. 45

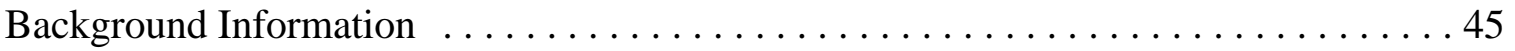

Secondary System Requirements . . . . . . . . . . . . . . . . . . . . . 47

Efficiency Data .................................... 47

Technical Advantages/Benefits . . . . . . . . . . . . . . . . . . . . . . 47

Technical Disadvantages .................................. 47

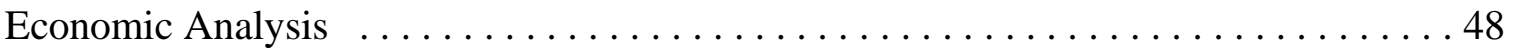

Contacts and Sources of Information . . . . . . . . . . . . . . . . . . . . 49

Obvious Holes in Knowledge, Understanding, Information $\ldots \ldots \ldots \ldots \ldots \ldots \ldots$

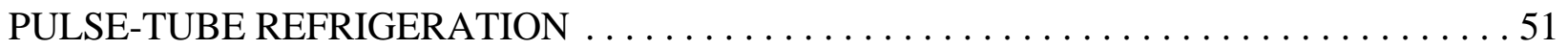

Basic Concept Description ................................. 51

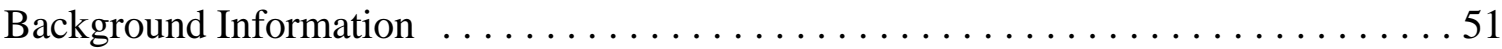

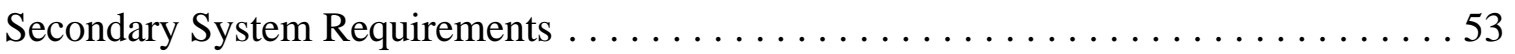

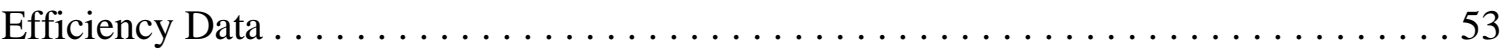

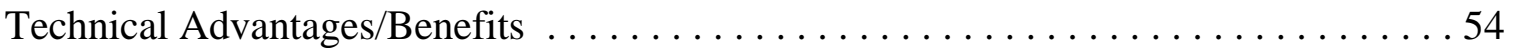

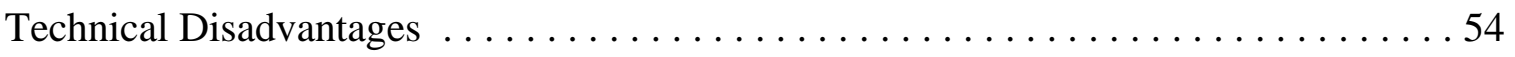

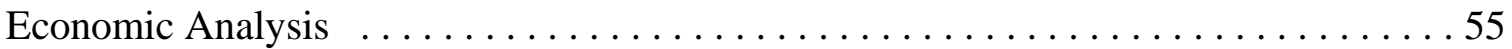




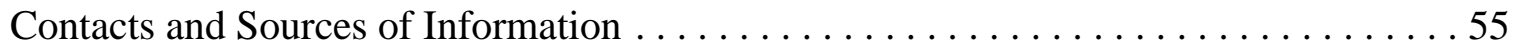

Obvious Holes in Knowledge, Understanding, Information . . . . . . . . . . 56

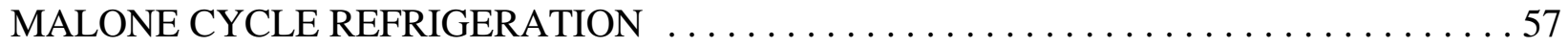

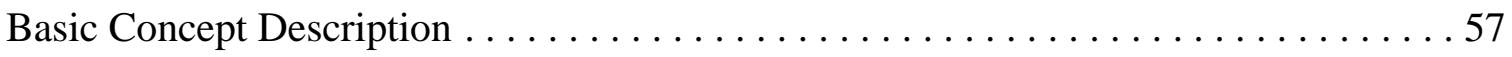

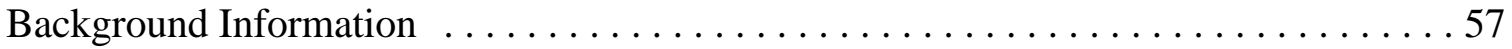

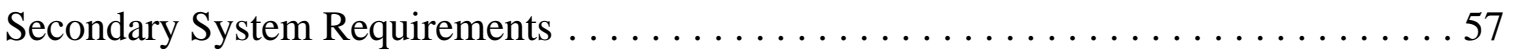

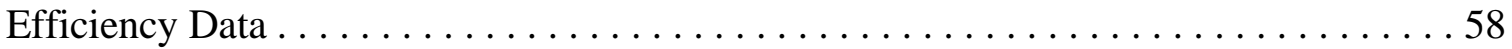

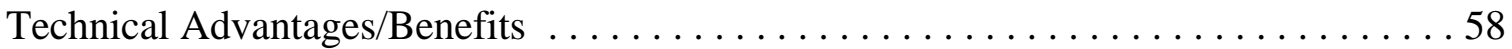

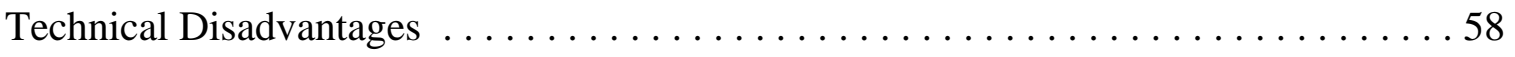

Economic Analysis . . . . . . . . . . . . . . . . . . . . . . 59

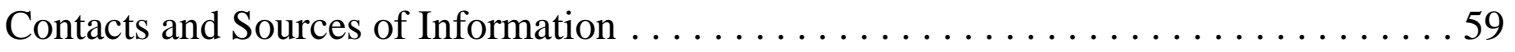

Obvious Holes in Knowledge, Understanding, Information . . . . . . . . . . . 60

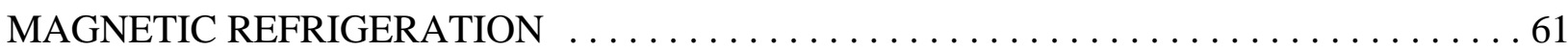

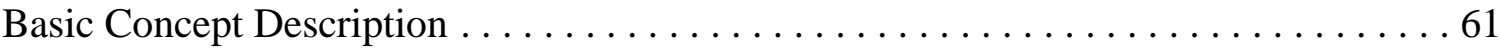

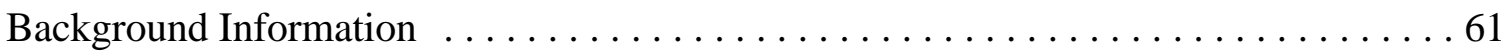

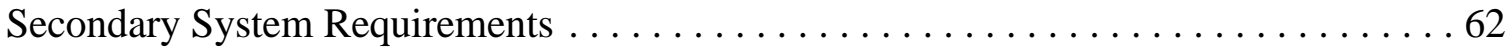

Efficiency Data . . . . . . . . . . . . . . . . . . . . . . . 62

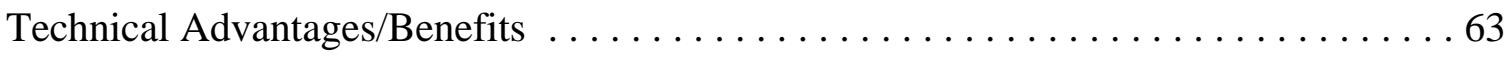

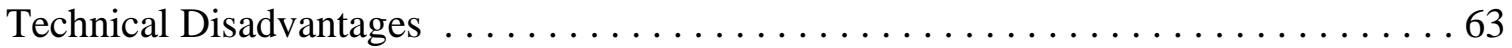

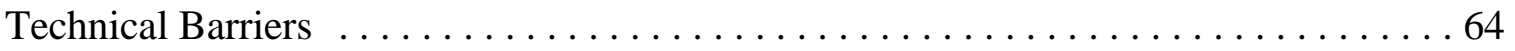

Economic Analysis . . . . . . . . . . . . . . . . . . . . 64

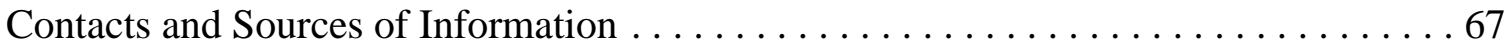

Obvious Holes in Knowledge, Understanding, Information $\ldots \ldots \ldots \ldots \ldots \ldots \ldots$

COMPRESSOR-DRIVEN METAL HYDRIDE HEAT PUMP . . . . . . . . . . . . . . . . . . . 69

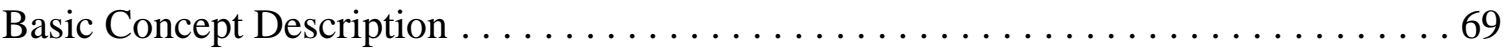

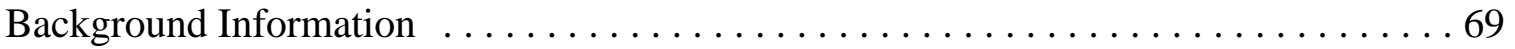

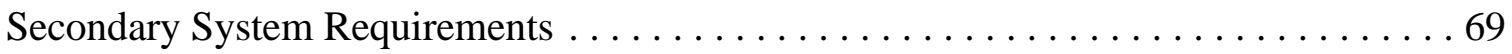

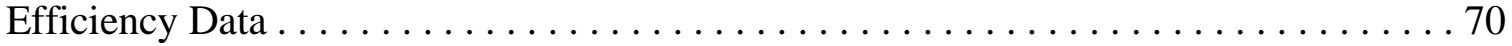

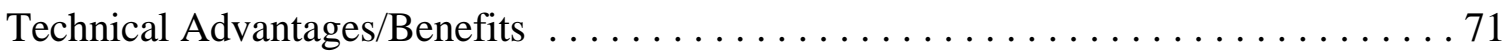

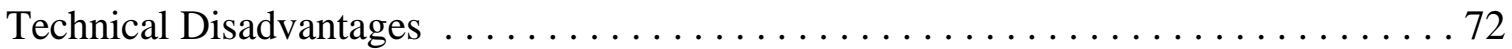

Economic Analysis . . . . . . . . . . . . . . . . . . . . 72

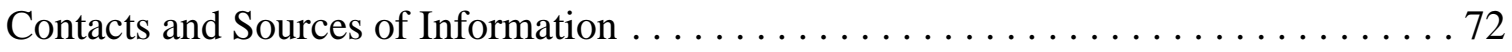

Obvious Holes in Knowledge, Understanding, Information $\ldots \ldots \ldots \ldots \ldots \ldots \ldots 72$

ELECTRO-CHEMICAL HEAT PUMP $\ldots \ldots \ldots \ldots \ldots \ldots \ldots \ldots \ldots \ldots \ldots \ldots \ldots \ldots$

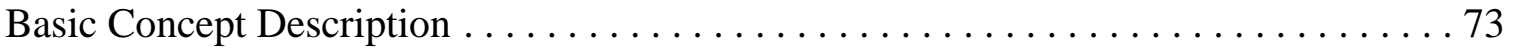

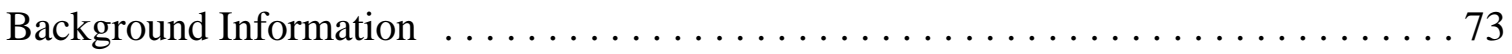

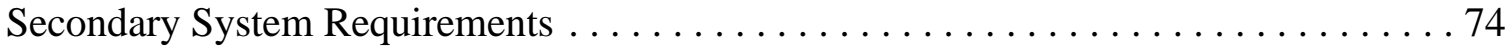

viii 
Efficiency Data .................................... 74

Technical Advantages/Benefits . . . . . . . . . . . . . . . . . . . . . . . 75

Technical Disadvantages ................................... 75

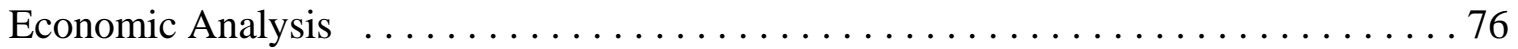

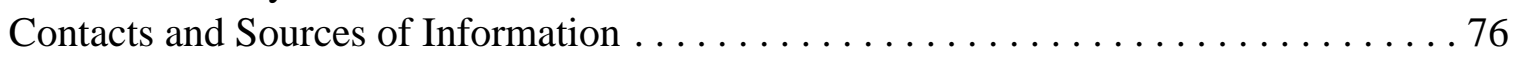

Obvious Holes in Knowledge, Understanding, Information ............... 76

GAS FURNACE / ELECTRIC AIR CONDITIONER $\ldots \ldots \ldots \ldots \ldots \ldots \ldots \ldots \ldots \ldots$

Basic Concept Description ................................. 77

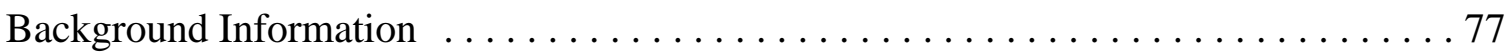

Secondary System Requirements . . . . . . . . . . . . . . . . . . . . . . 77

Efficiency Data ....................................... 77

Technical Advantages/Benefits . . . . . . . . . . . . . . . . . . . . . 77

Technical Disadvantages ................................. 77

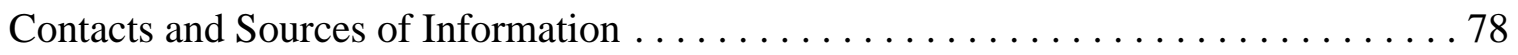

Obvious Holes in Knowledge, Understanding, Information ............. 78

ENGINE-DRIVEN COMPRESSION HEAT PUMPS $\ldots \ldots \ldots \ldots \ldots \ldots \ldots \ldots \ldots \ldots$

Basic Concept Description . . . . . . . . . . . . . . . . . . . . . . . . . . 79

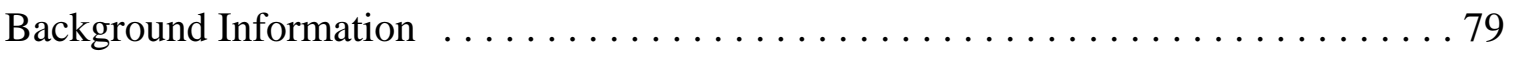

Secondary System Requirements . . . . . . . . . . . . . . . . . . . . 81

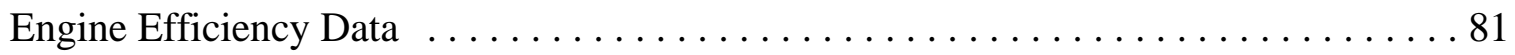

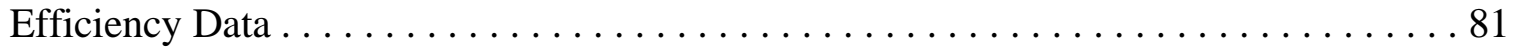

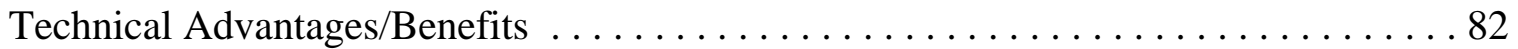

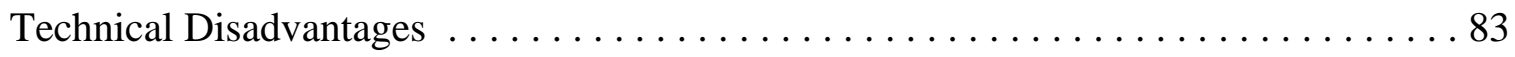

Economic Analysis . .................................. 84

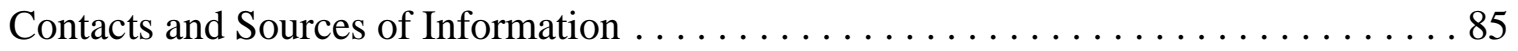

Obvious Holes in Knowledge, Understanding, Information $\ldots \ldots \ldots \ldots \ldots \ldots . \ldots 8$

FUEL CELL POWERED RANKINE CYCLE $\ldots \ldots \ldots \ldots \ldots \ldots \ldots \ldots$

Basic Concept Description .................................. 89

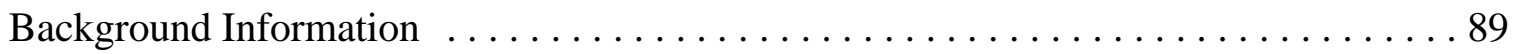

Secondary System Requirements . . . . . . . . . . . . . . . . . . . . 90

Efficiency Data ..................................... 90

Technical Advantages/Benefits . . . . . . . . . . . . . . . . . . . . . . 91

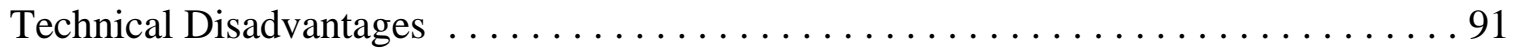

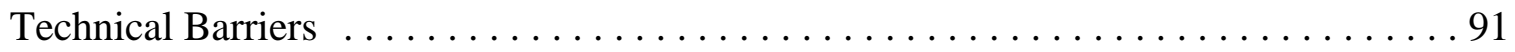

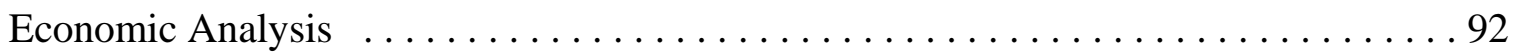

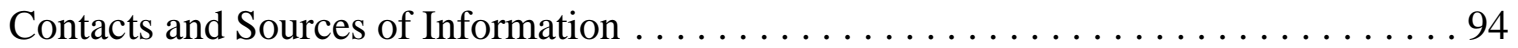

Obvious Holes in Knowledge, Understanding, Information . . . . . . . . . . . . . 94 


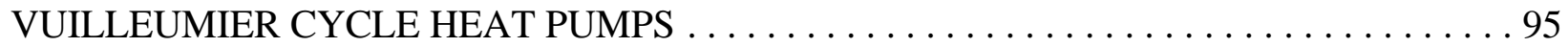

Basic Concept Description .................................. 95

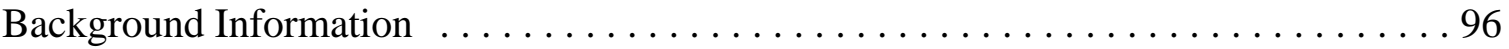

Secondary System Requirements . . . . . . . . . . . . . . . . . . . . . . . 97

Efficiency Data ..................................... 97

Technical Advantages/Benefits . . . . . . . . . . . . . . . . . . . . . . 97

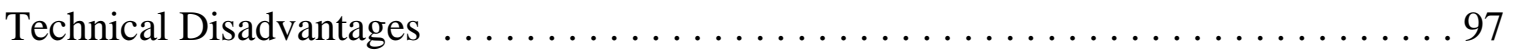

Economic Analysis . ..................................... 98

Contacts and Sources of Information $\ldots \ldots \ldots \ldots \ldots \ldots \ldots \ldots \ldots \ldots \ldots$

Obvious Holes in Knowledge, Understanding, Information . . . . . . . . . . . . . 99

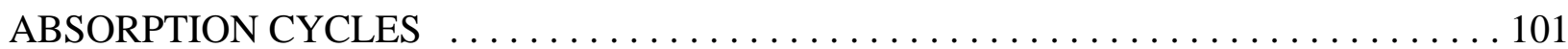

Basic Concept Description ................................... 101

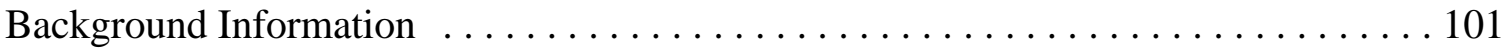

Secondary System Requirements . . . . . . . . . . . . . . . . . . . . . . . 103

Efficiency Data ......................................... 103

Technical Advantages/Benefits . . . . . . . . . . . . . . . . . . . . . . 104

Technical Disadvantages .................................... 104

Technical Barriers ........................................ 104

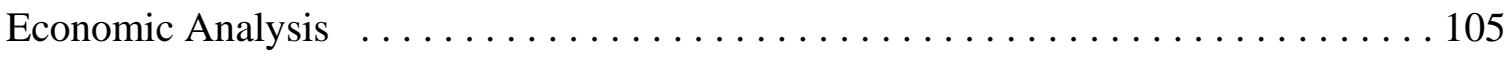

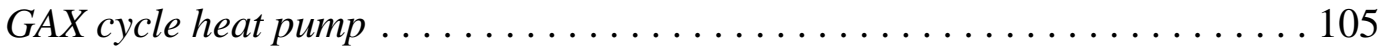

Contacts and Sources of Information ........................... 107

Obvious Holes in Knowledge, Understanding, Information . . . . . . . . . . . . 107

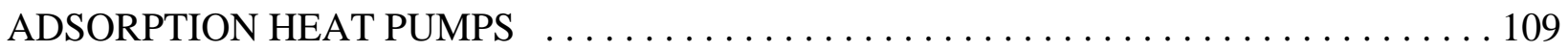

Basic Concept Description ................................... 109

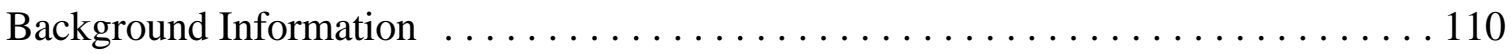

Secondary System Requirements ............................. 111

Efficiency Data ............................................ 111

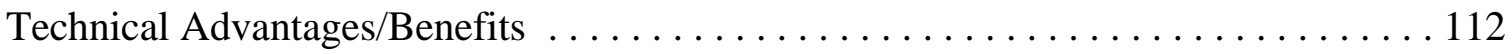

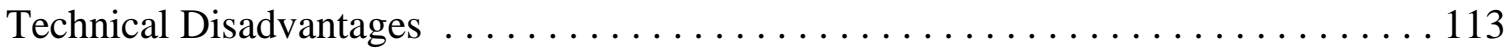

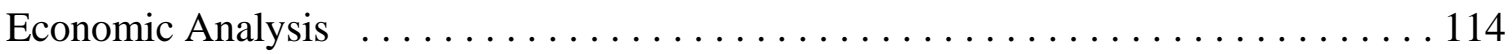

Technical Barriers ...................................... 114

Contacts and Sources of Information ........................... 114

Obvious Holes in Knowledge, Understanding, Information ............... 115

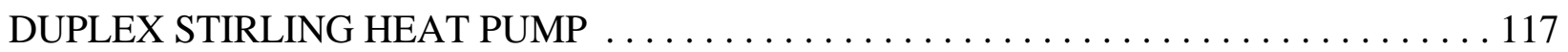

Basic Concept Description ................................... 117

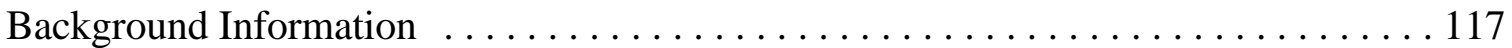

Secondary System Requirements . . . . . . . . . . . . . . . . . . . . . 118

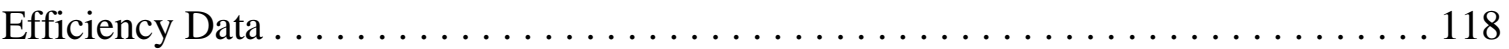




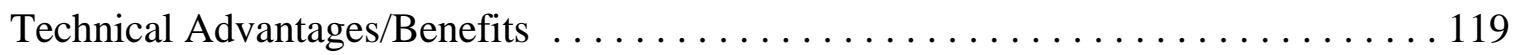

Technical Disadvantages ...................................... 119

Technical Barriers . ........................................ 119

Economic Analysis ....................................... 119

Contacts and Sources of Information . . . . . . . . . . . . . . . . . . 120

Obvious Holes in Knowledge, Understanding, Information . . . . . . . . . . . 121

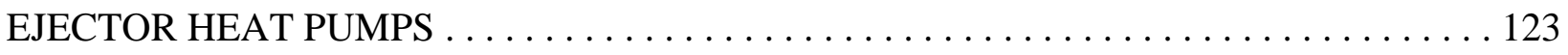

Basic Concept Description ................................. 123

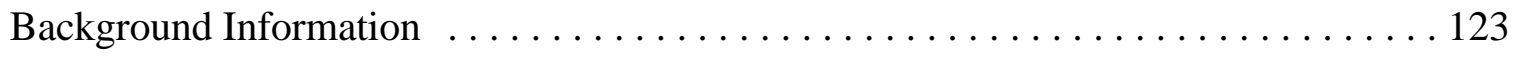

Secondary System Requirements . . . . . . . . . . . . . . . . . . . . . . 124

Efficiency Data ...................................... 124

Technical Advantages/Benefits . . . . . . . . . . . . . . . . . . . . . 124

Technical Disadvantages ................................... 125

Economic Analysis ....................................... 125

Contacts and Sources of Information .......................... 125

Obvious Holes in Knowledge, Understanding, Information . . . . . . . . . . 125

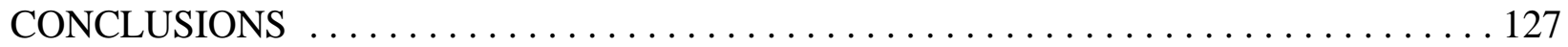

APPENDIX A: METAL HYDRIDE CALCULATIONS $\ldots \ldots \ldots \ldots \ldots \ldots \ldots \ldots$ A -1

APPENDIX B: TABULATED ASSUMPTIONS $\ldots \ldots \ldots \ldots \ldots \ldots \ldots \ldots \ldots \ldots \ldots \ldots \ldots \ldots \ldots$

APPENDIX C: MODELED, OBSERVED, AND REPORTED EFFICIENCIES (REALITY

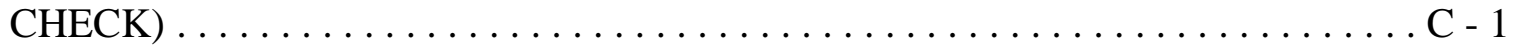

APPENDIX D: TABULATED ASSUMPTIONS $\ldots \ldots \ldots \ldots \ldots \ldots \ldots \ldots \ldots \ldots \ldots \ldots \ldots \ldots$

APPENDIX E: ECONOMIC ANALYSIS $\ldots \ldots \ldots \ldots \ldots \ldots \ldots \ldots \ldots \ldots \ldots \ldots \ldots \ldots \ldots \ldots \ldots$

APPENDIX F: MAINTENANCE COST ASSUMPTIONS $\ldots \ldots \ldots \ldots \ldots \ldots \ldots \ldots$ F 1

APPENDIX G: BUILDING LOAD CALCULATIONS $\ldots \ldots \ldots \ldots \ldots \ldots \ldots \ldots$ G -1

APPENDIX H: THERMIONIC CONVERTERS $\ldots \ldots \ldots \ldots \ldots \ldots \ldots \ldots \ldots \ldots . . \ldots \ldots$ H -1

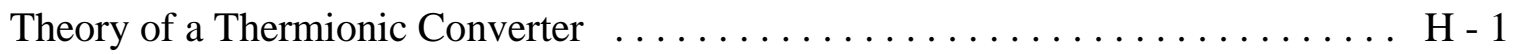

Model of a Thermionic Converter .......................... H -2

APPENDIX I: MALONE REFRIGERATION $\ldots \ldots \ldots \ldots \ldots \ldots \ldots \ldots \ldots \ldots \ldots$ I - 1 
APPENDIX J: GAS AND ELECTRICAL CONSUMPTION FOR EACH TECHNOLOGY J - 1

xii 


\section{LIST OF TABLES}

Table 1. Seasonal and Steady-State Efficiencies for Electric-Driven Heat Pumps . . . . . . . xviii Table 2. Seasonal and Steady-State Efficiencies for Gas-Fired Heat Pumps $\ldots \ldots \ldots \ldots \ldots$ xix Table 3. State Point Temperatures for Rankine Cycle Calculations $\ldots \ldots \ldots \ldots \ldots \ldots$ Table 4. Calculated and Observed Efficiencies for Rankine Cycle Heat Pumps with R-22 . . . . 9 Table 5. Calculated and Observed Efficiencies for Reverse Rankine Cycle Using Propane. . . 12 Table 6. Installed Cost Premiums Possible Relative to an Electric heat pump for a Rankine Cycle Heat Pumps Using Propane. ............................... 13

Table 7. State Point Temperatures for Transcritical $\mathrm{CO}_{2}$ Cycle Calculations . . . . . . . . . 17 Table 8. Calculated and Observed Efficiencies for Transcritical $\mathrm{CO}_{2}$ Cycle. . . . . . . . 18 Table 9. Installed Cost Premiums Possible Relative to an Electric Heat Pump for a Transcritical $\mathrm{CO}_{2}$

Heat Pump. ........................................ 19

Table 10. State Point Temperatures for Brayton Cycle Calculations. ............... 23

Table 11. Calculated and Observed Efficiencies for Closed Regenerative Brayton Cycle. . . . . 24

Table 12. Calculated and Observed Efficiencies for a Stirling Cycle Heat Pumps. . . . . . . . . 29

Table 13. Calculated and Observed Efficiencies for a Vortex Tube Cooler. ............. 32

Table 14. Calculated and Observed Efficiencies for Thermoelectric Cooling. . . . . . . . . . 39

Table 15. Calculated and Reported Efficiencies for Thermoacoustic Cooling. . . . . . . . . 48

Table 16. Installed Cost Premiums Possible for a Thermoacoustic Heat Pump Relative to an Electric

Heat Pump. ....................................... 49

Table 17. Calculated and Observed Efficiencies for Pulse Tube Cooling. . . . . . . . . . . . 54

Table 18. State Point Temperatures for Magnetic Refrigeration Calculations . . . . . . . . 62

Table 19. Calculated and Observed Efficiencies for Magnetic Refrigeration. . . . . . . . . 63

Table 20. Installed Cost Premiums Possible Relative to an Electric Heat Pump for a Magnetic Heat

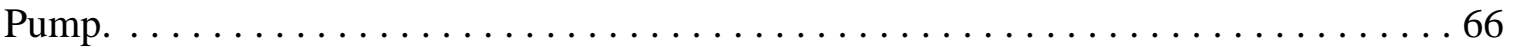

Table 21. Calculated and Observed Efficiencies for Compressor-Driven Metal Hydride Heat Puntps. Table 22. Theoretical Efficiency of Electro-Chemical Heat Pumps (Analytic Power Corporation).

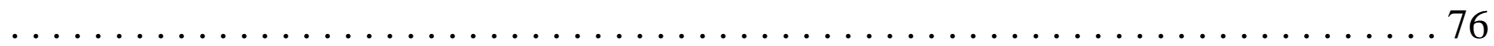

Table 23. State Point Temperatures for Engine Driven Heat Pump Cycle Calculations . . . . . 81

Table 24. Calculated and Observed Efficiencies for Engine-Driven Heat Pumps. . . . . . . . . 82

Table 25. Installed Cost Premiums for an IC Engine-Driven Heat Pump for 3 and 5 Year Payba84s.

Table 26. Fuel Cell Technologies (Lloyd 1999) ….................... 90

Table 27. Calculated and Observed Efficiencies for Fuel Cell Powered Heat Pumps. . . . . . . 91

Table 28. Installed Cost Premiums for a Fuel Cell Powered Electric Heat Pump Relative to the Gas

Baseline........................................ 92

Table 29. State Point Temperatures for Vuilleumier Cycle Calculations . . . . . . . . . . 97

Table 30. Calculated and Observed Efficiencies for Vuilleumier Heat Pumps. . . . . . . . . . 98

Table 31. Installed Cost Premiums for a Vuilleumier Cycle Heat Pump for 3 and 5 Year Paybaøls.

Table 32. Calculated and Observed Efficiencies for Ammonia Absorption Cycle Heat Pumps. 
Table 33. Installed Cost Premiums for a GAX Heat Pump for 3 and 5 Year Paybacks. . . . . . 106

Table 34. Calculated and Observed Efficiencies for Adsorption Cycles. . . . . . . . . . . . . 113

Table 35. Calculated and Observed Efficiencies for Duplex Stirling Heat Pumps. . . . . . . . 118

Table 36. Installed Cost Premiums for a Duplex Stirling Heat Pump. ................ 120

Table 37. Calculated and Observed Efficiencies for Ejector Heat Pumps. . . . . . . . . . . . . 124

Table 38. Specified Conversion Efficiencies, Temperatures and ) Ts for Electric Driven Heat Pump Cycle Calculations. ............................ 2

Table 39. Specified Conversion Efficiencies, Temperatures and ) Ts for Gas-Fired Heat Pump Cycle

Calculations. . . . . . . . . . . . . . . . . 3

Table 40. Comparison of Modeled and Reported COPs and Efficiencies. ........... C - 3

Table 41. Comparison of Modeled and Reported COPs and Efficiencies (cont). ......... C - 4 


\section{LIST OF FIGURES}

Fig. 1. Allowable installed cost premium (\$/ton) for a fuel cell powered heat pump relative to the gas

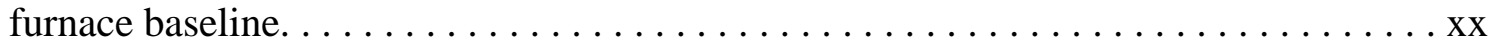

Fig. 2. Allowable installed cost premium (\$/ton) for an IC engine-driven heat pump relative to the gas

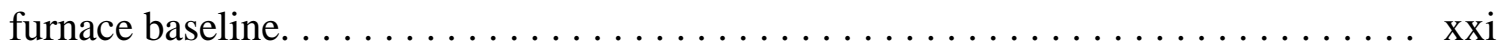

Fig. 3. Allowable installed cost premium ( $\$ /$ ton) for a GAX absorption heat pump relative to the gas

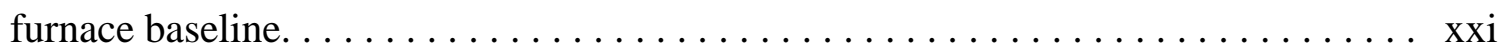

Fig. 4. Allowable installed cost premium (\$/ton) for a magnetic heat pump relative to the electric heat

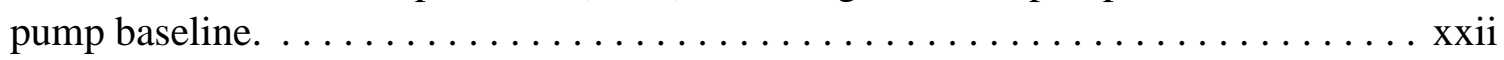

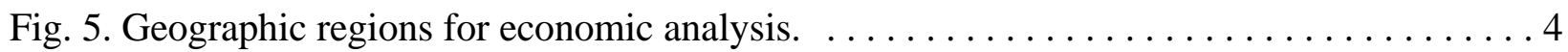

Fig. 6. Schematic diagram for reverse Rankine cycle heat pump. .............. 7

Fig. 7. Pressure - enthalpy (P-H) diagram for an idealized reverse Rankine cycle heat pump. . . 7

Fig. 8. Temperature-entropy (T-S) diagram for an idealized reverse Rankine cycle heat pump.

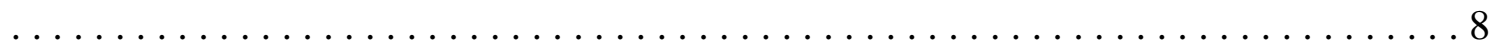

Fig. 9. Schematic diagram for transcritical $\mathrm{CO}_{2}$ heat pump with internal heat exchange. . . . . 15

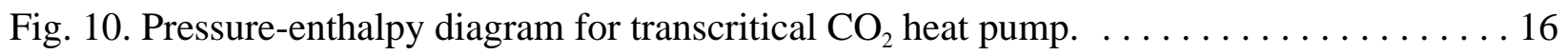

Fig. 11. Schematic diagram of a Brayton cycle heat pump................... 21

Fig. 12. T-S diagram for Brayton cycle showing refrigerant vapor dome. $\ldots \ldots \ldots \ldots \ldots 22$

Fig. 13. T-S diagram for Brayton cycle with regenerative heat transfer. . . . . . . . . . . 22

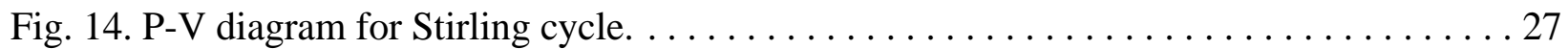

Fig. 15. T-S diagram for Stirling cycle. ........................... 27

Fig. 16. Schematics of Stirling cycle refrigeration system showing movement of power piston and displacer. . . . . . . . . . . . . . . . . . . . . . . 28

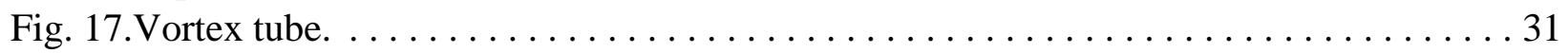

Fig. 18. Schematic for a simple thermoelectric couple..................... 36

Fig. 19. Schematic of a thermoacoustic refrigerator (Source: NASA Tech Briefs, Vol. 21, No. 11,

November 1997). . ................................. 46

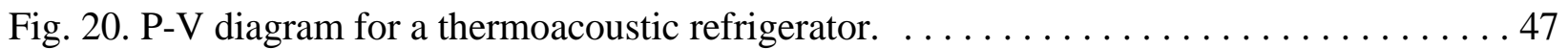

Fig. 21. T-S diagram for a thermoacoustic refrigerator. $\ldots \ldots \ldots \ldots \ldots \ldots \ldots \ldots \ldots \ldots$

Fig. 22. Allowable installed cost price differential for a thermoacoustic heat pump relative to the electric baseline. ...................................... 48

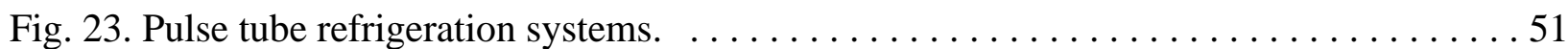

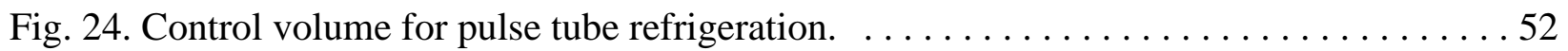

Fig. 25. Temperature - entropy diagram for pulse tube control volume. . . . . . . . . . 53

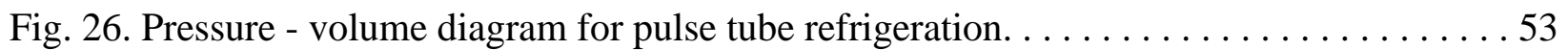

Fig. 27. Temperature-entropy variation for paramagnetic materials.. . . . . . . . . . 61

Fig. 28. Test stand for prototype magnetic refrigeration device (Source: http://www. external.ameslab.gov/news/Inquiry/fall97/bigchill.html). .............62

Fig. 29. Allowable installed cost price differential for a magnetic heat pump relative to the electric baseline exclusive of pumping power. . . . . . . . . . . . . . . . . . . 64 
Fig. 30. Allowable installed cost price differential for a magnetic heat pump relative to the gas baseline

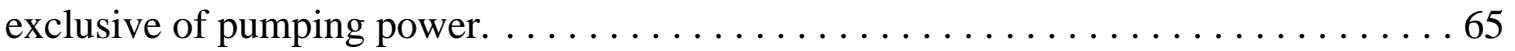

Fig. 31. Increase in life-cycle-cost of magnetic heat pump due to $1 / 4 \mathrm{hp}$ pump. . . . . . . . 65

Fig. 32. Compressor driven metal hydride heat pump (source: Kim 1997) . . . . . . . . . . . . 69

Fig. 33. Schematic of the experimental test stand for the prototype compressor driven metal hydride heat pump (source: Kim 1997). . . . . . . . . . . . . . . . . . . . . . . . . . 70

Fig. 34. Allowable installed cost premiums for IC engine-driven heat pumps. . . . . . . . . . 84

Fig. 35. Allowable installed cost premium for fuel cell powered heat pumps relative to the gas furnace

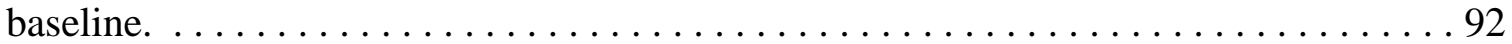

Fig. 36. Allowable installed cost premium and non-energy operating expenses for fuel cell powered

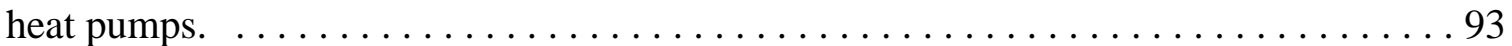

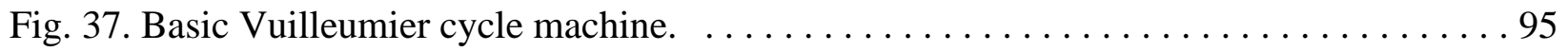

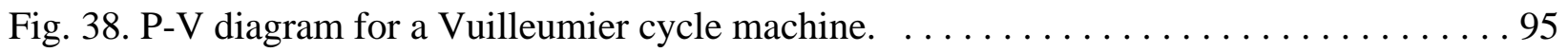

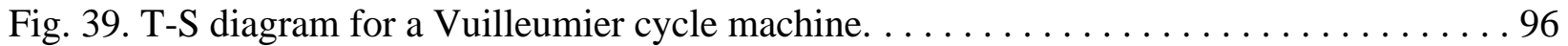

Fig. 40. Measured COPs and capacities for a Vuilleumier cycle heat pump. . . . . . . . . 96

Fig. 41. Allowable installed cost premiums for Vuilleumier cycle heat pumps. . . . . . . . . 98

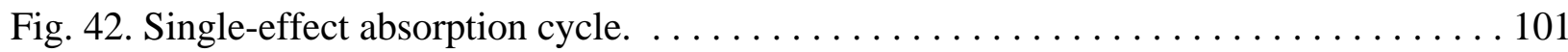

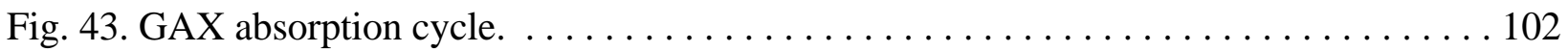

Fig. 44. Double effect absorption cycle (lithium bromide/water) . . . . . . . . . . . 103

Fig. 45. Allowable first cost premium for GAX heat pump for equal life cycle cost with gas furnace

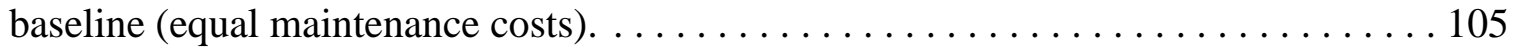

Fig. 46. Allowable first cost premium for GAX heat pump for same life cycle cost as an electric heat pump (equal maintenance costs). . . . . . . . . . . . . . . . . . 105

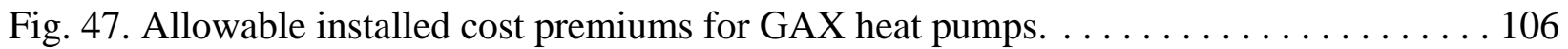

Fig. 48. Schematic of an adsorption cycle heat pump using R-134a. . . . . . . . . . . . . 109

Fig. 49. Adsorption system using two pairs of adsorbent beds for "continuous" output and regeneration

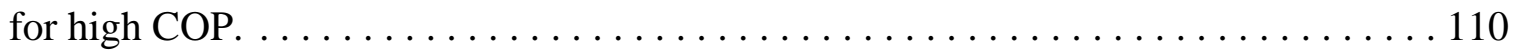

Fig. 50. Allowable installed cost premiums for duplex Stirling heat pumps relative to the gas furnace baseline. . . . . . . . . . . . . . . . . . . . . . . . . . . . . . . . . 119

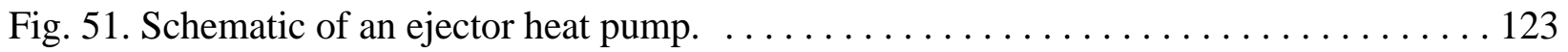

Fig. 52. Distribution of weather data across the U.S. for heating and cooling calculations. . . E - 1

Fig. 53. Relationship between the work function and electrode temperature for a Richardson current of

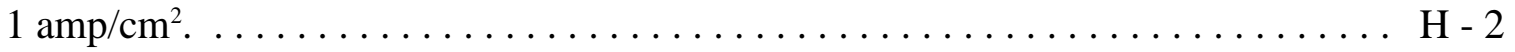

Fig. 54. Energy transfer rates in a thermionic refrigerator. $\ldots \ldots \ldots \ldots \ldots \ldots \ldots \ldots$ H 3

Fig. 55. Theoretical efficiency of a thermionic converter. . . . . . . . . . . . H - 5

Fig. 56. Reduction in real efficiency for a thermionic converter. $\ldots \ldots \ldots \ldots \ldots \ldots \ldots$ H 6

Fig. 57. $\mathrm{K}_{\mathrm{p}}$ (dashed lines) and $\$_{\mathrm{T}}$ (solid lines) near the critical point of $\mathrm{CO}_{2} \ldots \ldots \ldots$ 


\section{EXECUTIVE SUMMARY}

This project was initiated by the Department of Energy in response to a request from the HVAC industry for consolidated information about alternative heating and cooling cycles and for objective comparisons of those cycles in space conditioning applications. In the past individual companies investigated, or re-investigated, alternative cycles for each new generation of R\&D managers and engineers. There was a great deal of duplication of effort between companies and occasionally within companies. It was recognized by members of the Air Conditioning and Refrigeration Institute (ARI) Research and Technology committee, and by individuals in the HVAC industry, that a national laboratory is well suited to perform such an evaluation and to provide a reference document to the industry. This report should serve as a document that alleviates the needs of individual companies to investigate alternative cycles and to aid them in investigations of any cycles that they chose to pursue. In this context, both positive and negative results are valuable; the fact that many of the cycles investigated are not attractive for space conditioning avoids any additional investment of time or resources in evaluating them for this application. In other cases, negative results in terms of the cost of materials or in cycle efficiencies identify where significant progress needs to be made in order for a cycle to become commercially attractive.

ORNL worked with ARI and the ARTI 21-CR alternative cycles subcommittee to assemble a comprehensive list of technologies for evaluation and to create an outline for this report that provides a concise summary of the underlying principals of each technology, its advantages and disadvantages, obstacles to commercial development, and economic feasibility.

Information from over 300 sources, including technical journals and conference proceedings, personal contacts, patents, computer models, theses and dissertations, and product literature were collected and evaluated to compare the energy use of 27 possible heat pump cycles in the U.S. Modeled performance at the ARI rating conditions was used with TMY weather data for 117 cities to estimate gas and electricity use; state-wide average energy costs and DOE fuel escalation factors were used to estimate lifetime energy costs. Calculated steady-state and seasonal efficiencies are summarized in Tables 1 and 2.

It should be pointed out that while a broad selection of technologies are examined, the list is not all inclusive. There are heat pumping technologies under development that simply could not be fit into the framework of this project because of limitations on time and resources. Foremost among these, perhaps, is ground-coupled, or geothermal, heat pumps. These are very efficient, electrically-driven compression cycle heat pumps that have very low energy consumption but high first costs. Unfortunately, they could not be evaluated in this project because of the extensive analysis required to estimate their annual performance at different sites around the country. Such an evaluation would be very valuable. There is a similar situation with desiccant dehumidification systems. In most instances, desiccant systems are used in conjunction with a conventional vapor compression system. Evaluation of desiccant systems requires an hourly building simulation, similar to the intensive calculations required for geothermal heat pumps. This too is beyond the scope of this project.

Each of the alternative heat pump cycles that is considered is compared to either a conventional electric heat pump (HSPF 8.3, SEER 12) or a gas furnace with electric air conditioner (AFUE 80\%, 
Table 1 Seasonal and Steady-State Efficiencies for Electric-Driven Heat Pumps

\begin{tabular}{|c|c|c|c|c|c|c|}
\hline \multirow[b]{3}{*}{ Technology } & \multirow{3}{*}{$\begin{array}{c}\text { HSPF } \\
(\mathrm{Btu} / \mathrm{Wh})\end{array}$} & \multirow{3}{*}{$\begin{array}{c}\text { SEER } \\
(\mathrm{Btu} / \mathrm{Wh})\end{array}$} & \multicolumn{4}{|c|}{ System COPs } \\
\hline & & & \multicolumn{2}{|c|}{ Heating } & \multicolumn{2}{|c|}{ Cooling } \\
\hline & & & $47 \mathrm{EF}$ & $17 \mathrm{EF}$ & $82 \mathrm{EF}$ & $95 \mathrm{EF}$ \\
\hline $\begin{array}{ll}\text { a. } & \text { Reverse Rankine Cycle } \\
\text { R-22 } \\
\text { R-290 (propane) } \\
\text { R-744 (transcritical } \mathrm{CO}_{2} \text { ) }\end{array}$ & $\begin{array}{l}9.0 \\
8.1 \\
7.8\end{array}$ & $\begin{array}{l}11.9 \\
11.8 \\
9.5\end{array}$ & $\begin{array}{l}3.90 \\
3.84 \\
3.78\end{array}$ & $\begin{array}{l}2.60 \\
2.57 \\
2.32\end{array}$ & $\begin{array}{l}4.02 \\
4.00 \\
3.21\end{array}$ & $\begin{array}{l}3.20 \\
3.18 \\
2.26\end{array}$ \\
\hline $\begin{array}{ll}\text { b. } & \text { Brayton Cycle } \\
\text { Closed, Regenerative (current) } \\
\text { Closed, Regenerative (future) }\end{array}$ & $\begin{array}{l}5.0 \\
5.2\end{array}$ & $\begin{array}{l}2.9 \\
3.3\end{array}$ & $\begin{array}{l}1.77 \\
1.87\end{array}$ & $\begin{array}{l}1.75 \\
1.80\end{array}$ & $\begin{array}{l}0.99 \\
1.12\end{array}$ & $\begin{array}{l}0.93 \\
1.06\end{array}$ \\
\hline c. Stirling Cycle & 5.8 & 6.0 & 2.10 & 2.04 & 2.04 & 2.04 \\
\hline d. Vortex Tube & 0.3 & 0.3 & 0.08 & 0.08 & 0.08 & 0.08 \\
\hline $\begin{array}{l}\text { e. Thermoelectric } \\
\text { Current Technology } \\
\text { Future Technology }\end{array}$ & $\begin{array}{l}3.9 \\
5.8\end{array}$ & $\begin{array}{l}2.5 \\
8.3\end{array}$ & $\begin{array}{l}1.40 \\
2.30\end{array}$ & $\begin{array}{l}1.09 \\
1.73\end{array}$ & $\begin{array}{l}0.86 \\
2.79\end{array}$ & $\begin{array}{l}0.62 \\
2.40\end{array}$ \\
\hline f. Thermoacoustic & 6.6 & 8.9 & 2.87 & 1.90 & 3.02 & 2.38 \\
\hline g. Pulse Tube & 3.4 & 1.1 & 0.88 & 0.88 & 0.39 & 0.39 \\
\hline h. Malone Cycle & no data & no data & no data & no data & no data & no data \\
\hline I. Magnetic Refrigeration & 9.5 & 12.8 & 3.91 & 3.99 & 3.99 & 2.99 \\
\hline $\begin{array}{l}\text { j. Compressor Driven Metal } \\
\text { Hydride }\end{array}$ & 6.0 & 10.5 & 2.75 & 1.44 & 3.54 & 2.87 \\
\hline k. Electro-Chemical Heat Pump & no data & no data & no data & no data & no data & no data \\
\hline
\end{tabular}

SEER 12). The calculated HSPF of the baseline electric heat pump in Table 1 is slightly higher than that of the actual equipment chosen for the baseline; comparisons throughout this report are of calculated results to calculated results unless otherwise noted. Only the magnetic heat pump is competitive with the baseline heat pump in energy use although Rankine cycle machines using propane or $\mathrm{CO}_{2}$ are nearly as efficient as fluorocarbon systems. All of these electric driven systems have drawbacks that limit their viability as replacements for Rankine cycle fluorocarbon systems. GAX absorption, engine-driven, Vuilleumier cycle, and duplex Stirling gas-fired heat pumps are all viable alternatives to the gas furnace baseline. Insufficient data are available to compare adsorption concepts with the baseline systems.

Most of the gas-fired systems have significantly higher heating efficiencies than the baseline gas furnace / electric air conditioner combination but lower cooling gCOPs.

While the efficiencies provide insights into the relative energy costs of operating each system, they do not provide direct information on the ownership costs which require knowledge of manufacturing, installation, and maintenance costs in addition to operating efficiency and building loads. It is beyond the scope of this project to estimate the manufacturing and installation costs of the

xviii 
alternative technologies, but it is possible to look at limits of what those costs could be. The difference between the lifetime energy and maintenance costs for a new technology and a baseline system tells how much more, or how much less, the installed costs of the alternative system would need to be in order for that system to have the same ownership cost as the gas or electric baseline equipment.

Table 2 Seasonal and Steady-State Efficiencies for Gas-Fired Heat Pumps

\begin{tabular}{|c|c|c|c|c|c|c|c|}
\hline \multirow[b]{3}{*}{ Technology } & \multirow{3}{*}{$\begin{array}{l}\mathrm{HSPF} \\
\mathrm{gCOP}\end{array}$} & \multirow{3}{*}{$\begin{array}{l}\text { CSPF } \\
\text { gCOP }\end{array}$} & \multirow{3}{*}{$\begin{array}{l}\text { Parasitics } \\
\text { W/ton }\end{array}$} & \multicolumn{4}{|c|}{ System COPs } \\
\hline & & & & \multicolumn{2}{|c|}{ Heating } & \multicolumn{2}{|c|}{ Cooling } \\
\hline & & & & $47 \mathrm{EF}$ & $17 \mathrm{EF}$ & $82 \mathrm{EF}$ & $95 \mathrm{EF}$ \\
\hline $\begin{array}{l}\text { 1. Gas Furnace / Electric Air } \\
\text { Conditioner }\end{array}$ & 0.80 & 1.36 & 210 & 0.80 & 0.80 & 1.57 & 1.17 \\
\hline $\begin{array}{l}\text { m. Engine-Driven Heat Pump } \\
\text { Diesel Engine } \\
\text { IC (Otto) Engine } \\
\text { Stirling Engine } \\
\text { Brayton Engine } \\
\text { Rankine Engine }\end{array}$ & $\begin{array}{l}1.55 \\
1.43 \\
1.38 \\
1.35 \\
1.27\end{array}$ & $\begin{array}{l}1.27 \\
1.09 \\
1.02 \\
0.98 \\
0.87\end{array}$ & $\begin{array}{l}185 \\
185 \\
185 \\
185 \\
185\end{array}$ & $\begin{array}{l}2.07 \\
1.85 \\
1.76 \\
1.71 \\
1.58\end{array}$ & $\begin{array}{l}1.53 \\
1.39 \\
1.33 \\
1.30 \\
1.21\end{array}$ & $\begin{array}{l}1.35 \\
1.16 \\
1.08 \\
1.04 \\
0.93\end{array}$ & $\begin{array}{l}1.05 \\
0.90 \\
0.84 \\
0.81 \\
0.72\end{array}$ \\
\hline n. Fuel Cell Powered Heat Pump & 1.5 & 1.7 & 0 & 2.02 & 1.38 & 1.75 & 1.35 \\
\hline o. Vuilleumier Cycle & 1.2 & 0.7 & 320 & 1.30 & 1.32 & 0.71 & 0.63 \\
\hline $\begin{array}{l}\text { p. Absorption Cycles } \\
\text { Single-Effect } \\
\text { GAX } \\
\text { Double-Effect }\end{array}$ & $\begin{array}{c}\text { no data } \\
1.36 \\
1.55\end{array}$ & $\begin{array}{l}0.56 \\
0.67 \\
0.94\end{array}$ & $\begin{array}{c}230 \\
245 / 100 \\
220\end{array}$ & $\begin{array}{c}\text { no data } \\
1.52 \\
1.78\end{array}$ & $\begin{array}{c}\text { no data } \\
1.50 \\
1.75\end{array}$ & $\begin{array}{l}0.58 \\
0.71 \\
1.00\end{array}$ & $\begin{array}{l}0.53 \\
0.64 \\
0.80\end{array}$ \\
\hline $\begin{array}{l}\text { q. Adsorption Cycles } \\
\text { Metal Hydride } \\
\text { Carbon / Ammonia } \\
\text { Organic Salts }\end{array}$ & no data & $\begin{array}{c}\text { no } \\
\text { data }\end{array}$ & no data & no data & no data & $\begin{array}{l}\text { no } \\
\text { data }\end{array}$ & $\begin{array}{c}\text { no } \\
\text { data }\end{array}$ \\
\hline r. Duplex Stirling Heat Pump & 1.3 & 0.91 & 310 & 1.57 & 1.48 & 0.96 & 0.96 \\
\hline s. Ejector Heat Pump & 1.0 & 0.3 & 280 & 1.05 & 1.04 & 0.29 & 0.21 \\
\hline
\end{tabular}

Notes: electric air conditioner SEER converted to gCOP by backing out fan and blower power and scaling based on $3413 \mathrm{Btu}_{\text {site }} / 11,500 \mathrm{Btu}_{\text {plant }}$.

Fuel Cell Powered Rankine Cycle Heat Pumps: The combination of a fuel cell and an electric-driven Rankine cycle heat pump, with heat recovery, is the most efficient system considered in this project. The equipment and maintenance costs, however, need to be significantly below those achieved to date and the fuel cell functional lifetime significantly longer in order for this technology to be viable in large parts of the U.S. Assuming that target first costs $(\$ / \mathrm{kW})$ can be achieved for low capacity fuel cells, the economics are marginal in the northeastern states and unacceptable elsewhere.

Figure 1 shows the "allowable installed cost premium" for the fuel cell powered heat pump relative to the gas furnace / electric air conditioner baseline (maximum increase in equipment and 
installation costs that yields the same life-cycle costs) for the lower 48 states (assuming that maintenance costs for the fuel cell system are $\$ 100$ per year higher than those for the baseline gas furnace). The dashed lines separating the extreme southwest and the south eastern states indicates where the installed cost of the fuel cell powered heat pump could be $\$ 500$ per ton higher than the installed cost of the gas baseline and the two systems would still have the same life cycle costs. Below the northern panhandle of Florida the fuel cell powered system

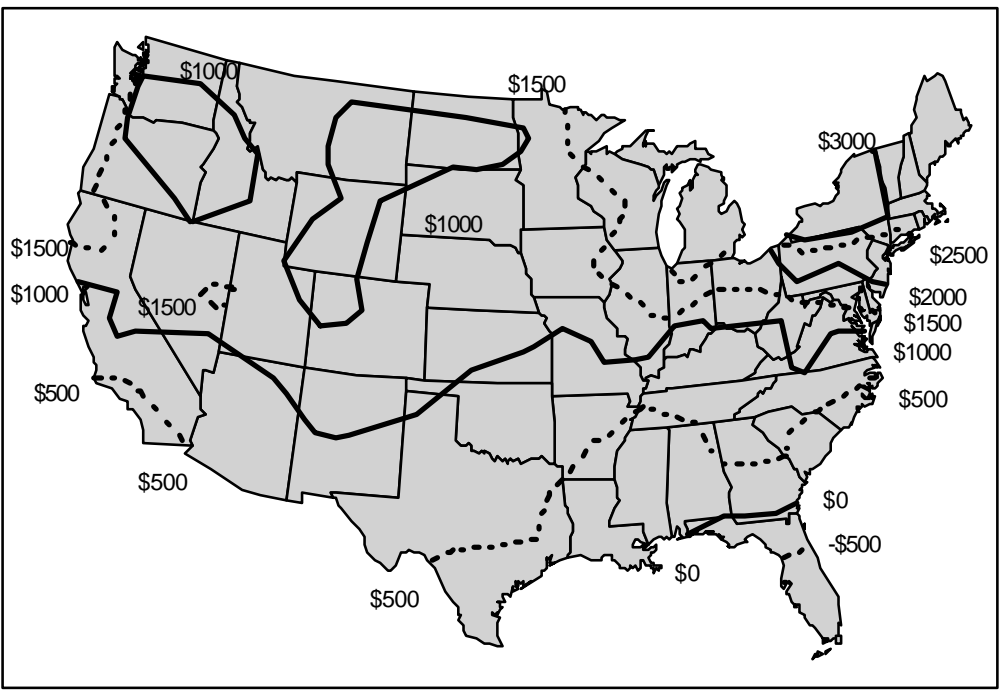

Fig. 1 Allowable installed cost premium (\$/ton) for a fuel cell powered heat pump relative to the gas furnace baseline. would need to cost less than the gas baseline while in the northeast and along the northern Pacific coast installed costs could be more than $\$ 1500$ per ton higher. Installed costs in New York could be up to $\$ 3000$ per ton higher at this maintenance costs and still have the same life cycle cost as the gas furnace baseline.

While the economics appear attractive, there are two noteworthy facts illustrated in Fig. 1. First, the "contours" on the map are widely separated so that underestimating the annual maintenance cost could have significant impacts; a small increase in maintenance costs will remove large portions of the country as viable markets. If the fuel cell has to be replaced once during the lifetime of the heat pump, then the " 0 " line shifts up above the current location of the $\$ 500$ contour in Fig. 1; effectively reducing the potential market for the new system. Differences in local energy costs from the state-wide averages will also alter the comparisons significantly. Second, the incremental installed cost of this technology is approximately the cost of the fuel cell, projected to be $\$ 1000$ to $\$ 1200$ per $\mathrm{kW}$ of capacity. This cost will make fuel cell powered unitary heat pumps uneconomical in terms of life cycle cost except in the northeast and a narrow band along the northern Pacific coast. Factoring in uncertainties in the maintenance and non-energy operating costs restrict the potential market to New England and New York.

Engine-Driven Heat Pumps: Engine driven heat pumps compare favorably against the gas furnace / electric air conditioner baseline in all parts of the country except the southeast. An IC engine-driven heat pump could achieve the same life cycle cost as the gas furnace baseline at an installed cost several hundred dollars to as much as $\$ 2000$ per ton higher than the gas furnace baseline depending on the region of the country and the differential in annual maintenance costs. These systems do not compare well in the southeast, south central, or southwestern states against the baseline gas furnace and electric air conditioner or in the southeast against the baseline electric heat pump. 
Results for an IC enginedriven heat pump are shown in Fig. 2 relative to the gas furnace baseline assuming maintenance cost of $\$ 125 / y$ (vs $\$ 100 / y$ for the baseline system). The contours in this drawing show that the high efficiency and low operating costs of this system justify fairly high installed cost premiums (on a life cycle cost basis) in large parts of the country. The northeast and upper Midwest in particular could have strong markets for this product. The economic analysis also yields favorable results in the Pacific northwest, although a comparison should be made with an electric heat pump in much of the northwest because of the low electric rates in that area.

\section{Absorption Cycle Heat Pumps:}

The GAX absorption cycle heat pump is an economically viable alternative to the gas furnace baseline in most of the U.S. Equal life cycle costs can be achieved at installed costs $\$ 500$ to $\$ 1000$ per ton higher than the gas furnace and electric air conditioner. The results of the economic evaluation of this technology relative to the gas furnace baseline are shown in Fig. 3

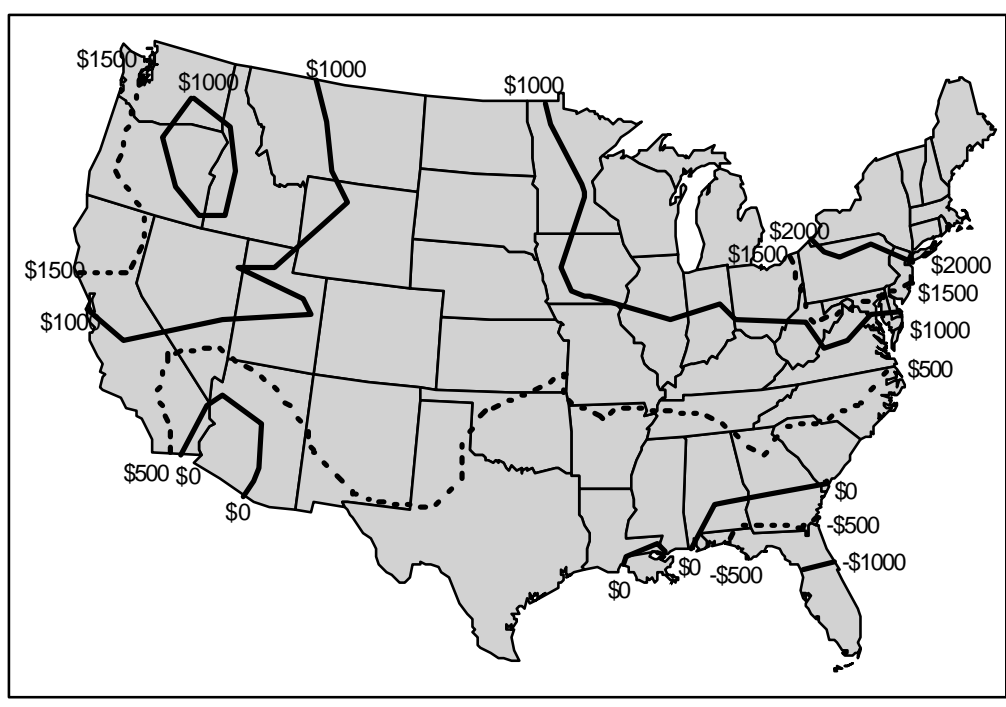

Fig. 2. Allowable installed cost premium (\$/ton) for an IC engine-driven heat pump relative to the gas furnace baseline. (assuming the same annual

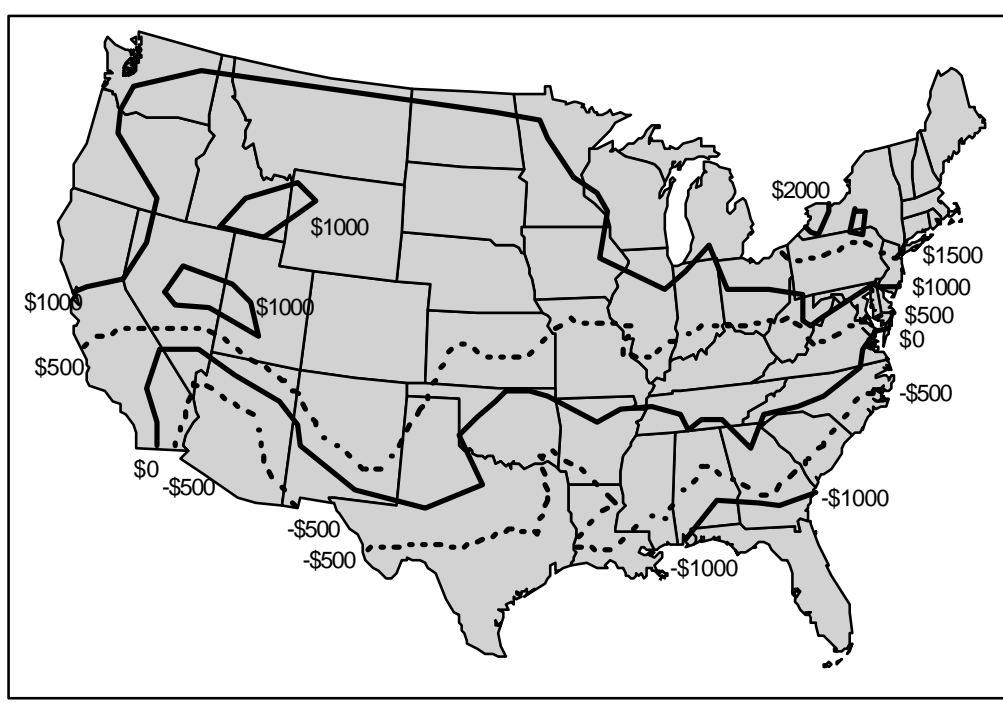

Fig. 3 Allowable installed cost premium (\$/ton) for a GAX absorption heat pump relative to the gas furnace baseline. maintenance costs for the furnace and GAX heat pump). These data also show that this technology could have the same life cycle cost as the baseline systems at higher installed costs outside of the southeastern, south central, and desert southwest regions.

For the most part, the remaining technologies listed in Tables 1 and 2 do not compare favorably with the electric and gas baseline heating and cooling systems. 
Rankine cycle with propane: No reduction in operating costs relative to the baseline electric heat pump; first costs could be as much as $35 \%$ higher due to flammable refrigerant

Transcritical $\mathrm{CO}_{2}$ : Reduced efficiencies relative to the baseline electric heat pump would require medium to high reductions in installed costs in order to have 3 year or 5 year payback or for equivalent life cycle costs. Actual installed costs are likely to be similar to those for the baseline system.

Brayton Cycle: The significantly lower efficiencies of the Brayton cycle result in an extremely unfavorable comparison with the baseline electric heat pump; life cycle costs cannot be equal even if the Brayton cycle machines have 0 installed costs.

Stirling Cycle: The efficiencies are reduced relative to the baseline electric heat pump and installed costs would need to be more the $\$ 2000$ per ton below the baseline costs to achieve equal life cycle costs. Manufacturing costs for the Stirling system are uncertain, but the estimated difference in lifetime energy costs exceeds the installed cost of the baseline system.

Magnetic Heat Pumps: Magnetic heat pumps have high theoretical efficiencies. The results of an economic evaluation with "reasonable" assumptions are shown in Fig. 4 (1/4 hp pump, 175 W linear motor , \$30/year maintenance differential). Installed costs can be $\$ 100$ per ton higher than the electric heat pump baseline throughout most of the U.S. Cost increases of more than $\$ 200$ per ton are supported in the northeast and parts of the Midwest with increases of up to $\$ 500$ per ton in New York. Material costs will be a problem facing the commercialization of this technology in spite of the favorable economics shown in Fig. 4. The paramagnetic material alone would cost on the order of $\$ 6400$ per ton of cooling capacity. The cost of superconducting magnet must also be considered.

\section{Thermoelectric and Thermionic}

Heating and Cooling: The best available thermoelectric cells have extremely low efficiencies and under the most favorable assumptions they would have lifetime operating costs in excess of $\$ 4000$ per ton above the electric heat pump baseline. Either

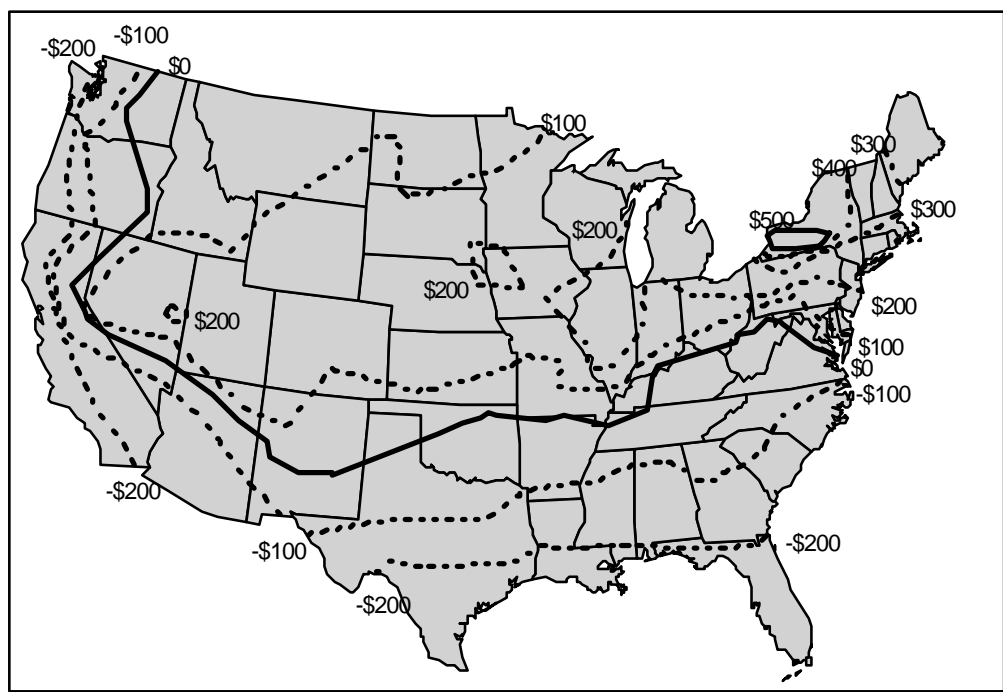

Fig. 4. Allowable installed cost premium (\$/ton) for a magnetic heat pump relative to the electric heat pump baseline. thermoelectric cells achieving the theoretical maximum efficiency or thermionic converters, however, could have the same life cycle cost as the baseline electric heat pump with reductions in installed costs of $\$ 300$ to $\$ 600$ per ton. That 
means they would have the same life cycle cost with an installed cost approximately $60 \%$ to $70 \%$ that of a conventional heat pump and a lower life cycle cost at an installed cost below that level. It is conceivable that such low costs could be achieved considering the dramatic reductions in manufacturing costs for other solid state electronics equipment.

Thermoacoustic Heat Pumps: In 1998, thermoacoustic heat pumps are projected to have efficiencies approximately $30 \%$ below those of conventional electric-driven heat pumps. The reduction in the number of moving parts may reduce equipment and maintenance costs sufficiently that thermoacoustic systems could have lower life cycle costs than the electric heat pump baseline, albeit at higher energy costs. Installed costs would need to be on the order of $\$ 600$ to $\$ 1000$ per ton below those of the baseline system however, which represents reductions on the order of $35 \%$ to $60 \%$ of the baseline costs.

Pulse-Tube Heat Pumps: This technology was developed for cryogenic applications and compares very unfavorably with the Rankine cycle heat pump at space conditioning temperature lifts. It is not suited to this application.

Malone Cycle Heat Pumps: Very little data are available to assess the potential of Malone cycles for space conditioning applications. Accurate thermodynamic and thermophysical data are needed for liquid $\mathrm{CO}_{2}$ or propylene near their critical points in order to estimate COPs; these data are not available and efficiencies can not be estimated accurately.

Compressor Driven Metal Hydride: This technology has high cooling efficiencies, though about 10\% below those of the baseline electric heat pump; the heating COPs are at best about $70 \%$ those of the electric heat pump. Cost reductions of more than $\$ 800$ per ton would be necessary for this technology to compete with the electric baseline. Such savings are unlikely since this technology employs all of the major components of an electric heat pump and also requires the hydriding materials and secondary heat transfer loop.

Vuilleumier Cycle Heat Pumps: Vuilleumier cycle heat pumps are less efficient than "conventional" engine driven systems but they are inherently less complicated and could be viable products in predominantly heating climates. Both the installed cost and annual maintenance costs of the Vuilleumier cycle heat pump are unknown. Arguments can be made that both factors are lower than the corresponding values for the gas and electric baseline systems. A comparison of the Vuilleumier cycle heat pump with an engine-driven system shows that the Vuilleumier machine could have lower life cycle costs if the installed cost is $\$ 400$ to $\$ 700$ per ton less than that for the engine driven system and the annual maintenance costs are $\$ 50$ lower.

Adsorption Cycle Heat Pumps: Insufficient data are available on COPs at the ARI rating conditions and independent cycle calculations could not be performed. Development of adsorption heat pumps appears to have ended without reaching commercialization. 
Duplex Stirling Cycle Heat Pumps: Duplex Stirling heat pumps have attractive economics in the regions of the U.S. with relatively high heating loads, although the supportable increases in first costs are less favorable than they are for IC and diesel engine driven Rankine cycle heat pumps. The duplex Stirling systems have the potential to have lower maintenance costs than the other engine driven systems because they have many fewer moving parts, but thus far the high reliability and reduced maintenance have not been demonstrated. Further development is needed in regenerators, gas springs and bearings, and heat exchanger design for reduced log mean temperature differences. While actively pursued earlier, there have been no major development efforts undertaken since the late 1980s.

Ejector Heat Pumps: These systems have extremely low efficiencies and are not viable alternatives to the gas and electric baseline systems. They could be well suited to applications employing waste heat. 


\section{INTRODUCTION}

\section{Objectives}

This project was initiated by the Department of Energy in response to a request from the HVAC industry for consolidated information about alternative heating and cooling cycles and for objective comparisons of those cycles in space conditioning applications. In the past individual companies investigated, or re-investigated, alternative cycles for each new generation of R\&D managers and engineers. There was a great deal of duplication of effort between companies and occasionally within companies. It was recognized by members of the Air Conditioning and Refrigeration Institute (ARI) Research and Technology committee, and by individuals in the HVAC industry, that a national laboratory is well suited to perform such an evaluation and to provide a reference document to the industry. This report should serve as a document that alleviates the needs of individual companies to investigate alternative cycles and to aid them in investigations of any cycles that they chose to pursue. ORNL worked with ARI and the ARTI 21-CR alternative cycles subcommittee to assemble a comprehensive list of technologies for evaluation and to create an outline for this report that provides a concise summary of the underlying principals of each technology, its advantages and disadvantages, obstacles to commercial development, and economic feasibility.

Approximately 30 different heat pumping technologies have been identified as possible alternatives to conventional vapor compression systems in residential and commercial unitary equipment. Many of these technologies are addressed in the literature presenting performance data or relative comparisons, but the operating conditions and assumptions are frequently omitted from the publications or inconsistent with data in other publications or ARI rating conditions. This project is structured to identify those refrigeration technologies from the 30 that could become viable commercial products to compete with conventional vapor compression equipment in unitary applications. The evaluation, thus requires performance estimates for each technology at a uniform set of operating conditions as well as the application of some economic assumptions to determine "commercial viability." These requirements, coupled with the large number of technologies, made it impossible to include promising technologies such as geothermal or ground-coupled heat pumps and desiccant dehumidification systems in the analysis. No definitive conclusions are drawn about whether or not a particular technology will succeed in space conditioning applications, though sufficient information is presented to gauge the likelihood of the technology competing successfully against the established electric heat pump and gas furnace technologies.

\section{Methodology}

Unfortunately, very little operating data are available for most of the technologies considered in this evaluation. Consequently theoretical analyses are performed to estimate what the efficiency would be under assumed operating conditions and component efficiencies; these assumptions are stated clearly throughout this report. Wherever possible the modeled COPs are compared with reported data from the literature or from personal communications with experts in each field. This comparison of 
steady-state or seasonal efficiency acts either as corroboration of the theoretical calculations or as an indication of the shortcomings of this report; there are some of each.

By the very nature of heat pumps, there are times when an auxiliary heat source is required because the system capacity is insufficient to meet the load. Electric heat pumps provide backup heating to meet this excess demand with resistance heaters. Since there are so few gas-fired heat pumps commercially available, there is no "standard" for providing this supplementary heat. The analysis summarized in this report assumes that gas-fired heat pumps provide heat from three sources: (1) the outdoor heat source, (2) recovered waste heat, and (3) a gas burner with an $80 \%$ efficiency.

\section{Economic Evaluations}

The economic comparisons presented in this report are not direct cost comparisons between the alternative technologies and baseline electric-driven or gas-fired systems. It is far beyond the scope of this project to estimate the manufacturing cost of any of the alternative technologies. The comparisons, instead, are in terms of the approximate premium in installed cost for the alternative technology that would give it the same life-cycle cost as a baseline system; or alternatively, the required reduction in installed cost for a system which is less efficient than the baseline system. Qualitative statements are then made, where possible, about the alternative technology which add some perspective as to whether or not the installed cost premium is likely, or unlikely, to be possible. Installed cost premiums are specified throughout this report in terms of 1998 \$/ton. Results are also presented for allowable cost premiums that would yield 3 and 5 year paybacks.

Each of the alternative technologies evaluated in this study is compared to either an electric heat pump or gas furnace / electric air conditioner baseline or both. The electric baseline is a commercially available three ton heat pump with rated performance HSPF of 8.3 and SEER of 12; while higher than the minimum standard SEER 10 heat pump, this unit is less efficient than the best available electric heat pump. The gas furnace baseline is defined as having an AFUE 80\% efficiency and an SEER 12 air conditioner.

Binned weather data and building loads for 117 cities in the U.S. are used with modeled steady-state COPs to compute seasonal energy use in each city. The modeled COPs for the electric heat pump are very close to the manufacturer's published values for the baseline unit. Each of the alternative technologies are assumed to have heat pumping and air conditioning capacities equal to those of the baseline heat pump; the capacity of gas-fired heat pumps is assumed to be augmented with heat recovery (up to $50 \%$ of the engine or absorber coolant and flue gas waste heat) to meet the building load. Cycling losses are computed using the $\mathrm{C}_{\mathrm{d}}=0.25$ for the fixed capacity heat pumps and $\mathrm{C}_{\mathrm{d}}=0.10$ for technologies with easily modulated capacity (e.g. engine-driven heat pumps, absorption systems).

The energy use data are used to compute lifetime operating costs for each system. Annual operating costs for 1998 are determined using statewide averages for gas and electricity rates for each of the 117 cities. This is a broad assumption and tremendous simplification; energy economics are city and utility area dependent and local rates should be used with estimated energy use data to determine more accurate economic comparisons. In this report, however, the present value of lifetime energy 
costs are computed using constant dollar energy costs from the Energy Information Administration, a discount rate of $4.1 \%$ and $3 \%$ for general inflation for an assumed 20 year equipment lifetime. The discount rate and rate of inflation are the values prescribed by DOE for life cycle cost analyses for federal projects.

The maintenance costs of the alternative cycles (relative to the baseline systems) and auxiliary energy use, unfortunately, are important if not crucial assumptions. In most instances results of the economic evaluation are presented across a range of "incremental" maintenance costs (e.g. \$25 per year higher than the baseline electric heat pump). Estimates of the maintenance costs are used to identify a range of installed cost increases or decreases allowable for the alternative technology to have the same life cycle cost as one of the baseline systems. The allowable installed cost premiums are also listed for technologies that could possibly achieve three and five year paybacks. Pumping power for secondary heat transfer loops is assumed to be $100 \mathrm{~W}$ per ton of design capacity.

The simplified economic analysis presented in this report does not incorporate regional demographics. While the calculations are based on climate data for particular cities and state-wide average energy rate data, it is easiest to discuss the results in terms of geographic regions or individual states. For this purpose, the discussion of the economic analysis is frequently presented as a summary of results in the nine geographic regions encompassing the 117 cities used in the analysis:

! Northeast: New York, Pennsylvania, Massachusetts, Vermont, Maine, and New Jersey,

! Southeast: Florida, Georgia, South Carolina, North Carolina, Virginia, West Virginia, Kentucky, Tennessee, Alabama, Mississippi, and Louisiana,

! South Central: Texas, Oklahoma, Kansas, Missouri, and Arkansas,

! Southwest: Arizona and New Mexico,

! Midwest: Ohio, Michigan, Indiana, Illinois, Iowa, Wisconsin, and Minnesota,

! Northern Plains: Nebraska, North Dakota, and South Dakota,

! Rocky Mountain: Colorado, Wyoming, Montana, Utah, and Idaho,

! Pacific Northwest: Oregon and Washington,

! California: California and Nevada

These divisions are also illustrated in Fig.5. Regional and state-wide averages of three and five year payback and life cycle cost premiums are calculated for each state and region based on the number of the 117 cities located there.

The discussion of the economic analysis of each alternative technology includes comments of where the technology is most competitive with the baseline, some comments as to why it is appropriate in those cities (e.g. high heating loads, relative costs of gas and electricity), and what hardware differences need to be supported by the price differential (e.g. gas engine in place of an electric motor, increased heat transfer surfaces). There have been detailed costs analyses performed in both DOE and industry R\&D projects for some of the technologies covered in this report. Where possible, the results obtained here are compared with those reported elsewhere to confirm or conflict with the findings reported here. 


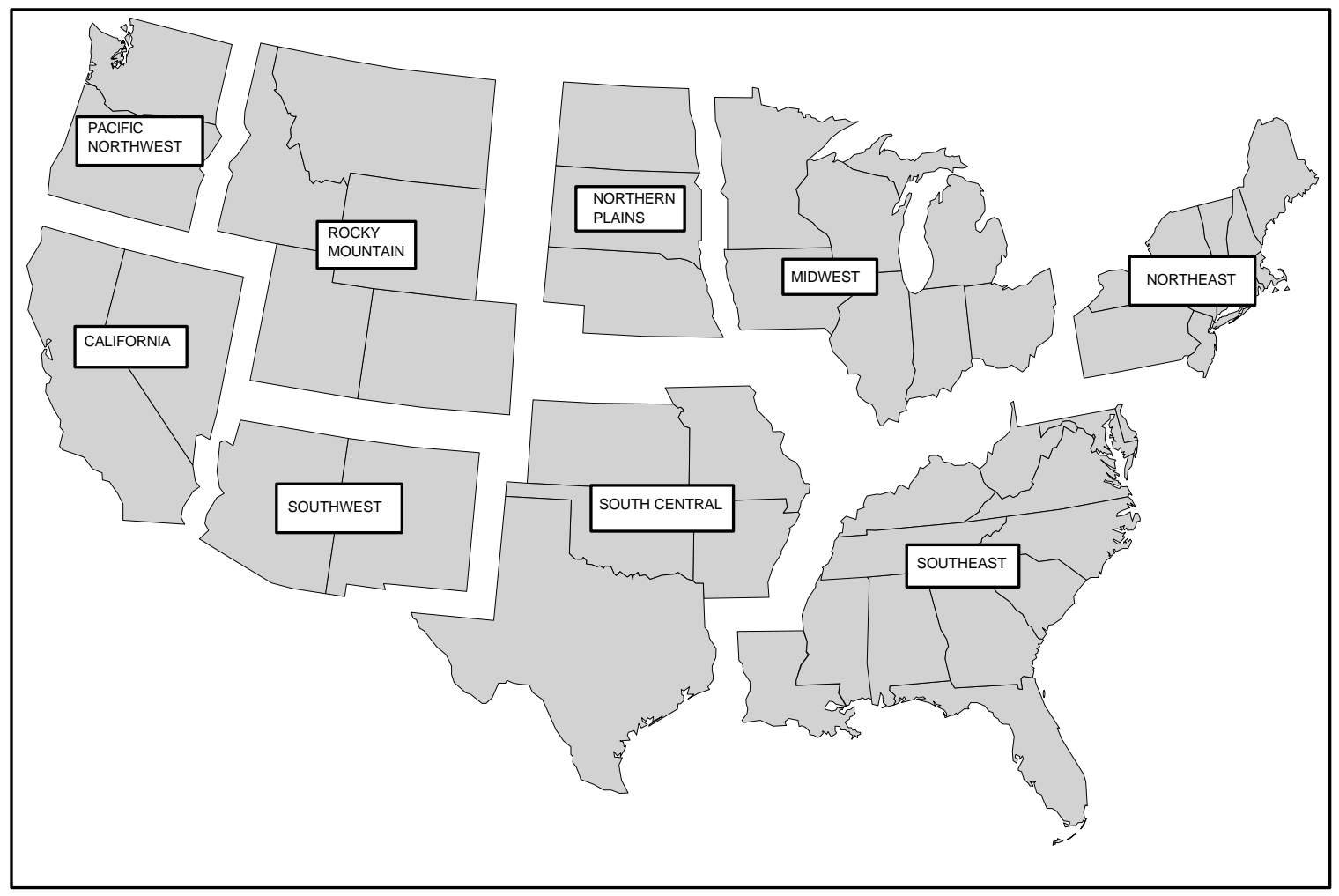

Fig. 5. Geographic regions for economic analysis.

\section{Summary}

Among the technologies which are not commercially available or do not have significant market share, there is current $R \& D$ activity in:

! thermionic and thermoelectric, primarily targeted at power generation,

! thermoacoustic heat pumps,

! compressor driven metal hydride heat pumps,

! transcritical $\mathrm{CO}_{2}$ heat pumps,

! reverse Rankine cycle heat pumps using hydrocarbon refrigerants,

! GAX, open cycle, and triple-effect absorption heat pumps,

! adsorption cycles (ammoniated carbon, metal hydride, complex compounds/organic salts, open cycle),

! IC engine driven heat pumps,

! magnetic refrigeration, and

! compressor driven metal hydride heat pumps.

There is no significant known current R\&D activity on:

! Stirling cycle refrigeration,

! Vuilleumier cycle cooling, 
! Stirling, Brayton, or Rankine engine driven heat pumps,

! ejector heat pumps,

! pulse tube heat pumps, and

! vortex tubes.

The Brayton cycle is being applied in transportation systems (airplanes and the European high speed train). There is a low level of activity in Malone cycle cooling. 


\section{REVERSED RANKINE CYCLE HEAT PUMPS}

\section{Basic Concept Description}

technology for electric-driven heat pumps and serves as a baseline for comparison of competing technologies. The schematic diagram in Fig. 6 illustrates the basic cycle. A hermetic compressor is used to compress a gas to a high temperature and pressure as shown in Figs. 7 and 8. Heat is rejected either to the ambient or to the conditioned space (depending on the mode of operation), cooling the gas and causing it to condense. The resulting hot, high pressure liquid is then expanded causing it to flash to a low pressure, low temperature mixture of liquid and vapor. This two-phase mixture is evaporated absorbing heat from the ambient (heating mode) or conditioned space (cooling mode) to form a low pressure, low temperature vapor that is returned to the compressor.

\section{Background Information}

Rankine cycle heat pumps grew out of the development of refrigeration systems for ice making and food preservation dating back to the 1830s. Reductions in size and improvements in reliability and safety led to the adaptation of refrigeration equipment to provide space comfort conditioning. Air conditioning was a novelty in the

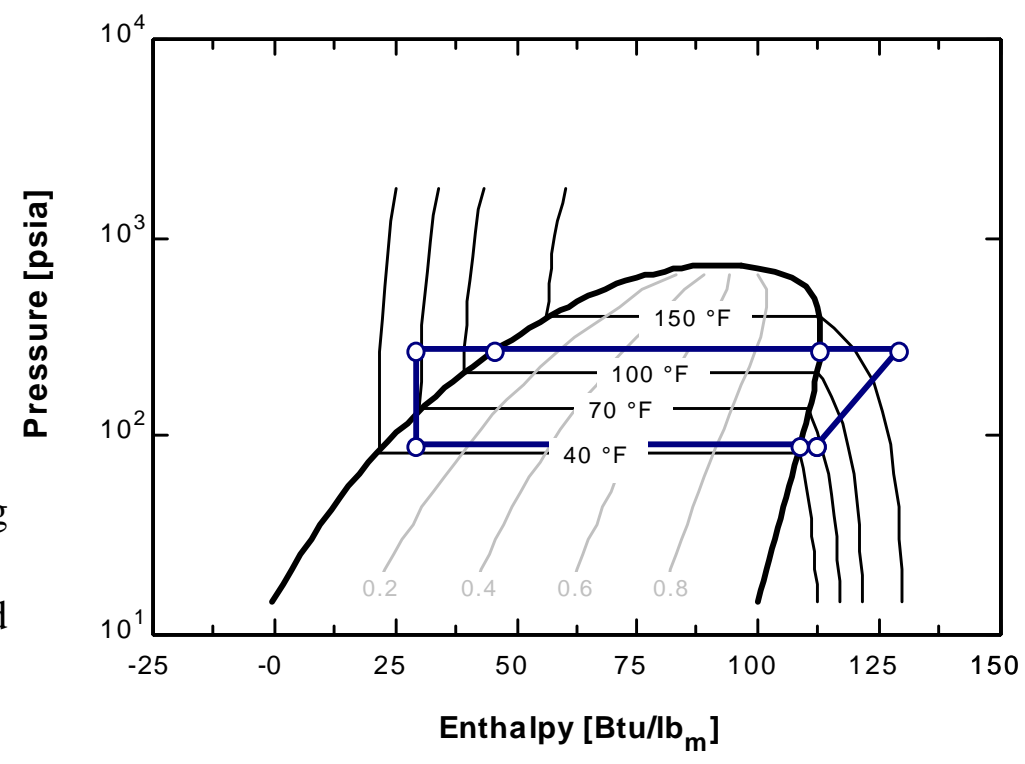

Fig. 7. Pressure - enthalpy (P-H) diagram for an idealized reverse Rankine cycle heat pump.

Fig. 6. Schematic diagram for reverse Rankine cycle heat pump.

Expansion

Valve

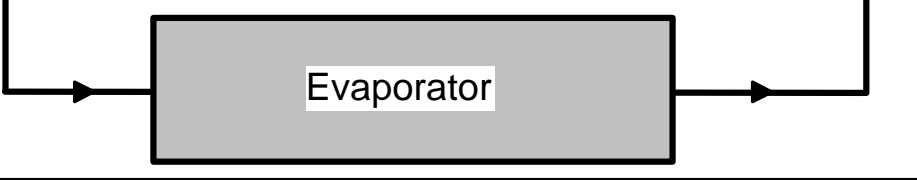




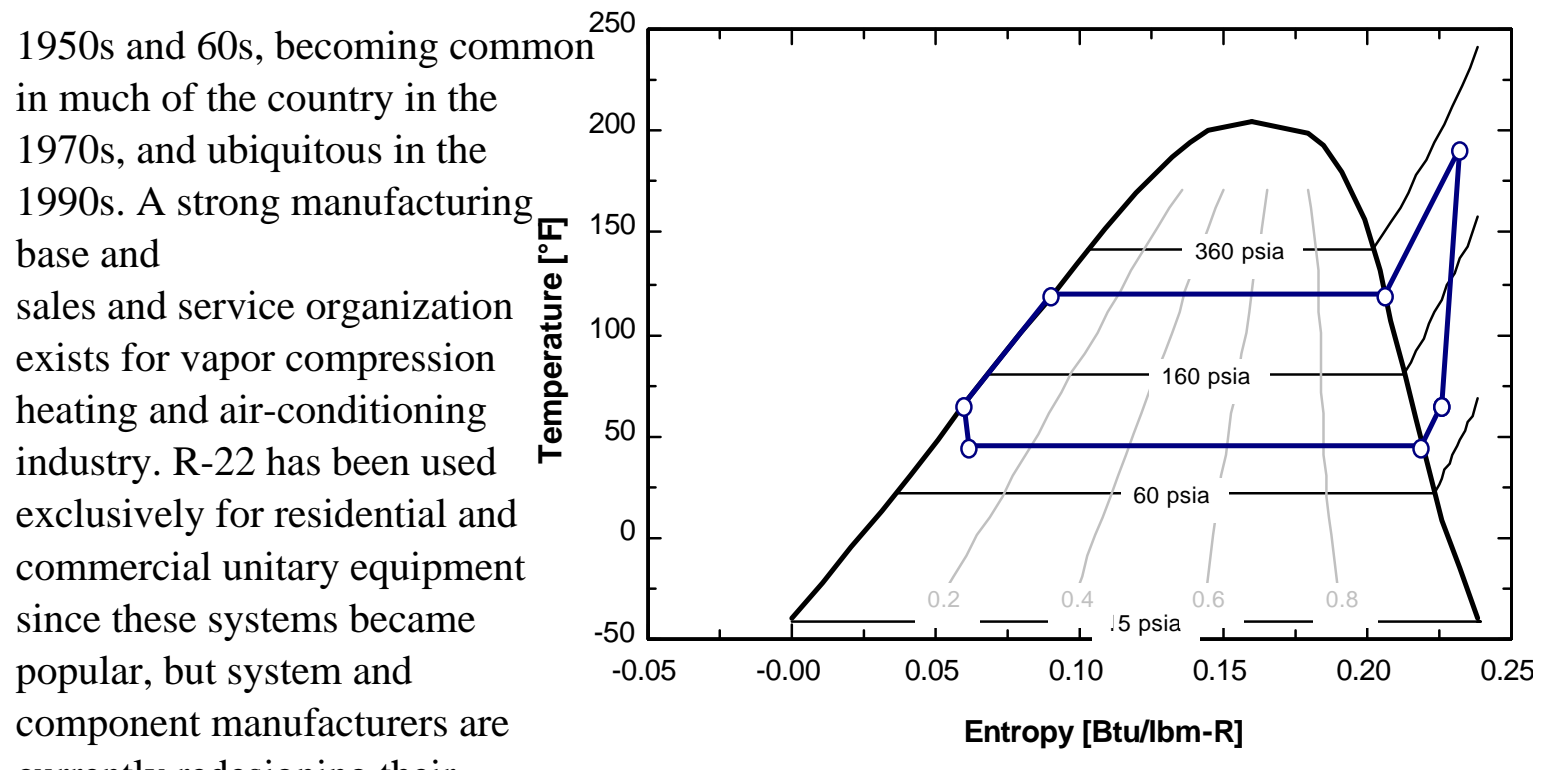

currently redesigning their equipment to use new refrigerants because

Fig. 8. Temperature-entropy (T-S) diagram for an idealized reverse Rankine cycle heat pump.

manufacturing and use of R-22

will be phased out under the Montreal Protocol. Future refrigerants in unitary systems could be blends of fluorocarbons, either azeotropic or zeotropic mixtures, hydrocarbons, or carbon dioxide; no single refrigerant has yet been determined as the preferred replacement for R-22.

\section{Secondary System Requirements}

No secondary systems are required in "standard" air-to-air system. Secondary heat transfer loops are required in water source or ground loop systems and they could be used as a safety feature if the working fluid is flammable.

\section{Efficiency Data}

Cycle efficiencies are computed using the state points defined in Table 3 with R-22 as the working fluid. The combined motor/compressor efficiency is assumed to be $70 \%$. The calculated steady-state COPs are listed in Table 4; separate entries are given for compressor only COPs

Table 3. State Point Temperatures for Rankine Cycle Calculations

\begin{tabular}{|l|c|c|c|c|}
\hline \multirow{2}{*}{$\begin{array}{l}\text { State Point } \\
\text { Temperatures }\end{array}$} & \multicolumn{4}{|c|}{ Ambient Temperatures } \\
\cline { 2 - 5 } condensing & $47 \mathrm{EF}$ & $17 \mathrm{EF}$ & $82 \mathrm{EF}$ & $95 \mathrm{EF}$ \\
\hline evaporating & $108 \mathrm{EF}$ & $95 \mathrm{EF}$ & $110 \mathrm{EF}$ & $120 \mathrm{EF}$ \\
\hline superheat & $32 \mathrm{EF}$ & $8 \mathrm{EF}$ & $47 \mathrm{EF}$ & $49 \mathrm{EF}$ \\
\hline subcooling & $10 \mathrm{EF}$ & $0 \mathrm{EF}$ & $20 \mathrm{EF}$ & $10 \mathrm{EF}$ \\
\hline
\end{tabular}


Table 4. Calculated and Observed Efficiencies for Rankine Cycle Heat Pumps with R-22.

\begin{tabular}{|r|c|c|c|c|c|c|}
\hline & \multicolumn{3}{|c|}{ Heating } & \multicolumn{3}{c|}{ Cooling } \\
\cline { 2 - 7 } Cycle Efficiency & $47 \mathrm{EF}$ & $17 \mathrm{EF}$ & $\begin{array}{c}\text { Seasonal } \\
(\text { Btu/Wh })\end{array}$ & $82 \mathrm{EF}$ & $95 \mathrm{EF}$ & $\begin{array}{c}\text { Seasonal } \\
(\mathrm{Btu} / \mathrm{Wh})\end{array}$ \\
\hline $\begin{array}{r}\text { Compressor only COP } \\
\text { theoretical } \\
\text { observed }\end{array}$ & 4.98 & 3.08 & & 5.30 & 3.97 & \\
\hline $\begin{array}{r}\text { System COP } \\
\text { theoretical } \\
\text { observed }\end{array}$ & 3.90 & 2.60 & 9.0 & 4.02 & 3.20 & 11.9 \\
\hline
\end{tabular}

notes: blank entries denote absence of calculated or measured information, calculated and observed cycle efficiencies do not apply for the shaded seasonal boxes

and system COPs. System efficiencies are computed assuming $140 \mathrm{~W}$ per ton of cooling capacity for the indoor blower and $70 \mathrm{~W}$ per ton for the outdoor fan. Outdoor fan power is adjusted for the alternative technologies evaluated in this report based on the heat rejection requirement relative to the R-22 Rankine cycle baseline; the lower the cooling COP, the greater heat rejection is, and the large the fan motor power requirement.

A computer program from NIST using algorithms for computing HSPF and SEER is used to compute seasonal performance factors. The results in Table 4 are from an Excel spreadsheet that duplicates the calculations based on the Fortran program from NIST. Both heating and cooling seasonal performance factors are computed using a cycling $\mathrm{Cd}$ of 0.25 . These results show a theoretical heating season performance factor $10 \%$ higher than the rated performance and a cooling SEER the same as the rated performance.

\section{Technical Advantages/Benefits}

These systems have been developed to the point where they are highly efficient, relatively inexpensive, and very dependable. There is an established network of sales and service personnel.

\section{Technical Disadvantages}

The fluorocarbon refrigerants that have been used traditionally, and all fluorocarbon alternatives to R-22, have appreciable global warming potentials (GWPs). Use of these refrigerants may be regulated or phased out under future international agreements to reduce emissions of greenhouse gases. 
Top of the line, Rankine cycle heat pumps are also approaching the limits of efficiency for this technology, although the efficiency of the "average" system in use is much lower.

\section{Technical Barriers}

None.

\section{Economic Analysis}

The estimated installed cost of a three ton electric air-to-air heat pump (SEER 12) was $\$ 4660$ to $\$ 5200$ in 1995 (E Source 1995), or $\$ 1553$ to $\$ 1733$ per ton. A second source reported installed costs of $\$ 3850$ to $\$ 4810$ depending on climate (EPA 1993), or $\$ 1285$ to $\$ 1600$ per ton. Adjusting for inflation these numbers range from $\$ 1430$ to $\$ 1830$ per ton. Maintenance cost is estimated to be $\$ 100$ per year.

\section{Contacts and Sources of Information}

Product literature.

EPA 1993. “Space Conditioning: The Next Frontier,” EPA 430-R-93-004.

E Source 1995. "Product Profile: The York Triathalon," November.

\section{Obvious Holes in Knowledge, Understanding, Information}

None. 


\section{RANKINE CYCLE: HYDROCARBONS}

\section{Basic Concept Description}

Fundamentally, the cycle is the same as the reverse Rankine cycle described on page 7 for fluorocarbon refrigerants. System redesign is necessary to use a flammable/explosive refrigerant safely.

\section{Background Information}

Hydrocarbons are excellent refrigerants and can be used in conventional reverse Rankine cycle electric-driven heat pumps. They have not been used in the U.S. because they are flammable and have not offered any compelling advantage over R-22 in unitary equipment. Some researchers, primarily in Europe, are promoting the use of hydrocarbons as refrigerants in commercial refrigeration and space conditioning because of the negligible GWPs of hydrocarbons. Use of hydrocarbons in these applications in the U.S. would necessitate changes in design to achieve levels of safety comparable to those achieved with non-flammable fluorocarbon refrigerants.

\section{Secondary System Requirements}

Secondary heat transfer loops can be used in unitary equipment designed with the entire mechanical package outside. This would isolate the flammable refrigerant from the occupied space, reducing fire hazards, and decrease the possibility of refrigerant leaks resulting in explosive concentrations. While improving safety, a secondary loop imposes thermodynamic losses and increased electrical parasitic power consumption.

Alternatively, lower life cycle costs may be possible for this system by modifying the design of a split system to use the flammable refrigerant safely. The analysis presented in this study assumes direct expansion heat exchangers with enhanced design to reduce the risks as listed by Keller (1997). These include:

! brazed tube joints isolated within the air handling section of the heat pump,

! pumping the refrigerant charge into a receiver in the outdoor unit during the off-cycle,

! totally enclosing the fan and blower motors and protecting the capacitor so it cannot serve as an ignition source,

! using thicker walled refrigerant tubing and providing additional external guards to protect the refrigerant circuit from accidental damage,

! use an explosion proof cover for the compressor terminals.

These, and additional safety features, are expected to increase unit costs by about 35\% relative to R-22 (Keller 1997), but they will not have a significant effect on system efficiency. 


\section{Efficiency Data}

The state point temperatures used to calculate cycle efficiencies for Rankine cycle heat pumps using a hydrocarbon as the refrigerant are listed in Table 3 on page 8. Calculated cycle and system efficiencies for a Rankine cycle heat pump using propane (R-290) are listed in Table 5. These values are based on an assumed motor/compressor efficiency of $70 \%$. System COPs are computed using fan and blower powers as described on page 8 (70 W/ton and $140 \mathrm{~W} /$ ton $)$.

Table 5. Calculated and Observed Efficiencies for Reverse Rankine Cycle Using Propane.

\begin{tabular}{|r|c|c|c|c|c|c|}
\hline & \multicolumn{3}{|c|}{ Heating } & \multicolumn{3}{c|}{ Cooling } \\
\cline { 2 - 7 } Cycle Efficiency & $47 \mathrm{EF}$ & $17 \mathrm{EF}$ & $\begin{array}{c}\text { Seasonal } \\
(\mathrm{Btu} / \mathrm{Wh})\end{array}$ & $82 \mathrm{EF}$ & $95 \mathrm{EF}$ & $\begin{array}{c}\text { Seasonal } \\
(\mathrm{Btu} / \mathrm{Wh})\end{array}$ \\
\hline $\begin{array}{r}\text { Cycle COP } \\
\text { theoretical } \\
\text { observed }\end{array}$ & 4.99 & 3.05 & & 5.27 & 3.93 & \\
\hline $\begin{array}{r}\text { System COP } \\
\text { theoretical } \\
\text { observed }\end{array}$ & 3.84 & 2.57 & 8.1 & 4.00 & 3.18 & 11.8 \\
\hline
\end{tabular}

notes: blank entries denote absence of calculated or measured information, calculated and observed cycle efficiencies do not apply for the shaded seasonal boxes

\section{Technical Advantages/Benefits}

Hydrocarbons have excellent thermodynamic and thermophysical properties that result in high COPs if additional losses are not imposed on the cycle due to safety considerations.

Hydrocarbons can be used with mineral oils, unlike the chlorine-free fluorocarbon refrigerants that require new lubricants.

\section{Technical Disadvantages}

The flammability of the refrigerant. 


\section{Technical Barriers}

Safe design.

\section{Economic Analysis}

There is essentially no difference in efficiency between a heat pump using propane and the baseline electric heat pump using R-22. The economic consequence of this is shown clearly in Table 6 where the system using propane cannot support any increase in first costs in much of the U.S. and in fact must be slightly less expensive in the heavy load regions of the northeast and southwest. This is in stark contrast with estimates of up to $35 \%$ higher costs to accommodate design changes necessary for safe use of a flammable refrigerant in unitary equipment (Keller 1997). Applying Keller's estimate to the cost data for the baseline heat pump listed on page 10 gives a likely increase in installed cost of $\$ 500$ to $\$ 640$ per ton.

\section{Contacts and Sources of Information}

Keller, F. et al., 1997. “Assessment of Propane as a Refrigerant in Residential AirConditioning and Heat Pump Applications,' Table 6. Installed Cost Premiums Possible Relative to an Electric heat pump for a Rankine Cycle Heat Pumps Using Propane.

\begin{tabular}{|l|c|c|c|}
\hline \multirow{2}{*}{ Region } & \multicolumn{3}{|c|}{ Installed Cost Premium (\$/ton) } \\
\cline { 2 - 4 } & $\begin{array}{c}3 \text { Year } \\
\text { Payback }\end{array}$ & $\begin{array}{c}5 \text { Year } \\
\text { Payback }\end{array}$ & $\begin{array}{c}\text { Equal Life } \\
\text { Cycle Cost }\end{array}$ \\
\hline Northeast & $-\$ 5$ & $-\$ 10$ & $-\$ 25$ \\
\hline Southeast & $\$ 0$ & $\$ 0$ & $\$ 0$ \\
\hline $\begin{array}{l}\text { South } \\
\text { Central }\end{array}$ & $\$ 0$ & $\$ 0$ & $\$ 0$ \\
\hline Southwest & $\$ 0$ & $\$ 0$ & $\$ 0$ \\
\hline Midwest & $-\$ 5$ & $-\$ 10$ & $-\$ 25$ \\
\hline $\begin{array}{l}\text { Northern } \\
\text { Plains }\end{array}$ & $-\$ 5$ & $\$ 0$ & $-\$ 25$ \\
\hline $\begin{array}{l}\text { Rocky } \\
\text { Mountain }\end{array}$ & $\$ 0$ & $\$ 0$ & $\$ 0$ \\
\hline $\begin{array}{l}\text { Pacific } \\
\text { Northwest }\end{array}$ & $\$ 0$ & $\$ 0$ & $\$ 0$ \\
\hline California & $\$ 0$ & $\$ 0$ & $\$ 0$ \\
\hline
\end{tabular}

Proceedings of Refrigerants for the 21st

Century, ASHRAE/NIST Conference,

October 6 and 7, pp. 57-65.

\section{Obvious Holes in Knowledge, Understanding, Information}

None. 


\section{RANKINE CYCLE: TRANSCRITICAL $\mathrm{CO}_{2}$}

\section{Basic Concept Description}

compression system to use $\mathrm{CO}_{2}$ as the refrigerant; this alternative can be attractive because of the benign environmental effects of $\mathrm{CO}_{2}$ but it requires special considerations because of the low critical point of $\mathrm{CO}_{2}$. A schematic of the basic equipment is shown in Fig. 9. The pressure-enthalpy diagram in Fig. 10 shows that the high-side operating pressure is above the critical point. A positive displacement compressor is used to compress the refrigerant above its critical point where it rejects heat to the ambient air through a gas cooler. The refrigerant is expanded to a pressure below the critical point and absorbs heat through an evaporator much like a conventional cycle. High-side heat transfer occurs at a fixed pressure

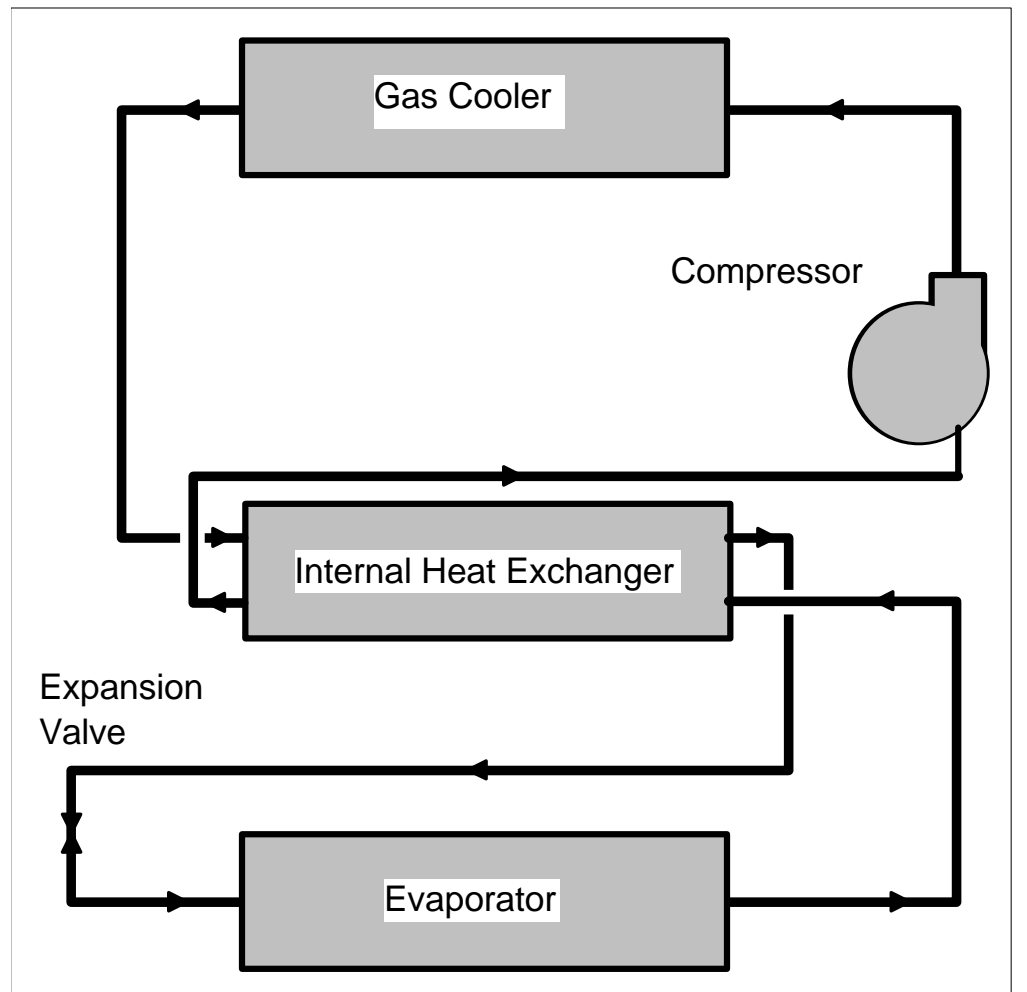

Fig. 9. Schematic diagram for transcritical $\mathrm{CO}_{2}$ heat pump with internal heat exchange. but across a wide temperature glide so there is an efficiency advantage in applications using counter-flow heat exchangers. Furthermore, there is a degree of freedom available in selecting the high-side pressure that is not available in conventional compression systems which can be used to maximize COP. It should be noted in Fig. 10 that the internal heat exchanger adds evaporator capacity by transferring heat between points " $D$ " and "E" on the high side to the region between points "A" and "B" on the low side. This heat transfer boosts cooling capacity and air conditioning COP.

\section{Background Information}

Carbon dioxide was used in very early refrigeration equipment dating back to the mid-1800s. It dominated shipboard refrigeration systems until the early 1950s (a period when ammonia dominated stationary equipment) because it is non-toxic and non-flammable. There was a decline in the use of $\mathrm{CO}_{2}$ after 1950 for a couple of reasons. First, the shipboard systems typically used seawater as the heat sink, and there was a rapid loss of capacity at the high cooling water temperatures they crossed in 
the tropics. Second, development of compressors for $\mathrm{CO}_{2}$ did not keep pace with the development of high speed, high efficiency compressors for fluorocarbon refrigerants. Shipboard $\mathrm{CO}_{2}$ systems were rapidly replaced by refrigeration systems using CFC-12 and R-502. The last shipboard $\mathrm{CO}_{2}$ system was taken ou of service in 1972.

The phase-out of CFCs that began in the late 1980s caused researchers, primarily in Norway, to reassess the potential of using $\mathrm{CO}_{2}$ as a refrigerant. SINTEF, a quasi-private corporation at the Norwegian Technical University (NTH) in Trondheim, did a significant amount of work on using the

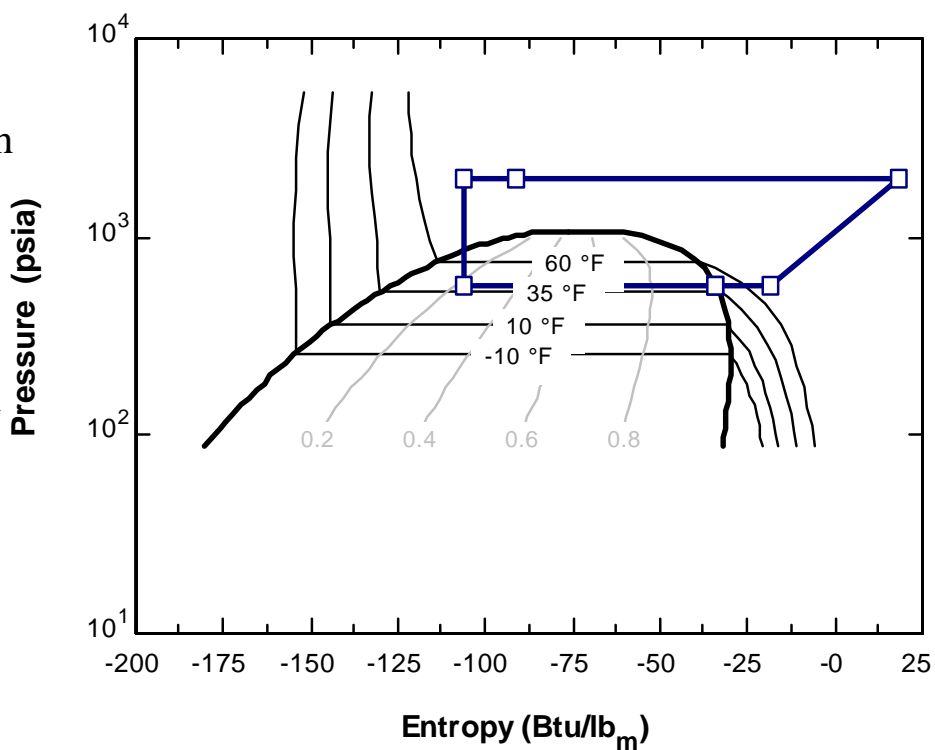

Fig. 10. Pressure-enthalpy diagram for transcritical $\mathrm{CO}_{2}$ heat pump. transcritical cycle in vehicle air-conditioning systems (primarily automobiles but also buses and trains) with some analysis in heat pumping applications. The early work at SINTEF relied on compressors built in their own machine shop which had low efficiencies and massive compressor shells. Later work at SINTEF, Denso, and elsewhere have produced compressors "comparable" to fluorocarbon compressors in size, weight, and efficiency (Quack 1994, Pettersen 1993, Lorentzen 1994, Nekså 1994, Nekså 1992, Lorentzen 1993).

Transcritical $\mathrm{CO}_{2}$ compression is currently being examined for application in automobile air conditioning, air conditioners and heat pumps with integrated water heating, and district heating. There is some problem inherent in $\mathrm{CO}_{2}$ that requires special consideration when applying the system to an application like automobile air conditioning where there is a wide range of compressor shaft speeds. $\mathrm{CO}_{2}$ experiences changes in density and volumetric capacity that causes the cooling capacity to drop off much more rapidly as the compressor speed drops than is experienced by fluorocarbon or hydrocarbon refrigeration systems. If the system is sized for highway speed operation, there is inadequate capacity under idle conditions; if it is sized for idle conditions there is far too much capacity at highway speeds and loads. Variable capacity compressors are being considered in efforts to address this loss of capacity.

Bullock presented a paper at the 1997 NIST/ASHRAE meeting on theoretical performance of an air-to-air heat pump using $\mathrm{CO}_{2}$. His analysis probably answers a lot of the questions surrounding this technology, but shows that significantly better heat exchangers and internal heat transfer are necessary to achieve the same efficiencies possible with less sophisticated R-22 heat pumps. Pettersen also published an analysis of a Japanese split-system heat pump. 


\section{Secondary System Requirements}

No secondary loop requirements.

\section{Efficiency Data}

Cycle calculations were performed for a transcritical $\mathrm{CO}_{2}$ cycle with internal heat exchange. Assumptions are consistent with those used in analysis of transcritical $\mathrm{CO}_{2}$ cycles by SINTEF (1995). The gas cooler effectiveness was specified at 0.95 which results in approach temperatures below $10 \mathrm{EF}$ in heating and $5 \mathrm{EF}$ in

cooling. Evaporating temperatures were specified as listed in Table 7 to be $5 \mathrm{EF}$ above the temperatures for the Rankine cycle heat pump because of the improved thermodynamics of $\mathrm{CO}_{2}$. The compressor efficiency is $75 \%$ (lower pressure ratio), internal heat exchange was computed using a heat exchanger UA of 10 (units to be determined). High-side operating pressures were determined to give the

Table 7. State Point Temperatures for Transcritical $\mathrm{CO}_{2}$ Cycle Calculations

\begin{tabular}{|l|c|c|c|c|}
\hline \multirow{2}{*}{$\begin{array}{l}\text { State Point } \\
\text { Conditions }\end{array}$} & \multicolumn{4}{|c|}{ Ambient Temperatures } \\
\cline { 2 - 5 } & $47 \mathrm{EF}$ & $17 \mathrm{EF}$ & $82 \mathrm{EF}$ & $95 \mathrm{EF}$ \\
\hline $\begin{array}{l}\text { gas cooler exit } \\
\text { temperature }\end{array}$ & $73 \mathrm{EF}$ & $78 \mathrm{EF}$ & $85 \mathrm{EF}$ & $100 \mathrm{EF}$ \\
\hline $\begin{array}{l}\text { evaporating } \\
\text { temperature }\end{array}$ & $33 \mathrm{EF}$ & $-10 \mathrm{EF}$ & $49 \mathrm{EF}$ & $49 \mathrm{EF}$ \\
\hline $\begin{array}{l}\text { high-side pressure } \\
\text { (psia) }\end{array}$ & 1160 & 1250 & 1240 & 1540 \\
\hline
\end{tabular}

Note: gas cooler effectiveness $95 \%$, compressor efficiency $75 \%$, internal heat exchanger UA 10.

maximum COP. The

calculated COPs and seasonal performance factors are listed in Table 8. The cooling COP at 95EF is about $30 \%$ below that for the baseline R-22 heat pump and the SEER is about $20 \%$ lower. There is about a $6 \%$ reduction in heating seasonal efficiency. The system COP at $95 \mathrm{EF}$ compares favorably with the value calculated by Bullock (2.26 vs. 2.27) while the COP at $47 \mathrm{EF}$ is about $50 \%$ higher (3.74 vs. 2.49) (Bullock 1997). The results in Table 8 are based on a higher isentropic efficiency (75\% vs. 66\%) and more optimistic assumptions about heat exchanger performance; Bullock's calculations employ detailed heat exchanger models but do not achieve the low gas cooler approach temperatures reported elsewhere (SINTEF 1995, Pettersen 1997a). 


\section{Technical Advantages/Benefits}

There are advantages to the concept because it uses an environmentally benign, non-flammable refrigerant, operates with a low pressure ratio, and has a low volume requirement. The large high-side temperature glide is also advantageous in water heating applications.

\section{Technical Disadvantages}

Table 8. Calculated and Observed Efficiencies for Transcritical $\mathrm{CO}_{2}$ Cycle.

\begin{tabular}{|r|c|c|c|c|c|c|}
\hline & \multicolumn{3}{|c|}{ Heating } & \multicolumn{3}{c|}{ Cooling } \\
\cline { 2 - 7 } Cycle Efficiency & $47 \mathrm{EF}$ & $17 \mathrm{EF}$ & $\begin{array}{c}\text { Seasonal } \\
(\mathrm{Btu} / \mathrm{Wh})\end{array}$ & $82 \mathrm{EF}$ & $95 \mathrm{EF}$ & $\begin{array}{c}\text { Seasonal } \\
(\text { Btu/Wh })\end{array}$ \\
\hline $\begin{array}{r}\text { Cycle COP } \\
\text { theoretical } \\
\text { observed }\end{array}$ & 4.88 & 2.70 & & 4.02 & 2.63 & \\
\hline $\begin{array}{r}\text { System COP } \\
\text { theoretical } \\
\text { observed }\end{array}$ & 3.78 & 2.32 & 7.8 & 3.21 & 2.26 & 9.5 \\
\hline
\end{tabular}

notes: blank entries denote absence of calculated or measured information, calculated and observed cycle efficiencies do not apply for the shaded seasonal boxes

The inherent disadvantages of $\mathrm{CO}_{2}$ compression cycles include the high operating pressure, the fact that conventional oils have low miscibility in transcritical fluids, and the low efficiency of the basic cycle. The inherently low efficiency can be compensated for by reducing expansion losses, reducing gas cooler approach temperature, and increasing compressor efficiency (Bullock 1997). High operating pressures may exacerbate problems with leaks; ASME pressure vessel requirements (multiple of highest pressure) are very high.

\section{Technical Barriers}

Heat transfer correlations have not been available and the transcritical cycle has not been treated in textbooks or classrooms. Recent activities are helping to overcome the lack of information and experience. Compressors need to be designed specifically for high efficiency space conditioning applications. 


\section{Economic Analysis}

The COPs in Table 8 result in calculated operating costs that would require medium to high reductions in installed costs for a transcritical $\mathrm{CO}_{2}$ heat pump relative to the baseline electric heat pump. These results are summarized in Table 9. The assumptions used to estimate these COPs, however, presume high heat exchanger effectivenesses and component efficiencies that have not yet been demonstrated in hardware.

In actuality, however, the installed costs of the $\mathrm{CO}_{2}$ heat pump are likely to be similar to those for a conventional heat pump; small differences are possible because of design changes with smaller tubing and stronger welds and fittings and compressor size, but large reductions are unlikely.

\section{Contacts and Sources of Information}

Bullock, C. 1997, “Theoretical Performance of Carbon Dioxide in Subcritical and Transcritical Cycles," Proceedings of Refrigerants for the 21st Century, ASHRAE/NIST Conference, October 6 and 7, pp. 20-26.

Lorentzen, G. 1993, “Application of 'Natural' Refrigerants: New System Concepts for the Use of $\mathrm{CO}_{2}$," NTHSINTEF, Proceedings of the 1993 NonFluorocarbon Insulation, Refrigeration, and Air-Conditioning Technology Workshop, pp. 251-261, Wiesbaden Germany, September 27-29, 1993.

Lorentzen, G. 1994, "Use of $\mathrm{CO}_{2}$ in Commercial Refrigeration: An Energy Efficient Solution," NTH-SINTEF. Proceedings of New Applications of Natural Working Fluids in Refrigeration and Air Conditioning, pp. 703-708, May 10-13, 1994, Hannover, Germany.

Nekså, P. 1992, “The Transcritical Vapour Compression Cycle: Its Potential in Heat Pump Processes,"NTH-SINTEF, Proceedings from the International
Table 9. Installed Cost Premiums Possible Relative to an Electric Heat Pump for a Transcritical $\mathrm{CO}_{2}$ Heat Pump.

\begin{tabular}{|l|c|c|c|}
\hline \multirow{2}{*}{ Region } & \multicolumn{2}{|c|}{ Installed Cost Premium (\$/ton) } \\
\cline { 2 - 4 } & $\begin{array}{c}\text { 3 Year } \\
\text { Payback }\end{array}$ & $\begin{array}{c}\text { 5 Year } \\
\text { Payback }\end{array}$ & $\begin{array}{c}\text { Equal Life } \\
\text { Cycle } \\
\text { Cost }\end{array}$ \\
\hline Northeast & $-\$ 110$ & $-\$ 170$ & $-\$ 500$ \\
\hline Southeast & $-\$ 75$ & $-\$ 120$ & $-\$ 350$ \\
\hline $\begin{array}{l}\text { South } \\
\text { Central }\end{array}$ & $-\$ 90$ & $-\$ 140$ & $-\$ 400$ \\
\hline Southwest & $-\$ 130$ & $-\$ 200$ & $-\$ 600$ \\
\hline Midwest & $-\$ 80$ & $-\$ 130$ & $-\$ 375$ \\
\hline $\begin{array}{l}\text { Northern } \\
\text { Plains }\end{array}$ & $-\$ 65$ & $-\$ 100$ & $-\$ 300$ \\
\hline $\begin{array}{l}\text { Rocky } \\
\text { Mountain }\end{array}$ & $-\$ 65$ & $-\$ 100$ & $-\$ 300$ \\
\hline $\begin{array}{l}\text { Pacific } \\
\text { Northwest }\end{array}$ & $-\$ 25$ & $-\$ 50$ & $-\$ 150$ \\
\hline \begin{tabular}{l} 
California \\
\hline
\end{tabular} & $-\$ 65$ & $-\$ 100$ & $-\$ 300$ \\
\hline
\end{tabular}


Symposium on Refrigeration, Energy, and Environment, pp. 273-289, June 22-24, 1992, Trondheim, Norway.

Nekså, P. 1994, "Transcritical Vapor Compression Heat Pumps," NTH-SINTEF, Proceedings of New Applications of Natural Working Fluids in Refrigeration and Air Conditioning, pp. 395-404, May 10-13, 1994, Hannover, Germany.

Pettersen, J. 1993, “A New, Efficient, and Environmentally Benign System for Automobile Air Conditioning,”Jostein Pettersen, SINTEF, SAE 1993 Annual Meeting, Paper \#931129

Pettersen, J. 1997, "Experimental Results of Carbon Dioxide in Compression Systems," Proceedings of Refrigerants for the 21st Century, ASHRAE/NIST Conference, October 6 and 7, pp. 27-37.

Pettersen, J. 1997a. Personal communication on gas cooler approach temperatures.

Quack, H. 1994, "Carbon Dioxide As A Refrigerant for Railway Refrigeration and Air Conditioning," H Quack and W. Kraus, Technische Universität Dresden Proceedings of New Applications of Natural Working Fluids in Refrigeration and Air Conditioning, pp. 489-494, May 10-13, 1994, Hannover, Germany.

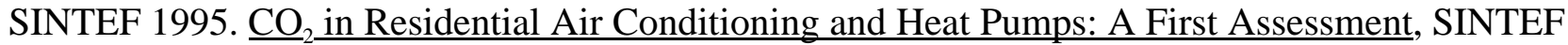
Refrigeration and Air Conditioning, The Norwegian Institute of Technology, N-7034 Trondheim, Norway, March.

\section{Obvious Holes in Knowledge, Understanding, Information}

Actual hardware testing and design optimization are necessary to support the assumed component efficiencies and calculated COPs. 


\section{BRAYTON (AIR) CYCLE}

\section{Basic Concept Description}

cycle consists of a compressor, a heat exchanger to reject heat, a turbine or expansion machine, and a second heat exchanger withdrawing heat from the conditioned space, as illustrated in Fig. 11. The fundamental principle is that when air is compressed, it is heated and that heat can be used for space conditioning; when the compressed air is expanded, it is cooled significantly and the cold air can be used for space conditioning. Expansion losses are recovered through a turbine sharing a common shaft with the compressor to reduce input power and boost COP. The

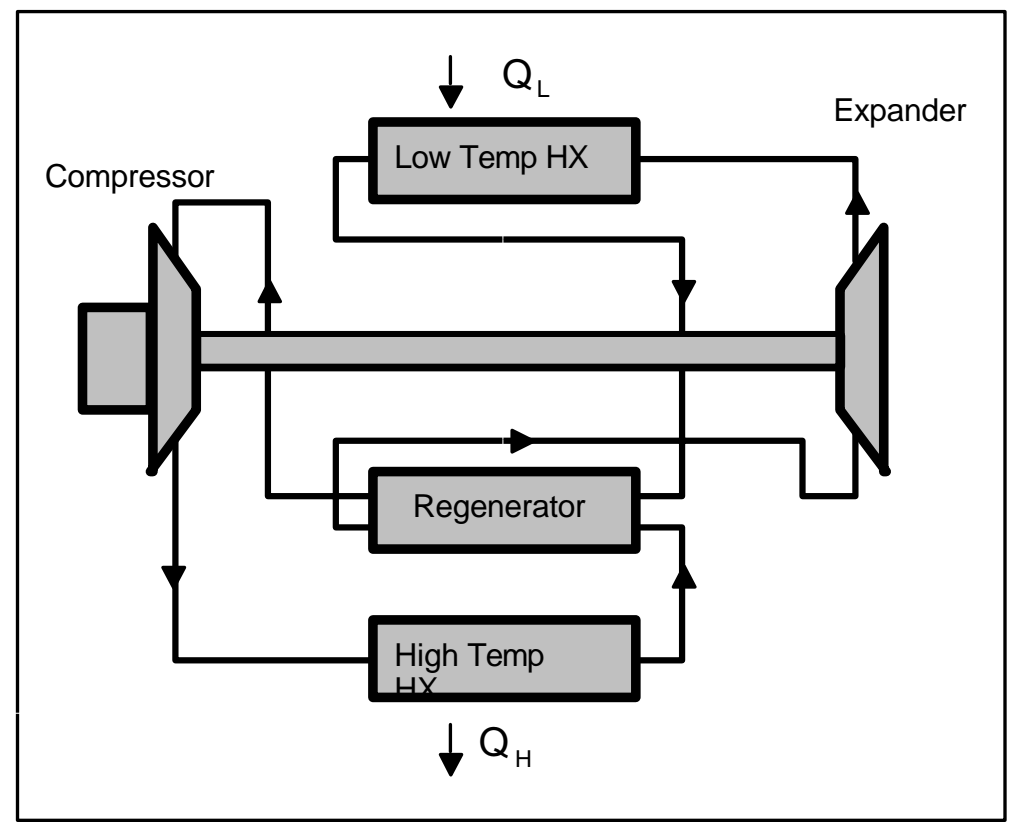

Fig. 11. Schematic diagram of a Brayton cycle heat pump. Brayton cycle is one of a group of thermodynamic processes referred to as "gas cycles" because the refrigerant or operating fluid is always in a gaseous state. This is illustrated in Fig. 12 showing the cycle superimposed on a temperature-entropy diagram above and to the right of the refrigerant vapor dome. The heat flows, $\mathrm{Q}_{\mathrm{H}}$ and $\mathrm{Q}_{\mathrm{L}}$, and constant pressure lines of a cycle with a regenerator are shown in Fig. 13.

Unlike vapor compression equipment, the pressures on both sides are not dependent on the source and sink temperatures, but are determined by the desired temperature difference between high and low pressure sides as well as the pressure ratio. Thus, one of the pressures can be chosen independent of the temperatures.

Selecting one of the pressures to be ambient pressure allows the use of open cycles, eliminating one of the heat exchangers. If the high pressure side heat exchanger is eliminated, a low pressure cycle is built, expanding outside air, rejecting heat from the conditioned space, and compressing the air to ambient pressure before it is discharged. High pressure systems use air from the conditioned space, which is compressed, the heat is rejected to the ambient before the air is expanded back into the conditioned space. Internal heat exchangers or regenerators can be used to enhance open or closed cycles, high or low pressure cycles. 


\section{Background Information}

Brayton cycle equipment
has been used for air conditioning

for commingereand. Inth maibiteny aircraft

investigated for applications in commercial water heating, automobile air conditioning, air conditioning on passenger trains, and transport refrigeration. Rovac Inc. tried to develop air-cycle equipment for automobile air conditioning, but finally gave up; it isn't clear whether they failed for technical reasons or failure to demonstrate any advantage over the established compression technology.

DOE/ORNL funded Foster

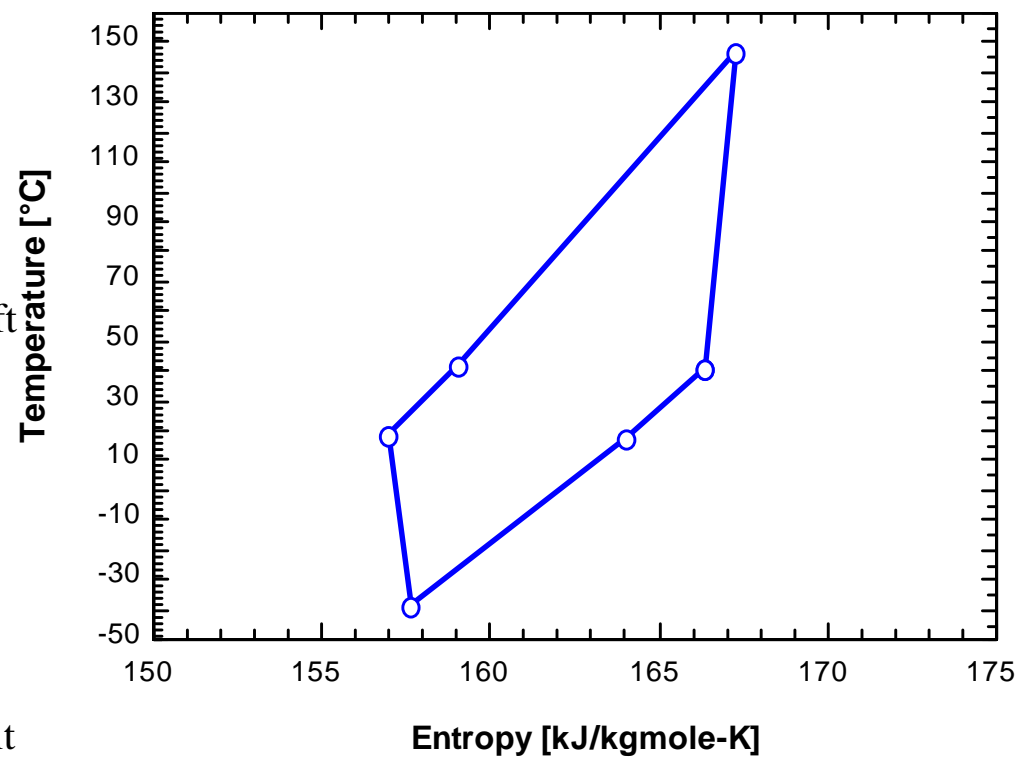

Fig. 12. T-S diagram for Brayton cycle showing refrigerant outside vapor dome.

Miller to design and build a

prototype residential air-cycle heat pump water heater and to do a marketing study. The payback period was favorable based on the project design goal COP of 1.7, but unit testing produced a COP of only 1.26. Significant valve losses were experienced in the expander. Murphy (1994) looked at 18 potential applications of aircycle equipment and identified both recommended applications and promising applications. The three recommended applications are freeze drying of foods, refrigerated containers for transport refrigeration, and fabric drying. Promising applications included heating only heat pumps, automobile air conditioning, and applications requiring concurrent heating and cooling. Murphy's evaluation included comparisons of first cost and maintenance; this

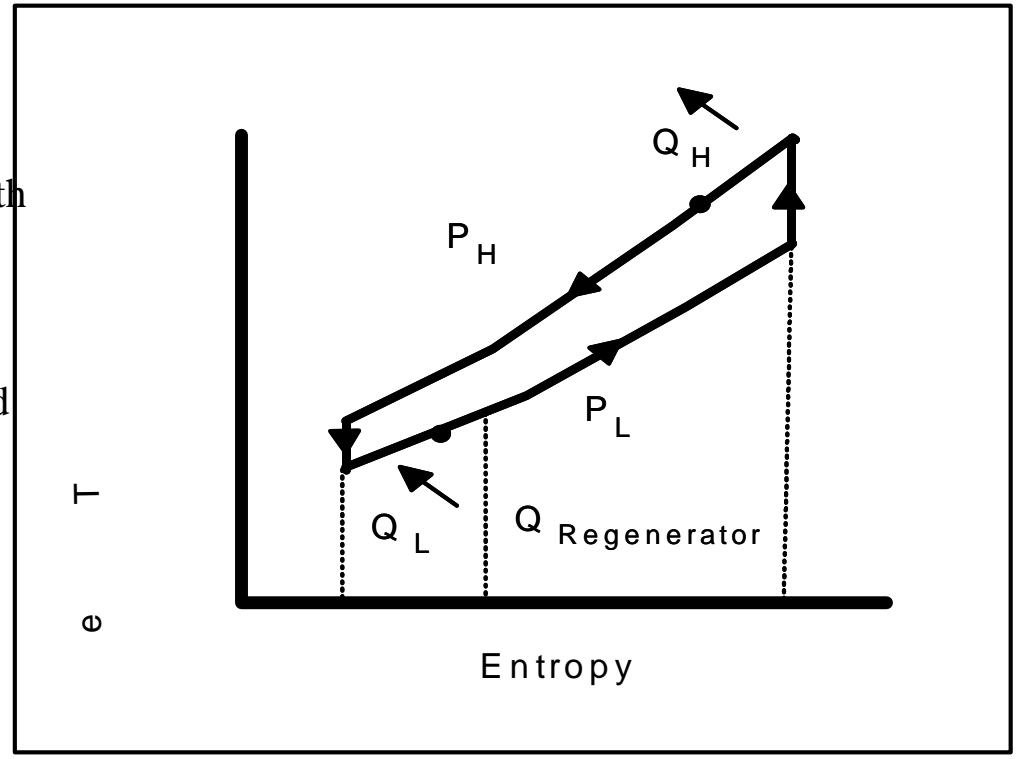

Fig. 13. T-S diagram for Brayton cycle with regenerative heat transfer. 
assessment may be suspect because the paper stated specifically that automobile air conditioners require servicing every 50 to 100 hours of operation. That is approximately a third of the annual operating hours for auto a/c in the U.S. (Murphy 1994, Hannover 1994a, Sicars, Hannover 1994b, FMA 1979, Hannover 1994c)

General Electric was under contract to DOE with a task to evaluate gas cycle refrigeration for domestic applications (refrigerator/freezers). Their analysis concluded " $[\mathrm{t}]$ he efficiency of Brayton open air cycle is higher than that of the closed cycle. With compressor and expander efficiencies lower than 0.9 , the system COP will generally be lower than the targeted COP of 1.5. Because of the unrealistically high efficiency requirements of Brayton cycle components in order to achieve parity with today's Rankine COP's, Brayton coolers are not practical for household refrigeration." This conclusion should be examined to see if it is relevant to space conditioning applications.

\section{Secondary System Requirements}

No secondary systems are required.

\section{Efficiency Data}

Cycle calculations were performed for a simple closed Brayton cycle with a recuperator using dry air as the working fluid. The state points were defined by the data in Table 10.

Calculations were performed using assumptions for component efficiencies based on the best currently available and the best efficiencies possible. The current technology steady-state COPs listed in Table 11 are computed using; compressor efficiency 0.88 , expander efficiency 0.92 , regenerator effectiveness 0.85 , heat exchanger ) T's $9 \mathrm{E}$ and $17 \mathrm{EC}$ for the low and high temperature hx'ers (. 0.85 effectiveness), pressure ratio 2.5. The best possible technology COPs are computed using; compressor efficiency 0.88 , expander efficiency 0.92 , regenerator effectiveness 0.95 , heat exchanger ) T's $3 \mathrm{E}$ and $5 \mathrm{EC}$ for the low and high temperature hx'ers (. 0.95 effectiveness), pressure ratio 2.5.

\section{Technical Advantages/Benefits}

The principal advantages of this cycle are its compact size and weight requirements, the fact that it uses a totally benign refrigerant, and it has a temperature glide in the heat exchanger.
Table 10. State Point Temperatures for Brayton Cycle Calculations.

\begin{tabular}{|l|c|c|c|c|}
\hline \multirow{2}{*}{$\begin{array}{l}\text { State Point } \\
\text { Temperatures }\end{array}$} & \multicolumn{4}{|c|}{ Ambient Temperatures } \\
\cline { 2 - 5 } & $47 \mathrm{EF}$ & $17 \mathrm{EF}$ & $82 \mathrm{EF}$ & $95 \mathrm{EF}$ \\
\hline hot heat exchanger & 100 & 85 & 105 & 120 \\
\hline cold heat exchanger & 29 & 10 & 49 & 49 \\
\hline
\end{tabular}




\section{Technical Disadvantages}

The disadvantages of the air cycle are the low efficiency (open cycle is more efficient than the closed cycle), the high volume flow rates necessary which require very high speeds (i.e. turbo compressors), the poor heat transfer, and the fact that the COP is strongly affected by pressure drop in the heat exchanger.

Table 11. Calculated and Observed Efficiencies for Closed Regenerative Brayton Cycle.

\begin{tabular}{|c|c|c|c|c|c|c|}
\hline \multirow[b]{2}{*}{ Cycle Efficiency } & \multicolumn{3}{|c|}{ Heating } & \multicolumn{3}{|c|}{ Cooling } \\
\hline & 47EF & $17 \mathrm{EF}$ & $\begin{array}{l}\text { Seasonal } \\
\text { (Btu/Wh) }\end{array}$ & $82 \mathrm{EF}$ & $95 \mathrm{EF}$ & $\begin{array}{l}\text { Seasonal } \\
\text { (Btu/Wh) }\end{array}$ \\
\hline $\begin{array}{r}\text { Cycle COP } \\
\text { theoretical } \\
\text { current technology } \\
\text { best possible }\end{array}$ & $\begin{array}{l}1.98 \\
2.11\end{array}$ & $\begin{array}{l}1.95 \\
2.02\end{array}$ & & $\begin{array}{l}1.05 \\
1.20\end{array}$ & $\begin{array}{l}0.99 \\
1.13\end{array}$ & \\
\hline $\begin{array}{r}\text { System COP } \\
\text { theoretical } \\
\text { current technology } \\
\text { best possible } \\
\text { measured }\end{array}$ & $\begin{array}{l}1.77 \\
1.87\end{array}$ & $\begin{array}{l}1.75 \\
1.80\end{array}$ & $\begin{array}{l}5.0 \\
5.2\end{array}$ & $\begin{array}{l}0.99 \\
1.12\end{array}$ & $\begin{array}{l}0.93 \\
1.06\end{array}$ & $\begin{array}{l}2.9 \\
3.3\end{array}$ \\
\hline
\end{tabular}

notes: blank entries denote absence of calculated or measured information, calculated and observed cycle efficiencies do not apply for the shaded seasonal boxes

\section{Technical Barriers}

Some of the technical problems facing successful commercial development of air cycle equipment applications other than aircraft air conditioning are:

- the expander efficiency (58\% in Foster Miller project vs. required 85\%),

- $\quad$ condensation in an open cycle, reducing COP and possibly obstructing air flow,

- $\quad$ possible turbine damage from water droplets, and

- $\quad$ lubrication of open cycle machines must avoid oil contamination of supply air and limit oil lost to environment 


\section{Economic Analysis}

The Brayton cycle was modeled using two sets of assumptions for component efficiencies; (1) those for equipment that is commercially available in 1998 and (2) estimates for highest possible component efficiencies. The economic analysis is reported only for the second case; it doesn't get any better than that. Equipment costs would need to be $\$ 3,000$ to $\$ 7,000$ per ton less than for a conventional electric heat pump for the two systems to have comparable life cycle costs.

\section{Contacts and Sources of Information}

H. Kruse, University of Hannover, Germany

U. Hesse, Robert Bosch GmbH, Stuttgart, Germany

McGovern, J. et al., 1994, "Environmentally Benign Air Cycle Heat Pumps and Refrigeration Systems, Part 1: Potential Applications for Air Cycles," Proceedings of New Applications of Natural Working Fluids in Refrigeration and Air Conditioning, Hannover, Germany, May 10-13 pp. 169-177.

Henatsch A., et al., 1994, "Cooling, Heating, and Electrical Power Cogeneration With Air as a Working Fluid," A. Henatsch, et al., Hochschule für Technik und Wirtschaft, Dresden, Germany Proceedings of New Applications of Natural Working Fluids in Refrigeration and Air Conditioning, Hannover, Germany, May 10-13 1994, pp. 519-530.

Sicars, S., 1994, “Air Cycle Systems for Transport Refrigeration”, Proceedings of New Applications of Natural Working Fluids in Refrigeration and Air Conditioning, Hannover, Germany, May 10-13, pp. 507-518.

FMA 1979, "Research and Development of an Air-Cycle Heat-Pump Water Heater," ORNL/Sub-7226/1 Foster-Miller Associates

Murphy, S. 1994, et al, "Environmentally Benign Air Cycle Heat Pumps and Refrigeration Systems," University of Dublin, and Netherlands Organization of Applied Technical Research, TNO

\section{Obvious Holes in Knowledge, Understanding, Information}

It is important to get corroborating information on the COPs for this cycle. 


\section{ELECTRICALLY-DRIVEN STIRLING CYCLE}

\section{Basic Concept Description}

constant volume processes with two constant temperature processes as illustrated in the pressurevolume (P-V) and T-S diagrams in Figs. 14 and 15. Basic operation is illustrated in Fig. 16. A system of pistons and displacers is used to move the working fluid, commonly hydrogen or helium, between volume spaces with a regenerator storing heat between steps of the cycle. Like the Brayton cycle, the Stirling cycle is a gas cycle and the working fluid does not change phase in the heat exchangers. System capacity, hence, is the product of the mass flow rate, specific heat, and ) $\mathrm{T}$ in the heat exchanger. Large flow rates are needed to produce large capacities.

\section{Background Information}

The Stirling cycle was first developed as a power cycle in the 1800s and in the past 100 years numerous attempts have been made to build refrigeration or power systems based on it. Developments include Stirling engines for automobiles and military generator sets and Stirling coolers for domestic, commercial, and transport refrigeration, heat pumps, and cryocoolers. Stirling cycle cryocoolers have been commercially successful in land-based and space-based systems.

\section{Secondary System Requirements}

Heat pipes or secondary heat transfer loops will be necessary to provide useful heating or cooling with a Stirling device. The working volume of gas in the Stirling cooler is a fundamental design property of the machine and the internal volume cannot be adjusted to circulate the gas through either an indoor or outdoor heat exchanger.

Fig. 14. P-V diagram for Stirling cycle.
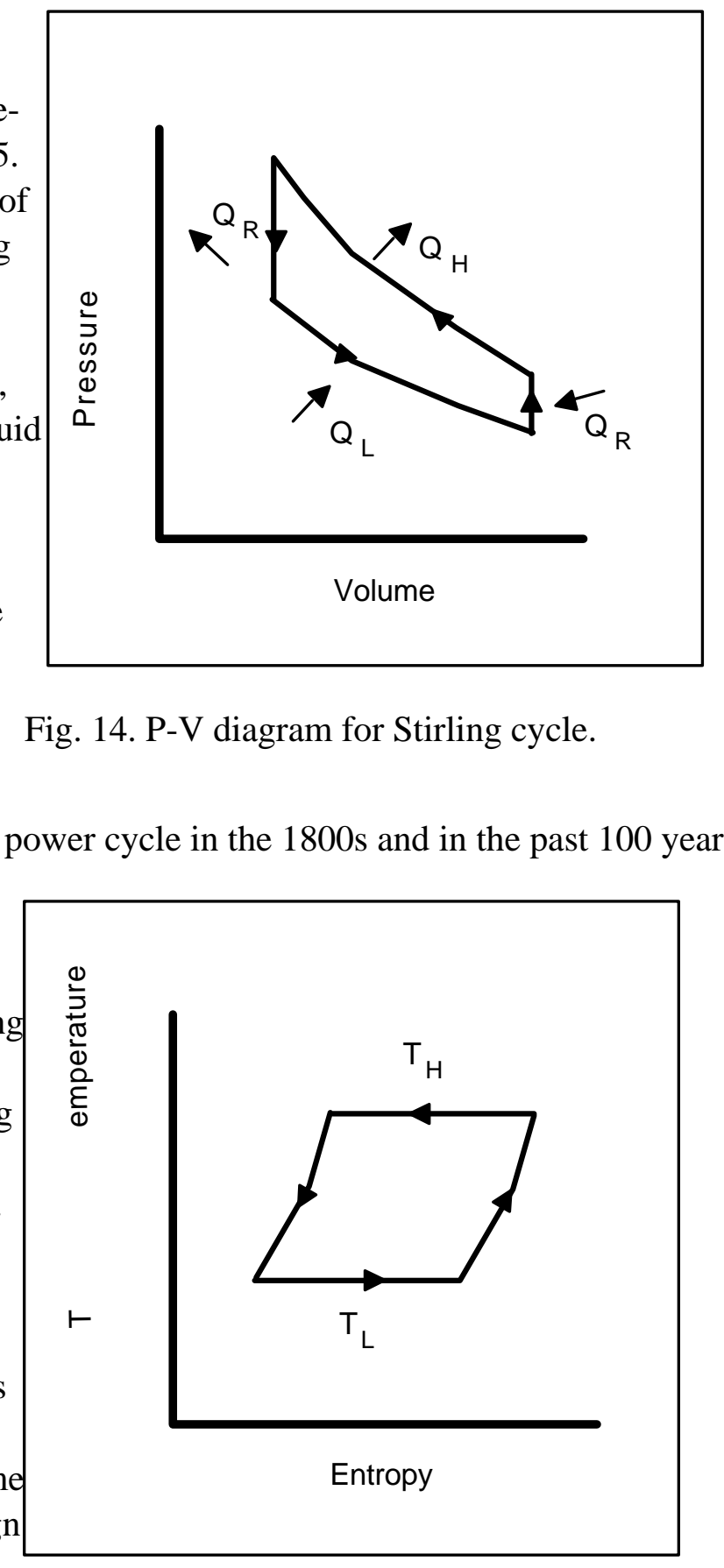

Fig. 15. T-S diagram for Stirling cycle. 


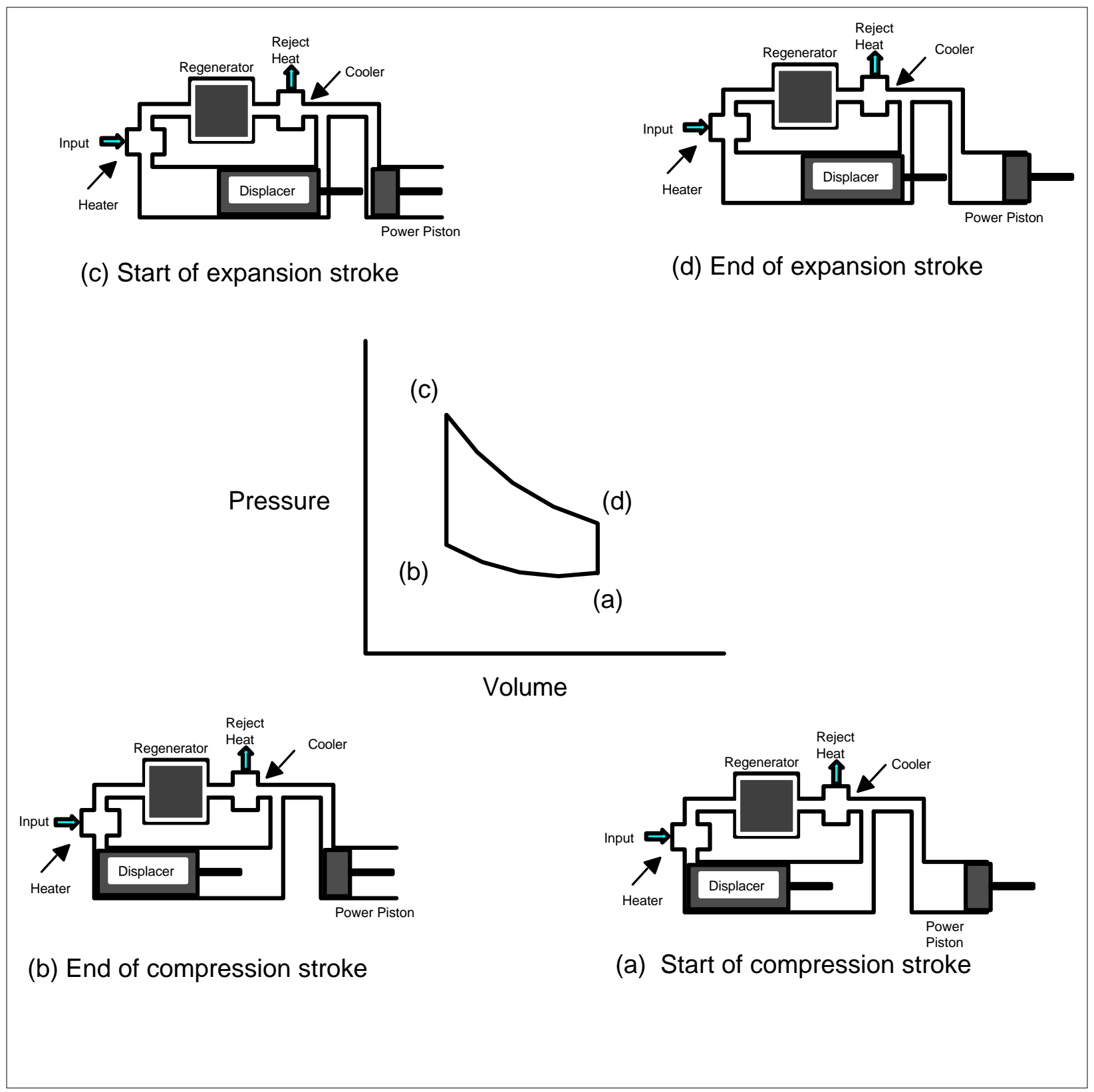

Fig. 16. Schematics of Stirling cycle refrigeration system showing movement of power piston and displacer.

\section{Efficiency Data}

The Stirling cycle was modeled using helium as the working fluid with a pressure ratio of 1.5 (low-side pressure of 1 atmosphere). The principal assumptions included component efficiencies, and gas pressure drops: 
! compression efficiency (90\%), regenerator efficiency (85\%), motor efficiency (97.5\%), and transmission efficiency (85\%), and

! no pressure drops in the heat exchangers.

The heat exchanger temperatures are listed in Table 10 on page 25. The calculated COPs are listed in Table 12. These efficiencies are extremely low and probably are not an accurate representation of this cycle. Additional data were located (ADL 1993) and included in Table 12. System, as opposed to cycle, efficiencies were computed that correspond to the ADL data by adding fan and blower power comparable to the power requirements for the reverse Rankine cycle heat pump and $100 \mathrm{~W} /$ ton pumping power for a secondary loop.

Table 12. Calculated and Observed Efficiencies for a Stirling Cycle Heat Pumps.

\begin{tabular}{|c|c|c|c|c|c|c|}
\hline \multirow[b]{2}{*}{ Cycle Efficiency } & \multicolumn{3}{|c|}{ Heating } & \multicolumn{3}{|c|}{ Cooling } \\
\hline & 47EF & 17EF & $\begin{array}{r}\text { Seasonal } \\
(\mathrm{Btu} / \mathrm{Wh})\end{array}$ & $82 \mathrm{EF}$ & $95 \mathrm{EF}$ & $\begin{array}{l}\text { Seasonal } \\
(\mathrm{Btu} / \mathrm{Wh})\end{array}$ \\
\hline $\begin{array}{r}\text { Cycle COP } \\
\text { theoretical } \\
\text { ADL (1993) } \\
\text { observed }\end{array}$ & $\begin{array}{c}1.91 \\
2.6\end{array}$ & $\begin{array}{c}1.69 \\
2.5\end{array}$ & & 0.99 & $\begin{array}{c}0.92 \\
2.5\end{array}$ & \\
\hline $\begin{array}{r}\text { System COP } \\
\text { theoretical } \\
\text { ADL } \\
\text { observed }\end{array}$ & $\begin{array}{l}1.67 \\
2.10\end{array}$ & $\begin{array}{l}1.50 \\
2.04\end{array}$ & $\begin{array}{l}4.7 \\
5.8\end{array}$ & $\begin{array}{l}0.93 \\
2.04\end{array}$ & $\begin{array}{l}0.86 \\
2.04\end{array}$ & $\begin{array}{l}2.7 \\
6.0\end{array}$ \\
\hline
\end{tabular}

notes: blank entries denote absence of calculated or measured information, calculated and observed cycle efficiencies do not apply for the shaded seasonal boxes

\section{Technical Advantages/Benefits}

Very few moving parts, theoretically long product lifetime. Environmentally benign refrigerant. Theoretically high efficiency.

\section{Technical Disadvantages}

Relatively low COP in low lift applications.

\section{Technical Barriers}

ADL (1993, p. 2-12) identified several research needs for Stirling cycle refrigeration in general:

! accurate cycle modeling capability, 
! improved regenerator performance to achieve higher effectiveness, lower pressure drop, lower void volume, lower cost, and less susceptibility to contaminant plugging.

! reduction in log mean temperature difference for the hot and cold heat exchangers where high density heat transfer is required, and

! improvement of secondary heat transfer loops.

\section{Economic Analysis}

The economic analysis for the Stirling cycle heat pump was performed using the efficiencies given by ADL (1993, p. A-47) and listed in Table 12. The maintenance costs assumed to be the same as those for the electric baseline ( $\$ 100$ per year). Stirling cycle heat pumps are most favorable in the South Central states where their installed cost would need to be nearly $\$ 2000$ per ton below the comparable costs for the baseline electric heat pump.

\section{Contacts and Sources of Information}

ADL 1993. Energy Efficient Alternatives to Chlorofluorocarbons (CFCs): A Research Needs Assessment Final Report, U.S. Department of Energy, Office of Energy Research, DOE/ER/30115H1, June.

Berchowitz, D. And Bessler, W. 1993. "Progress on Free-Piston Stirling Coolers," Sixth International Stirling Engine Conference and Exhibition, The Netherlands, May 26-28.

D.M.Berchowitz

Sunpower

Athens, OH 45701

Wurm, J., et al. 1990. Stirling and Vuilleumier Heat Pumps: Design and Application, McGrawHill, New York, NY.

\section{Obvious Holes in Knowledge, Understanding, Information}

It is important to get corroborating information on the COPs for this cycle. 


\section{VORTEX TUBE COOLING}

\section{Basic Concept Description}

Thompson effect and the Hilsch effect. Joule-Thompson is the cooling of a gas through adiabatic expansion across a restriction, the Hilsch effect refers to the use of a forced vortex in the gas stream causing the separation of gas and liquid and a temperature gradient across the vortex. As shown in Fig. 17, compressed gas in a vortex tube is fed through a tangential inlet nozzle. This gas spirals down the tube, producing two distinct flows, one hot and one cold. The temperature difference is due to the radial pressure gradient in any vortex and the viscosity of the air (Wood 1969). Due to the temperature gradient the expansion process in a vortex tube moves away from the adiabatic Joule-Thompson expansion toward a more efficient isentropic expansion.

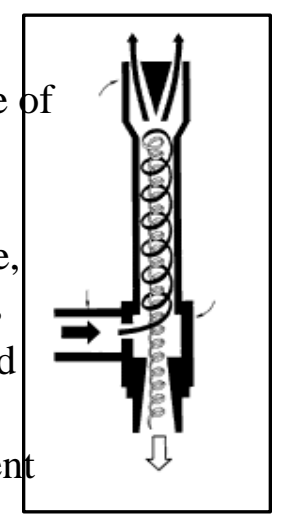

Fig. 17. Vortex tube.

\section{Background Information}

The vortex tube phenomenon was discovered in 1930 by French physicist Georges Ranque. In 1961 ITW Vortec was the first company to develop the process into practical and effective cooling equipment for industrial applications. Spot cooling equipment is commercially available that can provide refrigeration up to $6000 \mathrm{Btu} / \mathrm{h}$ or temperatures down to $-40 \mathrm{EF}$ (FILTRAN, Newman, Cockerill). Vortex tube cooling is currently applied toward gas dehydration; removal of water vapor and droplets from natural gas streams, gas dewpointing, and process and spot cooling for industrial processes with cold air guns.

\section{Secondary System Requirements}

Supply of compressed air.

\section{Efficiency Data}

Commercial products for spot cooling appear to be rated on capacity and inlet-to-outlet air ) $\mathrm{T}$ without any reported efficiency or input power. Cockerill reports a COP of 0.08 for a vortex tube household refrigerator. COPs were also calculated using product specification data from ITW Vortec and Air Compressor Products, Inc. using a motor efficiency of $85 \%$. These calculations also showed a COP of 0.08 for the ITW products independent of capacity and inlet to outlet ) $\mathrm{T}$.

\section{Technical Advantages/Benefits}

The major advantage of vortex tubes are the innate simplicity of the systems ( no moving parts), and their compact size and light weight. 
Table 13. Calculated and Observed Efficiencies for a Vortex Tube Cooler.

\begin{tabular}{|c|c|c|c|c|c|c|}
\hline \multirow[b]{2}{*}{ Cycle Efficiency } & \multicolumn{3}{|c|}{ Heating } & \multicolumn{3}{|c|}{ Cooling } \\
\hline & $47 \mathrm{EF}$ & 17EF & $\begin{array}{l}\text { Seasonal } \\
(\mathrm{Btu} / \mathrm{Wh})\end{array}$ & $82 \mathrm{EF}$ & $95 \mathrm{EF}$ & $\begin{array}{l}\text { Seasonal } \\
\text { (Btu/Wh) }\end{array}$ \\
\hline $\begin{array}{r}\text { Cycle COP } \\
\text { theoretical } \\
\text { observed }\end{array}$ & & & & & & \\
\hline $\begin{array}{r}\text { System COP } \\
\text { theoretical } \\
\text { observed }\end{array}$ & 0.08 & 0.08 & 0.3 & $\begin{array}{l}0.08 \\
0.08\end{array}$ & $\begin{array}{l}0.08 \\
0.08\end{array}$ & 0.3 \\
\hline
\end{tabular}

notes: blank entries denote absence of calculated or measured information, calculated and observed cycle efficiencies do not apply for the shaded seasonal boxes

\section{Technical Disadvantages}

The disadvantages are very low efficiency: 0.08 in cooling and domestic refrigeration (Cockerill) and low capacity: maximum 6,000 Btu/h (Cockerill and Newman Tools). The technology scales very poorly with performance dropping off substantially as the diameter of the vortex tube increases.

\section{Technical Barriers}

Limited capacity; Cockerill summarizes his conclusions that " "normalized' performance vortex tubes declines as their radius increases. Thus while increasing the size of a tube increases the maximum throughput of air, it also tends to reduce the maximum temperature difference achievable and hence there seems to be an overall physical limit on the thermal power that can be obtained from tubes of 'conventional' design." He goes further to discuss the possibility of cascading vortex tubes to achieve greater overall ) T's (he's funded to look at technologies for air liquefaction), but does not mention multiple tubes in parallel to increase capacity.

\section{Economic Analysis}

Vortex tubes are not considered a viable alternative to electric air-source heat pumps because of their low efficiency and limited capacity. The economic analysis was not performed for this technology. 


\section{Contacts and Sources of Information}

Wood, B. 1969. Applications of Thermodynamics, Addison-Wesley Publishing Company.

Cockerill, T., es0tco@environment.sunderland.ac.uk

FILTAN Web Sites: http://www.internetdienste.de/filtan/vortex.html

Newman Tools Web Site: http://www.newmantools.com/vortex.htm\#vortex

Newman Tools, Inc.

151 New Park Avenue

Hartford, CT 06106

1-800-465-1384

tom@newmantools.com

Keith Thomas

Falk \& Thomas Engineering GmbH

Rodheimer Strasse 4a

D-35435 Wettenberg 1

Germany

49641980187

fteng@t-online.de

FILTAN Filteranlagenbau GmbH

Gänsgasse 9

D-63505 Langenselbold

Germany

4961847081

ml.filtan@internetdienste.de

Obvious Holes in Knowledge, Understanding, Information

None. 


\section{THERMOELECTRIC COOLING}

\section{Basic Concept Description}

Thermoelectric refrigeration is based on the observation first made by Peltier in 1834 that a direct electric current passing through a circuit formed by two dissimilar conductors or semiconductors will cause a temperature difference to develop at the junctions of the two conductors. A refrigeration effect develops at the cold junction, and heat is rejected at the hot junction.

\section{Background Information}

There are several thermoelectric phenomena associated with joining two dissimilar materials. Perhaps the most familiar is the Seebeck effect; if a temperature difference is maintained between the two junctions, an open circuit electrical potential difference ) $\mathrm{V}$ develops which is proportional to the temperature difference ) $\mathrm{T}$ between the junctions, or:

The relationship in (1) is the basis for the widely used measurement of temperature using thermocouples. The constant of proportionality, ", is termed the Seebeck coefficient after the scientist who first described this process in 1822. The absolute Seebeck coefficient for a material is determined by using this material as one leg of a junction and lead as the reference leg. The "for the reference leg is taken to be zero. Therefore, for any material A the absolute Seebeck coefficient, " ${ }_{A}$, is a property of that material and can be positive or negative.

If a direct electrical current is made to flow through a junction of two dissimilar materials, A and $\mathrm{B}$, then the heat energy which is produced or absorbed at the junction is proportional to the current and to the absolute Seebeck coefficients by the relation:

$$
\mathrm{Q}^{\prime}(" \& ") \times \mathrm{i} \times \mathrm{T}
$$

where $\mathrm{T}$ is the absolute temperature of the junction and $\mathrm{I}$ is the direct electrical current. This relation was developed by Peltier. Whether this heat is absorbed or produced depends on the direction of current flow.

The magnitude of heat flow at a junction depends on the values of the absolute Seebeck coefficient for the individual materials. In the case of metals, this coefficient does not exceed $50 \mu \mathrm{V}$ per EC (ASHRAE 1981). However, in semiconductors, " can be much higher. Some materials with the 
highest " (. 250 $\mu \mathrm{V}$ per EC) are alloys of tellurium (Te) doped with antimony tri-iodide $\left(\mathrm{SbI}_{3}\right)$ to produce an "n-type" semiconductor and with excess Te to make a "p-type" material (Houst 1982).

The relation between the cooling delivered by a thermoelectric couple and its material properties and configuration can be used to determine the efficiency of thermoelectric cooling. A simple thermoelectric cooling device consisting two semiconductors and electrical connectors, which also serve as heat exchangers, is shown in Fig. 18. A direct electric current passes through the n-type semiconductor on the left, through the finned copper or aluminum conducting strap at the top, and then through the p-type material on the right. At the cold junction at the top heat $Q_{C}$ is removed from the ambient (the cooling effect), and at the hot junction, heat $\mathrm{Q}_{\mathrm{H}}$ is rejected. Theoretically the maximum efficiency is given by Eq. 3 where the variable " $\mathrm{Z}$ " is defined accordin $\$$ to (4), and $\mathrm{T}_{\mathrm{H}}$ and $\mathrm{T}_{\mathrm{C}}$ are the absolute temperatures at the hot and cold junctions. The relations in (4) show that the maximum $\mathrm{COP}$ of a

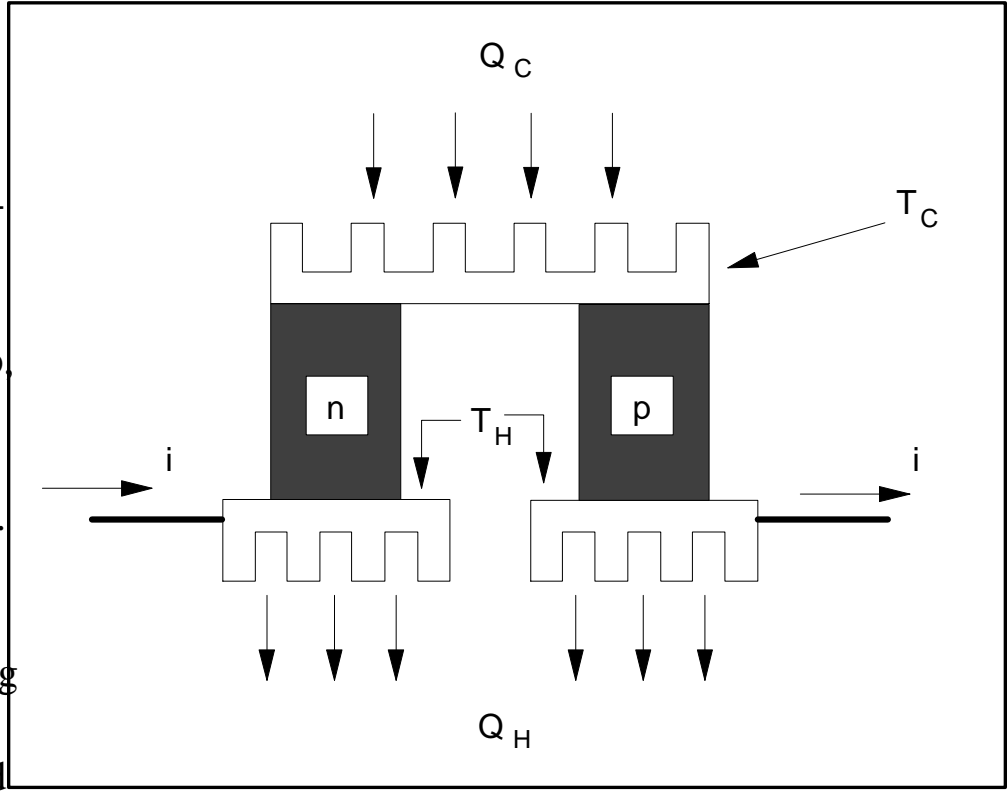

Fig. 18. Schematic for a simple thermoelectric couple. thermoelectric refrigerator depends simply on the Seebeck coefficients ", thermal conductivity K, and semiconductor resistivity Dof each leg, and on the operating temperatures. The expression $\mathrm{Z}$ is called the figure of merit for the couple. Selecting materials with high difference in "'s, low K, and low Draises the figure of merit and improves the maximum COP. At an average temperature $\mathrm{T}=25 \mathrm{EC}$ (77EF) for space cooling applications, typical off the shelf thermoelectric modules produce a value of $Z=0.0026$ (Mei 1992).

$$
\begin{aligned}
& \text { (⿻) } \quad \frac{T_{\mathrm{C}}}{\mathrm{T}_{\mathrm{H}} \& \mathrm{~T}_{\mathrm{C}}} \times \frac{\left[1 \% \mathrm{Z} \times \frac{\mathrm{T}_{\mathrm{H}} \% \mathrm{~T}_{\mathrm{C}}}{2}\right]^{1 / 2} \& \frac{\mathrm{T}_{\mathrm{H}}}{\mathrm{T}_{\mathrm{C}}}}{\left[1 \% \mathrm{Z} \times \frac{\mathrm{T}_{\mathrm{H}} \% / \mathrm{T}_{\mathrm{C}}}{2}\right]^{1 / 2} \%} \\
& Z^{\prime} \frac{[" \& "]}{[\sqrt{K D} \% \sqrt{K D}]}
\end{aligned}
$$


Thermoelectric modules are now being mass produced with $\mathrm{Z}=0.003 / \mathrm{K}$ (Mei 1998).

"The materials used in today's [thermoelectric] modules have a ZT [T is the mean operating temperature, the average of $\mathrm{T}_{\mathrm{H}}$ and $\mathrm{T}_{\mathrm{C}}$ ] of about 1.0, which is not enough. A ZT value of 3 and above is required to produce energy efficient cooling units (Mathiprikasam 1993)." At an absolute temperature of $300 \mathrm{~K}(27 \mathrm{EC}$ or $80 \mathrm{EF}), \mathrm{ZT}=1$ would correspond to a figure of merit $\mathrm{Z}=0.0033 ; \mathrm{Z}=0.0035$ is the highest figure of merit attained under laboratory conditions (Mei 1994).

Researchers have developed theories on the thermoelectric processes and projected limits on what values for the figure of merit may be possible with ideal materials. In developing his ideas Mahan found "the maximum value of ZT to be about one to two. This value is close to experimental reality, where it is hard to find values of ZT greater than one (1989)." Such an analysis adds emphasis to the difficulty in making the material breakthrough necessary to achieve the ZT $=3$ that is cited by Mathiprikasam as necessary to produce energy efficient cooling systems.

The literature on thermoelectric cooling can be confusing because three different terms are frequently used to measure or report the efficiency of semiconductor pairs; (1) the relative Seebeck coefficient ", (2) the figure of merit Z, and (3) the relative figure of merit ZT. Discussions or comparisons can become confused because of the similarity in the absolute "values" of these quantities while they differ substantially in orders of magnitude (e.g. " $=250$ to $300 \times 10^{-6} \mathrm{~V} / \mathrm{K}$ in Labinov's paper, $\mathrm{Z}=0.00274 / \mathrm{K}$ in Gauger's dissertation, $\mathrm{ZT}=0.25$ in Mahan's graphs). The following definitions might help:

" $\quad$ relative Seebeck coefficient $(\mu \mathrm{V} / \mathrm{K})$; the difference between the Seebeck coefficients for the two materials in the thermoelectric cell:

$$
\text { " } 1 " \& "
$$

$\mathrm{Z}$ figure of merit $(/ \mathrm{K})$, the best commercially available thermoelectric couples have $\mathrm{Z}=0.00274 / \mathrm{K}$ with laboratory couples a little higher at $\mathrm{Z}=0.0030 / \mathrm{K}$

$$
Z^{\prime} \frac{\prime}{(\sqrt{6 k} \% \sqrt{6 k})}
$$

ZT dimensionless figure of merit (no units), $T$ is the average of the hot and cold heat exchanger temperatures $(\mathrm{K})$; ZT generally ranges between 0.4 and 1.3 for current thermoelectric materials (Mahan 1997)

The maximum refrigeration COP for a thermoelectric pair is given by: 


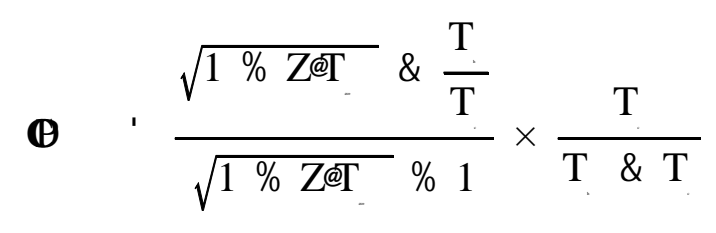

Increasing " and the dimensionless figure of merit, ZT, increases COP. Traditionally, research has focused on increasing " and $\mathrm{Z}$ through the selection of increasingly exotic materials for the thermoelectric couple. Aspden and Strachan and Thermodyne, Inc. have worked independently to use A/C electric fields to increase the Seebeck coefficient ". Their work has not been accepted by the scientific community.

Aspden and Strachan constructed a device as part of a project on power generation. Their unit essentially consisted of 500 planar capacitors with a film of polyvinylidene fluoride (PVFD) as the dielectric with nickel substrates on both sides covered with aluminum foil (Labinov 1998). The nickel and aluminum were joined in such a manner as to form a classic nickel-aluminum thermocouple; these were connected to form 20 parallel blocks, each with 25 thermocouples in series. An external, alternating current circuit was added, and tuned in some manner that achieved a significant increase in the thermoelectric effect between the nickel and aluminum couples.

Aspden and Strachan claimed to have observed a relative Seebeck coefficient for their device of " $=250-300 \mu \mathrm{V} / \mathrm{K}$, which is said to be the maximum theoretically possible for this pair and 15 times greater than previously reported for nickel-aluminum (Labinov 1998). There is no fundamental explanation of why the A/C field boosts " to the vicinity of its theoretical maximum. Their test lasted only 73 seconds before the device failed; efforts to repeat the test have failed. Labinov concluded that natural convection was inadequate to provide the cooling required by this device and that it overheated after 73 seconds causing its own failure. Aspden and Strachan's work is held in low regard by some of the best people in solid state electronics and their reported results are not accepted.

Thermodyne, Inc. is pursuing a device similar to that constructed by Aspden and Strachan, although they are using a ceramic layer instead of polyvinylidene fluoride. Thermodyne's initial interest is also for power generation instead of cooling. They are seeking funds $(\$ 30,000$ to $\$ 50,000)$ from an electronics manufacturer to produce a single "chip" using a 60 to $70 \mathrm{EC}$ ) $\mathrm{T}$ to drive a fractional wattage motor. Thermodyne is unwilling to discuss details of their work at this time, although they would be interested in getting assistance from national laboratories on material related problems. Their patented process uses lead scandium tantalate ceramics (Jaeger 1997). The primary interest at this time is the extremely high power densities claimed in the Thermodyne patent (hundreds of W/cm², Jaeger 1997).

\section{Secondary System Requirements}

No secondary systems are required. 


\section{Efficiency Data}

Steady-state cycle efficiencies are computed using the heat exchanger temperatures listed in Table 10 on page 23 . The figure of merit is assumed to be $0.00274 / \mathrm{K}$ which is representative of the best commercially available thermoelectric couples in 1998. Seasonal COPs are computed using a cycling $\mathrm{Cd}$ of 0.0. COPs for the thermoelectric cells and system COPs are shown in Table 14.

Table 14. Calculated and Observed Efficiencies for Thermoelectric Cooling.

\begin{tabular}{|r|c|c|c|c|c|c|}
\hline & \multicolumn{3}{|c|}{ Heating } & \multicolumn{3}{c|}{ Cooling } \\
\cline { 2 - 7 } & & & $\begin{array}{c}\text { Seasonal } \\
\text { (Btu/Wh) }\end{array}$ & $82 \mathrm{EF}$ & 95EF & $\begin{array}{c}\text { Seasonal } \\
(\text { Btu/Wh })\end{array}$ \\
\hline Cycle Efficiency & $47 \mathrm{EF}$ & $17 \mathrm{EF}$ & & & & \\
$\begin{array}{r}\text { Cycle COP } \\
\text { best possible (1998) }\end{array}$ & 1.58 & 1.20 & & 0.92 & 0.65 & \\
maximum possible ZT & 2.69 & 1.94 & & 3.38 & 2.82 & \\
\hline System COP & & & & & & \\
best possible (1998) & 1.40 & 1.09 & 3.9 & 0.86 & 0.62 & 2.5 \\
maximum possible ZT & 2.30 & 1.73 & 5.8 & 2.79 & 2.40 & 8.3 \\
\hline
\end{tabular}

notes: blank entries denote absence of calculated or measured information, calculated and observed cycle efficiencies do not apply for the shaded seasonal boxes

\section{Technical Disadvantages}

Inherently low efficiency. A relative figure of merit ZT of approximately 3 is needed to achieve efficiencies comparable to vapor compression equipment.

\section{Technical Barriers}

Low figure of merit requires significant breakthroughs in materials. Also, the limited supply of thermoelectric materials would limit production to a maximum of 100,000 to 200,000 units per year.

\section{Economic Analysis}

The inherently low efficiencies of thermoelectric cells results in very unfavorable economic comparisons. COPs derived from the maximum figure of merit currently achievable $(\mathrm{Z}=0.00274)$ results in operating costs that would require reductions in installed costs in excess of $\$ 4000$ per ton; the installed cost of either the electric or gas furnace baseline systems are less than $\$ 2000$ per ton. A 
comparison of the performance using the theoretical maximum efficiency, however, $(\mathrm{ZT}=3)$ results in operating costs that would require reductions in installed costs of only $\$ 300$ to $\$ 600$ per ton (20\% to $25 \%$ ) to have the same life cycle cost as the electric baseline heat pump. These results are discussed more thoroughly on page 43 for thermionic heat pumps.

\section{Contacts and Sources of Information}

ASHRAE 1981. ASHRAE Handbook: Fundamentals

Gerald Mahan

Oak Ridge National Laboratory

Solid State Division

P.O. Box 2008

Building 3025, MS 6032

Oak Ridge, TN 37831

(423) 576-8675

Obvious Holes in Knowledge, Understanding, Information

None at this time. 


\section{THERMIONIC COOLING}

\section{Basic Concept Description}

There is a fine distinction between thermionic and thermoelectric cooling. Thermoelectric uses a flow of electrons through a pair of semiconductors in intimate physical contact. Thermionic cooling uses the flow of electrons between two separated electrodes. Consider the old vacuum tube diodes, a negatively charged surface emits electrons that traverse an evacuated space to a positively charged surface. Thermionic cooling is the solid state equivalent with extremely small gaps separating the electrodes (on the order of microns). Theoretically, under an applied electrical potential, the electrons emitted by the electrode are at a higher energy level than those that are left behind which reduces the average energy level (temperature) of the emitting electrode. The electrons being absorbed on the other side of the gap are at a higher energy level than those in the electrode, the average energy level is increased, and the electrode is heated.

\section{Background Information}

Knowledge of thermionic converters goes back to Edison's study in 1885 that established experimentally that if two plane electrodes were placed in a vacuum an electrical current developed between them if one was heated to a temperature higher than the other. Most of the subsequent developments related to the direct conversion of heat energy into electricity. A number of experimental studies in 1957 established quite reliably that the efficiency of heat energy conversion to electricity is 5 to $10 \%$ with specific power of 3 to $10 \mathrm{~W} / \mathrm{cm}^{2}$. According to theory, a thermionic converter should operate in direct mode as a power generator and also in reverse mode as a heat pump. Little work was done until recently in applying thermionic converters as cooling devices.

Applying thermionic converters to cooling devices is limited, first of all, by the presence of materials capable of active electron emission in the temperature range of 250 to $300 \mathrm{~K}$ ( $-10 \mathrm{E}$ to $80 \mathrm{EF}$ ). The first tangible results of a 30 year long search for suitable materials brought results in the 1990's. Edelson and Cox received patents in 1995 and 1997 for two possible ways of providing cooling with thermionic converters and Mahan published a paper in 1997 on a third method. Edelson proposed using an evacuated space between two electrodes allowing free electron movement (ballistic electron motion). Mahan proposes a thin semiconductor between the electrodes employing the tunnel effect for electron movement. Cox proposed an ionized gas evaporating at one electrode and condensing on the other.

While each of these approaches has its own specific features, they all use one common idea. Each of proposed devices uses materials with high electrical conductivity because of free electrons. At a given temperature, the electrons move at various speeds and in various directions, and have various energy distributions that can be found using Fermi-Dirac statistics (Moelwyn-Hughes 1961). The portion of the electrons at energy levels sufficient to overcome the potential barrier, escape the boundary of the metal surface; this is called thermionic emission. 
If two parallel flat electrodes are placed in a vacuum, then the electrons have energy sufficient to overcome the potential barrier and be released from the surface of one electrode will move in a direction normal to the electrode surface until they reach the opposing electrode where they are absorbed. This free motion of electrons is called "ballistic" to differentiate it from "diffusion motion" which experiences the resistance of the medium where electron motion takes place. A similar effect is observed when the electrons move in a medium that has structural effects allowing a "tunneling effect" permitting free movement through the medium.

\section{Secondary System Requirements}

There are problems associated with heat transfer to and from the very small electrode surfaces which may require, or work best, using a secondary system like a heat pipe.

\section{Efficiency Data}

Mahan is working on a demonstration of solid-state thermionic converters; his primary interest is in using heat to generate electricity although he acknowledges that the reverse process has valuable applications. Mahan speaks of theoretical efficiencies equivalent to ZT between 3 and 4 for conventional thermoelectric cooling. Mahan has applied for patents on his ideas, but prefers not to discuss them in detail until after proof of concept testing has been successful. COPs assuming ZT of 3 are also listed in Table 14 for thermoelectric cooling on page 37.

Thermionic refrigerators will be competitive with thermoelectric cooling devices as they are developed for higher efficiencies. At the current stage of their development they are unable to compete with alternative cooling technologies because of significantly lower operating efficiencies. The greatest potential for thermionic cooling may be for very low and micro-power applications.

\section{Technical Advantages/Benefits}

There are no moving parts outside of the air handling equipment, no refrigerants, and the possibility of low manufacturing costs as exhibited by sectors of the electronics industry.

\section{Technical Disadvantages}

There are several disadvantages or problems with thermionic converters in space conditioning applications:

! electrodes must be made of materials with low work functions to provide sufficient electrical current at low temperatures, but this results in decreased capacity,

! an interelectrode space of 1 ton $5 \mu \mathrm{m}$ is necessary to decrease the power requirement of the converter which will be difficult to achieve or maintain in vacuum thermionic devices,

! the temperature difference between the electrodes must be kept small to decrease the radiant and conductivity heat losses, Mahan recommended 1 to $2 \mathrm{EC}$. Reducing radiant and conductive 
losses, thus, requires multilayer construction to achieve a useful ) $\mathrm{T}$ in this application with an increase in electrical resistance and additional energy losses,

! thermionic devices with a thin layer of a semiconductor between the electrodes need to be tested experimentally to determine their efficiencies under real values of the layer heat conductivity loss, and

! even with the heat transfer density of $1 \mathrm{~W} / \mathrm{cm}^{2}$, thermionic devices will need to overcome common problems associated with heat removal from very small surface areas; this task probably requires a cooling system with an actively pumped working fluid.

\section{Technical Barriers}

The greatest barrier to developing more efficient thermionic devices is probably the manufacturing technologies for achieving extremely small interelectrode spacing. Mahan speaks of using advanced technologies to build prototype systems essentially building the semiconductor divider in the interelectrode space an atom at a time. Developers of vacuum electrode gaps have not commented on manufacturing techniques.

\section{Economic Analysis}

The inherently low efficiencies of thermionic converters are compensated for in part by the absence of cycling losses and low maintenance costs. Comparisons were made for the theoretical maximum efficiencies using $\mathrm{C}_{\mathrm{d}}=0$ for the thermoelectric heating and cooling and maintenance costs of $\$ 25$ per year. Installed costs would need to be $\$ 325$ to $\$ 600$ per ton below the cost of the electric baseline heat pump for the systems to have comparable life cycle costs in the southeastern, south central, and southwestern states assuming the maximum theoretically possible cell efficiencies ( $\mathrm{ZT}=3)$.

\section{Contacts and Sources of Information}

Gerald Mahan

Oak Ridge National Laboratory

Solid State Division

P.O. Box 2008

Building 3025, MS 6032

Oak Ridge, TN 37831

(423) 576-8675

Moelwyn-Hughes, E.A. 1961. Physical Chemistry, Pergamon Press.

Hafsopoulos, G. N., et al. 1973, Thermionic Energy Conversion, The Massachusetts Institute of Technology 
Rowe, D. M. 1994. Proceedings of the 13th International Conference of Thermoelectrics.

Bogomolov, V. N., 1995. Proceedings of the 14th International Conference of Thermoelectrics.

Moyrhes, B., 1996. Proceedings of the 15th International Conference of Thermoelectrics.

Mahan, G. D. 1994. Journal of Applied Physics, 76 (7), p. 4362, October 1.

Mahan, G. D. 1998. Journal of Applied Physics, 83 (9).

\section{Obvious Holes in Knowledge, Understanding, Information}

No measured performance data, either capacity or efficiency, are available at any conditions. Mahan's proof of principal testing at ORNL in August 1998 may prove whether or not the phenomenon of thermionic exists for power generation, although further work would be needed to provide any information on efficiency. 


\section{THERMOACOUSTIC COOLING}

\section{Basic Concept Description}

Thermoacoustic cooling relies on a high energy standing sound wave to generate a temperature gradient across a stationary element called the stack; heat exchangers at the ends of the stack are used to transfer heat in and out of the system. This cycle is illustrated in Fig. 19; it consists of four principal components:

1. a "stack" of porous material, parallel plates, or sheets of a thin material rolled into a spiral

2. hot and cold heat exchangers consisting of finned tubes, parallel plates, screens, or metallic wool,

3. a rigid and sealed tube that may incorporate a Helmholz resonator to shorten the device and minimize losses, and

4. an acoustic energy source, referred to as an electroacoustic transducer (i.e. a loud speaker or a piston).

The working fluid is usually a mixture of perfect gases, such as xenon and helium. The driver operates at the resonance frequency of the system to produce fairly large pressure fluctuations that alternately compress and expand the working fluid adiabatically and cause the fluid to oscillate back and forth within the stack and heat exchangers. The stack serves as a regenerator as the working fluid oscillates back and forth, absorbing heat during the compression phase of the acoustic wave in the working fluid and rejecting heat back to the gas during the expansion phase. The complete cycle, then, resembles a series of Brayton cycles grouped together as illustrated in Figs. 20 and 21. The stack is typically fairly short, on the order of inches, and there can be hot and cold heat exchangers at each end of the stack to get heat in and out of the system (several different techniques are being investigated to get useful heating and cooling from the stack).

\section{Background Information}

Development of thermoacoustic cooling has been promoted in large part by the U.S. Department of Energy at Los Alamos National Laboratory for liquefaction of natural gas and by the U.S. Navy for shipboard applications such as cooling electronic equipment or crew spaces, although there have been commercially funded prototypes built in the U.S. by Cryenco, Tectronix, and Ford Motor Company. Greg Swift and his colleagues at LANL recently demonstrated a device which generated sound thermoacoustically by burning natural gas and used that sound to liquefy 140 gal/day of natural gas in a pulse-tube refrigerator. A 500 gal/day unit is currently under development. A related heat-driven device the size of a soft drink can was designed for cooling of "down hole" instrumentation in well drilling applications.

Steven Garrett (formerly of the Naval Postgraduate school, now at Penn State) and his colleagues designed and built two space-qualified prototypes which cooled below -60EC and provided a few watts of cooling power. One was flown on the space shuttle Discovery (STS42) in 19922. This was followed by a larger unit which cooled to a minimum temperature of -20EC. It consumed 216 


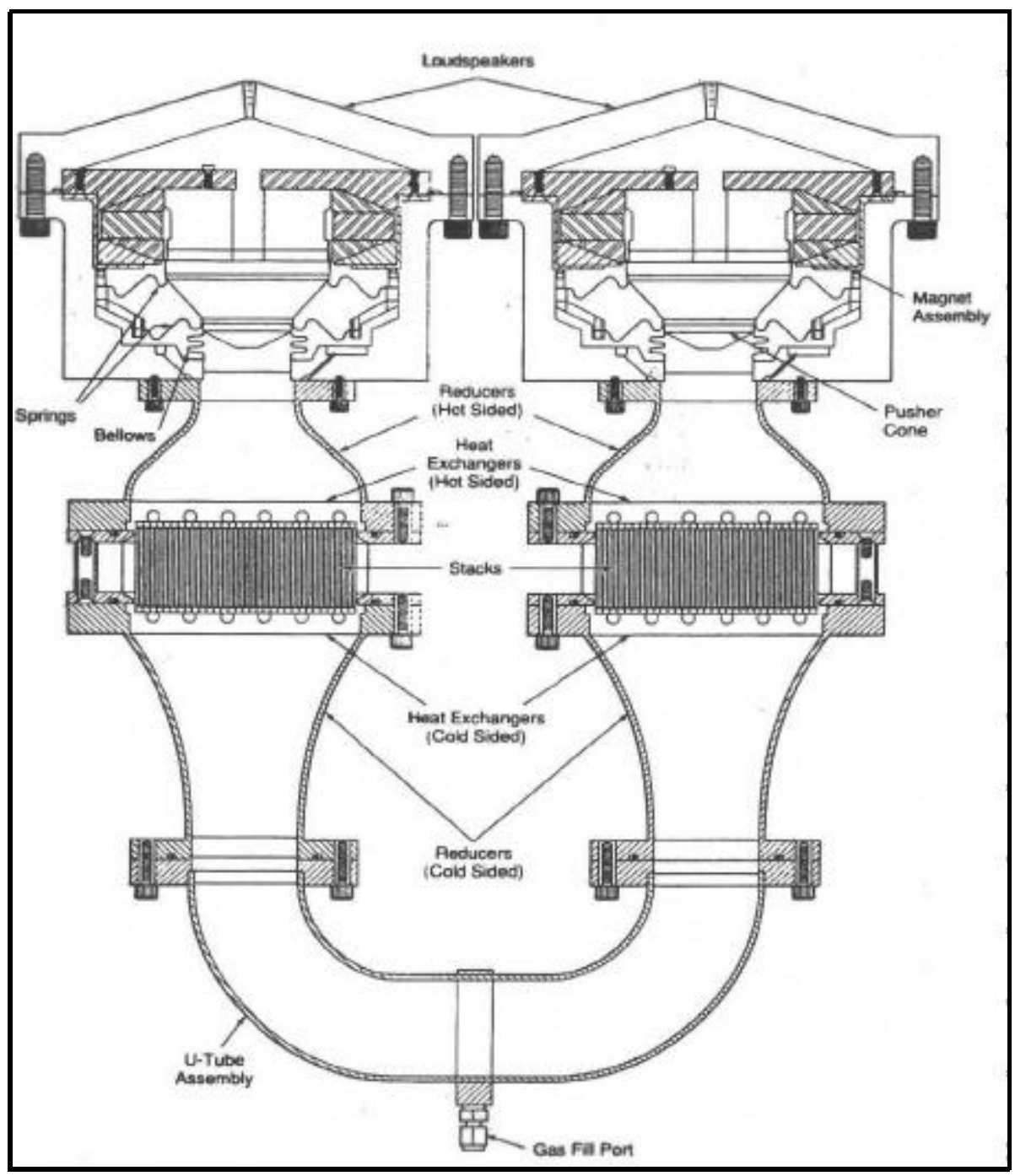

Fig. 19. Schematic of a thermoacoustic refrigerator (Source: NASA Tech Briefs, Vol. 21, No. 11, November 1997).

watts of acoustical power to produce 419 watts of useful cooling for a shipboard radar unit on board the USS Deyo (DD-989), a Spruance-class destroyer, in 1995. The loudspeakers used to produce the acoustical power had an electroacoustic efficiency of only 52\%. This resulted in about one watt of cooling for each watt of electrical input power. Garrett and his colleagues are currently working on a three ton shipboard air conditioning unit that uses $85 \%$ efficient loudspeakers and is due for sea trials in early 2000.

Minner and colleagues at Purdue University used the DELTAE thermoacoustic refrigerator computer model, developed by Greg Swift and Bill Ward at Los Alamos, and combined it with a simplex numerical optimization program to tweak the design of a prototype cooler to maximize COP. "Tweaking" in ther case means altering operating parameters such as mean pressure, inert gas mixture ratios, heat exchanger designs, and geometric parameters (e.g. stack position) for the resonation tube in 
a systematic way to reduce losses. Minner showed that systematic optimization could improve the COP significantly. Minner's analysis was based on a $200 \mathrm{~W}$ cooler with hot and cold heat exchanger temperatures of $260 \mathrm{~K}(8.3 \mathrm{EF})$ and $310 \mathrm{~K}(98 \mathrm{EF})$; parasitic energy requirements associated with heat transfer across the heat exchangers using the secondary fluids and air were not included.

\section{Secondary System Requirements}

To date, most systems have required a secondary heat transfer loop, but recent designs have cooled the process fluid (air) directly with improved efficiency.

\section{Efficiency Data}

The effort necessary to model a thermoacoustic cooler or heat pump was beyond the funding and time limitations of this project and beyond the expertise of its authors. Data reported in Table 15 are from Garrett and Swift. Both sources reported electroacoustic driver efficiencies between 75 and 90\%. Garrett Fig. 20. P-V diagram for a thermoacoustic is constructing a $10 \mathrm{~kW}$ air conditioner for the refrigerator. Navy with a COP at $95 \mathrm{EF}$ between 2.3 and 2.5. Swift predicts a COP 1.7 to 2.0 using a secondary loop and less optimistic assumptions.

\section{Technical Advantages/Benefits}

Thermoacoustic systems should have low cost and high reliability since there are no parts in contact with working fluid that require lubrication. With gas as the working fluid the system operates as well in near zero gravity conditions in space bound equipment as it does in terrestrial applications.

\section{Technical Disadvantages}

Thermoacoustic systems have had lower efficiency than conventional vapor compression systems in room temperature applications, but the rate of developments in this field have been

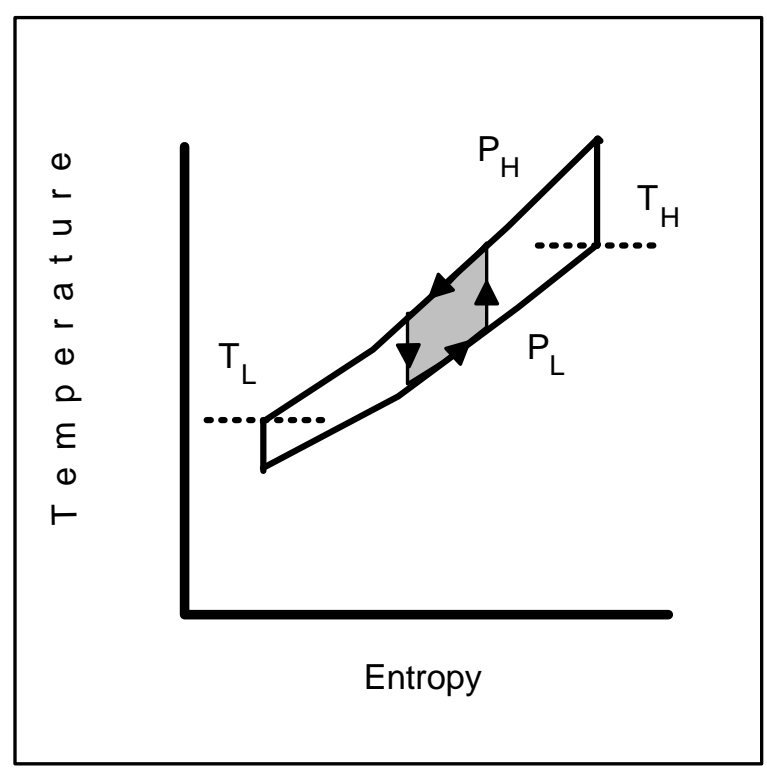

Fig. 21. T-S diagram for a thermoacoustic refrigerator. 
Table 15. Calculated and Reported Efficiencies for Thermoacoustic Cooling.

\begin{tabular}{|c|c|c|c|c|c|c|}
\hline \multirow[b]{2}{*}{ Cycle Efficiency } & \multicolumn{3}{|c|}{ Heating } & \multicolumn{3}{|c|}{ Cooling } \\
\hline & 47EF & $17 \mathrm{EF}$ & $\begin{array}{c}\text { Seasonal } \\
\text { (Btu/Wh) }\end{array}$ & 82EF & 95EF & $\begin{array}{c}\text { Seasonal } \\
\text { (Btu/Wh) }\end{array}$ \\
\hline$\frac{\text { Cycle COP }}{\text { reported }}$ & 3.49 & 2.16 & & 3.71 & 2.79 & \\
\hline $\begin{array}{r}\text { System COP } \\
\text { reported - electric } \\
\text { reported - gas }\end{array}$ & $\begin{array}{l}2.87 \\
1.15\end{array}$ & 1.90 & 6.6 & 3.02 & $\begin{array}{l}2.38 \\
0.50\end{array}$ & 8.9 \\
\hline
\end{tabular}

notes: "reported" efficiencies are from Garrett and Swift. Blank entries denote absence of calculated or measured information, calculated and observed cycle efficiencies do not apply for the shaded seasonal boxes

very rapid. The thermoacoustic systems are also relatively large in size for the power levels they achieve and may require secondary heat transfer loops. Noise was a problem in some test bench prototypes, not from the internal sound, but from vibration of the whole vessel. This has been largely solved and should not be a problem if thermoacoustic heat pumps are ever mass produced.

\section{Technical Barriers}

Developments are needed in the design of compact heat exchangers in oscillating flow. Cost and availability of acoustic drivers could be a problem. Major impediment to further development is a talent bottleneck with extremely few people trained to work in thermoacoustics.

\section{Economic Analysis}

An economic comparison was performed using an annual maintenance costs of equal to that for the baseline electric heat pump, cycling $\mathrm{C}_{\mathrm{d}}=0.10$, and $100 \mathrm{~W} /$ ton for secondary fluid pumps with Garrett's optimistic estimate of COP's $30 \%$

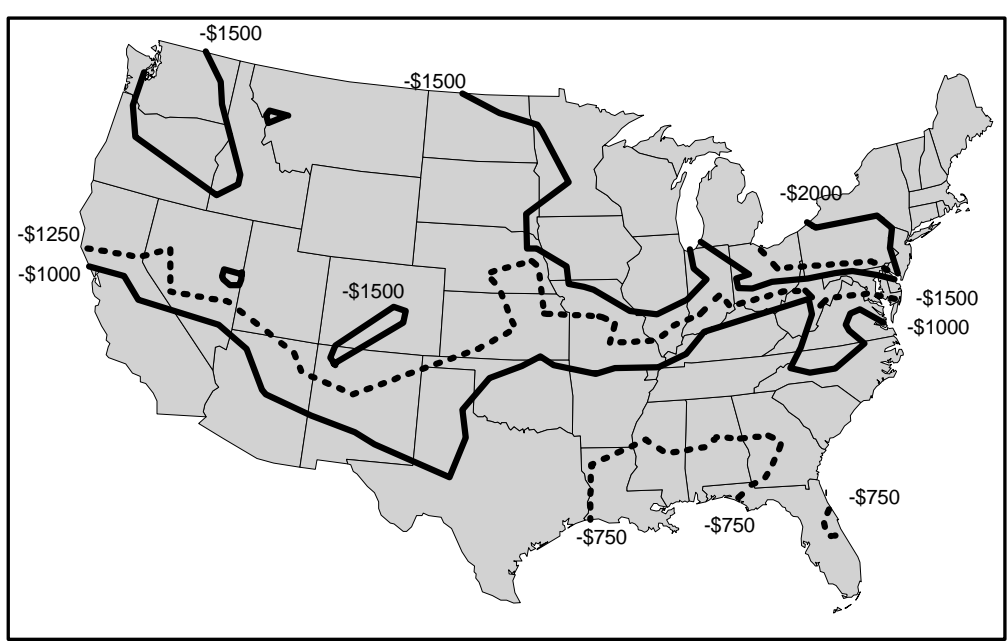

Fig. 22. Allowable installed cost price differential for a thermoacoustic heat pump relative to the electric baseline. 
below those of R-22 heat pumps. The results are shown in Fig. 22. Under those assumptions the thermoacoustic heat pump would have to have an installed cost of $\$ 600$ to $\$ 1000$ per ton below the baseline electric heat pump to have equivalent life cycle costs; essentially a $35 \%$ to $60 \%$ price reduction. The installed cost reductions indicated in Table 16 reflect the low cycle efficiencies; the longer it is in use the greater the economic losses. Significant efficiency improvements are necessary for thermoacoustic heat pumps to be cost effective relative to conventional electric heat pumps.

These results necessarily depend on the assumptions for secondary loop pumping power and annual maintenance costs. Lower pumping power for the secondary loop or maintenance costs significantly lower than those of the baseline heat pump would allow installed costs closer to those of the baseline system.

The thermoacoustic system eliminates the conventional electric motor and compressor at the expense of adding an acoustic generator, resonating chamber, and secondary fluid system. Although some cost reductions may be possible, it is unclear if the relative cost of the thermoacoustic system can be that much lower than the baseline system.

\section{Contacts and Sources of Information}

\section{Gregory Swift}

Condensed Matter and Thermal Physics

Group

Mail Stop K764

Los Alamos National Laboratory Los Alamos, New Mexico 87545

ph: (505) 665-0640

fax: (505) 665-7652

e-mail: swift@lanl.gov

Steve Garrett

Table 16. Installed Cost Premiums Possible for a Thermoacoustic Heat Pump Relative to an Electric Heat Pump.

\begin{tabular}{|l|c|c|c|}
\hline \multirow{2}{*}{ Region } & \multicolumn{3}{|c|}{ Installed Cost Premium (\$/ton) } \\
\cline { 2 - 4 } & $\begin{array}{c}3 \text { Year } \\
\text { Payback }\end{array}$ & $\begin{array}{c}\text { 5 Year } \\
\text { Payback }\end{array}$ & $\begin{array}{c}\text { Equal Life } \\
\text { Cycle Cost }\end{array}$ \\
\hline Northeast & $-\$ 541$ & $-\$ 858$ & $-\$ 2465$ \\
\hline Southeast & $-\$ 188$ & $-\$ 297$ & $-\$ 855$ \\
\hline $\begin{array}{l}\text { South } \\
\text { Central }\end{array}$ & $-\$ 214$ & $-\$ 339$ & $-\$ 982$ \\
\hline Southwest & $-\$ 233$ & $-\$ 380$ & $-\$ 1133$ \\
\hline Midwest & $-\$ 366$ & $-\$ 584$ & $-\$ 1705$ \\
\hline $\begin{array}{l}\text { Northern } \\
\text { Plains }\end{array}$ & $-\$ 283$ & $-\$ 452$ & $-\$ 1320$ \\
\hline $\begin{array}{l}\text { Rocky } \\
\text { Mountain }\end{array}$ & $-\$ 278$ & $-\$ 443$ & $-\$ 1322$ \\
\hline $\begin{array}{l}\text { Pacific } \\
\text { Northwest }\end{array}$ & $-\$ 192$ & $-\$ 303$ & $-\$ 903$ \\
\hline California & $-\$ 225$ & $-\$ 358$ & $-\$ 1067$ \\
\hline
\end{tabular}

Pennsylvania State University

P.O. Box 30

State College, PA 16804

ph: (814) 863-6373

fax: (814) 865-3119

e-mail: garrett@sabine.acs.psu.edu 
Jim Braun

Purdue University

West Lafayette, IN

e-mail: jbraun@ecn.purdue.edu

Appliance Manufacturer 1998. "Sound Idea: Acoustic Compressor to Power Residential Refrigerator," June, pp. 63-64.

\section{Obvious Holes in Knowledge, Understanding, Information}

Rigorous modeling using DELTAE is required evaluate the performance of thermoacoustic systems at standard HVAC rating conditions; the required effort is beyond the scope of this study. 


\section{PULSE-TUBE REFRIGERATION}

\section{Basic Concept Description}

A pulse tube refrigerator is a device for cooling to low temperatures operating at frequencies well below the resonance frequencies used in thermoacoustic devices. Two alternative configurations for a pulse tube cooler are shown in Fig. 23. These are closed systems that use an oscillating pressure at one end (typically produced by a compressor) to generate an oscillating gas flow in the rest of the system. This gas flow (usually helium) can carry heat away from a low temperature point (cold heat exchanger) if the conditions are right. An orifice controlling the flow at the other end of the cooler can provide the right condition for cooling to occur. The cycle is similar to thermoacoustic refrigeration thermodynamically where the tube walls act as a regenerator instead of the stack (see Figs. 20 and 21).

\section{Background Information}

$\quad$ Pulse tube
coolers are a recent
discovery. They
were first reported
by W. Gifford of
Syracuse University
in 1963 from his
observation of
heating in blanked off
plumbing lines
attached to gas
compressors. NASA
compressors. NASA

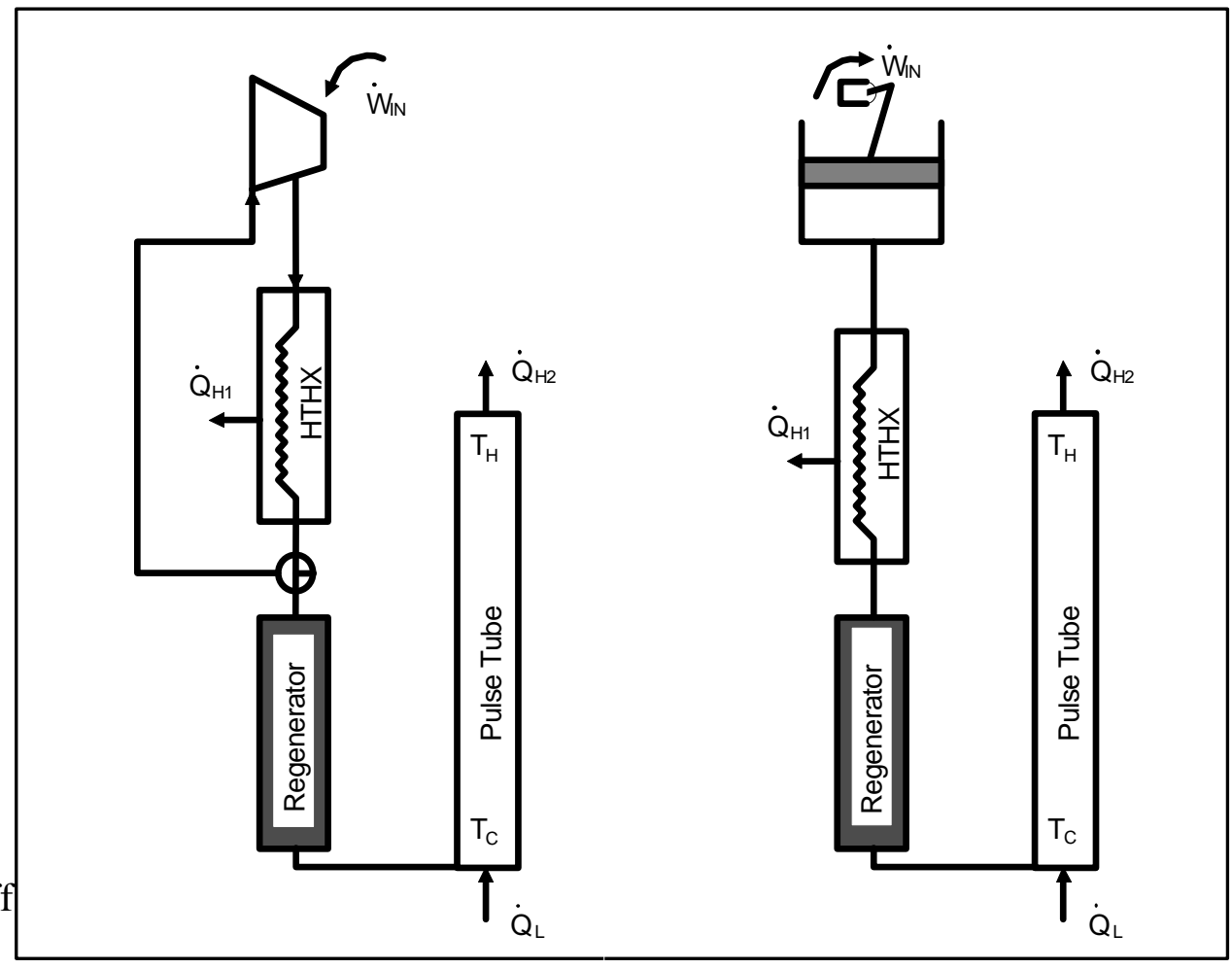

Fig. 23. Pulse tube refrigeration systems.

and DOE have

sponsored work in pulse tube refrigeration for cryocoolers. Pulse-tube refrigeration systems were developed for cryogenic applications. A single cooler can cool from room temperature to $70-80 \mathrm{~K}$ and multi-stage systems can cool much lower. The amount of heat they can remove is only limited by their size and the power used to drive them. Their efficiency as cryocoolers is comparable to other systems such as Stirling coolers.

Pulse tube refrigeration systems were developed for infrared sensors used in atmospheric monitoring, night vision, missile guidance. They are also used in gamma ray sensors (monitoring nuclear 
activity), cryogenic catheters and cryosurgery, and the liquefaction of gases. This equipment has a high reliability for cryogenic refrigeration; no moving parts at the cold end of cryocoolers. The efficiency is very low with COPs ranging from 0.005 to "comparable to Stirling coolers" for cryogenic applications. Scaling to high capacities may be a problem because current development appears to be for sensors at low capacities; more information is needed.

The following description is taken verbatim from the doctoral dissertation by Don Gauger (1993):

"The pulse-tube concept was developed by Gifford and Longsworth in the mid-1960s. Mikulin and Radebaugh improved the COP of the pulse tube by adding an orifice and an expansion chamber to the high-temperature end of the tube.

"An ideal pulse tube system is composed of a compressor, regenerator, high temperature heat exchanger, and the tube. Figure 23 depicts two pulse-tube schematics illustrating different methods of periodically compressing the working gas. Periodic compression can be accomplished by a steady flow compressor and rotary control valve, as shown on the left side of the figure or by a reciprocating compressor, as shown on the right. The heat generated due to compression of the gas is rejected by a high temperature heat exchanger; the gas then passes through a regenerator. The tube wall is constructed of a material with a low thermal conductivity, commonly stainless steel. The ends of the tube are capped with a highly conductive material like copper. The heat is accepted by the low temperature heat exchanger located at the entrance end of the tube, and rejected by the high temperature heat exchanger at the opposite end.

"The principal of operation of the ideal cycle may be understood by considering a thin cylindrical control mass segment as shown in Fig. 24. The following assumptions are made:

1. Invicid flow, both step functions with respect to time as shown in Fig 24,

3. Perfect regeneration,

4. The heat is transferred to and from the mass segment through the tube wall,

5. Ideal gas,

6. Isentropic compression, and

7. All ducts are adiabatic.

"The mass is initially contained in volume $\mathrm{V}_{1}$ of tube inside diameter and thickness $h_{1}$. As the pressure and temperature of the gas in the element are changed during the cycle, the volume will also change. Since the tube wall is rigid the diameter of the element will not change, however, the thickness of the element must change. The gas is at a thermodynamic state having properties $\mathrm{P}_{\mathrm{L}}$ and $\mathrm{T}_{1}$, and an initial height in the tube $x_{1}$. When the pressure in the tube is increased to $\mathrm{P}_{\mathrm{H}}$, the volume is compressed to $\mathrm{V}_{2}$, elevated to position $x_{2}$, and the temperature raised to $\mathrm{T}_{2}$. A temperature Fig. 24. Control volume for pulse gradient ranging from $T_{L}$ to $T_{H}$ exists along the length of the tube. tube refrigeration.

The local temperature of the tube wall at position $x_{2}$ is lower than the temperature of the mass segment, $\mathrm{T}_{2}$. Therefore, heat will be transferred from the mass segment to 
the wall, and the thermodynamic properties will be: $\mathrm{T}_{3}, \mathrm{P}_{\mathrm{H}}$, and $v_{3}$. When the pressure is lowered to $\mathrm{P}_{\mathrm{L}}$, the mass segment undergoes an isentropic expansion to state 4 with properties $\mathrm{T}_{4}, v_{4}$, and $\mathrm{P}_{\mathrm{L}}$, at a slightly higher elevation than the original position. As the gas is re-heated, it will be returned to the original thermodynamic state (state 1) and position in the tube; the cycle has been completed.

"Ideally, the control mass of gas in the tube undergoes an isentropic compression from states 1 to 2 , isobaric cooling from states 2 to 3 , an isentropic expansion from states 3 to 4 , and isobaric heating from 4 to 1 . The ideal cycle formed by the series of processes undergone by the control mass is the reversed Brayton cycle. Furthermore, the cycle for the entire mass of gas in the tube is an interconnected series of Brayton cycles as shown in Figs. 25 and 26. The tube wall acts as a continuous regenerator."

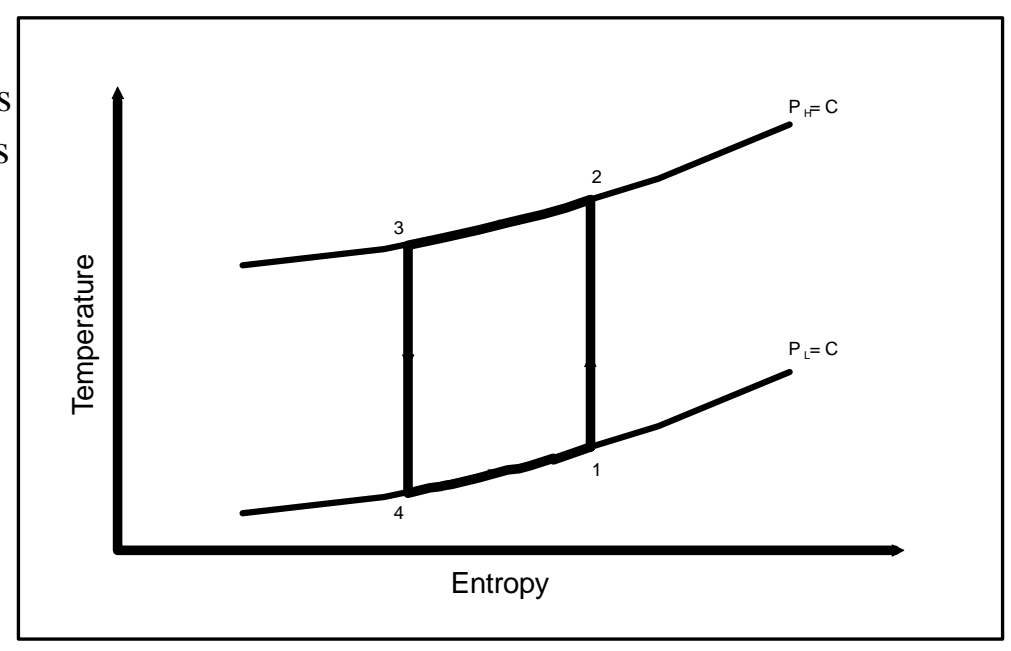

Fig. 25. Temperature - entropy diagram for pulse tube control volume.

\section{Secondary System Requirements}

A secondary heat transfer loop is required.

\section{Efficiency Data}

No information has been located relevant to applying pulse tubes at space conditioning temperatures, particularly for operating efficiencies. NASA Web sites have a reasonably large amount of measured performance data on-line giving tube dimensions, operating pressure, capacity, etc. but nothing on efficiency. Capacities are typically a few Watts. The highest cold heat exchanger temperature is in the neighborhood of $80 \mathrm{~K}$.

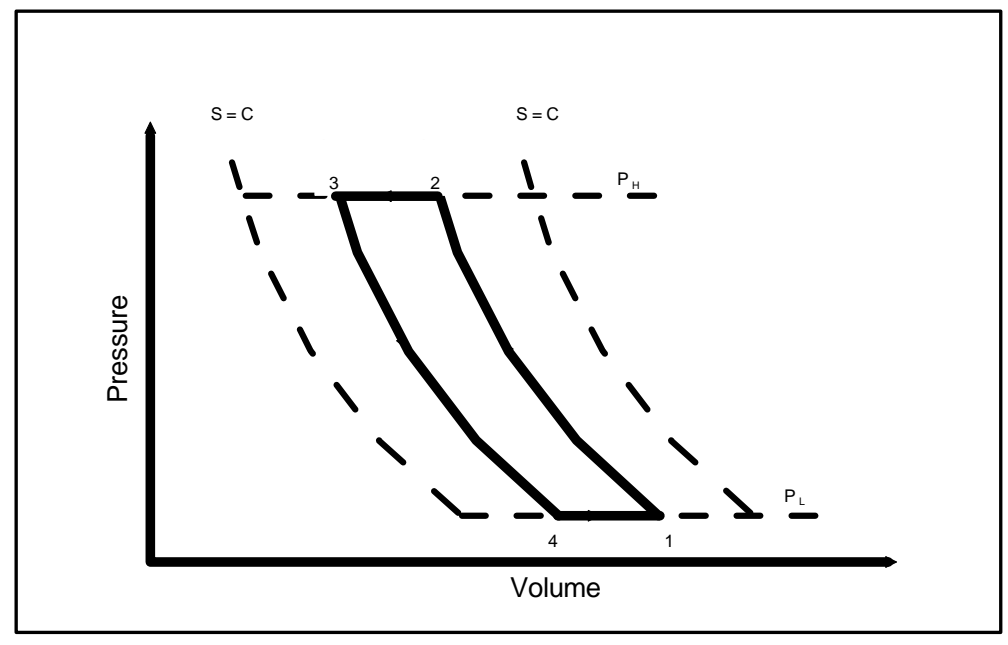

Fig. 26. Pressure - volume diagram for pulse tube refrigeration. 
! 1 Watt output / 200 Watt input at $35 \mathrm{~K}$

! $\quad 1.5$ Watt output / 100 Watt input at $55 \mathrm{~K}$

! 5 Watts output $/ 3 \mathrm{~kW}$ input at $120 \mathrm{~K}$

The theoretical calculations for the pulse tube system are in Table 17 are based on a computer model by Gauger.

Table 17. Calculated and Observed Efficiencies for Pulse Tube Cooling.

\begin{tabular}{|c|c|c|c|c|c|c|}
\hline \multirow[b]{2}{*}{ Cycle Efficiency } & \multicolumn{3}{|c|}{ Heating } & \multicolumn{3}{|c|}{ Cooling } \\
\hline & 47EF & $17 \mathrm{EF}$ & $\begin{array}{l}\text { Seasonal } \\
(\mathrm{Btu} / \mathrm{Wh})\end{array}$ & $82 \mathrm{EF}$ & $95 \mathrm{EF}$ & $\begin{array}{l}\text { Seasonal } \\
(\mathrm{Btu} / \mathrm{Wh})\end{array}$ \\
\hline$\frac{\text { Cycle COP }}{\begin{array}{r}\text { theoretical } \\
\text { observed }\end{array}}$ & 0.96 & 0.96 & & 0.40 & 0.39 & \\
\hline$\frac{\text { System COP }}{\begin{array}{r}\text { theoretical } \\
\text { observed }\end{array}}$ & 0.88 & 0.88 & 3.4 & 0.39 & 0.39 & 1.1 \\
\hline
\end{tabular}

notes: blank entries denote absence of calculated or measured information, calculated and observed cycle efficiencies do not apply for the shaded seasonal boxes

\section{Technical Advantages/Benefits}

Pulse-tube systems are well suited for cryogenic applications because there are no moving parts at the low temperatures.

\section{Technical Disadvantages}

Low efficiency at space conditioning lifts.

\section{Technical Barriers}

A single pulse-tube cannot be enlarged beyond an optimum surface-to-volume ratio, which depends on the cycle frequency and the desired temperature range. The capacity is increased by the operation of several tubes in parallel from the same source of compressed gas (Wood 1969). 


\section{Economic Analysis}

The modeled COPs for this system are extremely low and there is no independent corroboration of these values so calculated energy use data are highly questionable. Installed costs would need to be thousands of dollars per ton less than conventional heat pumps to have comparable life cycle costs. There are two configurations for pulse tube cooling, one using acompressor and the other a pump and valve. The compressor configuration is unlikely to have any significant equipment cost savings relative to conventional electric heat pumps; the pump and valve system may have smaller equipment costs but not thousands of dollars below a motor driven compressor driven system.

\section{Contacts and Sources of Information}

Swift, G., Gardner, D., and Backhaus, S. 1999. "Acoustic Recovery of Lost Power in Pulse Tube Refrigerators,” Journal of the Acoustic Society of America, Vol. 105, pp. 7110724.

NASA Web, http://ranier.oact.hq.nasa.gov/Sensors_page/Cryo/CryoPT/CryoPTHist.html

NASA Ames Research Center: http://irtek.arc.nasa.gov/WhatisOPT.html

Wood, B. 1969. Applications of Thermodynamics, Addison-Wesley Publishing Company, p. 281.

http://irtek.arc.nasa.gov/CryoGroup/PTDatabase/PTData-Basic.-html (data)

http://irtek.arc.nasa.gov/WhatisOPT.html

http://ranier.oact.hq.nasa.gov/Sensors_page/Cryo/CryoPTHist.html

Gordon.Johnston@hq.nasa.gov

Greg Swift

Physics Division

Los Alamos National Laboratory

K764

Los Alamos, NM 87545

phone: (505) 665-0640

fax: (505) 665-7652

e-mail: swift@lanl.gov

P. Kittel, NASA Ames Research Center

Dr. E. Mikulin, Moscow Bauman State Technical University, Russia,

Dr. R. Radebaugh, NIST. 


\section{Obvious Holes in Knowledge, Understanding, Information}

Refined efficiency calculations or corroboration of COPs at rating conditions from other sources. 


\section{MALONE CYCLE REFRIGERATION}

\section{Basic Concept Description}

The Malone "cycle" is perhaps a misnomer. Malone engines and refrigeration devices are really the application of liquids as the working fluid in a Brayton or Stirling cycle configuration. Liquids have attracted very little attention as operating fluids because "ideal" liquids are not appropriate for refrigeration cycles and "ideal" gases are. The working fluid in a heat pump must cool as the fluid is depressurized in order to absorb heat from the conditioned space. The cooling on depressurization (and thermal expansion for a heat engine) is proportional to the coefficient of thermal expansion. The thermal expansion coefficients for gases are large, essentially infinite for boiling and condensation. It is generally small for any liquid with "nearly ideal" behavior, but it can be large for liquids close to their critical points.

\section{Background Information}

Malone refrigeration exists primarily as a theoretical concept with little, if any, hardware development or proof of concept demonstration. John Malone built a liquid-based $50 \mathrm{hp}$ engine in 1925 that burned coal and used high pressure liquid water as the working medium. Malone's idea was largely ignored for 50 years, when John Wheatley developed in interest in innovative cooling and refrigeration technologies in the 1970's. The effort on Malone refrigeration has been done almost exclusively at Los Alamos National Laboratory with theoretical studies of liquids in both Stirling and Brayton cycle machines. Laboratory prototype cooling devices have been built at Los Alamos National Laboratory (LANL) to demonstrate the concept.

The staff at LANL examined several fluids, including hydrocarbons, CFCs, and inorganic fluids before selecting liquid propylene as the working fluid for a demonstration Malone/Stirling refrigerator. This machine was designed for ease of instrumentation and study rather than for high performance and it had a COP about half of that achieved by CFC based Rankine cycle equipment of the time. In 1993, the LANL staff began looking at using liquid $\mathrm{CO}_{2}$ in a free-piston Stirling machine to reach higher efficiencies with $2 \mathrm{~kW}$ cooling capacity. A $40 \mathrm{~kW}$ Brayton cycle, liquid $\mathrm{CO}_{2}$, system was under development at the Naval Surface Warfare Center at Annapolis, Maryland in 1993 (Swift 1993a). No further information has been found on the follow-on work at LANL.

\section{Secondary System Requirements}

A secondary heat transfer loop is probably necessary to minimize dead space in the operating volume. 


\section{Efficiency Data}

No performance data, at any conditions, have been located in the literature for Malone cycle refrigeration. Calculations cannot be performed without accurate thermodynamic properties of liquids $\left(\mathrm{CO}_{2}\right.$, propylene) near their critical points. Heat exchanger pressure drops are significant factors for a Malone machine, and viscosity data are also needed near the critical point in order to estimate cycle efficiency. No cycle calculations were performed as part of this project.

\section{Technical Advantages/Benefits}

The equations in Appendix I show several advantages of using a liquid working fluid near its critical point instead of a gas:

! the power requirements for compressing the working fluid are basically determined by the coefficient of isothermic compression, $\mathrm{K}_{\mathrm{p}}$, and these decrease as $\mathrm{K}_{\mathrm{p}}$ increases,

! the quantity of heat transferred and absorbed, $\mathrm{Q}$, depends on $\$_{\mathrm{T}}$ and this increases abruptly near the critical point,

! the quantity of heat transferred and absorbed depends on $\mathrm{C}_{\mathrm{V}}$, and $\mathrm{C}_{\mathrm{V}}$ is significantly larger for a liquid than it is for a gas, and

! the heat transfer coefficient for the regenerator is a couple of orders of magnitude higher for a liquid than it is for a gas which allows for a smaller surface for convective heat transfer.

The low compressibility of liquids means that a larger pressure change is generated than with a gas for a given change in volume. Swift states that heat transfer is proportional to the pressure change, so either smaller compressors can be used to meet a specified load, or greater heat transfer can be accomplished for a given compressor size (Swift 1993). Liquids also have heat capacities per unit volume that are orders of magnitude larger than those of gases at pressures generally encountered in refrigeration equipment. Thus, far less fluid needs to be circulated than with a gas cycle system and less work is required. The pressurization of a liquid without transferring heat, however, results in a small temperature change because of the large heat capacity; refrigeration requires that the working fluid undergo a large temperature change in order to move heat from source to sink. Regenerators are required in the Malone cycle in order to achieve acceptable ) T's.

\section{Technical Disadvantages}

There are several problems associated with using liquid working fluids that have not been resolved:

! the operating pressures can be extremely high with associated problems with mechanical stresses and operating safety,

! a refrigeration device using a liquid would have a significant mass of working fluid and there are associated lag times at starting, stopping, and changing modes of operation, 
! the operating controls need to be extremely accurate because proper operation is limited to a small region near the critical point; moving past the critical point to gaseous region results in sudden temperature drops and "water hammer" that could destroy the equipment,

! there are high pressure drops in the heat exchangers, particularly for the Stirling cycle Malone machine because of the pulsating nature of the working fluid flow in the Stirling cycle. The heat exchanger pressure drops will be high for space conditioning application and offset possible efficiency gains from low compression power.

\section{Technical Barriers}

The principal barriers in development of applications of the Brayton/Malone cycle are in funding and trained engineers. Development of Stirling/Malone is more difficult because of the spatially distributed oscillating flows.

\section{Economic Analysis}

An economic comparison is not performed due to the absence of modeled and reported efficiencies.

\section{Contacts and Sources of Information}

Malone, J. F. J. 1931. Journal of the Royal Society of Arts, Vol. 179, p. 679.

Allen, P. C. Et al. 1980. Proceedings of the National Academy of Science, Vol. 177, p. 39.

Swift, G. 1989. Journal of Applied Physics, Vol. 65, p. 4157.

Swift, G. 1990. “Malone Refrigeration,” ASHRAE Journal, November, pp. 28-34.

Swift, G., 1993, “Malone Refrigeration: An Old Solution to a New Problem,” Los Alamos Science, Number 21, 1993, pp. 112-123.

Swift, G., 1993a, “Malone Refrigeration,” Proceedings of the 1993 Non-Fluorocarbon Refrigeration and Air Conditioning Technology Workshop, Breckenridge, Colorado June 23-25, 1993, ORNL6797. 
Greg Swift

Physics Division

Los Alamos National Laboratory

K764

Los Alamos, NM 87545

phone: (505) 665-0640

fax: (505) 665-7652

e-mail: swift@lanl.gov

\section{Obvious Holes in Knowledge, Understanding, Information}

Steady-state data at the ARI test conditions or seasonal performance factors, costs 


\section{MAGNETIC REFRIGERATION}

\section{Basic Concept Description}

magnetic materials, there is a decrease in entropy within the material related to an increase in the ordering of the electron spin state. This is illustrated in Fig. 27. The decreased entropy is associated with a decrease in internal energy and an increase in temperature of the material for an adiabatic process. If the process occurs isothermally, heat must be rejected to the surroundings through a secondary loop. The process is nearly reversible with very small internal losses, at least for small temperature rises, and can be used in a heat pump. The maximum temperature rise is proportional to the magnetic field; for gadolinium the maximum ) $\mathrm{T}$ is $25 \mathrm{EF}$ at $68 \mathrm{EF}$. In actual practice the temperature rise is on the order of $10 \mathrm{E}$ to $15 \mathrm{EF}$ so regenerative heat transfer is necessary to employ the magneto-

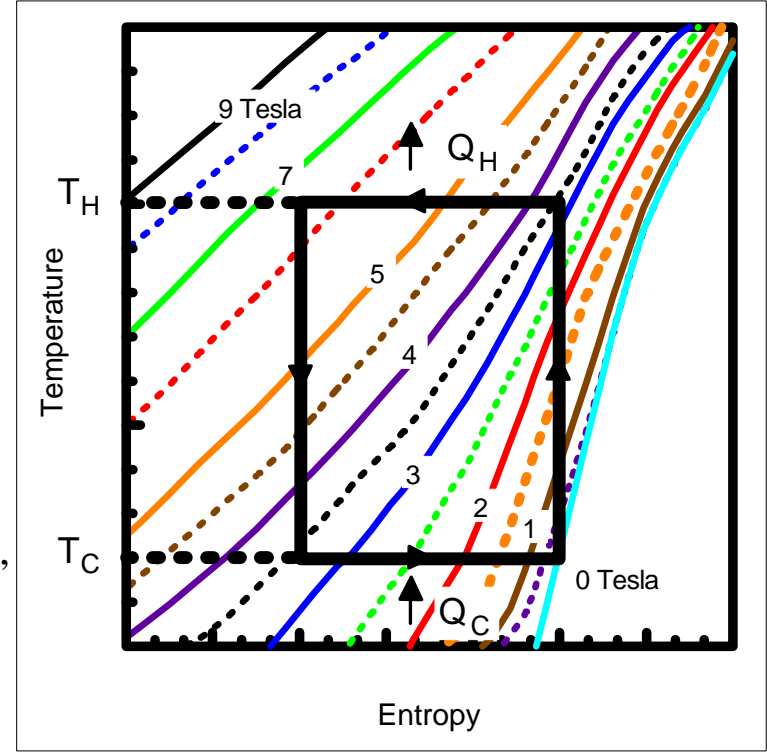

Fig. 27. Temperature-entropy variation for paramagnetic materials.. caloric effect in practical applications.

\section{Background Information}

Magnetic refrigeration systems are applied perhaps exclusively to cryogenic coolers because they have no moving parts or working fluids at temperatures near absolute zero. The design of a new type of near-room temperature magnetic refrigerator and the demonstration of its technical feasibility as an alternative refrigeration technology for energy-intensive industrial and commercial refrigeration systems is under development at Iowa State University. The magnetic refrigeration cycle has a very high intrinsic efficiency; the efficiency appears to be limited by factors susceptible to control, such as non-ideal materials properties, parasitic heat transfer, and flow losses. Replacement of vapor cycle refrigerators with magnetic refrigerators offers a significant potential energy savings.

DOE is supporting a $\$ 1$ million project at Iowa State to investigate magnetic refrigeration for room temperature applications. Astronautics Corp. is under contract to Ames Laboratory (ISU) to develop a magnetic refrigerator; one of their working prototypes is depicted in Fig. 28. Some of their results were published at a Cryogenic Engineering Conference in Portland, Oregon in July 1997 (Zimm). These results show a strong dependence of COP on the temperature lift with a maximum COP of 8 with an $8 \mathrm{~K}$ lift falling to just above 1 with a $23 \mathrm{~K}$ lift. The experimental rig is using a hydronic loop as a heat transfer medium; the data is massaged to provide efficiency as a fraction of Carnot COP across the range of ) T's including all the losses except heat added to the water from the pump seal 
friction (they used a very inefficient pump). The coefficient of performance of the Astronautics device has also set a record for magnetic refrigerators, suggesting that recent design innovations can make magnetic refrigeration competitive with conventional gas compression technology.

Magnetic refrigeration could be applied to gas liquefaction (low temperatures for separating gases), large scale refrigeration, and supermarket refrigeration. There are claimed high efficiencies; although it is not clear what is meant by "high" and whether that is for cryogenic conditions or nearroom temperature conditions.

\section{Secondary System Requirements}

Super-conducting magnets and regenerative and secondary heat transfer loops.

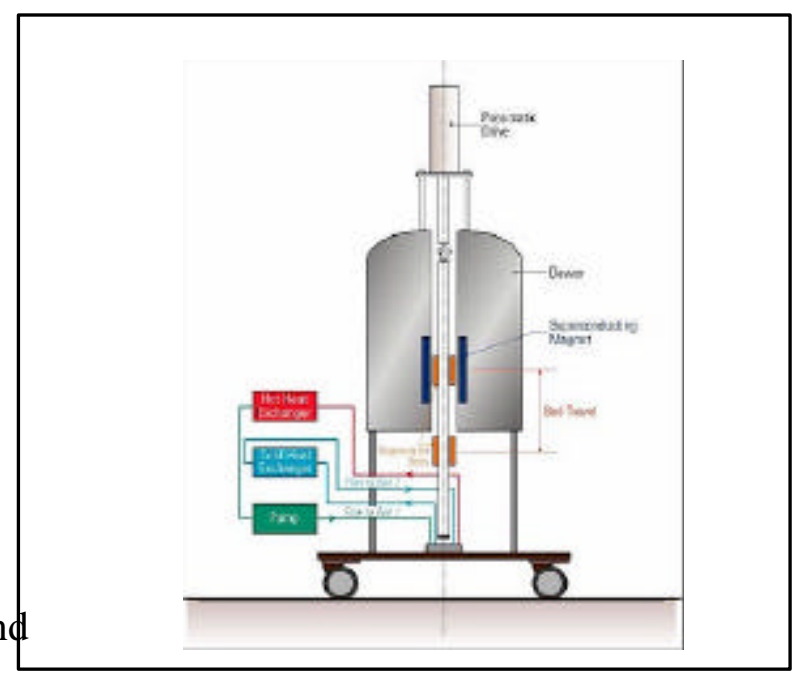

Fig. 28. Test stand for prototype magnetic refrigeration device (Source: http://www. external.ameslab.gov/news/Inquiry/fall97/bigchill. html).

\section{Efficiency Data}

A computer program developed at Iowa State University (Gauger 1993) was used to calculate cycle COPs for a magnetic heat pump with field strength varying between 0 and 7 Tesla. Hot and cold heat exchanger temperatures used in these calculations are listed in Table 18. The cycle COPs listed in Table 19 exclude all electrical peripheral energy; the device under development at Astronautics uses an electrically-driven device to move canisters of gadolinium pellets into and out of the superconducting magnetic field. This is a high loss for their system because they use a secondary heat transfer loop with complicated circuitry and valving that circulates brine through the gadolinium pellets. Consequently the electrical drive system is working against high friction losses from the seals required by the secondary loop. The secondary loop pumping power and electrical requirements for the superconducting magnets are also unknown. The system COPs in Table 19 are based on $200 \mathrm{~W} /$ ton for the secondary loop pump, superconducting magnets, and drive 
mechanism. Results are also included in Table 19 for a magnetic heat pump operating between 0 and 5 Tesla, which is achievable without superconducting magnets.

Table 19. Calculated and Observed Efficiencies for Magnetic Refrigeration.

\begin{tabular}{|r|c|c|c|c|c|c|}
\hline & \multicolumn{3}{|c|}{ Heating } & \multicolumn{3}{c|}{ Cooling } \\
\cline { 2 - 7 } & & & $\begin{array}{c}\text { Seasonal } \\
(\text { Btu/Wh })\end{array}$ & $82 \mathrm{EF}$ & $95 \mathrm{EF}$ & $\begin{array}{c}\text { Seasonal } \\
(\mathrm{Btu} / \mathrm{Wh})\end{array}$ \\
\hline Cycle Efficiency & $47 \mathrm{EF}$ & $17 \mathrm{EF}$ & & & & \\
Cycle COP & & & & 5.78 & 3.89 & \\
theoretical - 7 Tesla & 5.58 & 5.76 & & 4.59 & 2.34 & \\
- - 5 Tesla & 4.66 & 5.00 & & & & \\
- observed & & & & & & \\
System COP & & & & & & \\
theoretical - 7 Tesla & 4.18 & 4.28 & 9.9 & 4.29 & 3.15 & 13.7 \\
-5 Tesla & 3.60 & 3.80 & 9.1 & 3.56 & 2.04 & 11.3 \\
- 7 Tesla w/ 1/4 hp pump & 3.90 & 3.99 & 9.5 & 3.99 & 2.99 & 12.8 \\
\hline
\end{tabular}

notes: system COPs do not include pumping power for the secondary circulating pump except in the very last line. Blank entries denote absence of calculated or measured information, calculated and observed cycle efficiencies do not apply for the shaded seasonal boxes

\section{Technical Advantages/Benefits}

Some of the major losses present in conventional gas-compression systems are absent in magnetic refrigerators, and thus it is expected that cooling systems based on this new technology can attain substantially higher efficiency than conventional gas-compression coolers.

\section{Technical Disadvantages}

Requires superconducting magnets and regenerative heat transfer. Very high regenerator effectiveness and very low parasitic power consumption for the secondary loop are required to approach system efficiencies competitive with conventional vapor compression. 


\section{Technical Barriers}

Breakthroughs needed in magnetic materials and high temperature super-conducting materials in order to reduce both equipment and maintenance costs. Major developments are required in the regenerator to improve effectiveness, reduce pressure drop, while decreasing size and cost.

\section{Economic Analysis}

The economic evaluation of magnetic heat pumps is somewhat open ended because of unknown parasitic energy consumption and cost of peripheral equipment. As mentioned earlier, current configurations of magnetic refrigeration use an electric pump to circulate water or a brine solution through canisters packed with gadolinium pellets. They also use a linear motor or pneumatic device to move the canisters in and out of the magnetic field. Finally, the systems require superconducting magnets. Four sets of results are shown for the economic evaluation:

! contours of installed cost price differential relative to the electric heat pump baseline excluding all peripheral energy use by the magnetic heat pump,

! contours of installed cost price differential relative to the gas furnace baseline excluding magnetic system peripherals,

! a bar chart showing approximate increases in life cycle cost for the magnetic system using a $1 \frac{1}{4}$ hp pump in the secondary loop, and

! tabulated installed cost price differentials under three payback scenarios for a magnetic system with a $1 / 4$ hp pump and 60

$\mathrm{W} / \mathrm{ton}$ for a linear motor.

The first two cases show the highest possible values for the differential in installed costs between magnetic heat pumps and both baselines; the second two cases provide some insights into how the system economics are affected by parasitic energy use.

The results presented here assume that there would be low cycling losses $\left(\mathrm{C}_{\mathrm{d}}=0.10\right)$ because

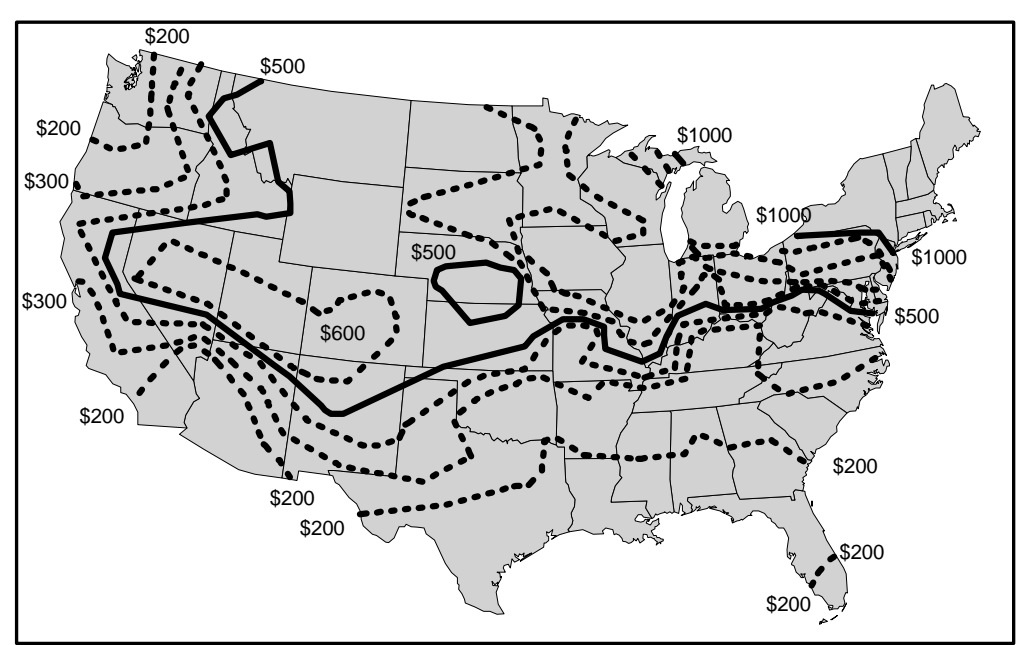

the system does not need to build a Fig. 29. Allowable installed cost price differential for a magnetic high pressure differential each time heat pump relative to the electric baseline exclusive of pumping it cycles on. The results for a 7 power.

Tesla superconducting magnetic heat pump exclusive of pumping power are shown in Figs. 29 and 30 (assuming a $\$ 30$ per year differential in maintenance costs).. The curves in Fig. 29 indicate that the system requires a lower installed costs than the baseline electric heat pump in order to have the same life cycle cost; $\$ 200$ to 
$\$ 500$ per ton in the southern tier of the country ranging to more than $\$ 1000$ per ton in the northeast. The results relative to the gas furnace and electric air conditioner baseline in Fig. 30 show that substantial cost reductions ( $\$ 500$ to $\$ 1000$ per ton and more) would be needed outside of the southeast and desert southwest. In both sets of comparisons, though, the increase in life cycle cost for the power required to circulate the heat transfer fluid is not included. Approximate values for the life cycle cost of pumping power are shown in Fig. 31 for a system using

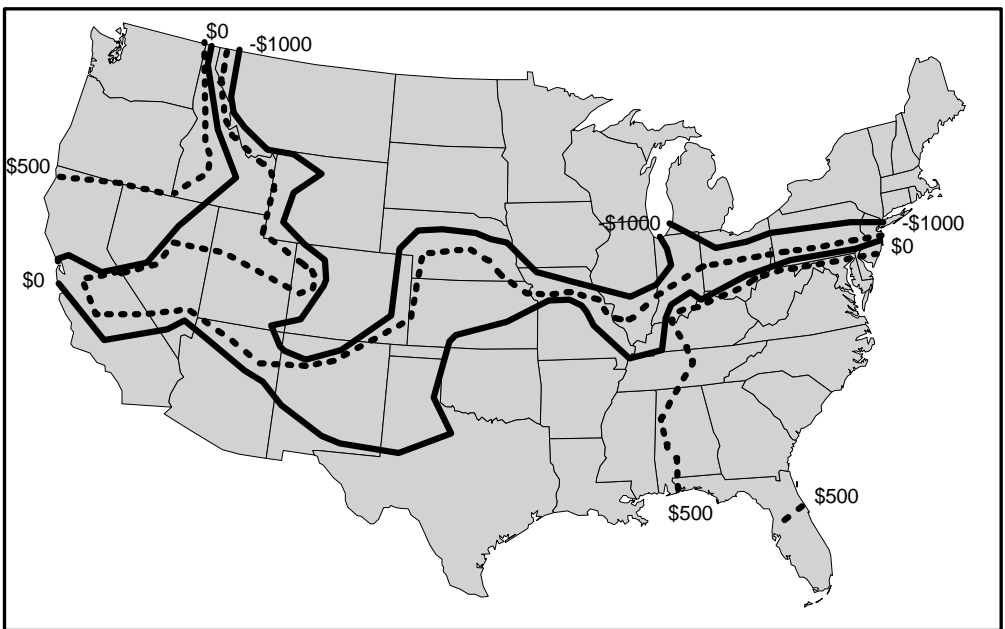

Fig. 30. Allowable installed cost price differential for a magnetic heat pump relative to the gas baseline exclusive of pumping power. a $1 / 4$ hp pump. The $\$ 200$ per ton allowable first cost premium in the southeast and southwest of Fig. 29 is reduced to only about $\$ 50$ per ton because of the increase in life cycle cost from pumping power; the extra $\$ 1000$ per ton that could be spent on the magnetic heat pump in the northeast is nearly cut in half due to the pumping power.

The addition of energy to move the gadolinium canisters in and out of the magnetic field reduces the allowable installed cost premiums even further. Again, the energy necessary to do this is not well defined; results are listed in Table 20 assuming $185 \mathrm{~W}$ for a three-ton heat pump (125 W/ton, or $375 \mathrm{~W}$, for pump and linear motor). These data indicate that installed costs would need to be lower than the electric baseline

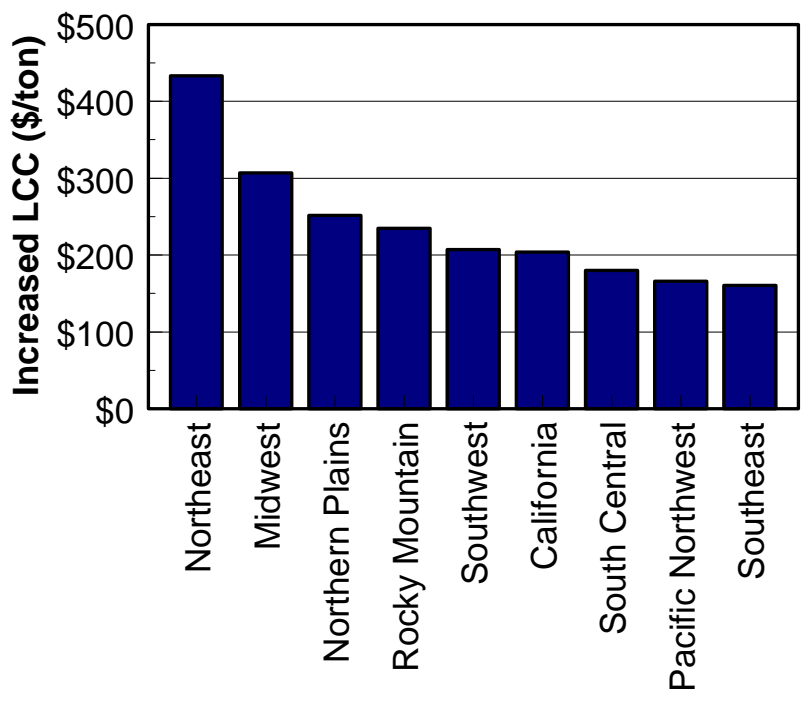
system (described on page xiii) in the traditional heat pump markets in the southeast, south central, and southwestern states (Fig. 31 
shows that magnetic heat pumps compare unfavorably with the gas baseline described on page xiii outside the traditional heat pump markets).

The economic results are also dependent on the assumed increase in annual maintenance costs. Current configurations of magnetic refrigeration devices (outside of cryogenic work) assume a secondary fluid with sliding seals. It is assumed that maintenance of such a system will be more expensive than for a conventional vapor compression heat pump or a gas furnace. This additional cost is arbitrarily assumed to be $\$ 30$ per year, but it really is not known. Every $\$ 10$ increment in annual maintenance costs for this system raises the life cycle cost by $\$ 65$ to $\$ 90$ per ton, depending on the area of the country (variation occurs because maintenance costs are specified in absolute figures and results are expressed in \$/ton). Savings in maintenance costs would have corresponding decreases in life cycle costs. Any increase in life cycle costs due to higher maintenance costs would necessarily reduce the allowable first cost premium by an equal amount.

Considering the actual

hardware for a magnetic heat pump, this system saves on the costs associated with a hermetic compressor in the baseline systems, but has additional costs associated with the pump and heat exchangers for a secondary heat transfer loop, gadolinium canisters, and superconducting magnets. The costs of magnets and gadolinium alone are very large and reductions of two orders of magnitude would be required for this technology to be competitive. Currently (1998) all superconducting magnets are custom made with costs around $\$ 30,000$ apiece (dimensions unknown). Zimm reported measured cooling powers on the order of 400 to $600 \mathrm{~W}$ for $3.6 \mathrm{~kg}$ of gadolinium spheres fashioned from $13.6 \mathrm{~kg}$ of gadolinium purchased from China at $\$ 110 \mathrm{per} \mathrm{kg}$. The price has since gone down to approximately $\$ 80$ per $\mathrm{kg}$. Consequently, the cost of gadolinium (excluding the extensive processing required) is approximately $\$ 6400$ per ton of cooling capacity. Material costs and pumping power are likely to make magnetic heat pumps impractical relative to both the gas and electric baseline systems in spite of the high cycle efficiency possible with the magnetic system.

Table 20. Installed Cost Premiums Possible Relative to an Electric Heat Pump for a Magnetic Heat Pump.

\begin{tabular}{|l|c|c|c|}
\hline \multirow{2}{*}{ Region } & \multicolumn{3}{|c|}{ Installed Cost Premium (\$/ton) } \\
\cline { 2 - 4 } & $\begin{array}{c}3 \text { Year } \\
\text { Payback }\end{array}$ & $\begin{array}{c}5 \text { Year } \\
\text { Payback }\end{array}$ & $\begin{array}{c}\text { Equal Life } \\
\text { Cycle Cost }\end{array}$ \\
\hline Northeast & $\$ 92$ & $\$ 143$ & $\$ 349$ \\
\hline Southeast & $-\$ 11$ & $-\$ 19$ & $-\$ 104$ \\
\hline South Central & $\$ 4$ & $\$ 4$ & $-\$ 32$ \\
\hline Southwest & $\$ 0$ & $\$ 5$ & $-\$ 23$ \\
\hline Midwest & $\$ 55$ & $\$ 86$ & $\$ 199$ \\
\hline Northern Plains & $\$ 37$ & $\$ 58$ & $\$ 121$ \\
\hline Rocky Mountain & $\$ 33$ & $\$ 50$ & $\$ 102$ \\
\hline Pacific Northwest & $-\$ 14$ & $-\$ 14$ & $-\$ 94$ \\
\hline California & $-\$ 2$ & $-\$ 6$ & $-\$ 64$ \\
\hline
\end{tabular}




\section{Contacts and Sources of Information}

ADL 1993. Energy Efficient Alternatives to Chlorofluorocarbons (CFCs): A Research Needs Assessment Final Report, U.S. Department of Energy, Office of Energy Research, DOE/ER/30115H1, June.

“Description and Performance of a Near-Room Temperature Magnetic Refrigerator," Zimm, C. Jastrab, A., Sternberg, A. Pecharsky, V., Gschneidner, K., Osborne, M. And Anderson, I., CEC July 1997.

MIT Website, http://lost.pfc.mit.edu/technology_engineering/mr.html

Ames Website, http://www.ameslab.gov/cool.html

Karl A. Gschneidner, Jr., Metallurgy and Ceramics Division, Iowa State University

Carl Zimm, Astronautics, Madison, WI (608-221-9001)

Steve Karsjen, Ames Lab (515-294-1856 )

\section{Obvious Holes in Knowledge, Understanding, Information}

Magnitude of electrical parasitics and confirmation of modeled COPs. 


\section{COMPRESSOR-DRIVEN METAL HYDRIDE HEAT PUMP}

\section{Basic Concept Description}

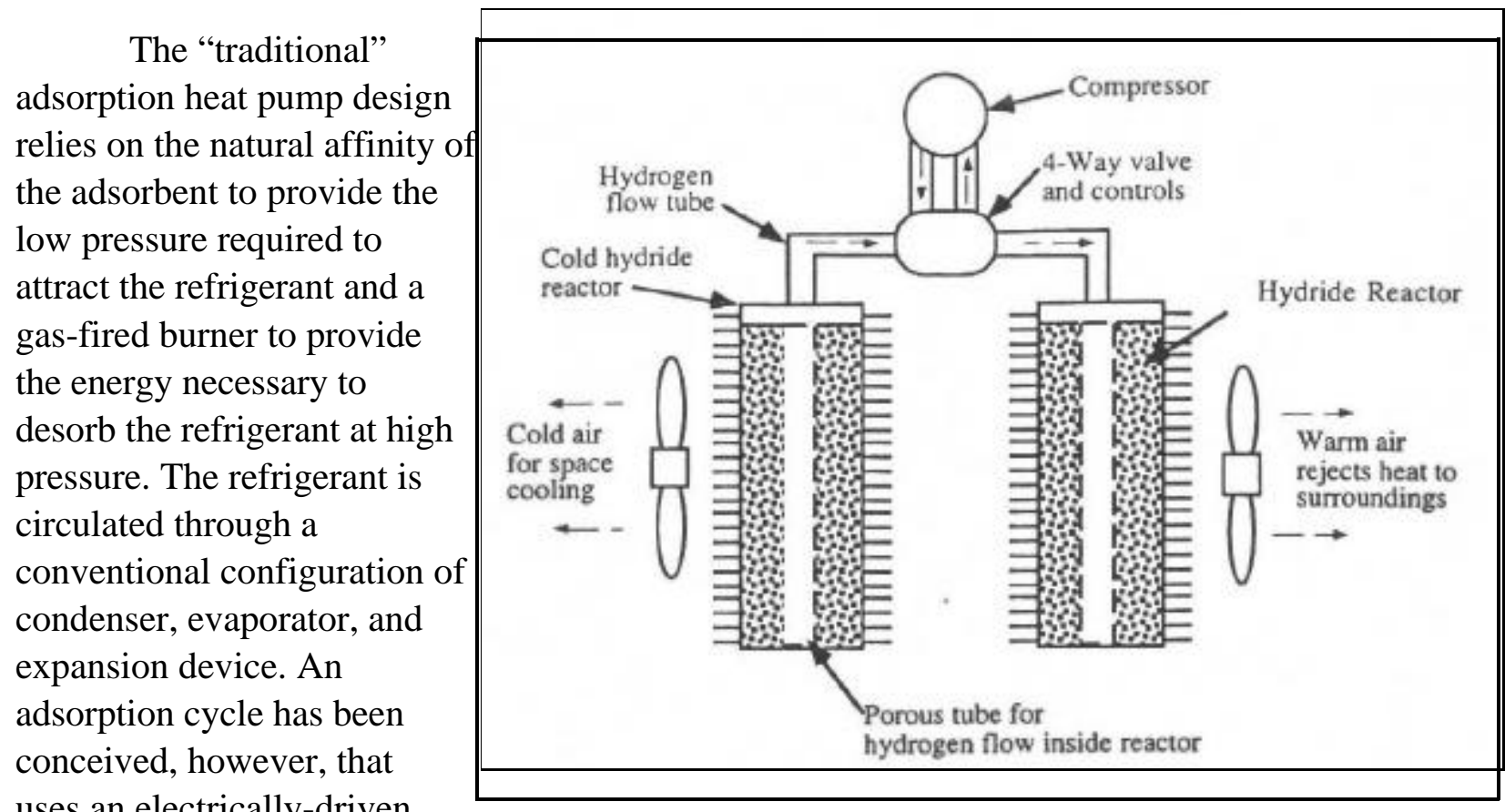

uses an electrically-driven

compressor to impose a

pressure drop causing the

Fig. 32. Compressor driven metal hydride heat pump (source: Kim 1997).

gas, hydrogen in this case, to

desorb from the metal hydride bed. The suction line of a conventional refrigeration compressor is connected to a bank of fully charged "reactors" of porous metal hydride "compacts." The discharge line is connected to a second discharged reactor. The refrigerant, hydrogen, is desorbed from the lanthanum pentanickle $\left(\mathrm{LaNi}_{5}\right)$ adsorbent at low pressure and temperature on the suction side and adsorbed on the $\mathrm{LaNi}_{5}$ on the high pressure side. A three or four-way valve is used to cycle alternating hydrogen flow back and forth between the reactors. A schematic of this system is shown in Figs. 32 and 33.

\section{Background Information}

Work is being done under a DOE grant at the University of New Mexico on a compressor driven metal hydride heat pump. They have built and tested a laboratory prototype.

\section{Secondary System Requirements}

A secondary heat transfer loop would be required for safety reasons to avoid circulating pure hydrogen gas through a heat exchanger inside the occupied space. 


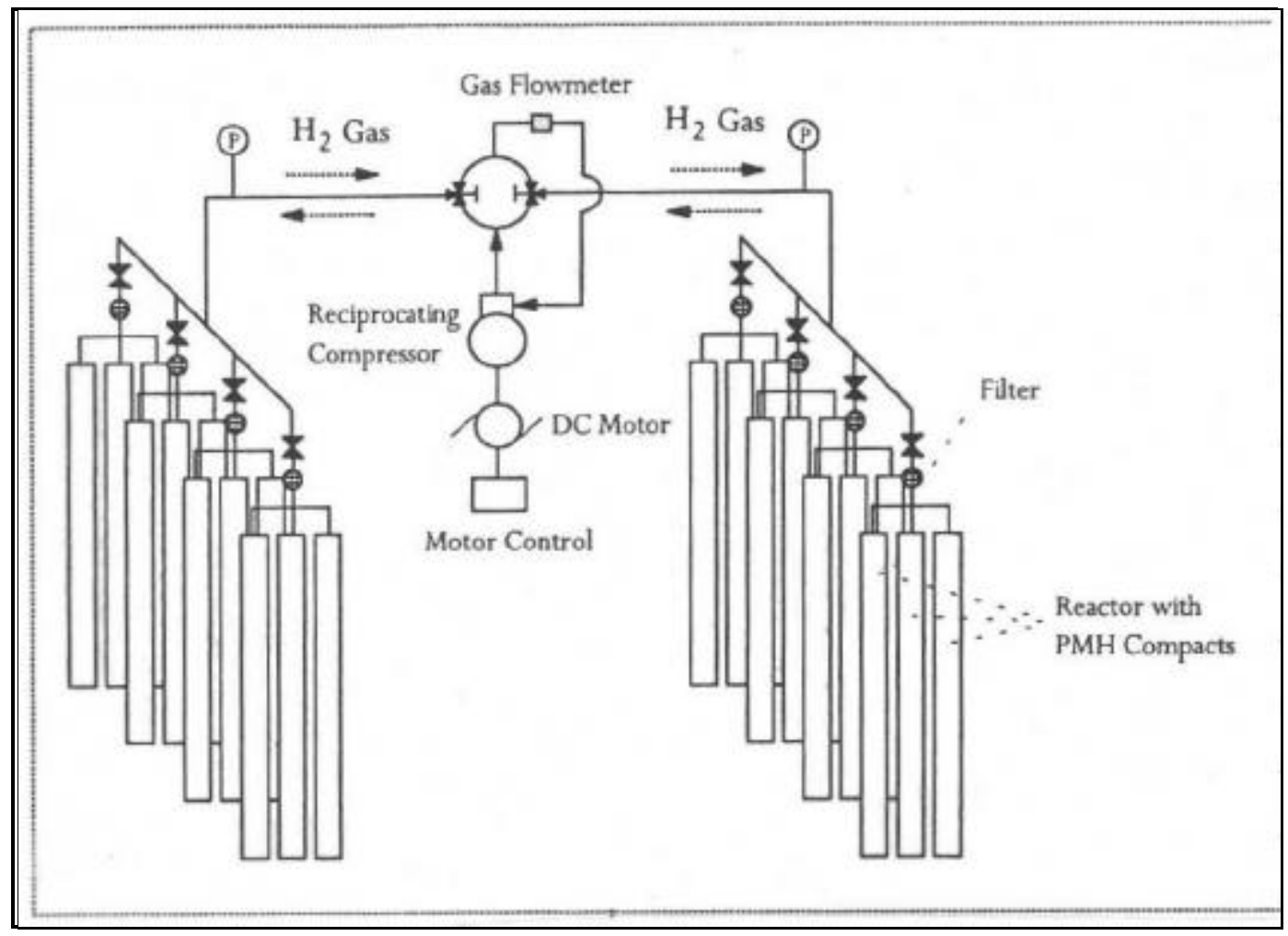

Fig. 33. Schematic of the experimental test stand for the prototype compressor driven metal hydride heat pump (source: Kim 1997).

\section{Efficiency Data}

Feldman et al. (1996) provide formulas for computing the theoretical COP for a metal hydride heat pump from the hot and cold heat exchanger absolute temperatures. They specify the useful cooling as:

\section{$\mathrm{q} \quad \&) \mathrm{H} \& \mathrm{q}$}

where $\mathrm{q}_{\text {loss }}$ is the energy required to cool the container and metal hydride to the cold heat exchanger temperature. The effective cooling can be rewritten as:

$$
\mathrm{q} \quad \text { ' } \&) \mathrm{H} \& \overline{\mathrm{m}}\left(\mathrm{C} \% \frac{\mathrm{C}^{\prime}}{\mathrm{R}}\right)(\mathrm{T} \& \mathrm{~T})
$$




$$
\left.\mathrm{q}^{\prime} \quad \& \not \quad .8(\$ .1 \% 0.1 / 2) \propto \mathrm{T} \quad \& \mathrm{~T}\right)
$$

The ideal work of compression (cal/mole hydrogen) is given by:

$$
\text { W ' } R @\left[\mathrm{e}^{-\cdots \cdot\left(-\frac{1}{\mathrm{~h}} \cdot \frac{-}{\mathrm{c}}\right)} \& 1\right] \varliminf_{\mathrm{k} \& 1}^{\mathrm{k}}
$$

where $\mathrm{k}$ is $\mathrm{C}_{\mathrm{p}} / \mathrm{C}_{\mathrm{v}} ; \mathrm{k}=1.4$ for hydrogen. Equations 9 and 11 are used to compute the COPs for a heat pump using $\mathrm{LaNi}_{5}$ at the conditions listed in Table 10; the results are in Table 21. These results are based on a 70\% compressor efficiency and cycling $\mathrm{Cd}$ factors of 0.25 ; the current laboratory test unit uses a secondary heat transfer loop so these results include $100 \mathrm{~W}$ of pumping power for the secondary loop (short brine loop with fluid pumped through tightly packed $\mathrm{LaNi}_{5}$ heat exchanger bed).

Table 21. Calculated and Observed Efficiencies for Compressor-Driven Metal Hydride Heat Pumps.

\begin{tabular}{|r|c|c|c|c|c|c|}
\hline & \multicolumn{3}{|c|}{ Heating } & \multicolumn{3}{c|}{ Cooling } \\
\cline { 2 - 7 } & & & $\begin{array}{c}\text { Seasonal } \\
(\mathrm{Btu} / \mathrm{Wh})\end{array}$ & $82 \mathrm{EF}$ & $95 \mathrm{EF}$ & $\begin{array}{c}\text { Seasonal } \\
(\mathrm{Btu} / \mathrm{Wh})\end{array}$ \\
\hline Cycle Efficiency & $47 \mathrm{EF}$ & $17 \mathrm{EF}$ & & & & \\
\hline $\begin{array}{r}\text { Cycle COP } \\
\text { theoretical } \\
\text { observed }\end{array}$ & 3.64 & 1.65 & & 5.16 & 3.85 & \\
\hline $\begin{array}{r}\text { System COP } \\
\text { theoretical } \\
\text { observed }\end{array}$ & 2.75 & 1.44 & 6.0 & 3.54 & 2.87 & 10.5 \\
\hline
\end{tabular}

notes: blank entries denote absence of calculated or measured information, calculated and observed cycle efficiencies do not apply for the shaded seasonal boxes

\section{Technical Advantages/Benefits}

Working fluid without GWP or ODP. 


\section{Technical Disadvantages}

Costs of the metal hydride and use of an explosive or highly flammable refrigerant are possible disadvantages.

\section{Technical Barriers}

Work needs to be done on effective heat and mass transfer in the metal hydride beds and efficient compressors need to be developed for use with hydrogen.

\section{Economic Analysis}

The economic analysis was performed assuming a secondary loop pumping power of 100 W/ton and an annual maintenance cost of $\$ 110$. The installed cost of equipment for compressor driven metal hydride heat pumps would need to be at least $\$ 825$ per ton below that of the electric heat pump baseline, or roughly half the installed cost, for this system to have the same life cycle cost as the electric baseline. The most competitive regions are the Southeast, South Central, and Southwest.

There are no apparent cost savings in this technology (since it employs a hermetic compressor) and cost increases associated with the hydriding material $\left(\mathrm{LaNi}_{5}\right)$, heat exchangers and pump for the secondary loop, and safety provisions necessary for using hydrogen as a refrigerant.

\section{Contacts and Sources of Information}

Kim, K. et al. 1997, “Compressor-Driven Adsorption Heat Pump Development Employing Porous Metal Hydride Compacts,” submitted for 1998 ASHRAE Absorption Symposium.

Kwang J. Kim, Ph.D.

Research Assistant Professor

Artificial Muscles Research Institute \& Mechanical Engineering Department

University of New Mexico

Albuquerque, New Mexico 87131

Tel/Fax: (505) 277-1335

E-mail: kwangkim@slider.unm.edu

\section{Obvious Holes in Knowledge, Understanding, Information}

Cycle performance data at $82 \mathrm{E}, 47 \mathrm{E}$, and $17 \mathrm{EF}$.

Effects of air cooled heat exchangers. 


\section{ELECTRO-CHEMICAL HEAT PUMP}

\section{Basic Concept Description}

The electro-chemical heat pump uses a conventional reverse Rankine cycle with an electrochemical pump in place of the motor driven compressor. In the two systems proposed for cooling applications, hydrogen is ionized in either water or ammonia forming a "solvated" positive ion. An electrical field will then cause the ions to move through a semipermeable membrane, against a pressure gradient, from a positive electrode to a negative electrode. The two components are returned to neutral states at the positive electrode, the liquid and vapor are separated at high pressure, and the vapor is condensed and evaporated to provide heating and cooling.

\section{Background Information}

Electro-chemical pumps are based on the electrophoresis effect. This principle was first applied by the Swedish scientist Arne Tiselius in 1930 to separate molecules that differed in sizes. Since then various applications have been successfully developed with the majority of the work being in analytical chemistry and chemical technology. Most projects currently proposed are to develop electro-chemical pumps for use as artificial hearts; they are able to pump blood without the damage to red blood corpuscles caused by mechanical pumps. Several proposals to use electro-chemical pumps for refrigeration applications were made in the 1960s; only one company appears to have a current interest in the field.

Several special chemical and physical processes occur in the operation of an electro-chemical pump which do not have analogies for existing gas and liquid compression. For a system using hydrogen as the refrigerant and water as the solvent, the thermophysical properties of the solvated ion, $\left(2 \mathrm{H}+8 \mathrm{H}_{2} \mathrm{O}\right)^{+}$differ from those of the initial neutral substances of hydrogen and water. The equivalent "molecular weight" is 148 , which is several times that of the mixture of neutral hydrogen and water. Also, the fluid of charged particles will be much less compressible than the neutral mixture because of the repulsive forces between like charges.

The COP for an electro-chemical heat pump can be derived from basic thermodynamics. The first and second laws state that:

$$
\mathrm{T} \mathbb{\&} \quad \mathbb{U} \% \mathbb{E}
$$

where $\mathrm{T}$ is the temperature of the process, $\mathrm{S}$ is the entropy, $\mathrm{U}$ is the internal energy, and $\mathrm{L}$ is the work. For an adiabatic process, $\mathrm{dS}=0$, so:

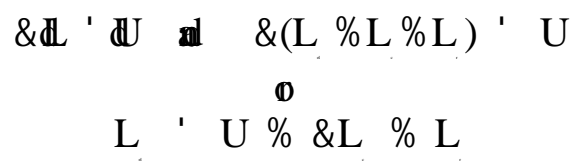


where $\mathrm{L}_{\mathrm{el}}$ is the work of the electrical current driving the electro-chemical compressor, $\mathrm{L}_{\mathrm{c}}$ is the work consumed to compress the working fluid, and $\mathrm{L}_{\mathrm{r}}$ is the work consumed to overcome the internal electrical resistance of the compressor. Equation 13 can be expanded as:

$$
\text { \&, @ ' C (T \& }) \text { \% . @ @ }{ }_{2 \mathrm{~T}}^{\mathrm{T}} \text { @ }\left(\frac{\mathrm{p}}{\mathrm{p}}\right) \% \text { "@ }
$$

where $\mathrm{A}, \mathrm{C}_{\mathrm{v}}$ and . are the molecular weight, constant volume specific heat and compressibility factor of the solvated ions, $\mathrm{R}$ is the universal gas constant (per mole), " is the electrical resistance of the membrane, $\mathrm{I}$ is the current flow, and the temperatures and pressures are $\mathrm{T}$ and $\mathrm{p}$. The applied voltage is , and $\mathrm{Z}$ is the total charge moving through the membrane. A little manipulation yields:

$$
\begin{aligned}
& \text { Q. ' G@(T \& }) \text { \% . @@@ } \\
& \text { Q ' }
\end{aligned}
$$

with $\mathrm{G}$ being the flow rate of the working fluid (mole/sec) and $r$ the heat of vaporization of the mixture (J/gmole). Thus the COP for an electro-chemical pump is:

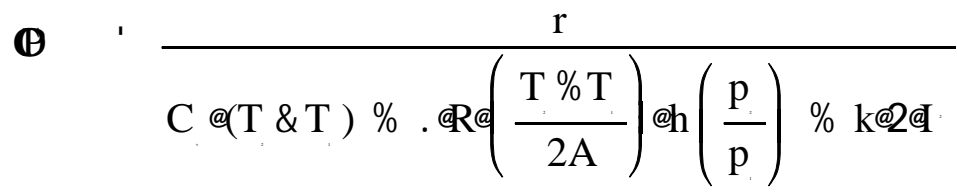

where " $=\mathrm{k} 2, \mathrm{k}$ is the membrane resistance coefficient $\left(\mathrm{ohm} / \mathrm{cm}^{2}\right)$, and $2=\mathrm{A} / \mathrm{G}$ is the specific transparency of the membrane $\left(\mathrm{cm}^{2} /\right.$ mole, $A$ is the membrane area, $\left.\mathrm{cm}^{2}\right)$. Equation 16 gives the efficiency in terms of the operating temperatures and pressures, four mixture properties ( $\mathrm{r}, \mathrm{Cv},$. , and A), two membrane properties ( $\mathrm{k}$ and 2 ), and the current (I).

\section{Secondary System Requirements}

None.

\section{Efficiency Data}

The only known efficiency data for an electro-chemical heat pump are for a system using hydrogen with ammonia as the refrigerant and solvent. Analytical Power Corporation provided measured and calculated efficiencies in a short technical memo. They cited a cooling capacity of $500 \mathrm{~W}$ 
with $413 \mathrm{~W}$ of electrical input for a COP of 1.21 at pressures of 2.1 and $19 \mathrm{~atm}$ and temperatures of $0 \mathrm{EF}, 85 \mathrm{EF}$, and $110 \mathrm{EF}$ at the compressor inlet, condenser (average), and compressor outlet and a membrane resistance coefficient, $\mathrm{k}$, of $0.2 \mathrm{ohms} / \mathrm{cm}^{2}$ (best available). This is approximately $22 \%$ of Carnot efficiency. Calculated COPs of 0.68 and 1.92 were also reported for membrane resistance coefficients of 0.4 (commercially available) and 0.05 (not available), respectively (13\% and $35 \%$ of Carnot), at the operating conditions previously mentioned.

ORNL has not been able to perform independent calculations of COP for this cycle because of the strong dependence on the unknown properties of the solvated ions. The memo from Analytic Power Corporation tabulates COPs for a matrix of cell, condenser, and evaporator exit temperatures, membrane resistivities, current densities, and membrane areas (see Table 22). Unfortunately Analytic Power did not provide the fluid or membrane properties needed to compute COPs using Eq. 16 so ORNL was unable to derive corresponding efficiencies at different conditions. Efforts to estimate these parameters using the data in Table 22 were not successful. Generally, the efficiencies from ACP are small fractions of the Carnot COP, as shown in the last column of Table 22, reaching $36 \%$ for membranes with resistivities that are significantly better than the best available membranes (" $=0.05 \mathrm{vs}$ $"=0.20$ ) and $33 \%$ for very low current densities (which would require multiple units to achieve the same capacity as the higher current densities, hence higher costs); the theoretical COPs for compression systems at the operating conditions used in this analysis are above $50 \%$ of Carnot efficiency. A membrane resistance of approximately $0.01 \mathrm{ohms} / \mathrm{cm}^{2}$ would be necessary to reach COPs comparable to conventional compression systems (personal communication, Solomon Labinov).

\section{Technical Advantages/Benefits}

There are a number of advantages that support the development of electro-chemical pumps for some applications:

! there are no moveable parts or mechanical systems to transfer energy,

! silent operation,

! simple control of the flow rate and operating pressures of the working fluid, and

! the ability to mixtures of liquids and gases as well as single-phase working fluids.

\section{Technical Disadvantages}

The major disadvantage of electro-chemical heat pumps appears to be their low efficiencies. There could be additional losses associated with mixtures of gases (i.e. water vapor/hydrogen and hydrogen/ammonia) in the heat exchangers further reducing capacity and efficiency.

\section{Technical Barriers}

Knowledge of the properties of the solvated ions for hydrogen in water or hydrogen in ammonia needed to calculate COPs at the rating points.. 
Table 22. Theoretical Efficiency of Electro-Chemical Heat Pumps (Analytic Power Corporation).

\begin{tabular}{|c|c|c|c|c|c|c|c|c|}
\hline \multirow[b]{2}{*}{$\begin{array}{l}\text { Test } \\
\text { Case }\end{array}$} & \multicolumn{3}{|c|}{ Temperatures (EF) } & \multirow[b]{2}{*}{$\begin{array}{l}\text { Resistivity } \\
\left(\mathrm{ohm} / \mathrm{cm}^{2}\right)\end{array}$} & \multirow{2}{*}{$\begin{array}{c}\text { Current } \\
\text { Density } \\
\left(\mathrm{amps} / \mathrm{ft}^{2}\right)\end{array}$} & \multirow{2}{*}{$\begin{array}{c}\text { Membrane } \\
\text { Area } \\
\left(\mathrm{in}^{2}\right)\end{array}$} & \multicolumn{2}{|c|}{ Efficiency } \\
\hline & Cell & $\begin{array}{l}\text { Condenser } \\
\text { Exit }\end{array}$ & $\begin{array}{c}\text { Evaporator } \\
\text { Exit }\end{array}$ & & & & COP & $\begin{array}{c}\% \\
\text { Carnot }\end{array}$ \\
\hline 1. & 110 & 85 & 0 & 0.20 & 500 & 9.35 & 1.21 & $22 \%$ \\
\hline 2. & 100 & 85 & 0 & 0.20 & 500 & 11.86 & 1.00 & $18 \%$ \\
\hline 3. & 90 & 85 & 0 & 0.20 & 500 & 43.06 & 0.29 & $5 \%$ \\
\hline 4. & 100 & 95 & 0 & 0.20 & 500 & 13.23 & 0.85 & $18 \%$ \\
\hline 5. & 100 & 75 & 0 & 0.20 & 500 & 7.85 & 1.44 & $24 \%$ \\
\hline 6. & 100 & 85 & 40 & 0.20 & 500 & 7.88 & 1.85 & $17 \%$ \\
\hline 7. & 100 & 85 & -40 & 0.20 & 500 & 11.62 & 0.79 & $24 \%$ \\
\hline 8. & 100 & 85 & 0 & 0.40 & 500 & 12.44 & 0.68 & $13 \%$ \\
\hline 9. & 100 & 85 & 0 & 0.05 & 500 & 7.88 & 1.92 & $35 \%$ \\
\hline 10. & 100 & 85 & 0 & 0.20 & 500 & 15.12 & 0.87 & $16 \%$ \\
\hline 11. & 100 & 85 & 0 & 0.20 & 500 & 35.51 & 0.44 & $8 \%$ \\
\hline 12. & 100 & 85 & 0 & 0.20 & 1000 & 6.73 & 0.59 & $11 \%$ \\
\hline 13. & 100 & 85 & 0 & 0.20 & 250 & 16.21 & 1.76 & $33 \%$ \\
\hline
\end{tabular}

\section{Economic Analysis}

The economic analysis has not been performed for electro-chemical Rankine cycle heat pumps because of the absence of reported or modeled efficiency data.

\section{Contacts and Sources of Information}

Analytic Power Corporation

P.O. Box 1189

Boston, MA 02117

(617) 542-6352

\section{Obvious Holes in Knowledge, Understanding, Information}

Calculated COPs at the ARI rating conditions. 


\section{GAS FURNACE / ELECTRIC AIR CONDITIONER}

\section{Basic Concept Description}

The baseline technology for unitary residential and commercial gas-fired equipment is a high efficiency, non-condensing gas furnace (AFUE 0.80) and an SEER-12 electric reverse Rankine cycle air conditioner. Both products are commercially available and established technologies. The baseline applied commercial system is a gas boiler and centrifugal chiller.

\section{Background Information}

This is a conventional gas furnace and electric air conditioner; albeit not the least efficient on the market, but not the most efficient either. The installed cost of the baseline system is approximately the same as that of the baseline electric heat pump (E-Source); see page 10.

\section{Secondary System Requirements}

None are required.

\section{Efficiency Data}

The theoretical heating energy consumption is based on $80 \%$ combustion efficiency and a blower power of $420 \mathrm{~W}$ (140 W/ton design cooling load); the air conditioner requires an additional $210 \mathrm{~W}$ (70 W/ton) for the outdoor fan. The theoretical (calculated) compressor only air-conditioner COPs are 5.59 and 4.37 at $82 \mathrm{E}$ and $95 \mathrm{EF}$ respectively with steady-state system (including blower and fan power at $210 \mathrm{~W} /$ ton) COPs of 4.19 and 3.47 at $82 \mathrm{E}$ and $95 \mathrm{EF}$ with a calculated SEER of 12.4. This is slightly higher than the rated SEER 12.

\section{Technical Advantages/Benefits}

High efficiency systems with established base of sales and service organizations.

\section{Technical Disadvantages}

Possible regulation of fluorocarbon refrigerants.

\section{Technical Barriers}

None 
Contacts and Sources of Information

Product Literature

Obvious Holes in Knowledge, Understanding, Information

None 


\section{ENGINE-DRIVEN COMPRESSION HEAT PUMPS}

\section{Basic Concept Description}

The refrigeration circuit of the engine-driven heat pumps is similar to that discussed elsewhere for electric driven systems with the addition of engine waste heat recovery to augment the system heating capacity. Multiple engine types are grouped together in this section of the report rather than repeating much of the discussion separately for Otto, Diesel, Stirling, Brayton, and Rankine engines.

\section{Background Information}

Diesel engine driven heat pumps: Yanmar manufactures and sells a diesel-engine driven heat pump in Japan. The product guide contains a table with capacity and gas input for heating and cooling at two rating points (one heating, one cooling). The products appear to span $7500-60,000 \mathrm{~kW}$ capacity $\left(2 \frac{1 / 2}{2}\right.$ to 20 tons cooling @ 95EF). The rated COPs are 1.3 heating and 0.9 cooling. Some products appear to have an additional electrical load while the large capacity systems appear to include generators and may not require external electrical connections.

Otto engine driven heat pumps: papers were located reporting on several different field tests, including the York Triathalon and an R\&D project involving Tokyo Gas. The Triathalon is now a commercial product in the U.S. and there is a reasonably sized market for $1 \frac{1}{2}$ to 5 ton units in Japan. Miyairi (1989) describes some of the government and utility incentives in marketing engine driven heat pumps Japan.

Efficiency data for IC engine-driven Rankine cycle heat pumps are published in Nowakowski (1992), Nowakowski (1995), Taira (1992), Miyairi (1989), Kazuta (1989), and Kaneko (1992). Kazuta's (1989) paper includes graphs of capacity, COP, and power input as functions of engine speed. He also gives electrical data of $78 \mathrm{~W}$ for the 1.3 ton heat pump. Steady-state data are reported for the Triathalon at the $47 \mathrm{E}$ and $95 \mathrm{EF}$ rating points and also seasonal values from field tests.

Stirling engine driven heat pumps: the free-piston Stirling engine was an attractive power source for a reverse-Rankine cycle heat pump system because of the potential long life/low maintenance of the Stirling engine. DOE funded several contractors to develop and test prototype Stirling engine driven systems. GRI participated in these activities through their funding of Stirling engine development. Stirling engine driven heat pumps did not appear to offer any clear cost advantage to the consumer, they were projected to be too expensive, and there was no strong support or efforts at commercialization by the gas industry.

Aisin Seiki developed a Stirling engine-driven heat pump for the commercial space conditioning market in Japan. Their 20 ton machine had a target cooling COP of 1.09 without exhaust heat recovery and 1.57 with $70 \%$ heat recovery. Limited testing showed a cooling COP of 0.91 (apparently at the 95EF condition). Maximum engine efficiency with auxiliaries was approximately 34\% (ADL 1987). 
Stirling Power Systems (SPS) developed a 10 ton heat pump system with performance targets of 1.1 COP cooling and 1.8 heating. Environmental and reliability testing was conducted in 1987. This project was under development for more than 10 years and was planned for commercialization in the late 1980s. Engine efficiency with auxiliaries was approximately 25\% (ADL 1987).

General Electric was under contract to DOE to develop a Stirling engine driven heat pump for residential applications. Two prototype systems were to be built and tested based on an inertial compressor concept. Testing of the Phase I prototype verified the 82-83\% combustor efficiency (program goal) with a 76\% isentropic efficiency for the free-piston linear compressor (exceeding the goal) with a $3 \mathrm{~kW}$ output. The Stirling engine efficiency was only 20 to $26 \%$, below the $30 \%$ program goal. The Phase II performance goals were (1) Stirling engine efficiency of 35\%, (2) a refrigeration loop COP of 3.5, and (3) overall combustion efficiency of $80 \%$.

Phase II failed to meet its performance goals due to deficiencies in the performance of the freepiston Stirling engine and mismatching of the dynamic characteristics of the engine and compressor (GE 1982). A third phase of the contract examined problems revealed in the Phase II testing; test engine met the output power goals but the engine efficiency was found to be $25 \%$ instead of the required $27 \%$, maximum brake efficiency was $21 \%$. Reduction in efficiency from earlier testing was believed to be due to better measurements and data acquisition equipment in the second series of tests rather than poorer engine performance. Analysis showed the gas spring losses were too high resulting in lower efficiency.

Another effort at developing a Stirling engine driven heat pump included the participation of several contractors including MTI, Consolidated Natural Gas, Lennox, and John Deere with funding from DOE and GRI. GRI had primary responsibility for engine development and DOE was primarily responsible for "system" development. The engine / transmission / compressor assembly operated successfully and demonstrated many of the project goals, but it did not achieve the capacity goal of 3.0 tons cooling. GRI terminated their interest in engine development. DOE decided against further hardware development and sponsored a workshop on July 14-15, 1994 in Albany, NY to transfer the technology to the private sector. The workshop was eventually canceled because of lack of interest from manufacturers and the gas industry (BER 1991).

Sunpower developed and tested a magnetic coupling of a free-piston Stirling engine to a 3 ton heat pump module. The engine operated at an estimated $28 \%$ efficiency. The system assembly was tested and COPs of 0.42 and 1.0 were measured at $95 \mathrm{E}$ and $85 \mathrm{EF}$ cooling conditions and 1.36 and 1.08 at $47 \mathrm{E}$ and $15 \mathrm{EF}$ heating conditions, assuming $90 \%$ heat recovery. The major loss in the system was identified as the gas spring in the lower end.

Brayton engine driven heat pumps: a Brayton engine is used to drive a hermetic centrifugal compressor for a conventional Rankine cycle vapor compression heat pump. GRI and DOE/ORNL jointly supported a contract with AirResearch in the early 1980s to develop a 10 ton Brayton/Rankine heat pump for light commercial applications. A Brayton engine was to be used with a centrifugal compressor using R-12 in a subatmospheric system (GRI 1982, p. 1-1). The predicted overall engine efficiency was $27 \%$ with cooling COP of 1.0 at $95 \mathrm{EF}$ and heating COP of 1.2 to 1.4 at $47 \mathrm{EF}$. Dunham Bush and Lennox Industries were both brought into the project to do marketing surveys. The project outcome is unknown (GRI 1982). 
Rankine engine driven heat pumps: No background information was located relative to applying Rankine engines to general purpose space conditioning; one source was located in which a Rankine engine was used for a heat pump application in conjunction with a solar pond.

\section{Secondary System Requirements}

A "four pipe" system is required to recover engine waste heat for heating purposes which increases equipment and installation costs.

\section{Engine Efficiency Data}

The scope of this project limited the analysis of engine-driven systems to the combination of a single, "representative" engine efficiency with compressor-only COPs. The assumed engine efficiencies are:

! diesel engine: $35 \%$

! IC (Otto) engine: $30 \%$

! Stirling engine: $28 \%$

! Brayton engine: $27 \%$

! Rankine Engine: $24 \%$

A more rigorous analysis would vary engine efficiency with speed and load.

\section{Efficiency Data}

Cycle COPs are computed using the state points listed in Table 23 with a compressor-only efficiency of $80 \%$. The condensing temperature in cooling mode is assumed to be $15 \mathrm{EF}$ higher than the condensing temperature for the electric heat pump in cooling mode because in at least one commercial design the outdoor air flow is used to cool the engine compartment before it crosses the condenser. This ) $\mathrm{T}$ was determined to give a COP for an IC engine driven heat pump of 0.90 at 95EF. The calculated cycle COPs are combined with a single fixed engine efficiency for each of the engine types.

The heating COPs include $50 \%$ waste heat recovery and a belt and pulley efficiency of $85 \%$; seasonal COPs assume a cycling $\mathrm{Cd}$ of 0.10 . The theoretical system gCOPs

Table 23. State Point Temperatures for Engine Driven Heat Pump Cycle Calculations

\begin{tabular}{|l|c|c|c|c|}
\hline \multirow{2}{*}{$\begin{array}{l}\text { State Point } \\
\text { Temperatures }\end{array}$} & \multicolumn{4}{|c|}{ Ambient Temperatures } \\
\cline { 2 - 5 } & $47 \mathrm{EF}$ & $17 \mathrm{EF}$ & $82 \mathrm{EF}$ & $95 \mathrm{EF}$ \\
\hline condensing & $100 \mathrm{EF}$ & $85 \mathrm{EF}$ & $120 \mathrm{EF}$ & $135 \mathrm{EF}$ \\
\hline evaporating & $29 \mathrm{EF}$ & $-14 \mathrm{EF}$ & $49 \mathrm{EF}$ & $49 \mathrm{EF}$ \\
\hline superheat & $18 \mathrm{EF}$ & $18 \mathrm{EF}$ & $11 \mathrm{EF}$ & $11 \mathrm{EF}$ \\
\hline subcooling & $16 \mathrm{EF}$ & $16 \mathrm{EF}$ & $0 \mathrm{EF}$ & $0 \mathrm{EF}$ \\
\hline
\end{tabular}


Table 24. Calculated and Observed Efficiencies for Engine-Driven Heat Pumps.

\begin{tabular}{|c|c|c|c|c|c|c|c|}
\hline \multirow[b]{2}{*}{ Cycle Efficiency } & \multirow[b]{2}{*}{$\begin{array}{l}\text { engine } \\
\text { efficiency }\end{array}$} & \multicolumn{3}{|c|}{ Heating } & \multicolumn{3}{|c|}{ Cooling } \\
\hline & & $47 \mathrm{EF}$ & 17EF & $\begin{array}{c}\text { Seasonal } \\
\text { gCOP }\end{array}$ & $82 \mathrm{EF}$ & 95EF & $\begin{array}{c}\text { Seasonal } \\
\text { gCOP }\end{array}$ \\
\hline$\underline{\text { Compressor COP }}$ & & 5.78 & 3.98 & & 4.54 & 3.52 & \\
\hline Diesel engine & $35 \%$ & 2.07 & 1.53 & 1.55 & 1.35 & 1.05 & 1.27 \\
\hline IC engine & $30 \%$ & 1.85 & 1.39 & 1.43 & 1.16 & 0.90 & 1.09 \\
\hline Stirling engine & $28 \%$ & 1.76 & 1.33 & 1.38 & 1.08 & 0.84 & 1.02 \\
\hline Brayton engine & $27 \%$ & 1.71 & 1.30 & 1.35 & 1.04 & 0.81 & 0.98 \\
\hline Rankine engine & $24 \%$ & 1.58 & 1.21 & 1.27 & 0.93 & 0.72 & 0.87 \\
\hline $\begin{array}{r}\text { Measured COP } \\
\text { Diesel engine } \\
\text { IC engine } \\
\text { Stirling engine } \\
\text { Brayton engine } \\
\text { Rankine engine }\end{array}$ & & 1.09 & & 1.44 & & $\begin{array}{c}0.9 \\
0.91\end{array}$ & \\
\hline
\end{tabular}

notes: blank entries denote absence of calculated or measured information, calculated and observed cycle efficiencies do not apply for the shaded seasonal boxes

are listed in Table 24. Conditions were selected to obtain a cooling COP of 0.9 at $95 \mathrm{EF}$ for an IC engine-driven heat pump, but the calculated results at $82 \mathrm{EF}$ compare well with data measured by Domitrovic at ORNL. The steady-state COP of the IC engine-driven system at 47EF compares well with the specification of 1.8 for an engine-driven heat pump in Nowakowski (1992), as does the computed seasonal heating efficiency (1.43) and that reported by Nowakowski (1.44) three years later.

The gCOPs in Table 24 do not include peripheral energy use for fans or blowers; a combined COP including both gas and electrical input may be cited in some references, but usually without any acknowledgment that this has been done. Aisin Seiki reported Stirling engine-driven heat pump system gCOPs of 1.09 and 1.57 (70\% heat recovery) at 47EF and 0.91 at 95EF. SPS report a gCOP of 1.80 at $47 \mathrm{EF}$ and 1.10 at $95 \mathrm{EF}$. Sunpower reported heating COPs of 1.36 and 1.08 at $47 \mathrm{EF}$ and $15 \mathrm{EF}$ with $90 \%$ heat recovery and cooling gCOPs of 1.0 at $85 \mathrm{EF}$ and 0.42 at $95 \mathrm{EF}$.

\section{Technical Advantages/Benefits}

Each of the engine-driven heat pumps has the advantages of (1) low energy costs for natural gas, (2) low $\mathrm{CO}_{2}$ emissions from fuel combustion, and (3) high heating efficiencies attainable using 
waste heat recovery. The Stirling, Brayton, and Rankine engine-driven heat pumps also should have long engine life and low maintenance because of the low number of moving parts. Emissions for these engines should be lower than with an internal combustion and diesel engines.

\section{Technical Disadvantages}

The principal technical obstacle of engine-driven systems is the engine lifetime and the annual maintenance costs. Annual and lifetime operating hours are an order of magnitude higher than the operating hours for a motor vehicle engine. Long life, low maintenance engines are required for any of these technologies to be successful. The low efficiency of the Rankine engines makes them a poor choice for gas-fired systems, though they may be applicable to solar or waste heat driven systems.

First cost is the major non-technical disadvantage for engine-driven systems. A relatively high efficiency, low cost electric motor is being replaced by an internal or external combustion engine and more sophisticated controls.

Arthur D. Little (ADL) reviewed the recent experience in free-piston Stirling engine driven heat pumps to identify key technical and cost issues which should be the focus of future program efforts. ADL concluded that several key requirements for a successful HVAC system have been demonstrated (GE and MTI) including engine efficiencies approaching 30\%.

Significant progress had also been made recently $(1984,1985)$ in demonstrating good life potential as a result of endurance testing for space power systems. Integrated free-piston Stirling engine heat pump systems have not demonstrated some of the essential requirements for a commercially viable product including high season performance factor, long life, and low maintenance. Outstanding issues that need to be resolved include:

! a reliable low cost means of coupling the free piston Stirling engine to a heat pump cycle,

! analytical models that can provide a reasonable level of accuracy for projecting the performance of current and future system configurations,

! accurate assessments of loss mechanisms associated with bearings, gas springs, gas flow through heat exchangers, and identification of design options for minimizing such losses, and

! development of seals, bearings, combustors, etc. which meet the stringent requirements of a gas fired heat pump system.

Furthermore, the potential for mechanical simplicity that could lead to long life has not been fully demonstrated in current (1984) designs (ADL 1986).

Several conclusions have been reached in analyses of Stirling engine driven heat pumps:

"The kinematic Stirling engine should not be used in residential application because the small $5 \mathrm{hp}(3.73 \mathrm{~kW})$ engine model has relatively low efficiency; however, the $17 \mathrm{hp}$ $(12.7 \mathrm{~kW})$ unit in commercial application is competitive with the alternative engine types." (Fischer 1987).

"Good performance potential of the free-piston unit [in residential application] (as indicated by reasonably good weighted engine and compressor efficiencies) may not result in attractive savings because of the high transmission loss (roughly 15\%) and parasitic electrical power consumption of $300 \mathrm{~W}$ (in residential size) not needed in 
other units." (Fischer 1987). The "other units" probably refers to the Otto and Wankel engine driven heat pumps and the conventional electric heat pump.

\section{Technical Barriers}

IC engine-driven heat pumps (Otto and Diesel) are commercially available products, so "barriers" may better be understood as impediments to increasing market share -- cost, inertia, etc. These products have been more successful in Japan than in North America and it may be informative to examine the underlying reasons for that.

There are several technical problems that would need to be resolved before Stirling engine driven heat pumps can be commercialized. These include matching the dynamic characteristics of the engine and compressor in a free-piston duplex Stirling configuration, the transmission efficiency for either a kinematic or free-piston configuration, and the gas spring in the lower end. These problems notwithstanding, Stirling engine-driven heat pumps would be very expensive. The inherent low efficiencies of the Brayton and Rankine engines are barriers to their development for this application.

\section{Economic Analysis}

Figure 34 shows the results of the economic calculations IC engine-driven heat pump assuming that the enginedriven system costs $\$ 25$ per year more to maintain than the gas baseline furnace and air conditioner. The results show that installed costs could be $\$ 1000$ per ton higher than the baseline system, or more, in the upper Midwest and northeastern states and $\$ 500$ to $\$ 1000$ per ton throughout the central regions of the country. Higher maintenance

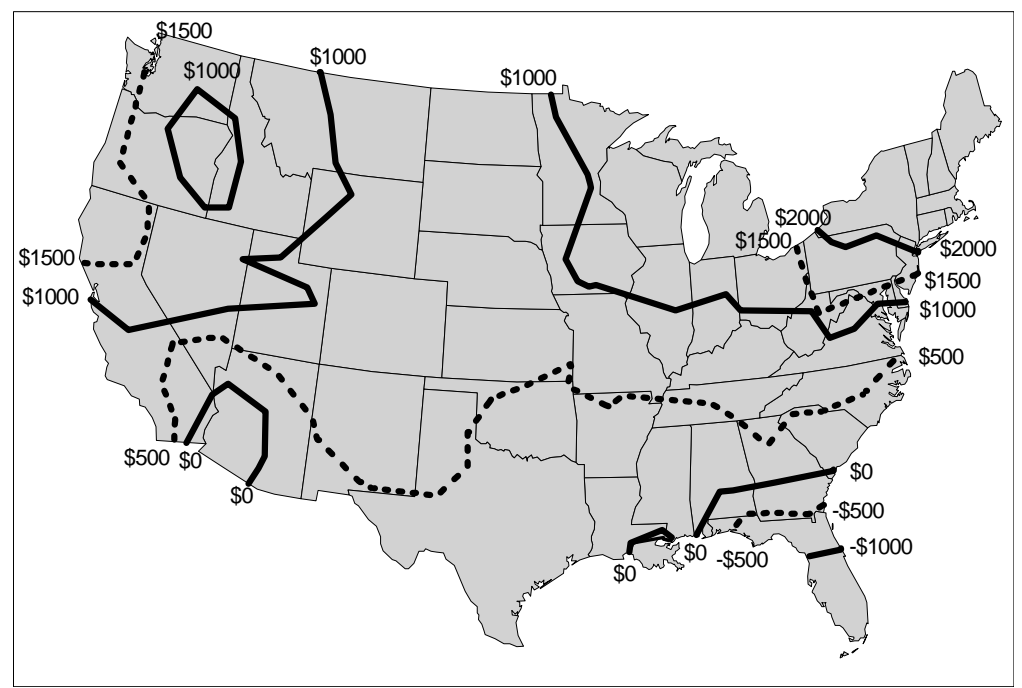
costs, of course, reduce the allowable installed cost premiums. A maintenance cost differential of $\$ 100$ per year (instead of $\$ 25$ ) reduces the installed cost premiums by $\$ 490$ to $\$ 690$ greatly restricting the regions of the country where engine-driven heat pumps compare favorably with traditional gas furnaces. 
Table 25 shows that three or five year paybacks can be achieved ( with a $\$ 25 / y$ higher maintenance costs) outside of the high cooling states with installed costs $\$ 200$ to $\$ 500$ per ton higher than a gas furnace and electric air conditioner. The costs could be as much as $\$ 700$ per ton higher in the northeast and still achieve a five year payback.

The engine driven systems compare poorly against the baseline electric heat pump in Florida, southern Alabama, and extreme southeast Louisiana, but favorably in the southwest, south central states, Pacific Northwest and California where electric heat pumps may be used.

The hardware for an engine driven heat pump adds the relatively large cost of the engine, water pump, and installation of heat recovery loop while saving the relatively low cost of an electric motor. Maintenance costs are a significant factor and they are certainly going to be higher than they are for either baseline system.

While the economic analysis is only reported for IC engine driven heat pumps, it is clear that the results are somewhat more favorable for diesel engine driven systems because of the assumed higher engine efficiency and slightly less favorable for Stirling engine driven systems because of the slightly lower efficiency (absent a lower maintenance cost). A more rigorous analysis is necessary that incorporates differences in maintenance costs to obtain a definitive comparison of these three enginedriven heat pumps.

\section{Contacts and Sources of Information}

ADL 1986, "Status of Free Piston Stirling Engine Driven Heat Pumps - Development, Issues, and Options Final Report,” ORNL/Sub/84-00205/1, Arthur D. Little, April 1986.

ADL 1987, "Technology Status of Components for Gas-Fired Cooling Systems," Arthur D. Little for GRI, April 1987, pp. 2-43 to 2-46.

Colosimo, D., 1987, Introduction to Engine-Driven Heat Pumps - Concepts, Approach, and Economics, ASHRAE Transactions, Volume 93, Part 2, pp. 987-996.

D’Aponte, F. et al., 1996, Test Application of a Small Size Gas Engine Driven Heat Pump, Proceedings of the 5th International Energy Agency Conference on Heat Pumping Technologies, Volume II, pp. 85-93. 
E Source 1995, "Product Profile: The York Triathalon Natural Gas-Fired, Engine-Driven Heat Pump,” November 1995.

Fischer, R.D. et al, 1987. "Engine-Driven Heat Pump Performance Analysis," ASHRAE Transactions, Vol. 93, pt 2, pp. 1046-1077.

Freedman, S., et al., 1992, Unitary Gas Heat Pump Development Status in the USA, IEA Heat Pump Centre Newsletter, Vol. 10, No. 4, pp. 4-8.

Fukuda, T. 1987, Development of Gas-Engine Heat Pumps in Japan, Proceedings of the 1987 International Energy Agency Heat Pump Conference: Prospects in Heat Pump Technology and Marketing, pp. 389-402, Lewis Publishers.

GE 1982, "Development and Demonstration of a Stirling/Rankine Heat Activated Heat Pump: Final Report Phase IIIB - Engine Technology Development Testing," ORNL/Sub/82-17485/1, General Electric Co.

GRI 1982, Phase II Brayton/Rankine 10-Ton Gas-Fired Space Conditioning System, ORNL/Sub80/24706/1, July 1982.

GRI, 1987, “Technology Status of Components for Gas-Fired Cooling Systems,” GRI-87/0023, pp. 2.70-2.81.

Kaneko, T., et al., 1992, The Performance of a Four-Ton Gas-Engine-Driven Heat Pump, ASHRAE Transactions, Volume 98, Part 1, pp., 989-993.

Kazuta, H., 1989, “Development of Small Gas Engine Heat Pump,” ASHRAE Transactions, Volume 95, Pt. 1, pp. 982-990.

Leslie, N. et al., 1991, Gas Engine-Driven Air-Conditioner Performance in an Unoccupied Research House, ASHRAE Transactions, Volume 97, Part 2, pp. 1054-1061.

Miyairi, T., 1989, “Introduction to Small Gas Engine-Driven Heat Pumps in Japan - History and Marketing,” ASHRAE Transactions Vol. 95, Pt. 1, pp. 975-981.

MTI 1986a, "Free-Piston Stirling Engine Diaphragm-Coupled Heat-Actuated Heat Pump Technology Program: Volume I Phase IIA and IIB Final Report: Technical Discussion," ORNL/Sub/8647985/2\&V1. 
MTI 1986b, "Free-Piston Stirling Engine Diaphragm-Coupled Heat-Actuated Heat Pump Technology Program: Volume II Phase IIA and IIB Final Report: Technical Discussion," ORNL/Sub/86-47985/2\&V2.

MTI 1986c, "Free-Piston Stirling Engine Diaphragm-Coupled Heat-Actuated Heat Pump Technology Program: Phase 1C Final Report" R. A. Ackerman, Mechanical Technology Inc.

MTI 1986d, "Free-Piston Stirling Engine Diaphragm-Coupled Heat-Actuated Heat Pump Technology Program: Phase 1B Final Report" R. A. Ackerman.

MTIe 1986, "Free-Piston Stirling Engine Diaphragm-Coupled Heat-Actuated Heat Pump Technology Program: Phase 1/1A Final Report" Mechanical Technology Inc.

Nowakowski, G. 1996, An Introduction and Status Update on Unitary Engine-Driven Heat Pumps, ASHRAE Journal, December, pp. 42-47.

Nowakowski, G., et al., 1992, Development and Field Testing of a High-Efficiency Engine-Driven Gas Heat Pump for Light Commercial Applications, ASHRAE Transactions, Volume 98, Part 1, pp. 994-1000.

Nowakowski, G., et al., 1995, Field Performance of a 3-Ton Natural Gas Engine-Driven Heating and Cooling System, ASHRAE Transactions, Volume 101, Part 2, pp. 1382-1388.

ORNL 1991, ORNL BER Program Monthly Progress Report, March 1991

Rusk, R. P., et al. 1990, "Development and Use of a Mathematical Model of an Engine-Driven Heat Pump,” ASHRAE Transactions, Vol. 96, Pt. 2, pp. 282-290.

Shelton, S., 1987, Natural gas I.C. Engine-Driven Heat Pumps, ASHRAE Transactions, Volume 93, Part 2, pp. 1034-1045.

Struck, W., et al. 1987, Gas-Engine-Driven Heat Pumps - Design, Components, Experience, Layout, and Economic Feasibility, Proceedings of the 1987 International Energy Agency Heat Pump Conference: Prospects in Heat Pump Technology and Marketing, pp. 403-414, Lewis Publishers.

Taira, K., 1992, Development of a 2.5 RT Multiple-Indoor-Unit Gas Engine Heat Pump, ASHRAE Transactions, Volume 98, Part 1, pp. 982-988.

The Triatholon System from York, http://www.york.com/newtri.html

Wurm, J., et al., 1987, History and Status of Engine-Driven Heat Pump Developments in the U.S., ASHRAE Transactions, Volume 93, Part 2, pp. 997-1005. 
Yamaha Motor Corporation

P.O. Box 6555 / 6555 Katella Avenue

Cypress, CA 90630

Yanmar Diesel Engine Co., Ltd.

Yokoyama, T., 1992, Design Considerations for Gas-Engine Heat Pumps, ASHRAE Transactions, Volume 98, Part 1, pp. 975-981.

\section{Obvious Holes in Knowledge, Understanding, Information}

Calculated COPs should be corroborated using detailed performance data on the York and Yanmar IC and diesel engine driven heat pumps. Cost analysis should be compared with economic evaluations from DOE projects on Stirling and Brayton engine driven heat pumps. 


\section{FUEL CELL POWERED RANKINE CYCLE}

\section{Basic Concept Description}

A fuel cell could be used to convert natural gas to electricity $(60 \mathrm{hz}, \mathrm{A} / \mathrm{C})$ to power a conventional Rankine cycle heat pump. The fuel cell itself consists of four major components: (1) a fuel processor ore reformer (which converts the fuel, natural gas or naphtha, into a hydrogen rich gas mixture), (2) a stack (which produces direct current electricity), (3) an inverter for converting DC to $\mathrm{AC}$ power, and (4) a heat recovery system, which removes surplus heat from the fuel cell stack and fuel processor for use in space conditioning and water heating. The fuel cell transforms the fuel directly to electricity without combustion. Electricity from a fuel cell can be used to power a conventional electrically driven heat pump with waste heat providing supplemental heating.

\section{Background Information}

The fuel-cell principle has been known for more than 150 years since it was described by Sir W. R. Grove in 1839. Some sporadic research was done during the 30s, but it was not until the 1950s that significant amounts of money were put into fuel-cell research. The first application of fuel cells was during the Gemini and Apollo space missions in the U.S. The principal components of a fuel cell are catalytically activated electrodes for the fuel (anode) and the oxidant (cathode) and an electrolyte to conduct ions between the two electrodes. The fuel is hydrogen, or a reformed hydrogen-rich hydrocarbon such as methanol or natural gas, and the oxidant is derived from air (i.e., oxygen). In a phosphoric acid or polymer electrolyte fuel cell, hydrogen is fed to the anode and then "split" into protons and electrons. The protons are transmitted through the electrolyte to the cathode where they combine with oxygen to form water. The remaining electrons, which cannot be transported by the electrolyte, then move through an electrical conductor.

There is a great deal of research and development underway on fuel cells. There are five different basic types of fuel cells which have fundamental differences in their design and operation:

! alkaline fuel cells,

! molten carbonate fuel cells (MCFC),

! solid oxide fuel cells (SOFC),

! phosphoric acid fuel cells (PAFC), and

! proton exchange membrane (PEM) fuel cells

Some of their properties are summarized in Table 26. Alkaline fuel cells are used on the space shuttle and have a relatively long history of development. They can have efficiencies as high as $70 \%$ but are not seeing much development for commercial applications becuase of their high costs. Both molten carbonate and solid oxide fuel cells attractive for large capacity applications because they have high conversion efficiencies $(>60 \%)$. Their operating temperature are high (above 1200EF, 650EC) which may create disadvantages (e.g. response to startup and load changes, costs) that may make them inappropriate for building applications. The greatest amounts of fuel cell development activity are in phosphoric acid and proton exchange membrane fuel cells. Each of these technologies has conversion 
efficiencies from 40 to $50 \%$, they each use platinum as a catalyst, and require an external reformer for preparing the fuel. Both the platinum and external reformer raise issues associated with high costs. PAFCs are commercially available in capacities above $100 \mathrm{~kW}$, but prices are around $\$ 4000$ per $\mathrm{kW}$ and have not changed significantly for several years. This is significantly higher than other electric generating technologies (e.g. engine-driven generators, microturbine generators). Operating temperatures for PAFCs are around 390EF which might make them very attractive for building applications where waste heat can be recovered and used. Many development activities for PAFCs center around reducing the cost by reducing the amount of platinum required for a given capacity. Much of the recent development of PEM fuel cells has been for use in automobiles and buses. This work has been primarily in the areas of permeable membranes and reduced platinum requirements. Operating temperatures are around $170 \mathrm{EF}$, which may be too low to provide useful waste heat recovery.

Table 26. Fuel Cell Technologies (Lloyd 1999)

\begin{tabular}{|l|c|c|c|}
\hline Fuel Cell Technology & $\begin{array}{c}\text { Conversio } \\
\mathrm{n} \\
\text { Efficiency }\end{array}$ & $\begin{array}{c}\text { Operating } \\
\text { Temperature }\end{array}$ & Status of Development \\
\hline Proton Exchange Membrane (PEM) & $40-50 \%$ & $175 \mathrm{EF}(80 \mathrm{EC})$ & demonstration systems up to 50 kW \\
\hline Phosphoric Acid (PAFC) & $40-50 \%$ & $\begin{array}{c}\text { around 390EF } \\
(200 \mathrm{EC})\end{array}$ & $\begin{array}{c}\text { commercial systems } 100 \mathrm{~kW} \text { and up; } \\
\text { most in use are } 200 \mathrm{~kW}\end{array}$ \\
\hline Molten Carbonate (MCFC) & $>60 \%$ & $1200 \mathrm{EF}(650 \mathrm{EC})$ & demonstration systems up to 2 MW \\
\hline Solid Oxide (SOFC) & $>60 \%$ & $\begin{array}{c}1475-1800 \mathrm{EF} \\
(800-1000 \mathrm{EC})\end{array}$ & demonstration units up to $100 \mathrm{~kW}$ \\
\hline
\end{tabular}

\section{Secondary System Requirements}

A waste heat recovery system is required.

\section{Efficiency Data}

COPs for a fuel cell powered heat pump are computed in the same manner as those for engine driven heat pumps using a conversion efficiency of $40 \%$ and a combined compressor and motor efficiency of $75 \%$, the state point temperatures listed in Table 3 on page 8, and cycle COPs in Table 4. The results are listed in Table 27. 
Table 27. Calculated and Observed Efficiencies for Fuel Cell Powered Heat Pumps.

\begin{tabular}{|c|c|c|c|c|c|c|c|}
\hline \multirow[b]{2}{*}{ Cycle Efficiency } & \multirow[b]{2}{*}{$\begin{array}{c}\text { conversion } \\
\text { efficiency }\end{array}$} & \multicolumn{3}{|c|}{ Heating } & \multicolumn{3}{|c|}{ Cooling } \\
\hline & & 47EF & $17 \mathrm{EF}$ & $\begin{array}{c}\text { Seasonal } \\
\text { gCOP }\end{array}$ & $82 \mathrm{EF}$ & 95EF & $\begin{array}{c}\text { Seasonal } \\
\text { gCOP }\end{array}$ \\
\hline $\begin{array}{r}\text { Compressor Only } \\
\frac{\mathrm{COP}}{\text { theoretical gCOP }} \\
\text { observed }\end{array}$ & $40 \%$ & $\begin{array}{l}4.98 \\
2.02\end{array}$ & $\begin{array}{l}3.08 \\
1.38\end{array}$ & 1.5 & $\begin{array}{l}5.30 \\
1.75\end{array}$ & $\begin{array}{l}3.98 \\
1.35\end{array}$ & 1.7 \\
\hline
\end{tabular}

notes: theoretical gCOPs include gas consumption required to produce electricity for $140 \mathrm{~W} /$ ton fan power and $70 \mathrm{~W} /$ ton blower power.

\section{Technical Advantages/Benefits}

Fuel cell powered heat pumps have the advantages of high conversion efficiency of gas to electricity and the capability to supplement low ambient heating capacity with waste heat from the fuel cell. Fuel cell could be sized to provide electricity to power more than just the heat pump.

\section{Technical Disadvantages}

It is not clear whether fuel cells can be scaled down, economically or not, to the capacity required for single-residence space conditioning applications. The costs of certain components, such as the signal conditioning equipment, probably will not scale with the capacity. The fuel cell "package" includes both power conversion and also signal conditioning equipment to provide AC current at $60 \mathrm{~Hz}$ and $240 \mathrm{~V}$; the signal conditioning adds a degree of electronic complexity that is not a factor in conventional single-speed electric heat pumps. The electronics package could also be vulnerable to lightning strikes and power surges if the fuel cell is not electrically isolated from the power grid.

\section{Technical Barriers}

Application of this technology is limited by the development of long lived, affordable fuel cells in relatively low capacities. Cost reductions associated with catalyists (reduced platinum requirement) and permeable membranes are necessary. 


\section{Economic Analysis}

Results for a fuel cell powered electric heat pump are shown in Fig. 35 assuming an annual maintenance cost $\$ 100$ higher than that for the baseline system. Installed cost premiums can be $\$ 500$ to $\$ 1000$ per ton outside the southern tier of states. Installed cost premiums higher than $\$ 1000$ per ton are justified in the northeast under these assumptions. Average regional installed cost premiums are

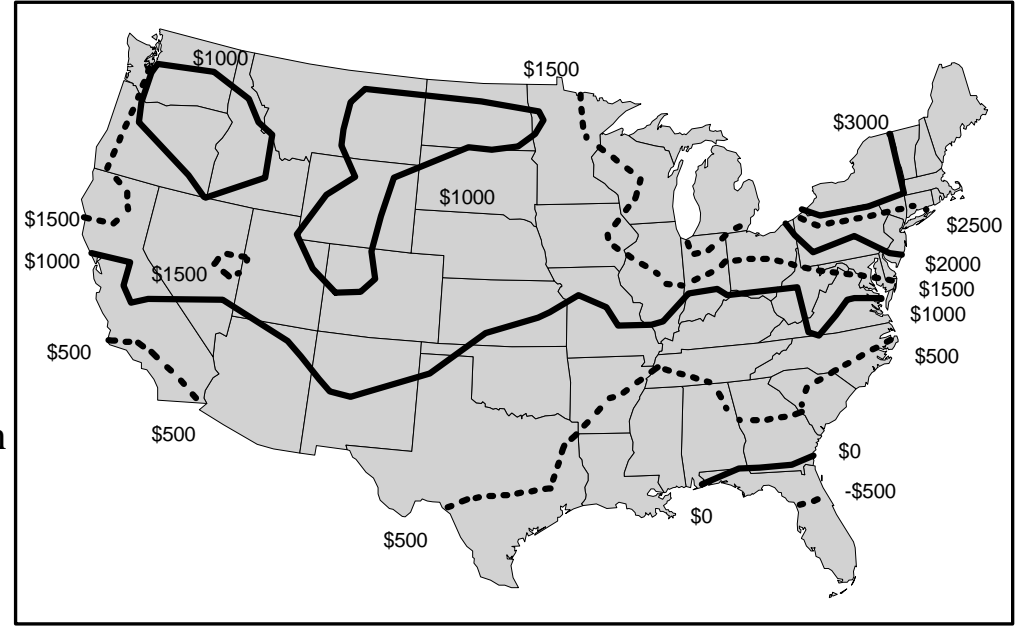

Fig. 35. Allowable installed cost premium for fuel cell powered heat pumps relative to the gas furnace baseline. listed in Table 28 for three-year and five-year paybacks and for equal life cycle costs.

There is a great deal of uncertainty surrounding the installed cost, annual maintenance costs, and the functional lifetime of "small" fuel cells, all of which have strong impacts on the system economics. This is shown graphically in Fig. 36 where there are eight curves showing the allowable installed cost premium for a fuel cell powered heat pump compared to the gas furnace / electric air conditioner baseline. The horizontal axis in Fig. 36 is the difference in annual maintenance costs (or nonenergy operating costs if the fuel cell is replaced during the lifetime of the heat pump) between the fuel cell powered system and the gas baseline.

Consider an example to illustrate the significance of these unknowns. Suppose that the difference in maintenance costs between the fuel cell powered and Table 28. Installed Cost Premiums for a Fuel Cell Powered Electric Heat Pump Relative to the Gas Baseline.

\begin{tabular}{|l|c|c|c|}
\hline \multirow{2}{*}{ Region } & \multicolumn{3}{|c|}{ Installed Cost Premium (\$/ton) } \\
\cline { 2 - 4 } & $\begin{array}{c}3 \text { Year } \\
\text { Payback }\end{array}$ & $\begin{array}{c}\text { 5 Year } \\
\text { Payback }\end{array}$ & $\begin{array}{c}\text { Equal Life } \\
\text { Cycle Cost }\end{array}$ \\
\hline Northeast & $\$ 627$ & $\$ 988$ & $\$ 2,646$ \\
\hline Southeast & $\$ 147$ & $\$ 224$ & $\$ 478$ \\
\hline South Central & $\$ 191$ & $\$ 296$ & $\$ 709$ \\
\hline Southwest & $\$ 209$ & $\$ 341$ & $\$ 902$ \\
\hline Midwest & $\$ 359$ & $\$ 566$ & $\$ 1,495$ \\
\hline Northern Plains & $\$ 256$ & $\$ 402$ & $\$ 1,028$ \\
\hline Rocky Mountain & $\$ 259$ & $\$ 404$ & $\$ 1,025$ \\
\hline Pacific Northwest & $\$ 309$ & $\$ 438$ & $\$ 1,103$ \\
\hline California & $\$ 248$ & $\$ 387$ & $\$ 982$ \\
\hline
\end{tabular}
gas furnace baseline is $\$ 100$ per 
year. Then Fig. 36 shows that installed costs could be $\$ 750$ to $\$ 2500$ per ton higher in the northeast, Pacific Northwest, Midwest, and California and the two systems would have the same life cycle costs. Collectively, those regions represent a reasonably large market. Those cost premiums are also in line with the fuel cell development cost targets discussed below. If the fuel cell must be completely replaced once during the lifetime of the heat pump (20 years), at the target cost of $\$ 1000 / \mathrm{kW}(\$ 1200 /$ ton) there is an additional $\$ 3600$ in operating costs to be averaged over the lifetime of the heat pump or $\$ 180$ per year. The total annual non-energy operating costs of the fuel cell system are thus $\$ 280$ and the installed cost premium is the cost of the initial fuel cell or $\$ 1200$ per ton. The point corresponding to these estimates falls above the line for the northeast in Fig. 36, consequently the life cycle costs of the fuel cell powered system is always higher than the gas baseline in every part of the country. Substantially longer fuel cell lifetimes and installed costs are necessary for this alternative to be competitive with the gas baseline.

The equipment cost of this alternative technology is essentially that of an electric heat pump plus the cost of the fuel cell, installation costs will be higher than an electric heat pump. A fuel cell powered three ton heat pump would require a peak electrical capacity of approximately $3.6 \mathrm{~kW}^{1}$ or $1.2 \mathrm{~kW}$ per ton of cooling capacity.

The cost and lifetime of the fuel cell are thus critical factors. Fuel cells fall into five different categories: (1) alkaline, (2) phosphoric acid, (3) molten carbonate, (4) solid oxide, and (5) proton exchange membrane fuel cells. Much of the development effort on fuel cells has been for mega-Watt applications for power plants and the costs will not scale with size to the capacities appropriate for single-family or business unitary equipment. Phosphoric acid fuel cells have been built in $12.5 \mathrm{~kW}$ capacity, but cost information is not known. In the late 1980s $200 \mathrm{~kW}$ PAFCs cost on the average $\$ 2000$ to $\$ 3600 / \mathrm{kW}$; SoCalGas projected that with mass production the costs could fall to $\$ 1000 / \mathrm{kW}$ (Hadder 1992). Avista Laboratories of Spokane, Washington is developing a $2 \mathrm{~kW}$ proton exchange

\footnotetext{
${ }^{1}$ Carrier 38AY(M)036-30 with FK4BNB005 indoor unit.
} 
membrane fuel cell; costs are not known. Cost estimates in the Argonne (ORNL/CON-38) report were supplied by UTC and were probably pretty good at the time. Adjusting the costs simply based on the Consumer Price Index translates the 1979 numbers to $\$ 1055 / \mathrm{kW}$ to $\$ 1315 / \mathrm{kW}$ for 25 to 250 $\mathrm{kW}$ fuel cells (decreasing in price as capacity goes up). (Christian 1978).

\section{Contacts and Sources of Information}

ADL, 1994, “Fuel Cells for Building Applications: Market Analysis, Technology Status, and Program Plan Overview,” Draft Topical Report prepared for U.S. DOE Building Equipment Division, Office of Building Technologies, Volume II, Rev. 1, September.

Borys, S. And Marianowski, L. 1998. “Fuel Cells -- Where They Are and Where They Are Going,” Canadian Gas Association Operating and Technical Workshop and Conference, April 24, Institute of Gas Technology.

Hadder, G. 1992, "Fuel Cells Background Information for Residential and Commercial Applications," Draft report prepared for U.S. Department of Energy, Office of Building Technologies, June.

Jacoby, M. 1999, “Fuel Cells Heading for Sale,” Chemical and Engineering News, June 14, pp. 3137.

Lloyd, A. 1999, “The Power Plant in Your Basement," Scientific American, July, pp. 80-86.

Mixon, W., et al, March 1979, “Market Assessment of Fuel Cell Total Energy Systems, Summary Report”, ORNL/CON-36.

G. Pine, et al, 1980, "Development of an Energy Consumption and Cost Data Base for Fuel Cell Total Energy Systems and Conventional Building Energy Systems”, ORNL/CON-38, July 1980.

\section{Obvious Holes in Knowledge, Understanding, Information}

Lifetime and maintenance costs for fuel cells. Pros and cons of alternative fuel cell technologies should be discussed with emphasis on which is most appropriate for stationary building application. 


\section{VUILLEUMIER CYCLE HEAT PUMPS}

\section{Basic Concept Description}

Although the Vuilleumier cycle has been around since 1918, it is not taught in most thermodynamics classes or textbooks. First, the Vuilleumier cycle is by definition a combination of a heat engine and a refrigeration cycle. Two distinct features of the cycle are that it is a thermocompression cycle instead of a mechanical compression cycle and that the engine and refrigeration cycles share the same working fluid. The basic Vuilleumier machine is shown in Fig. 37. P-V and T-S diagrams are in Figs. 38 and 39. Heat is input at the high temperature heat exchanger to increase the pressure of the working fluid, normally helium. Heat is rejected, to the ambient in a cooling application or to the conditioned space for a heat pump, through the two intermediate heat exchangers. Cooling is performed for an air conditioner at the low temperature heat exchanger. The working fluid is moved between hot and cold volumes in the machine through the use of two displacers operated by a crank mechanism 90E out of phase (mechanical energy is input to rotate the crank and move the displacers). The displacers are operating only against the pressure drops across the heat exchangers and regenerators and friction along the tube walls so there is a low pressure ratio. The low pressure ratio results in a low specific volume for the basic Vuilleumier cycle.

While the basic cycle relies on thermal compression, compounded machines may use mechanical compression These machines closely resemble duplex Stirling cycles, the primary difference being that the working fluid is shared between the engine and refrigerator segments in the Vuilleumier machine while the working fluid Fig. 38. P-

Fig. 37. Basic Vuilleumier cycle machine.

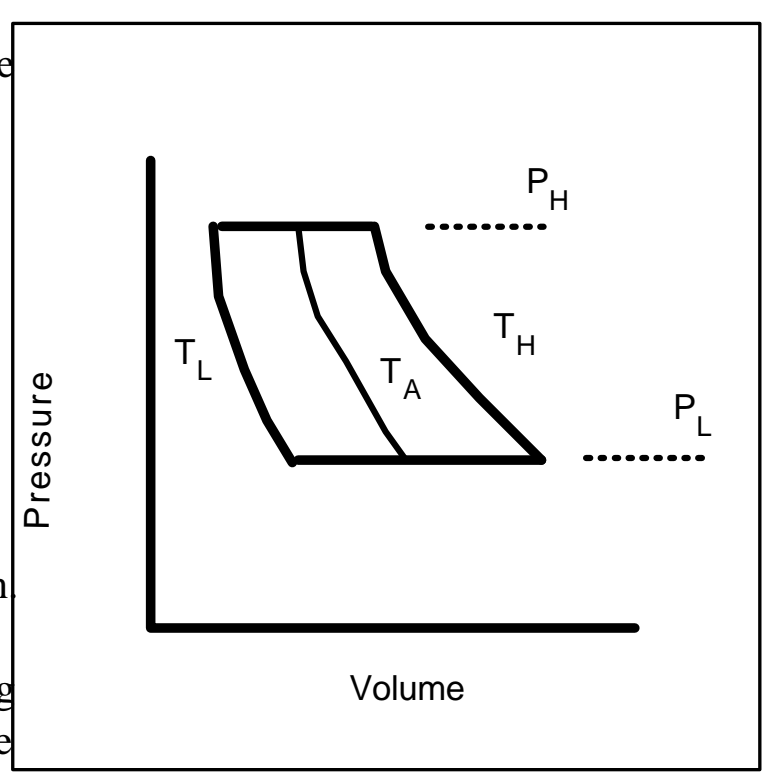

Fig. 38. P-V diagram for a Vuilleumier cycle 
in the engine-warm space of the duplex Stirling is separated from the working fluid in the refrigerator-warm space. The Vuilleumier cycle transfers work between components through transfers of the working fluid. The duplex Stirling cycle transfers work from the engine to the refrigerator segments through mechanical means (movement of the piston). A Vuilleumier cycle machine can be configured either as a kinematic or a free-piston machine; the freepiston Vuilleumier system is expected to have lower costs than kinematic version because of the reduction in equipment size and weight (Carlsen, Hannover 1994).

\section{Background Information}

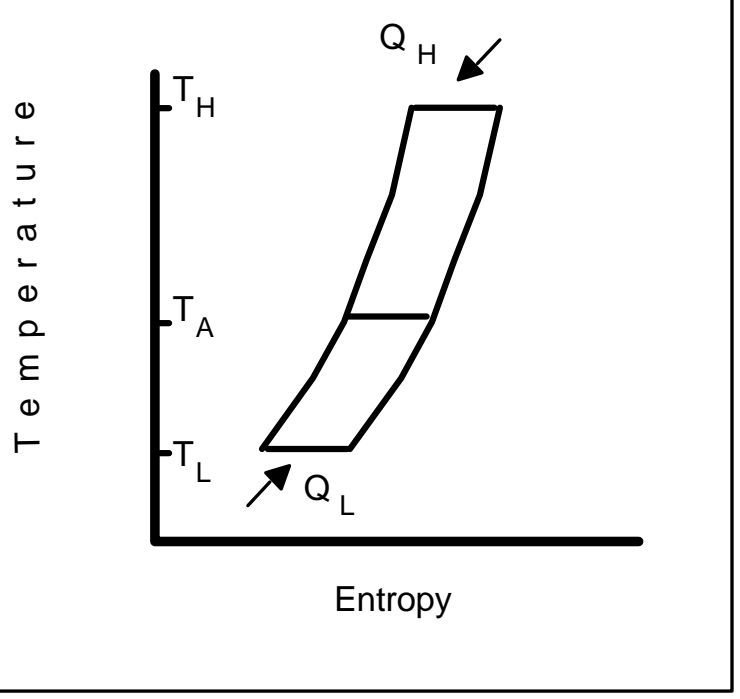

Fig. 39. T-S diagram for a Vuilleumier cycle machine.

Carlsen et al. mention the existence of more than 10 prototype Vuilleumier machines, though it isn't clear whether this is worldwide or just represents their own work at the Universities of Denmark and Dortmund. They provide test results for a $20 \mathrm{~kW}$ (5.7 ton) kinematic heat pump which was converted to a free-piston prototype.

Development work has also occurred in Japan. Sanyo has worked in cooperation with the Japan Gas Association and four gas utilities to develop a Vuilleumier cycle heat pump for space conditioning applications. Sanyo gives data for measured steady-state $\mathrm{COP}$ and capacity at various hot space helium temperatures (as shown in Fig. 40). They also cite performance data for the outdoor unit (though not stated explicitly, this is probably a multiple indoor unit system so that overall performance is defined by the outdoor unit) with a cooling COP of 0.63 and a heating COP of 1.34. These numbers are stated in terms of the helium hot space temperature and not related to an ambient condition.

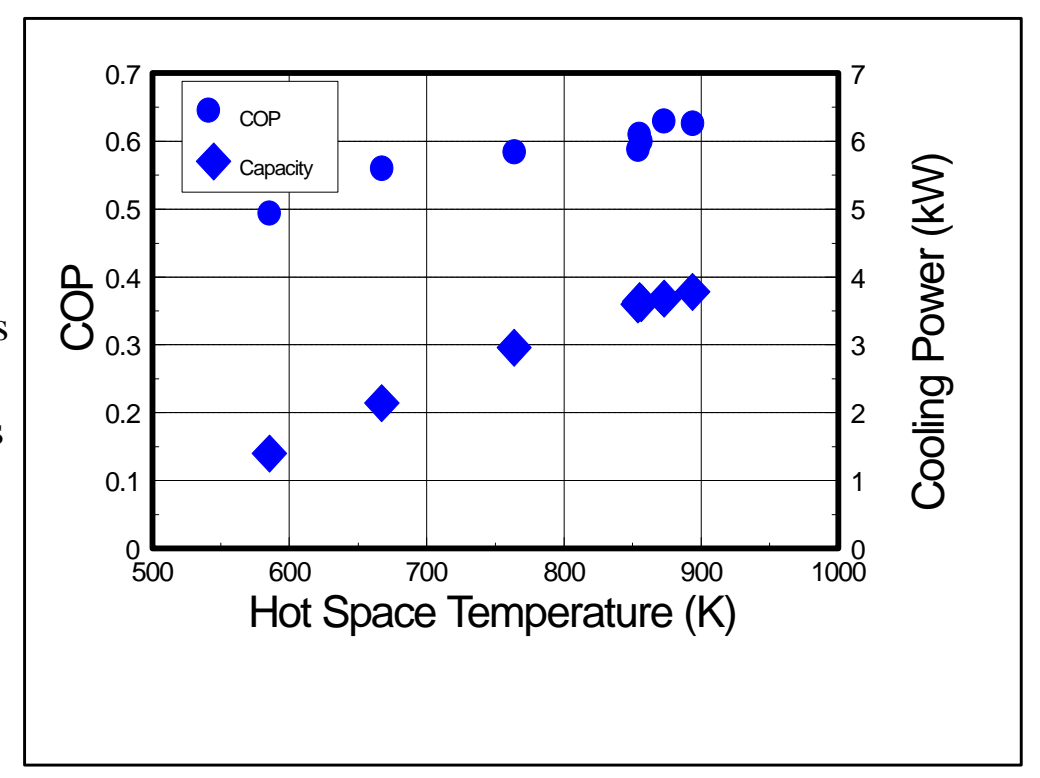

Fig. 40. Measured COPs and capacities for a Vuilleumier cycle heat pump. 


\section{Secondary System Requirements}

The performance of this cycle is strongly dependent on the dead space volume, so the heat exchangers need to be located very close to the primary mechanical package. A secondary heat transfer loop is needed between the indoor and outdoor units.

\section{Efficiency Data}

The computer

model TCVLM.BAS

(Wurm 1990) was used to compute steady-state COPs for a thermalcompression Vuilleumier cycle heat pump.

Recommended data provided with the program were used for the regenerator efficiencies (95\%), mean operating pressure, cycle speed $(16.67 \mathrm{~Hz})$, and fin specifications. Heat exchanger temperatures are specified at the values listed in Table 29. Calculated gCOPs are reported in Table 30 using a combustion efficiency of $80 \%$. The cycling coefficient $\mathrm{Cd}$ was set at 0.10 to approximate variable speed operation. The resulting heating season gCOP of 1.0 is credible compared with the 1.3 measured in field testing by Sanyo at 47EF; the cooling COP of 0.20 is significantly below the 0.63 at $95 \mathrm{EF}$ reported by Sanyo. The difference, particularly in cooling, could be explained if the Sanyo machine is a mechanicalcompression device rather than a thermal compression device.

\section{Technical Advantages/Benefits}

Gas-fired systems are expected to have lower emissions than internal combustion driven systems and they use a benign operating fluid (helium). There is a potentially high COP despite the disadvantages of Stirling/Vuilleumier as a cooling cycle (Carlsen) and potentially long equipment lifetimes and low maintenance requirements.

\section{Technical Disadvantages}

The disadvantage to the cycle is that the ideal efficiency is lower than Carnot cycle because the temperature of the gas in the cylinder volumes differs from the heat exchanger temperatures (Carlsen). There is also a low specific output so that an application requires larger, more expensive, equipment to meet a specified load. 
Table 30. Calculated and Observed Efficiencies for Vuilleumier Heat Pumps.

\begin{tabular}{|r|c|c|c|c|c|c|c|}
\hline \multirow{2}{*}{} & \multirow{2}{*}{$\begin{array}{c}\text { conversion } \\
\text { efficiency }\end{array}$} & $47 \mathrm{EF}$ & $17 \mathrm{EF}$ & $\begin{array}{c}\text { Seasonal } \\
\mathrm{gCOP}\end{array}$ & $82 \mathrm{EF}$ & $95 \mathrm{EF}$ & $\begin{array}{c}\text { Heating } \\
\mathrm{gCOP}\end{array}$ \\
\cline { 3 - 8 } Cycle Efficiency & & & & & & \\
\hline $\begin{array}{r}\text { Cycle COP } \\
\text { theoretical } \\
\text { observed }\end{array}$ & $80 \%$ & 1.21 & 1.23 & 1.1 & 0.27 & 0.24 & 0.3 \\
scaled observed & & 1.30 & & & & 0.63 & \\
\hline
\end{tabular}

notes: blank entries denote absence of calculated or measured information, calculated and observed cycle efficiencies do not apply for the shaded seasonal boxes

\section{Technical Barriers}

A major technical problem relates to centering the displacer pistons in free-piston machine and reduced efficiency relative to kinematic version. There is also a low specific output requiring relatively large and expensive equipment

\section{Economic Analysis}

The installed cost premiums in Fig. 41 are calculated using the "scaled observed" efficiencies in Table 30 with electrical use of 320 W/ton for fans, blowers, and the secondary fluid pump and an annual maintenance cost $\$ 25$ below the baseline gas system (the low pressure differentials across the displacers in the cylinders should result in low maintenance costs). The results are similar to the enginedriven heat pumps, although the economics are not quite as favorable. Installed costs can be

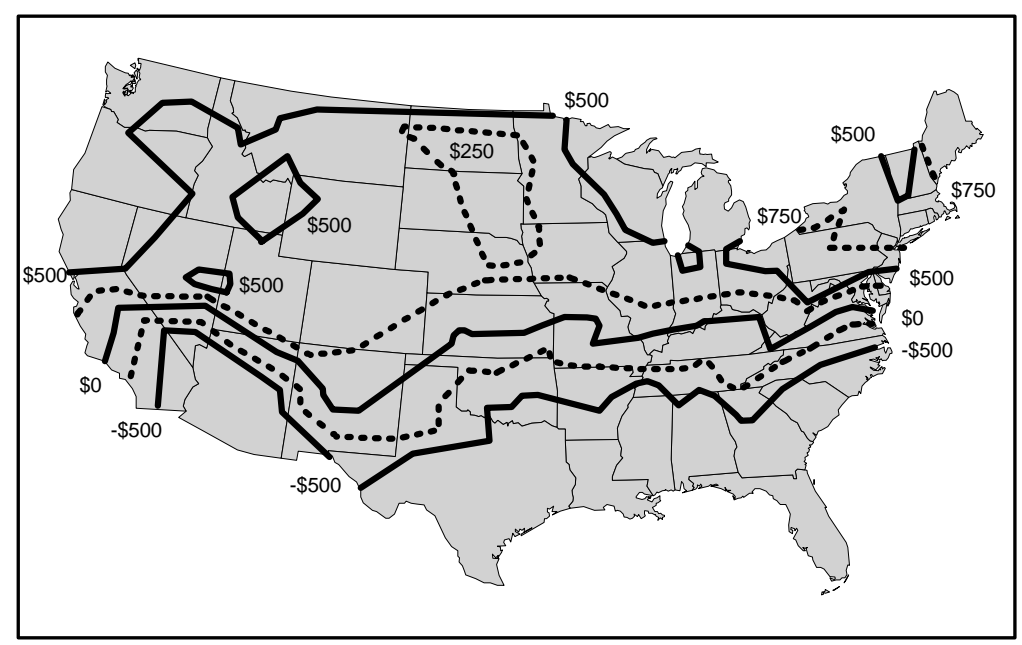

Fig. 41. Allowable installed cost premiums for Vuilleumier cycle heat pumps. from $\$ 0$ to $\$ 500$ per ton higher than the gas baseline system outside of the southern tier of states and can be over $\$ 500$ per ton in the northeast and some regions in the west and $\$ 750$ per ton in New York. 
This cycle eliminates the electric motor and compressor of a conventional electric heat pump or air conditioner saving both equipment and maintenance costs. In their stead, however, is a secondary fluid heat transfer system and possibly a low torque displacer motor. The data in Table 31 show the installed cost premiums for the northern states for three and five year paybacks assuming that the average annual maintenance cost is $\$ 25$ less than that for the gas furnace and electric air conditioner baseline. These results indicate that the Vuilleumier cycle heat pump should be economically viable (accepting the Sanyo COPs) at installed equipment costs slightly higher than the baseline gas furnace and electric air conditioner combination.

\section{Contacts and Sources of Information}

Toshikazu Ishihara, Yoshiaki Kurosawa, Yonezou Ikumi, and Junji Matsue

Sanyo Electric Co., Ltd

Environmental Systems R\&D Center

Sakata 1-1-1, Oizumi-Machi, Oura-Gun

Gunma 370-05, Japan

Rakesh Vidyadharan (student) and Ivan

Maldonado (professor)

Iowa State University

Ames, Iowa

e-mail: rakeshv@iastate.edu

e-mail: maldonad@iastate.edu
Table 31. Installed Cost Premiums for a Vuilleumier Cycle Heat Pump for 3 and 5 Year Paybacks.

\begin{tabular}{|l|c|c|}
\hline Region & $\begin{array}{c}3 \text { Year Payback } \\
(\$ / \text { ton })\end{array}$ & $\begin{array}{c}5 \text { Year Payback } \\
(\$ / \text { ton })\end{array}$ \\
\hline Northeast & $\$ 120$ & $\$ 200$ \\
\hline Midwest & $\$ 65$ & $\$ 100$ \\
\hline Northern Plains & $\$ 30$ & $\$ 50$ \\
\hline Rocky Mountain & $\$ 65$ & $\$ 100$ \\
\hline Pacific Northwest & $\$ 220$ & $\$ 290$ \\
\hline California & $\$ 30$ & $\$ 50$ \\
\hline
\end{tabular}

H. Carlsen, Technical University of Denmark

H. Kühl, University of Dortmund, Germany

S. Schulz, University of Dortmund, Germany

Stirling and Vuilleumier Heat Pumps Design \& Application, J. Wurm, J. Kinast, T. Roose, and W. Staats, McGraw-Hill, Inc. 1991.

\section{Obvious Holes in Knowledge, Understanding, Information}

Understanding of differences between theoretical calculations and Sanyo measurements; also the results of the Sanyo field test -- were the systems produced and sold? Was performance too low for a viable product? If so, why? Requests for information from Sanyo have not been successful, probably due to lack of contact with the appropriate person at Sanyo. 


\section{ABSORPTION CYCLES}

\section{Basic Concept Description}

The absorption cycle is typically employed in cooling applications, though development of the GAX cycle is directed toward providing both high efficiency heating and cooling. Most absorption cycles use an electric pump to raise the pressure of a liquid solution of absorbent and absorbate. An external heat source, a gas burner in a direct fired system, steam in an indirect fired system, or waste heat, is used in the generator (or desorber) to cause the refrigerant to desorb from the absorbent creating a high pressure vapor. In cases where a volatile absorbent is used, such as when the working pair is ammonia-water, a rectifier is needed to reduce the concentration of the volatile absorbent (e.g. water) in the vapor to the condenser. The refrigerant vapor flows through a condenser, expansion valve, and evaporator providing useful heating or cooling. The high temperature and pressure liquid solution remaining in the generator has a relatively low concentration of the refrigerant (i.e. ammonia in an ammonia-water system or water in a lithium bromide-water system). This weak solution flows through a pressure valve to the absorber where it is recombined with the refrigerant vapor leaving the evaporator. Heat is generated during the absorption process and the absorber needs to be cooled in order for sufficient vapor to be absorbed into the solution to have adequate refrigerant flow. Various improvements are possible to the basic absorption cycle to boost its efficiency with the addition of heat exchangers to make use of heat rejected at the absorber, the weak solution leaving the generator, etc. Some possibilities are illustrated below.

\section{Background Information}

Single- and double-effect absorption cycle machines have been produced commercially for waste heat and "large" chiller applications. Development work in ongoing for triple-effect chillers for commercial buildings and GAX absorption systems for residential and light commercial applications.

Single-effect cycle: the single-effect absorption cycle is pictured in Fig. 42. Waste heat, steam from a boiler, or heat from a direct-fired burner is added $\left(Q_{\text {desorb }}\right)$ to separate the refrigerant (generally water or ammonia) from the solution. The refrigerant passes through a condenser where heat is rejected from the cycle $\left(\mathrm{Q}_{\text {cond }}\right)$ either to be used for space conditioning for a heat pump or to the ambient for a chiller or air conditioner. The refrigerant passes through an expansion valve and into the evaporator where heat $\left(\mathrm{Q}_{\text {evap }}\right)$ is added to the cycle providing useful cooling or providing energy from the ambient for heat pumping. The high pressure, hot solution

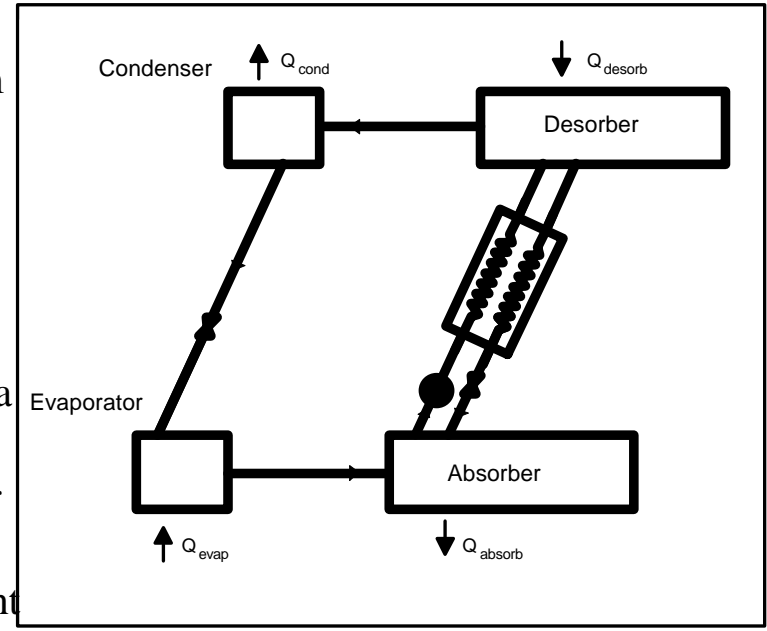

Fig. 42. Single-effect absorption cycle. 
from the desorber (or generator) with a weak concentration of the refrigerant is passed through an internal heat exchanger and pressure valve to the absorber. The refrigerant and weak solution are combined in the absorber, heat is rejected to the ambient $\left(\mathrm{Q}_{\mathrm{absorb}}\right)$ and the resulting strong solution pumped back to the desorber to complete the cycle.

GAX cycle: Several different R\&D projects are currently underway to develop GAX chillers and heat pumps. Servel is developing a direct fired GAX ammonia-water chiller for light commercial and residential applications; they are represented in the U.S. by Robur Corporation. This system has a cooling COP of 0.62 ; an optional boiler can be added with a heating efficiency of $81 \%$. Five ton modules can be combined to provide 10 to 25 ton light commercial units. Electrical consumption is on the order of $220 \mathrm{~W} /$ ton. This unit is scheduled to enter the commercial market in 1999.

The GAX cycle is a single-effect absorption cycle that employs heat energy recovered within the "power cycle" (as opposed to refrigeration cycle) to generate additional refrigerant vapor. A GAX cycle is shown in Fig. 43. The top of the absorber is relatively hot compared to the solution entering the top of the generator. Various methods have been developed to recover the heat from the top of the absorber to preheat the solution into the generator. This internal heat recovery can be viewed as generating more refrigerant vapor for a given energy input or requiring less energy input from an external source to generate a fixed flow of vapor.

development programs have been pursued in the past both in North America, Europe, and Japan. Heating COPs are theoretically in the range of 1.4 to 1.5 and cooling COPs in the neighborhood of 0.70 . At low ambient heating temperatures, the evaporator temperature and pressure is forced down, removing the overlap of temperature between the absorber and desorber. In that event there is no heat of absorption that can be employed to provide part of the energy input to the

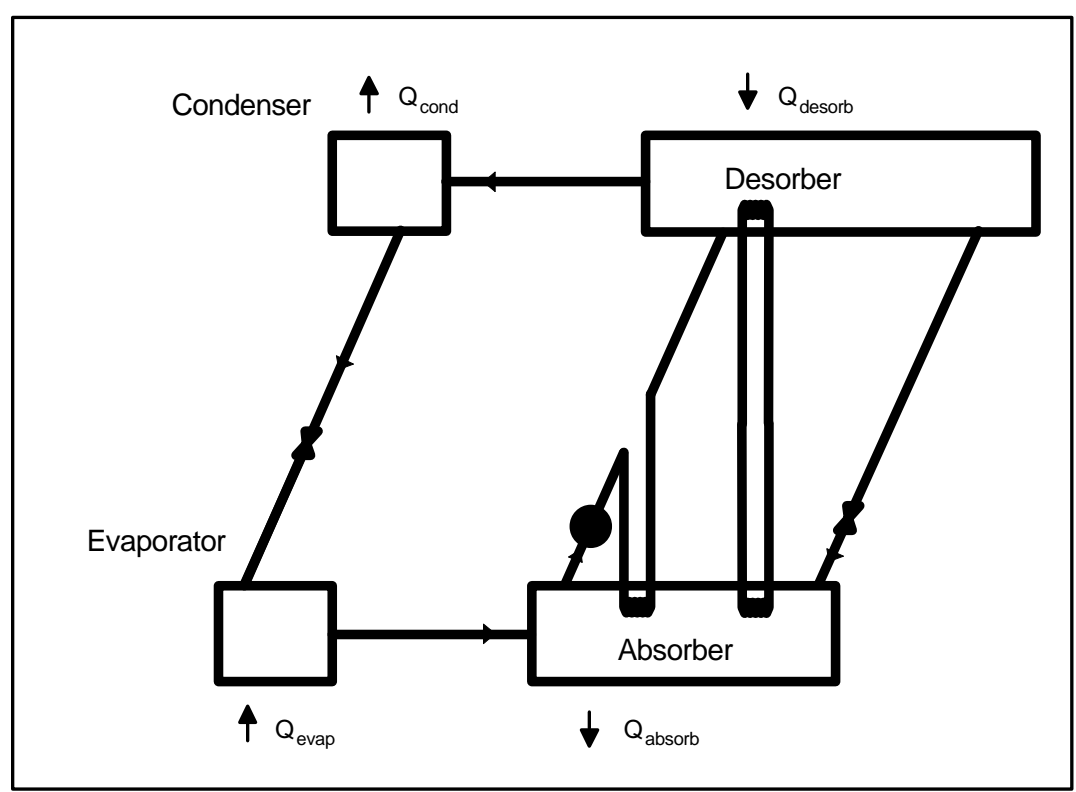

Fig. 43. GAX absorption cycle. desorber and the cycle functions as a single-effect absorption cycle.

Double-effect cycle: a double effect absorption cycle is shown in Fig. 44. The condensing temperature in the high pressure condenser at the top is higher than the temperature required to drive the medium 
pressure desorber in the middle. The energy of condensation is used to generate additional vapor for the refrigeration cycle.

Many direct-fired double effect absorption machines are commercially available for large chiller applications. American Yazaki has a series of 30 to 100 ton chillers that may compete in the commercial unitary market. These systems have cooling COPs at full load of 1.00 and electrical power consumption on the order of 25 to $35 \mathrm{~W} /$ ton.

\section{Secondary System Requirements}

Traditionally, absorption systems have been applied as water chillers and consequently

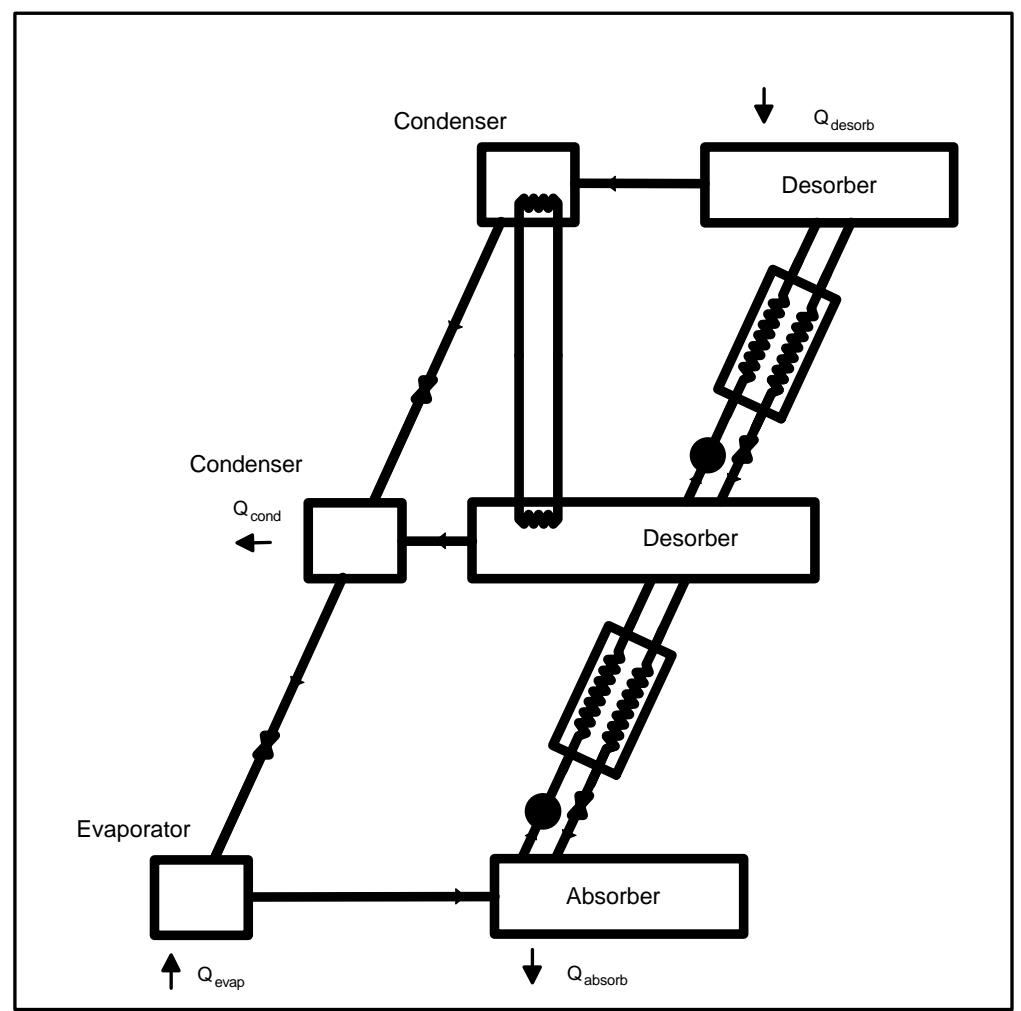

Fig. 44. Double effect absorption cycle (lithium bromide / water).

they require a hydronic

distribution system. The GAX system developments have all used ammonia as the refrigerant, necessitating the isolation of the refrigerant in the outdoor package and a secondary brine loop between the indoor and outdoor units.

\section{Efficiency Data}

Absorption theoretical and observed efficiency data are summarized in Table 32. The assumed operating temperatures for the theoretical gCOPs of each cycle are listed in Table 39 on page B-3.

Single-effect cycles: the gCOP of a single-effect chiller is calculated for an ammonia-water working pair using a computer model by Herold, Radermacher, and Klein (1995). Results are listed only for cooling mode, since this cycle is only employed in cooling. The burner combustion and pump efficiencies are assumed to be $80 \%$ and $50 \%$, respectively, and the effectiveness of the internal heat exchangers $100 \%$. The ammonia concentration in the refrigerant circuit is set at $99.96 \%$. The calculated gCOPs at $82 \mathrm{E}$ and $95 \mathrm{EF}$ are 0.58 and 0.53 , with an annual performance factor of 0.56 . Servel markets a direct-fired single effect chiller with a gCOP at conditions for the 95EF rating point of 0.48; Yazaki markets an indirect-fired single-effect chiller with an efficiency of 0.60 (combustion efficiency not included). 
Table 32. Calculated and Observed Efficiencies for Ammonia Absorption Cycle Heat Pumps.

\begin{tabular}{|c|c|c|c|c|c|c|}
\hline \multirow[b]{2}{*}{ Cycle Efficiency } & \multicolumn{3}{|c|}{ Heating } & \multicolumn{3}{|c|}{ Cooling } \\
\hline & 47EF & $17 \mathrm{EF}$ & $\begin{array}{l}\text { Seasonal } \\
\text { gCOP }\end{array}$ & $82 \mathrm{EF}$ & $95 \mathrm{EF}$ & $\begin{array}{l}\text { Seasonal } \\
\text { gCOP }\end{array}$ \\
\hline $\begin{array}{r}\text { Single Effect: theoretical } \\
\text { observed }\end{array}$ & & & & 0.58 & $\begin{array}{l}0.53 \\
0.48\end{array}$ & 0.56 \\
\hline $\begin{array}{r}\text { GAX: theoretical } \\
\text { observed }\end{array}$ & 1.52 & 1.50 & 1.36 & 0.71 & $\begin{array}{c}0.64 \\
0.62 \text { to } 0.71\end{array}$ & 0.67 \\
\hline
\end{tabular}

notes: theoretical steady-state COPs include $80 \%$ burner efficiency, seasonal heating COPs include $50 \%$ waste heat recovery. Blank entries denote absence of calculated or measured information, calculated and observed cycle efficiencies do not apply for the shaded seasonal boxes

GAX cycles: extensive development work has been done for the application of the GAX cycle in small capacity heat pumping equipment. Field test prototypes of a cooling only unit were introduced in the in 1997 in 3 and 5 ton capacities with 110,000 to 165,000 Btu/h heat from an 80\% to 82\% AFUE gas burner (Servel 1998). Of the five models available, one has a gCOP of 0.62 at 55EF return water temperature and a supply water temperature of $45 \mathrm{EF}$. The gCOP for the other four units is 0.48 . The higher efficiency model requires $740 \mathrm{~W}$ in cooling mode and $300 \mathrm{~W}$ in heating $(245 \mathrm{~W} /$ ton and 100 $\mathrm{W} /$ ton); the other models require up to $425 \mathrm{~W} /$ ton in cooling and $138 \mathrm{~W} /$ ton in heating.

\section{Technical Advantages/Benefits}

Absorption chillers can be a cost effective way of providing gas-fired cooling. Single effect chillers are most economically attractive when driven by process waste heat; advances in efficiency improvements and cost reductions for double-effect chillers have caused them to displace single-effect chillers in almost all other applications. The GAX cycle has the potential to provide significantly higher heating efficiency than a gas furnace in the residential and commercial unitary market. All absorption systems share the advantages of low emissions, quiet operation, low vibrations, and energy savings.

\section{Technical Disadvantages}

Absorption equipment is at a disadvantage to electric driven equipment in that absorption chillers must reject significantly more heat than electrically driven equipment and consequently require more heat exchanger surface. Larger heat exchangers translate into higher cost and overall size of the equipment package for absorption machines compared to conventional electric-driven heat pumps. 


\section{Technical Barriers}

Single- and double-effect chillers are established technologies so they are not discussed in this section. Heat pumping applications, as opposed to water chilling, require a pair of working fluids that can operate below 32EF; ammonia-water is considered most seriously for GAX development. The use of ammonia creates potential corrosion problems for heat exchangers, piping, and the solution pump that must be resolved at acceptable cost. There may also be problems associated with system controls.

\section{Economic Analysis}

GAX cycle heat pump: There is poor agreement between the modeled COPs for the GAX cycle and those reported as observed in prototype testing. Results of the economic analysis are reported using the observed, prototype efficiencies. The results in Fig.45 show the installed cost premiums that would give the same life cycle cost as the baseline gas system. The data for the northeast indicate that costs could be as much as $\$ 1000$ per ton higher than the baseline system with $\$ 1500$ per ton or higher justified in northern Pennsylvania, throughout New York, and all of New England. Most of the Midwest, plains, Rocky Mountain region, and California have allowable first cost increments of at least $\$ 500$ per ton for the GAX system. Most of the southeast and south central states would have to have lower installed costs than the gas furnace baseline to achieve equal life cycle costs. Figure 46 shows similar results in the southeast for a comparison of the GAX heat pump with a conventional electric heat pump.

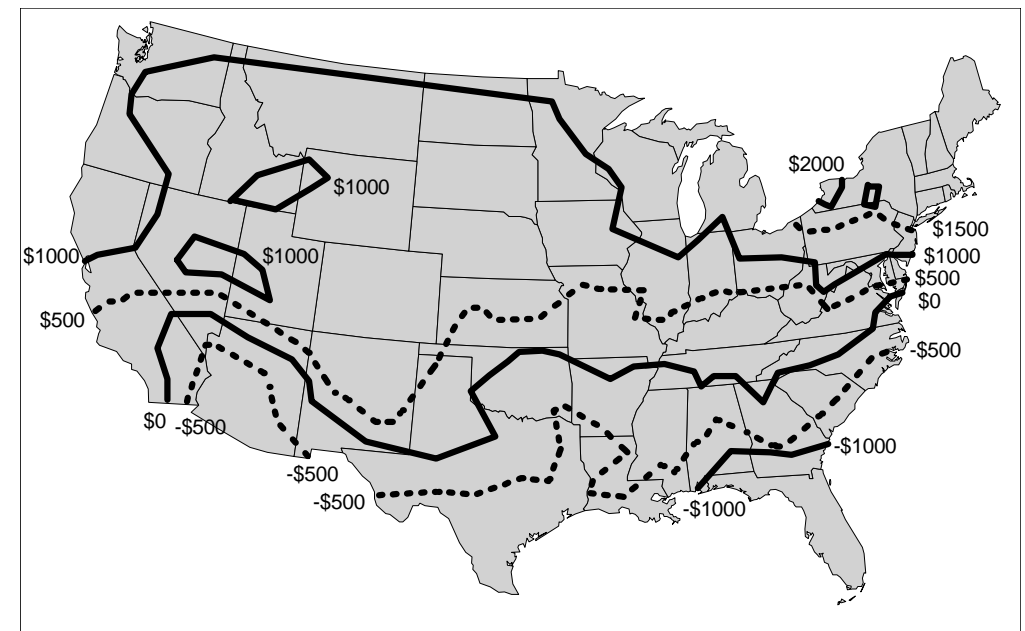

Fig. 45. Allowable first cost premium for GAX heat pump for equal life cycle cost with gas furnace baseline (equal maintenance costs).

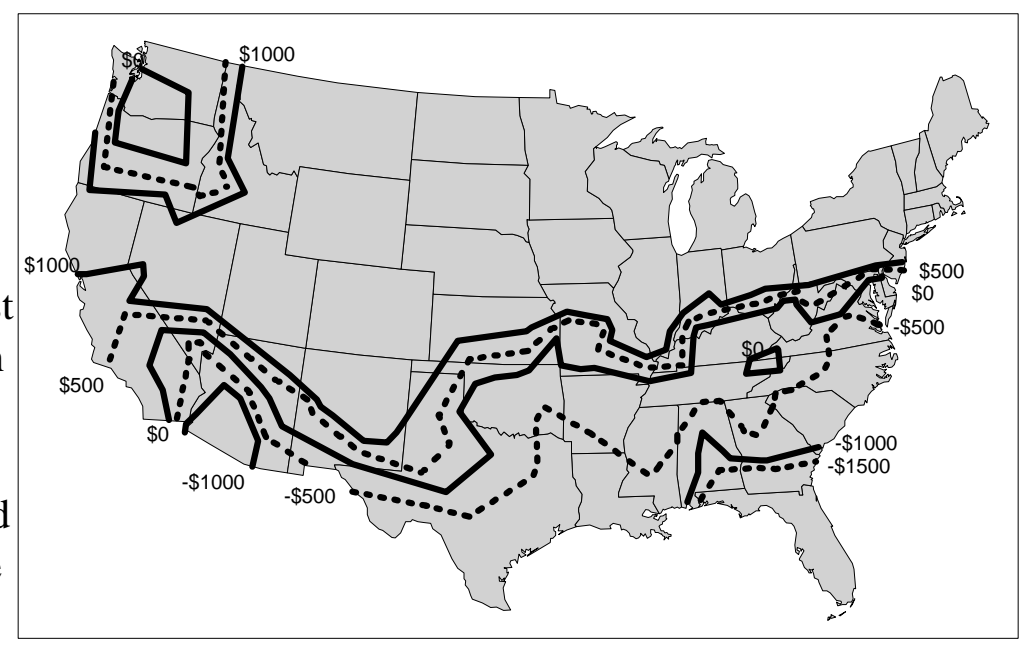

Fig. 46. Allowable first cost premium for GAX heat pump for same life cycle cost as an electric heat pump (equal maintenance costs). 
There is some uncertainty concerning the annual maintenance cost differentials between the baseline furnace and air conditioner and the GAX absorption heat pump. The sensitivity of the results are shown in Fig. 47 in each of the nine geographic regions. The GAX system is expected to have the same maintenance cost as the gas furnace / electric air conditioner baseline (\$0 /y differential), in which case it would have the same life cycle cost as the gas baseline at installed cost price differentials of $\$ 550$ to $\$ 1600$ per ton in California, the Northern Plains, the Rocky Mountain states, the Midwest, the Pacific Northwest, and the Northeast. Reasonable installed cost premiums are possible Fig. 47. Allowable installed cost premiums for GAX heat in these six regions even when the pumps. maintenance costs are $\$ 25$ to $\$ 50$ per year higher than those of the gas baseline. Installed costs would need to be $\$ 50$ to $\$ 500$ per ton lower in the Southeast, South Central, and Southwestern states even with the same maintenance costs as the gas baseline. The comparison of the GAX and the electric heat pump baseline in these three regions is similar to the comparison to the gas furnace and electric air conditioner; installed cost premiums are about $\$ 25$ lower than those shown in Fig. 47. Although the installed cost premiums for equal life cycle costs are fairly high in much of the country, the allowable cos premiums for three and five year paybacks are fairly low as shown in Table 33.

It is not clear how actual equipment costs will compare between a GAX heat pump and the gas furnace baseline system. The GAX requires more heat transfer surfaces, a secondary loop, and both brine and solution pumps. All refrigerant tubing will need to be iron or steel at a higher cost than
Table 33. Installed Cost Premiums for a GAX Heat Pump for 3 and 5 Year Paybacks.

\begin{tabular}{|l|c|c|}
\hline Region & $\begin{array}{c}3 \text { Year Payback } \\
(\$ / \text { ton })\end{array}$ & $\begin{array}{c}5 \text { Year Payback } \\
(\$ / \text { ton })\end{array}$ \\
\hline Northeast & $\$ 345$ & $\$ 550$ \\
\hline Midwest & $\$ 205$ & $\$ 320$ \\
\hline Northern Plains & $\$ 140$ & $\$ 220$ \\
\hline Rocky Mountain & $\$ 165$ & $\$ 260$ \\
\hline Pacific Northwest & $\$ 290$ & $\$ 400$ \\
\hline California & $\$ 115$ & $\$ 190$ \\
\hline
\end{tabular}


copper tubing. The GAX heat pump will not include cost of the compressor and motor for a net cost saving. Further cost information is needed.

\section{Contacts and Sources of Information}

Herold, K., Radermacher, R., and Klein, S., 1995. Absorption Chillers and Heat Pumps, CRC Press, Boca Raton, New York, London, and Tokyo.

Robert DeVault

Oak Ridge National Laboratory

P.O. Box 2008, MS-6070

Oak Ridge, Tennessee 37831

(423) 574-0738

Servel 1998, Product literature: "Servel: The Chiller-Heater, Advanced Absorption Cooling Technology, Sand and Efficient Hot Water Heating."

Robur Corporation North American Headquarters

2300 Lynch Road

Evansville, IN 47711-2951

ph: 1-812-424-1800

fax: $1-812-422-5117$

\section{Obvious Holes in Knowledge, Understanding, Information}

No major gaps in knowledge for the GAX cycle. It is unfortunate that there is such a difference between the modeled and observed efficiencies, but the measured values are at the desired rating points and are considered to be of comparable "quality" to the efficiencies stated for the gas and electric baseline equipment. 


\section{ADSORPTION HEAT PUMPS}

\section{Basic Concept Description}

Some solids such as activated carbon and zeolites have an affinity to adsorb vapor onto or into their surface structure. If the materials (solid and gas) undergo adsorption in a reversible thermal reaction the pair can be used in a heat pump. Such a cycle is illustrated in Fig. 48. At "low" temperatures, molecular forces cause these gases to attach to the surface or move into the crystalline structure of the solid. The adsorption of the gas creates a pressure gradient and heat is also released. The process is reversed through the addition of heat which causes the refrigerant gas to desorb from the solid at high temperature and pressure. The high temperature, high pressure vapor can be circulated through a condenser, expansion device, and evaporator to provide useful heating or cooling.

The adsorption/desorption is not a continuous process, as are vapor compression or absorption. A sorption "bed" is charged with refrigerant at low temperature and pressure; when adsorption stops or slows down, the sorption bed is heated and high temperature and pressure gas is released from it. Pairs of beds are used with one bed adsorbing vapor (charging) while the other is desorbing vapor (regenerating) to provide "continuous" heating or cooling (actually oscillating between high and low cooling rates). An

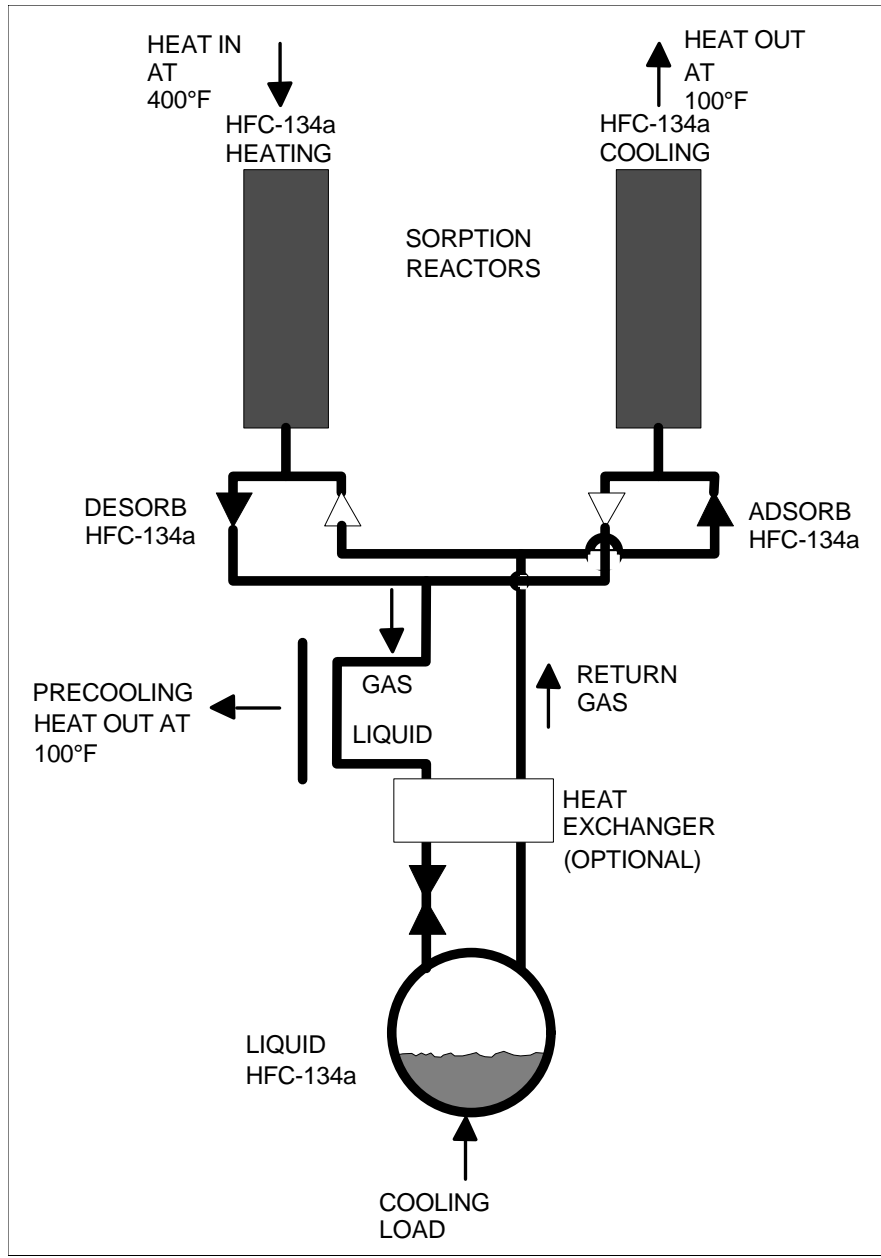

"Fig. 48 Schematic of an adsorption cycle heat pump using R-134a. adsorption system with two pairs of beds is shown in Fig. 49. The addition of more sorption beds allows a steadier heating or cooling rate and also permits the use of heat rejected from the adsorption process to be used as part of the energy input for regenerating fully charged beds. These "advanced" cycles improve efficiency at the cost of adding a pump and heat recovery loops. 


\section{Background Information}

Concepts for adsorption heat pumps differ fundamentally in the adsorbent-adsorbate pairs that are chosen and the molecular forces underlying the interaction of the pair. Commonly discussed adsorption pairs are:

! ammonia-carbon,

! water-zeolite,

! metal hydride, and

! organic salts or complex compounds.

Each pair has its advantages and

disadvantages which may be shared with

other pairs or may be unique to a particular pair.

Ammonia-carbon: activated carbon and ammonia adsorption systems use less exotic materials than most proposed adsorption heat pumps.

Water-Zeolite Adsorption: water has been used as the refrigerant in adsorption airconditioning systems but cannot be used in a heat pump operating near $0 \mathrm{EC}(32 \mathrm{EF})$.

Zeolite adsorption systems are distinguished from many other adsorption processes because they employ the adsorption of a vapor into a solid crystalline structure instead of using surface effects. The adsorption of refrigerant vapor on surface adsorbents (e.g. silica gel, activated carbon) depends

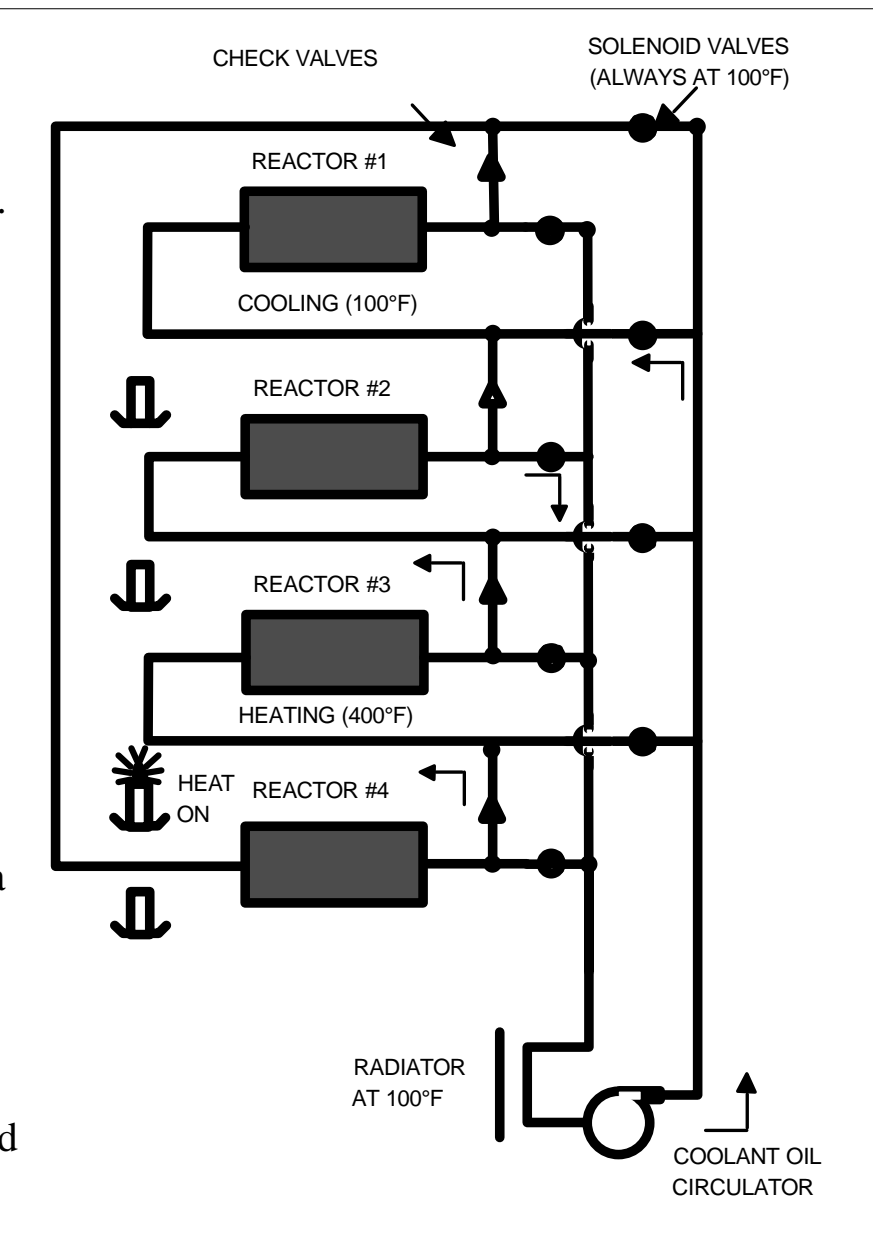

Fig. 49. Adsorption system using two pairs of exponentially on H/RT where H is the energy adsorbent beds for "continuous" output and of adsorption, $\mathrm{R}$ is the universal gas constant, regeneration for high COP. and $\mathrm{T}$ is the absolute temperature. The adsorption of vapor into the crystalline structure of the zeolite depends exponentially on the second to fifth powers of H/RT. This makes zeolites well suited for heat pumping applications by reducing the influence of condensation temperature and pressure on the COP of the cycle. When it is heated, the zeolite desorbs most of the refrigerant vapor even at high vapor pressure. This behavior allows the adsorption system to operate at high temperatures without a cooling tower with little loss in performance. Zeolites are used in heat exchangers with copper tubing. 
Metal-Hydride Adsorption: "there are a number of metals that possess the remarkable ability to adsorb large quantities of hydrogen gas. The hydrogen combines with the metal to form a 'solid solution' which is, in effect, a new metal alloy. Hydrogen adsorption occurs under specific temperature and pressure conditions. The hydrogen is released (desorbed) when the alloy temperature is elevated or the pressure is reduced. The metal hydride alloys are used in powdered form within stainless steel tubes. Ergenics has miniaturized the design of a metal hydride air conditioner in order to get a ton of cooling from a mechanical package weighing less than $50 \mathrm{lb}$. A major factor in the size and weight reductions is due to obtaining cycle times on the order of 15 seconds, allowing the use of fewer adsorption beds.

Organic salts or complex compounds: this adsorption concept employs a complex organic salt as the adsorbent and ammonia as the adsorbate and refrigerant. "A specific salt will adsorb or desorb [ammonia] at a specific temperature over an entire 'coordination sphere.' If a salt has three 'coordination spheres,' this means that the ammonia can array itself around the salt in three ways. The first molecules of ammonia form a 'shell' or 'coordination sphere' around the salt molecule. If more ammonia molecules are added once the first shell is filled, they arrange themselves further from the salt in a second coordination sphere. Some salts may form as many as three of these coordination spheres at increasing distances from the salt. (Ryan 1993)" These systems lend themselves well to high efficiency cycles because the outer coordination spheres can be regenerated at the relatively low temperatures of heat recovered from the charging adsorbent beds..

\section{Secondary System Requirements}

High efficiency systems require regenerator loops with circulating oils; this adds an electric parasitic to the gas-fired system. Metal hydride systems would require secondary loops to isolate the explosive hydrogen gas from the conditioned space.

\section{Efficiency Data}

Very little information has been located on the efficiencies of adsorption heat pumps and no independent modeling has been performed as part of this project. The data that are available are listed in Table 34. The published COPs rarely include any discussion or explanation of the operating conditions.

Ammonia-carbon: Vasiliev et al. (1977) reported on calculated and prototype measurements on a carbon fiber-ammonia adsorption device providing capacity measurements and predictions across a range of evaporator and condenser temperatures. They cite a COP "greater than 1 " and a cooling capacity or $200 \mathrm{~W} / \mathrm{kg}$ carbon fiber. Wave Air Corporation was funded to develop an ammonia-carbon heat pump with seasonal heating and cooling gCOPs of 1.30 and 1.00, respectively (AGCC 1996); the status of this project is unknown. 
Water-Zeolite Adsorption: Tchernev and Emerson (1988) reported measured seasonal gCOPs of 1.8 heating and 1.2 cooling on a regenerative prototype system. Two 45 pound zeolite heat exchangers provided $6000 \mathrm{Btu} / \mathrm{h}$ of cooling; $82 \mathrm{~kg}$ zeolite/ton capacity.

Metal-Hydride Adsorption: Ergenics constructed a prototype metal hydride heat pump using $27 \mathrm{lb}$ of alloy with a net cooling capacity of $8172 \mathrm{Btu} / \mathrm{h} ; 18 \mathrm{~kg} / \mathrm{ton}$ capacity. The Japan Metals and Chemicals Company has cooling only metal hydride air conditioners using $\mathrm{LaNi}$ and $\mathrm{MmNi}_{1}$ alloys with gCOPs of 0.45 providing $50 \mathrm{EF}$ air at 4 cycles per hour. They also have a $\mathrm{LmNi}_{3}$ heat pump with a gCOP of 1.6 (presumed to be heating efficiency) at 8.5 cycles per hour providing water at either $113 \mathrm{E}$ or $59 \mathrm{EF}$.

Organic salts or complex compounds: Rockenfeller (1992) reported that a residential sized adsorption heat pump with complex compounds would have a gCOP of 1.0 at "rating conditions" and heating gCOP of approximately 1.7 at $30 \mathrm{EF}$.

\section{Technical Advantages/Benefits}

"The absence of the liquid phase in the generator makes corrosion a much slower process than with liquids [absorption]. Corrosion studies of ammoniates in aluminum have been favorable up to 400EF (DOE 1993, p. A-27).”

Water-Zeolite Adsorption: regeneration of the adsorbent beds can begin at temperatures as low as $100 \mathrm{EF}$, this allows some of the heat of adsorption to be used to regenerate the adsorbent in multiple bed regenerative systems. Water can be a very desirable refrigerant because of its benign environmental properties.

Metal-hydride: the metal hydride pair employs a process in which hydrogen is adsorbed into the crystalline structure of the metal. The lattice work of the crystals allow large masses of hydrogen to be adsorbed providing greater capacity per unit mass of adsorbent than may be possible with adsorption pairs that use a surface effect.

Organic salts or complex compounds: the nature of the "coordination spheres" of complex compounds provide opportunities for high efficiency for this adsorption pair through heat transfer for regenerating adsorption beds. Each coordination sphere has its own regeneration energy requirement; the further the sphere is from the salt molecule, the less energy is required to desorb the ammonia. Heat recovered from sorbent beds adsorbing ammonia can be used effectively to desorb ammonia from the outer coordination spheres in a second bed. External heat sources may be needed only to desorb ammonia from the innermost coordination sphere.

\footnotetext{
${ }^{1} \mathrm{Mm}$ - mixed metal, Lm - lanthanum-rich mixed metal
} 


\section{Technical Disadvantages}

Adsorption heat pumping is an inherently cyclical process and multiple adsorbent beds are

Tble 34. Calculated and Observed Efficiencies for Adsorption Cycles.

\begin{tabular}{|c|c|c|c|c|c|c|}
\hline \multirow[b]{2}{*}{ Adsorption Cycle } & \multicolumn{3}{|c|}{ Heating } & \multicolumn{3}{|c|}{ Cooling } \\
\hline & $47 \mathrm{EF}$ & 17EF & $\begin{array}{c}\text { Seasonal } \\
\text { gCOP }\end{array}$ & $82 \mathrm{EF}$ & 95EF & $\begin{array}{c}\text { Seasonal } \\
\mathrm{gCOP}\end{array}$ \\
\hline $\begin{array}{r}\text { Water/Zeolite } \\
\begin{array}{r}\text { theoretical } \\
\text { observed }\end{array}\end{array}$ & & & 1.8 & & & $0.7^{\dagger}$ to 1.2 \\
\hline $\begin{array}{r}\text { Ammoniated Carbon } \\
\text { theoretical } \\
\text { observed }\end{array}$ & & & 1.3 & & & $0.7^{\dagger}$ to 1.0 \\
\hline $\begin{array}{r}\text { Metal Hydride } \\
\begin{array}{r}\text { theoretical } \\
\text { observed }\end{array}\end{array}$ & & & 1.6 & & & 0.45 to $0.7^{\dagger}$ \\
\hline $\begin{array}{r}\text { Organic Salts: } \\
\text { Complex Compounds } \\
\begin{array}{r}\text { theoretical } \\
\text { observed }\end{array}\end{array}$ & 1.7 & & & 1.0 & & \\
\hline 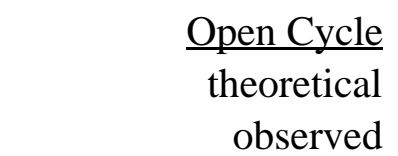 & & & & & & \\
\hline
\end{tabular}

notes: blank entries denote absence of calculated or measured information, calculated and observed cycle efficiencies do not apply for the shaded seasonal boxes

${ }^{\dagger}$ one reviewer reported that the cooling season gCOP of 0.7 is more likely for water/zeolite, ammoniated carbon, and metal hydride adsorption systems than the values the authors reported from other sources.

necessary to provide approximately continuous capacity. Adsorption systems inherently require large heat transfer surfaces to transfer heat to and from the adsorbent materials which automatically makes cost an issue. High efficiency systems require that heat of adsorption be recovered to provide part of the heat needed to regenerate the adsorbent. These regenerative cycles consequently need multiples of 
two-bed heat exchangers and complex heat transfer loops and controls to recover and use waste heat as the heat exchangers cycle between adsorbing and desorbing refrigerant. This exacerbates issues concerning first cost and also adds an electric parasitic.

Performance can deteriorate over numerous adsorption cycles because of decrepitation and surface contamination.

Ammonia-carbon: materials compatibility issues with ammonia, stainless steel heat exchanger tubes and pipes. Ammonia is not universally accepted as a refrigerant in residential applications because it is toxic and flammable in some concentrations; precautions must be made to isolate ammonia from the occupied space and to contain it within a machine room or disperse it in the atmosphere safely if a leak occurs.

Water-Zeolite Adsorption: size and cost are both factors working against zeolite adsorption heat pumps. A three ton heat pump would require $240 \mathrm{~kg}$ of zeolite and large amounts of copper. ADL estimated that materials and components alone for a three ton system would cost $\$ 2500$ exclusive of labor, overheads, dealer markups, and installation costs (DOE 1993).

Metal-Hydride Adsorption: flammability of the refrigerant (i.e. hydrogen).

Organic salts or complex compounds: materials compatibility issues with ammonia, stainless steel heat exchanger tubes and pipes. Rocky Research has reported that absorbent salts have shown no change in properties over thousands of cycles (DOE 1993, p. A-28).

\section{Economic Analysis}

The absence of efficiency data for any of the solid/vapor pairs makes it impossible to perform any kind of analysis for annual energy use or any economic comparisons. Rockenfeller projected that the manufacturing cost of a complex compound, residential heat pump would be less than $\$ 400$ per ton (1992);

\section{Technical Barriers}

Not known at this time.

\section{Contacts and Sources of Information}

AGCC 1996. Natural Gas Cooling Equipment Guide, American Gas Cooling Center, 1515 Wilson Boulevard, Arlington, Virginia 22209, April 1996, p. 153.

DaCosta D., 1993. "Metal Hydride Heat Pumps," Proceedings of the 1993 Refrigeration, Heat Pump, and Air Conditioning Workshop, Breckenridge, CO, June. 
DOE 1993. "A Research Needs Assessment: Energy Efficient Alternatives to Chlorofluorocarbons (CFCs)," DOE/ER/30115-H1, June.

Rockenfeller, U., Kirol, L, and Ryan, W., 1992. "Solid-gas chemisorption: Efficient HVAC\&R Without CFCs," ASHRAE Journal, March 1992, pp. 54-58.

Ryan, W., 1993. "CFC-Free Chemisorption Heat Pumps and Refrigeration," Proceedings of the 1993 Refrigeration and Air-Conditioning Technology Workshop, Breckenridge, Colorado, June 23-25.

Tchernev, D.I. and Emerson, D. T. 1988. "High-Efficiency Regenerative Zeolite Heat Pump," ASHRAE Transactions, Vol 94, Pt. 2, pp. 2024-2032.

Vasliev, L., et al. 1996. "Adsorption Heat Pump Using Carbon Fiber $/ \mathrm{NH}_{3}$ and Heat Pipes," Heat Pump 96: Proceedings of the 5th International Energy Agency Conference on Heat Pumping Technologies, September 22-26, Toronto, Canada.

\section{Obvious Holes in Knowledge, Understanding, Information}

Efficiency data at rating points and also status of past and current R\&D projects. 


\section{DUPLEX STIRLING HEAT PUMP}

\section{Basic Concept Description}

This technology combines a Stirling engine with a Stirling cycle cooler. The following description is from the Ohio University Internet site:

"In a Stirling machine, a confined volume of gas is repeatedly expanded at one temperature and recompressed at another with the result that heat energy is absorbed from the environment during expansion and rejected to the environment during compression. Regardless of whether energy is being absorbed or rejected, more is transferred at a higher temperature than at a lower temperature. Thus, the difference between the amount of energy absorbed at high temperature and rejected at a warm temperature by a Stirling engine appears as the mechanical, hydraulic, or electrical power it delivers to a load. Conversely, the difference between the amount of energy absorbed at a low temperature and rejected at a warm temperature by a Stirling cooler or heat pump must be provided to the machine in order to keep it operating. In a duplex Stirling cooler, this power is provided by a directly coupled Stirling engine. (Ohio 1998)"

Stirling engines can transfer their output to a load with either a mechanical linkage using a crank and piston rods or with pistons and displacers acting as harmonic mechanical oscillators in a hermetically sealed cylinder. The performance of the Stirling engine is proportional to the mean operating pressure of the working gas, and leakage of gas around the shaft seals of the kinematic machine (mechanical linkages) progressively degrades performance. In addition, unbalanced forces acting on the drive mechanism can lead to greater wear than is experienced with the free-piston machine and the lubricant necessary for the piston rods in the kinematic machine fouls heat exchanger surfaces requiring periodic maintenance. By contrast the free-piston Stirling engine employs balanced forces in a sealed cylinder using inertial, spring, and damping forces to control the frequency and phase of the piston oscillations without an external drive mechanism.

\section{Background Information}

Dr. William Beale and Sunpower, Inc. of Athens, Ohio have been strong advocates of duplex Stirling heat pumps. The U.S. Department of Energy and NASA have both supported work on freepiston Stirling engines. Duplex Stirling cryocoolers are commercially available for remote sensing applications. Silena Germany is a distributor for alpha-, beta -, and gamma- spektrometer, including the CoCoS HPGe and X-ray detextion device with duplex Stirling cooler. Duplex Stirling machines have been proposed for refrigeration and space conditioning applications, but have not been developed commercially. Much of the related R\&D performed since the mid-1970's has focused on basic understanding of the forces and hysterisis effects of the Stirling cycle in order to apply it to heating and 
air conditioning applications. During the late 1980's, DOE funded work at the Massachusetts Institute of Technology to study Stirling cycle processes in support of contracted work on engine/compressor couplings for free-piston Stirling engine/Rankine cycle heat pumps at Mechanical Technology Inc. and Sunpower.

\section{Secondary System Requirements}

Heat pipes or secondary heat transfer loops will be necessary to provide useful heating or cooling with a Stirling device. The working volume of gas in the Stirling cooler is a fundamental design property of the machine. Additional internal volume as would be necessary to circulate the working gas through either an indoor or outdoor heat exchanger represents increased void volume that reduces efficiency or makes operation impossible altogether..

\section{Efficiency Data}

ADL derived comparable efficiencies for electric driven reverse Rankine and Stirling cycle heat pumps at three of the ARI rating points (82EF was omitted). Duplex Stirling COPs were derived by using the relative performance of R-22 and Stirling cycle from the ADL report (1993, p. A-47), the theoretical R-22 cycle efficiency with an $80 \%$ compression efficiency, 95\% transmission efficiency, and a $28 \%$ Stirling engine efficiency. The resulting gCOPs, HSPF, and SEER are listed in Table 35.

Table 35. Calculated and Observed Efficiencies for Duplex Stirling Heat Pumps.

\begin{tabular}{|r|c|c|c|c|c|c|c|}
\hline & \multirow{2}{*}{\begin{tabular}{c} 
conversion \\
\cline { 3 - 8 }
\end{tabular}} & \multicolumn{3}{|c|}{ Heating } & \multicolumn{3}{c|}{ Cooling } \\
\cline { 3 - 8 } Cycle Efficiency & efficiency & $47 \mathrm{EF}$ & $17 \mathrm{EF}$ & $\begin{array}{c}\text { Seasonal } \\
\text { gCOP }\end{array}$ & $82 \mathrm{EF}$ & $95 \mathrm{EF}$ & $\begin{array}{c}\text { Seasonal } \\
\mathrm{gCOP}\end{array}$ \\
\hline $\begin{array}{r}\text { Cycle COP } \\
\text { theoretical (ADL) }\end{array}$ & $28 \%$ & 4.98 & 3.08 & & 5.30 & 3.98 & \\
theoretical (ORNL) & & 1.57 & 1.48 & 1.3 & & 0.96 & 0.91 \\
observed & & 1.69 & 1.19 & 1.3 & 1.41 & 1.06 & 1.3 \\
\hline
\end{tabular}

Notes: gCOPs computed using relationship between Stirling COPs listed in ADL (1993, p. A-47) and R-22 cycle COPs with $80 \%$ compression efficiency. Blank entries denote absence of calculated or measured information, calculated and observed cycle efficiencies do not apply for the shaded seasonal boxes 


\section{Technical Advantages/Benefits}

The Stirling cycle is claimed to have higher efficiency than the Rankine cycle, although this has not yet been demonstrated in laboratory or prototype equipment suitable for HVAC applications. Likewise, the Stirling engine has potential for long life that also has not been demonstrated.

\section{Technical Disadvantages}

Requires secondary heat transfer loop, very high regenerator effectiveness, understanding complex relationships between power and displacer pistons, gas springs, etc.

\section{Technical Barriers}

ADL (1993, p. 2-12) identified several research needs that for Stirling cycle refrigeration in general:

! accurate cycle modeling capability,

! improved regenerator performance to achieve higher effectiveness, lower pressure drop, lower void volume, lower cost, and less susceptibility to contaminant plugging.

! reduction in log mean temperature difference for the hot and cold heat exchangers where high density heat transfer is required, and

! improvement of secondary heat transfer loops.

\section{Economic Analysis}

used in the economic analysis because they are believed to be more accurate than the COPs modeled for this project; the COP at $82 \mathrm{EF}$ is assumed to be the same as the value ADL estimated for the 95EF condition. This latter assumption overestimates the energy use in cooling mode and may result in misleading economic comparisons

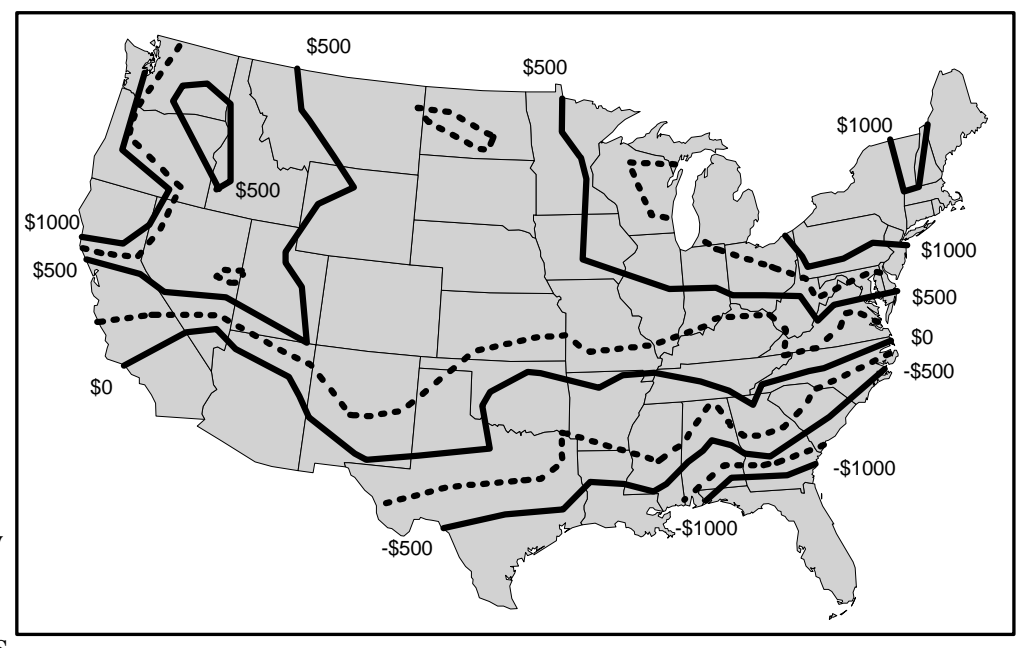
in the southern states. This is not perceived as a major error since as a rule the gas-fired systems are most Fig. 50. Allowable installed cost premiums for duplex Stirling competitive in the predominantly heat pumps relative to the gas furnace baseline. heating climates. The supportable installed cost premiums for duplex Stirling heat pumps relative to the gas baseline are shown in Fig. 50 for a difference in maintenance costs of $\$ 25$ per year. A higher installed cost could be supported 
outside of the southern tier of states, ranging from $\$ 0$ to $\$ 500$ throughout the central parts of the country, $\$ 500$ to $\$ 100$ per ton in the northeast and northwest, and above $\$ 1000$ per ton in New York, parts of New England, and the Pacific Northwest. Installed costs significantly below the baseline system would be necessary in the southern states.

The duplex Stirling heat pump should have a long life with low maintenance requirements, though this has not been demonstrated or disproved through hardware testing. In this system, the compressor and electric motor of a conventional heat pump have been replaced by the duplex Stirling module and a secondary heat transfer loop has been added. The Stirling module must include a regenerator with high effectiveness, a complex heater head, and more complicated controls than an electric heat pump. Each of these factors increases materials and manufacturing costs negating the savings from eliminating the motor and compressor and possibly resulting in a more expensive machine than the baseline electric heat pump. Since the installed costs of the gas and electric baseline systems are comparable, the duplex Stirling system will be more expensive than the gas furnace and electric air conditioner system.

The installed cost premiums permitting three and five year paybacks for the duplex Stirling heat pump are listed in Table 36 for an annual maintenance cost \$25 higher than that of the gas furnace baseline. A higher maintenance cost is selected because of the addition of a secondary heat transfer loop and the high reliability of the motor/compressor in a conventional air conditioner. These results show that reasonable paybacks can be achieved with the duplex Stirling heat pump, but the increase in installed costs must be on the

Table 36. Installed Cost Premiums for a Duplex Stirling Heat Pump.

\begin{tabular}{|l|c|c|c|}
\hline Region & $\begin{array}{c}3 \text { Year } \\
\text { Payback } \\
(\$ / \text { ton })\end{array}$ & $\begin{array}{c}5 \text { Year } \\
\text { Payback } \\
(\$ / \text { ton })\end{array}$ & $\begin{array}{c}\text { Equal Life } \\
\text { Cycle Cost } \\
(\$ / \text { ton })\end{array}$ \\
\hline Northeast & $\$ 267$ & $\$ 423$ & $\$ 1173$ \\
\hline Southeast & $-\$ 66$ & $-\$ 108$ & $-\$ 370$ \\
\hline South Central & $\$ 10$ & $\$ 14$ & $-\$ 8$ \\
\hline South West & $-\$ 4$ & $\$ 12$ & $\$ 24$ \\
\hline Midwest & $\$ 138$ & $\$ 219$ & $\$ 609$ \\
\hline Northern Plains & $\$ 87$ & $\$ 136$ & $\$ 369$ \\
\hline Rocky Mountain & $\$ 117$ & $\$ 184$ & $\$ 493$ \\
\hline Pacific Northwest & $\$ 234$ & $\$ 322$ & $\$ 892$ \\
\hline California & $\$ 98$ & $\$ 153$ & $\$ 413$ \\
\hline
\end{tabular}
order of $\$ 100$ to $\$ 175$ per ton in much of the country.

\section{Contacts and Sources of Information}

ADL 1993. Energy Efficient Alternatives to Chlorofluorocarbons (CFCs): A Research Needs Assessment Final Report, U.S. Department of Energy, Office of Energy Research, DOE/ER/30115H1, June. 
Ohio 1998. http://www.cns.ohiou.edu/ mcab/260.html

\section{Obvious Holes in Knowledge, Understanding, Information}

Measured COPs at ARI rating conditions or direct reference to simulated COPs. 


\section{EJECTOR HEAT PUMPS}

\section{Basic Concept Description}

reverse Rankine cycle in that it includes a condenser, evaporator, and expansion valve; the compressor is replaced by a pump, a boiler, and an ejector. The pump uses relatively little energy to raise the pressure of most of the liquid from the condenser to a higher pressure where additional heat is added at the boiler to create a high pressure, high temperature vapor. The vapor is expanded through a jet ejector, where it entrains some low pressure vapor from the evaporator, with the combined reduced pressure stream of vapor flowing to the condenser. Heat is rejected at the condenser, the resulting high pressure liquid flow is split, with most of it flowing back to the circulating pump and part flowing through an expansion valve to the

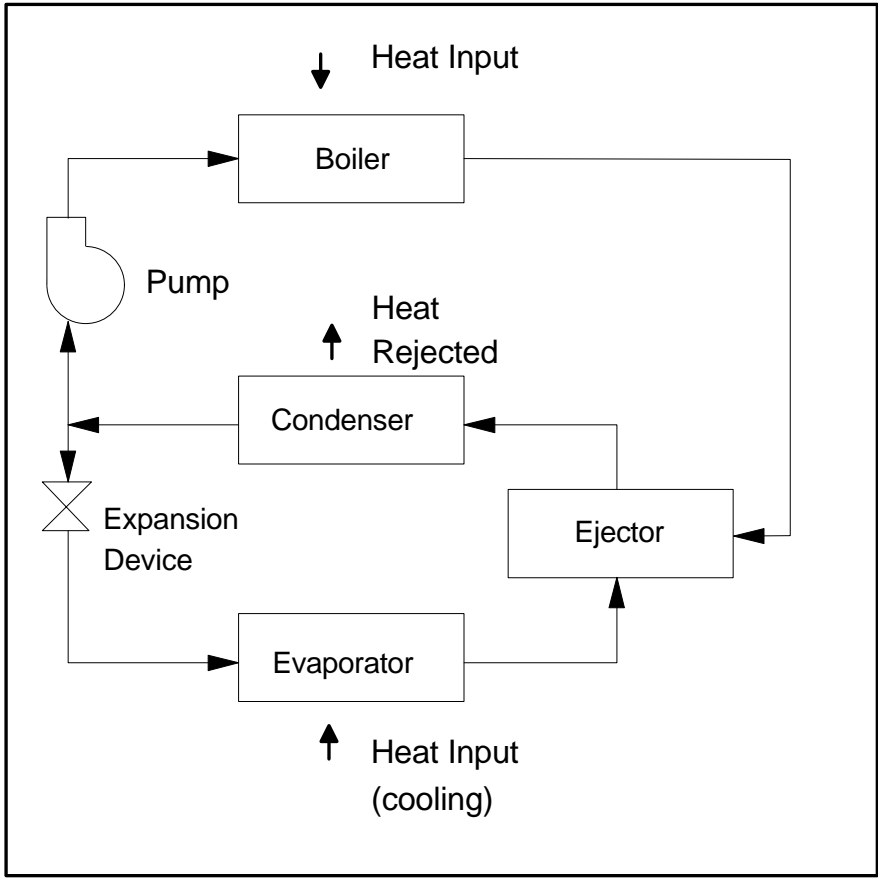

Fig. 51. Schematic of an ejector heat pump. evaporator. Heat is absorbed in the evaporator either providing useful cooling or energy for heat pumping in heating mode. The cycle is illustrated in Fig. 51.

\section{Background Information}

A steam-jet ejector was first used some time prior to 1901 by LeBlanc in France and by Parsons in England; Parsons used water as the refrigerant. C. T. Hsu investigated ejectors for heat pump applications for DOE and ORNL while he was a graduate student at the University of Tennessee in the 1980s. Hsu found that the COP is proportional to the boiler temperature and that the boiler temperature could be increased up to the critical temperature of the refrigerant (1984). Charan looked at the application of fluorocarbon refrigerants in ejector refrigeration systems at conditions for cold food storage and air conditioning (1990). Khalidy (1995) accepted Hsu's conclusion on the relationship of boiler temperature and efficiency, but concluded through analytical and experimental investigations that the condenser temperature is the most significant variable in ejector heat pump COP, especially at low evaporator temperatures. 


\section{Secondary System Requirements}

No secondary systems are required. Electric parasitics would include air handling equipment for the evaporator and condenser and a pump to circulate liquid refrigerant from the evaporator back to the boiler.

\section{Efficiency Data}

Charan (1990) calculated COPs for ejector systems at evaporator temperatures from $0 \mathrm{E}$ to $40 \mathrm{EF}$, a $200 \mathrm{EF}$ boiler temperature and $90 \mathrm{EF}$ condensing temperature for five fluorocarbon refrigerants. The COPs at $40 \mathrm{EF}$ ranged from 0.63 to 0.79 for a system that does not include a pump to supply high pressure liquid to the boiler. Charan's COPs are a factor of 3 to 4 higher than values calculated by Hsu (1984) and measured by Khalidy (1995) under similar conditions.

Hsu (1984) published a model for an ejector heat pump and presented parametric results for several fluorocarbon refrigerants. Khalidy (1995) built upon Hsu's model and also constructed and tested an ejector heat pump using R-113, a solar concentrator to power the boiler, and a $2 \mathrm{~kW}$ electric heater to supplement the solar concentrator on cloudy days. Khalidy presents his analytical results in terms of ejector efficiency and COPs from observations. The results in Table 37 are from Hsu's model using the evaporating and condensing conditions in Table 3.

Table 37. Calculated and Observed Efficiencies for Ejector Heat Pumps.

\begin{tabular}{|r|c|c|c|c|c|c|c|}
\hline & & \multicolumn{3}{|c|}{ Heating } & \multicolumn{3}{c|}{ Cooling } \\
\cline { 3 - 8 } Cycle Efficiency & $\begin{array}{c}\text { conversion } \\
\text { efficiency }\end{array}$ & $47 \mathrm{EF}$ & $17 \mathrm{EF}$ & $\begin{array}{c}\text { Seasonal } \\
\text { gCOP }\end{array}$ & 82EF & $95 \mathrm{EF}$ & $\begin{array}{c}\text { Seasonal } \\
\text { gCOP }\end{array}$ \\
\hline $\begin{array}{r}\text { Cycle COP } \\
\text { theoretical } \\
\text { observed }\end{array}$ & 0.80 & 1.052 & 1.036 & 0.98 & 0.293 & 0.214 & 0.27 \\
\hline
\end{tabular}

Notes: boiler temperature set at 200EF, with nozzle and diffuser efficiencies of 0.97 and 0.75 , refrigerant is R-22, pump power excluded from calculations. The observed COPs are from Khalidy (1995) at similar though not identical conditions excluding solar panel efficiencies. Blank entries denote absence of calculated or measured information, calculated and observed cycle efficiencies do not apply for the shaded seasonal boxes

\section{Technical Advantages/Benefits}

One feature of the ejector heat pump is that the boiler can operate at relatively low temperatures which enables them to be driven with waste heat or solar energy. An ejector heat pump 
using a low pressure refrigerant (e.g. R-11, R-123) can operate effectively with a boiler temperature of about $200 \mathrm{EF}$. Ejector heat pumps should also have high reliability and low equipment costs.

\section{Technical Disadvantages}

Ejector heat pumps have very low efficiencies relative to conventional compression systems and are best employed where low quality heat is available at little or low cost.

\section{Technical Barriers}

There are considerable losses associated with the mixing of the high velocity gas from the boiler and the low velocity gas from the evaporator. The gas also goes through shock waves which add additional losses. The mixing and shock processes are irreversible losses (ADL 1993).

\section{Economic Analysis}

The very low heating and cooling efficiencies make gas-fired ejector heat pumps compare extremely unfavorably with the gas furnace baseline in every part of the U.S. Some reductions in equipment cost would be possible as a result of replacing the air conditioner compressor with an relatively inexpensive ejector and pump. Both systems, however, employ gas burners and air handling equipment at comparable costs. This technology could be more attractive if driven by waste heat or solar energy.

\section{Contacts and Sources of Information}

ADL 1993. Energy Efficient Alternatives to Chlorofluorocarbons (CFCs): A Research Needs Assessment Final Report, U.S. Department of Energy, Office of Energy Research, DOE/ER/30115H1, June.

Charan, V. 1990. “A Comparative Performance of Freon Ejector Refrigeration Systems,” Proceedings of the 1990 USNC/IIR-Purdue Refrigeration Conference, July 17-20, pp. 55-60.

Hsu, C. T. 1984. Investigation of an Ejector Heat Pump by Analytical Methods, Oak Ridge National Laboratory, ORNL/CON-144, July.

Khalidy, N., and Zayonia, A., 1995. "Design and Experimental Investigation of an Ejector In an Air-Conditioning and Refrigeration System,” ASHRAE Transactions, Vol 101, Pt 2, pp. 383-391.

\section{Obvious Holes in Knowledge, Understanding, Information}

Modeled performance at ARI rating conditions. 


\section{CONCLUSIONS}

This project was initiated by the Department of Energy in response to a request from the HVAC industry for consolidated information about alternative heating and cooling cycles and for objective comparisons of those cycles in space conditioning applications. Twenty-seven different heat pumping technologies are compared on energy use and operating costs using consistent operating conditions and assumptions about component efficiencies for all of them. This report provides a concise summary of the underlying principals of each technology, its advantages and disadvantages, obstacles to commercial development, and economic feasibility. Both positive and negative results in this study are valuable; the fact that many of the cycles investigated are not attractive for space conditioning avoids any additional investment of time or resources in evaluating them for this application. In other cases, negative results in terms of the cost of materials or in cycle efficiencies identify where significant progress needs to be made in order for a cycle to become commercially attractive.

Although reverse Rankine cycle heat pumps using hydrocarbons have similar energy use to conventional electric-driven heat pumps, there are no significant energy savings due to the minor differences in estimated steady-state performance; higher costs would be required to accommodate the use of a flammable refrigerant. Magnetic and compressor-driven metal hydride heat pumps may be able to achieve efficiencies comparable to reverse Rankine cycle heat pumps, but they are likely to have much higher life cycle costs because of high costs for materials and peripheral equipment. Both thermoacoustic and thermionic heat pumps could have lower life cycle costs than conventional electric heat pumps because of reduced equipment and maintenance costs although energy use would be higher.

There are strong opportunities for gas-fired heat pumps to reduce both energy use and operating costs outside of the high cooling climates in the southeast, south central states, and the southwest. Diesel and IC (Otto) engine-driven heat pumps are commercially available and should be able to increase their market share relative to gas furnaces on a life cycle cost basis; the cost premiums associated with these products, however, make it difficult to achieve three or five year paybacks which adversely affects their use in the U.S. Stirling engine-driven and duplex Stirling heat pumps have been investigated in the past as potential gas-fired appliances that would have longer lives and lower maintenance costs than diesel and IC engine-driven heat pumps at slightly lower efficiencies. These potential advantages have not been demonstrated and there has been a low level of interest in Stirling engine-driven heat pumps since the late 1980's. GAX absorption heat pumps have high heating efficiencies relative to conventional gas furnaces and are viable alternatives to furnace/air conditioner combinations in all parts of the country outside of the southeast, south central states, and desert southwest. Adsorption heat pumps may be competitive with the GAX absorption system at a higher degree of mechanical complexity; insufficient information is available to be more precise in that assessment. 


\section{APPENDIX A: METAL HYDRIDE CALCULATIONS}

Quoting (and paraphrasing) from Feldman'

"For a frictionless, adiabatic, isentropic process of an ideal gas with constant specific heats, $\mathrm{pv}^{\mathrm{k}}$ is constant, where " $\mathrm{k}$ " is the ratio of specific heats, $\mathrm{k}=\mathrm{C}_{\mathrm{p}} / \mathrm{C}_{\mathrm{v}} ; \mathrm{k}=1.4$ for hydrogen. In a process between states 1 and $2, \mathrm{p}_{1} \mathrm{v}_{1}{ }^{\mathrm{k}}=\mathrm{p}_{2} \mathrm{v}_{2}{ }^{\mathrm{k}}$, and with $\mathrm{pv}=\mathrm{RT}$ :

$$
\frac{\mathrm{T}}{\mathrm{T}},\left[\frac{\mathrm{p}}{\mathrm{p}}\right] \div \cdot\left[\frac{\mathrm{p}}{\mathrm{p}}\right] \div \frac{\mathrm{p}}{\cdots}
$$

The compression work may be determined for a steady flow process in an open compressor system from,

$$
\text { w. ' } \left.\mathrm{m}_{2}^{\mathbf{\phi}} \quad \frac{\mathbf{R}}{\mathrm{E}} @_{\mathrm{k} \& 1}^{\mathrm{k}} \oint\left(\frac{\mathrm{p}}{\mathrm{p}}\right) \cdots \mathrm{*}\right]
$$

where $\mathrm{E}_{\mathrm{c}}$ is the total compressor efficiency, $\mathrm{v}$ is the specific volume, and $\mathrm{R}$ is the gas constant.

At temperature $T_{c}$ the hydrogen gas pressure desorbing from the cold hydride is given by the van't Hoff equation, where ) $\mathrm{H}$ and ) $\mathrm{S}$ are the heat and entropy of desorption, respectively:

$$
\left.\operatorname{Rh} \mathrm{p}, \frac{\text { ) } \mathrm{H}}{\mathrm{T}} \&\right) \mathrm{S}
$$

and at the temperature $\mathrm{T}_{\mathrm{m}}$ the hydrogen gas pressure absorbing into the warm hydride is,

$$
\text { Rh p ' } \left.\frac{\text { ) H }}{\mathrm{T}} \&\right) \mathrm{S}
$$

Combining equations 19 and 20, we obtain the pressure ratio,

$$
\frac{\mathrm{p}}{\mathrm{p}}\left[\frac{) \mathrm{H}}{\mathrm{R}}\left(\frac{1}{\mathrm{~T}} \& \frac{1}{\mathrm{~T}}\right)\right]
$$

${ }^{1}$ K.T. Feldman, Jr., K. J. Kim, T. R. Way, G. Lloyd, A. Razani, “Compressor Driven Metal Hydride Heat Pumps," Conference Proceedings, 1996. 
For the hydrides the pressure and temperature of the gas are described by the van't Hoff equations 19 ? and 20?. Equation 21? May be combined with equation 11 ? to give,

$$
\text { W. } \left.\left.\quad \frac{\mathrm{RT}}{\mathrm{E}} \oint_{\mathrm{k} \& 1}^{\mathrm{k}} \oint_{\Phi}\left[\frac{\mathrm{k} \& 1}{\mathrm{k}} \oint_{\mathrm{R}} \oint_{\mathrm{H}} \frac{1}{\mathrm{~T}} \& \frac{1}{\mathrm{~T}}\right)\right] \& 1\right)
$$

Equation 22 includes the assumption that the hydrogen flowing out of the compressor is cooled from $T_{h}$ to $\mathrm{T}_{\mathrm{m}}$. To determine the efficiency, we must calculate the amount of cooling produced per mole of hydrogen,

$$
\left.q^{\prime} \&\right) H \& q
$$

where $\mathrm{q}_{\mathrm{loss}}$ is the parasitic heat loss per mole of hydrogen due to heating and cooling the mass $\left(\mathrm{m}_{\mathrm{c}}+\mathrm{m}_{\text {cont }}\right)$,

$$
\mathrm{q} \quad \frac{1}{\mathrm{n}}(\mathrm{mC} \quad \% \mathrm{~m} \quad \mathrm{CN})(\mathrm{T} \quad \& \mathrm{~T})
$$

where the mass of the hydride is $\mathrm{m}_{\mathrm{c}}$ with specific heat $\mathrm{C}_{\mathrm{p}}$, and the mass of the hydride container is mcont with specific heat CN, the amount of cooling per mole of hydrogen is given by $\overline{\mathrm{m}} \cdot \mathrm{m} / \mathrm{n}$ and $\mathrm{m} \quad \mathrm{m} / \mathrm{R}$, where $\mathrm{R}_{\mathrm{m}}$ accounts for the mass of the container with fins, and $\mathrm{n}$ is the number of moles of hydrogen desorbed per cycle. Thus equation 23 becomes,

$$
\mathrm{q} \quad \&) \mathrm{H} \& \overline{\mathrm{m}}\left(\mathrm{C} \quad \% \frac{\mathrm{CN}}{\mathrm{R}}\right)(\mathrm{T} \quad \& \mathrm{~T})
$$

The COP can then be calculated from equations 27 and 11. For example, a hydride air conditioner operating with $\mathrm{LaNi}_{5}$, where ) $\mathrm{H}=-7380 \mathrm{cal} / \mathrm{mole}, \mathrm{C}_{\mathrm{p}}=0.1 \mathrm{cal} / \mathrm{g}-\mathrm{K}, \mathrm{CN}=0.11 \mathrm{cal} / \mathrm{g}-\mathrm{K}, \mathrm{R}_{\mathrm{m}}=2$ (for a thin wall finned tube), $\overline{\mathrm{m}} \quad \square .8 \mathrm{~g} / \mathrm{m} \quad, \mathrm{T}_{\mathrm{m}}=46 \mathrm{EC}, \mathrm{T}_{\mathrm{c}}=8 \mathrm{EC}$ (the "standard" rating temperatures for air conditioners, including an 11EC temperature drop across each heat exchanger coil), and the cooling per mole is,

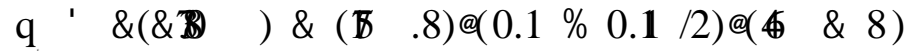

$$
\begin{aligned}
& \text { 6) d / i lo }
\end{aligned}
$$

A - 2 
For isentropic compression, the efficiency for cooling is given by,

$$
\begin{aligned}
& \boldsymbol{\theta}, \frac{\mathrm{q}}{\mathrm{w}}, 5 . \overline{\mathrm{b}} \\
& \mathrm{W} . \quad(1 . \$)(\mathrm{K}) @ \frac{1.4}{1.4 \& 1}\left[\Phi\left(\frac{1.4 \& 1}{1.4} @ \frac{1}{1 . \$}\left[\frac{1}{9} \& \frac{1}{8}\right]\right) \& 1\right]
\end{aligned}
$$

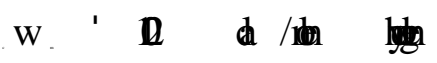

A - 3 
A - 4 
APPENDIX B: TABULATED ASSUMPTIONS

B - 1 
Table 38. Specified Conversion Efficiencies, Temperatures and ) Ts for Electric Driven Heat Pump Cycle Calculations.

\begin{tabular}{|c|c|c|c|c|c|c|c|c|c|c|c|c|c|c|c|c|c|c|c|c|c|c|c|c|}
\hline \multirow[b]{2}{*}{ Technology } & \multicolumn{6}{|c|}{ 47EF Rating Point } & \multicolumn{6}{|c|}{ 17EF Rating Point } & \multicolumn{6}{|c|}{ 82EF Rating Point } & \multicolumn{6}{|c|}{ 95EF Rating Point } \\
\hline & source & HX & $\begin{array}{l}\text { ) } \\
\mathrm{T}\end{array}$ & HX & $\begin{array}{c}\sin \\
\mathrm{k}\end{array}$ & $\begin{array}{l}\text { ) } \\
\mathrm{T}\end{array}$ & source & HX & ) $\mathrm{T}$ & HX & $\begin{array}{c}\sin \\
\mathrm{k}\end{array}$ & $\begin{array}{l}\text { ) } \\
\mathrm{T}\end{array}$ & source & HX & $\begin{array}{l}\text { ) } \\
\mathrm{T}\end{array}$ & HX & $\begin{array}{c}\sin \\
\mathrm{k}\end{array}$ & $\begin{array}{l}\text { ) } \\
\mathrm{T}\end{array}$ & source & $\mathrm{HX}$ & $\begin{array}{l}\text { ) } \\
\mathrm{T}\end{array}$ & HX & $\begin{array}{c}\sin \\
\mathrm{k}\end{array}$ & $\begin{array}{l}\text { ) } \\
\mathrm{T}\end{array}$ \\
\hline $\begin{array}{l}\text { Electric Reverse } \\
\text { Rankine Cycle }\end{array}$ & 47 & 29 & 18 & 100 & 68 & 32 & 17 & -14 & 31 & 85 & 68 & 17 & 80 & 49 & 31 & 105 & 82 & 23 & 80 & 49 & 31 & 120 & 95 & 25 \\
\hline $\begin{array}{l}\text { Rankine Cycle } \\
\text { (Hydrocarbon) }\end{array}$ & 47 & 29 & 18 & 100 & 68 & 32 & 17 & -14 & 31 & 85 & 68 & 17 & 80 & 49 & 31 & 105 & 82 & 23 & 80 & 49 & 31 & 120 & 95 & 25 \\
\hline Transcritical $\mathrm{CO}_{2}$ & 47 & 33 & 14 & 73 & 68 & 5 & 17 & -10 & 27 & 78 & 68 & 10 & 80 & 49 & 31 & 85 & 82 & 3 & 80 & 49 & 31 & 100 & 95 & 5 \\
\hline Brayton Cycle & 47 & 29 & 18 & 100 & 68 & 32 & 17 & 10 & 7 & 85 & 68 & 17 & 80 & 49 & 31 & 105 & 82 & 23 & 80 & 49 & 31 & 120 & 95 & 25 \\
\hline Stirling Cycle & 47 & 29 & 18 & 100 & 68 & 32 & 17 & -14 & 31 & $\begin{array}{c}10 \\
0\end{array}$ & 68 & 32 & 80 & 49 & 31 & 105 & 82 & 23 & 80 & 49 & 31 & 120 & 95 & 25 \\
\hline Thermoelectric & 47 & 29 & 18 & 100 & 68 & 32 & 17 & -14 & 31 & 85 & 68 & 17 & 80 & 49 & 31 & 105 & 82 & 23 & 80 & 49 & 31 & 120 & 95 & 25 \\
\hline Thermoacoustic & 47 & 29 & 18 & 100 & 68 & 32 & 17 & -14 & 31 & 85 & 68 & 17 & 80 & 49 & 31 & 105 & 82 & 23 & 80 & 49 & 31 & 120 & 95 & 25 \\
\hline Pulse Tube & 47 & 29 & 18 & 100 & 68 & 32 & 17 & -14 & 31 & 85 & 68 & 17 & 80 & 49 & 31 & 105 & 82 & 23 & 80 & 49 & 31 & 120 & 95 & 25 \\
\hline Magnetic Cooling & 47 & 29 & 18 & 105 & 68 & 37 & 17 & 5 & 12 & 90 & 68 & 22 & 80 & 44 & 36 & 110 & 82 & 28 & 80 & 44 & 36 & 125 & 95 & 30 \\
\hline $\begin{array}{l}\text { Compressor } \\
\text { Driven Metal } \\
\text { Hydride }\end{array}$ & 47 & 29 & 18 & 100 & 68 & 32 & 17 & -14 & 31 & $\begin{array}{c}10 \\
0\end{array}$ & 68 & 32 & 80 & 49 & 31 & 105 & 82 & 23 & 80 & 49 & 31 & 120 & 95 & 25 \\
\hline
\end{tabular}


Table 39. Specified Conversion Efficiencies, Temperatures and ) Ts for Gas-Fired Heat Pump Cycle Calculations.

\begin{tabular}{|c|c|c|c|c|c|c|c|c|c|c|c|c|c|c|c|c|c|c|c|c|c|c|c|c|c|}
\hline \multirow[b]{2}{*}{ Technology } & \multirow[b]{2}{*}{$\begin{array}{l}\text { Conversion } \\
\text { Efficiency }\end{array}$} & \multicolumn{6}{|c|}{ 47EF Rating Point } & \multicolumn{6}{|c|}{ 17EF Rating Point } & \multicolumn{6}{|c|}{ 82EF Rating Point } & \multicolumn{6}{|c|}{ 95EF Rating Point } \\
\hline & & source & $\mathrm{HX}$ & $\begin{array}{l}\text { ) } \\
\mathrm{T}\end{array}$ & HX & $\begin{array}{c}\sin \\
\mathrm{k}\end{array}$ & $\begin{array}{l}\text { ) } \\
\mathrm{T}\end{array}$ & source & HX & $\begin{array}{l}\text { ) } \\
\mathrm{T}\end{array}$ & HX & $\begin{array}{c}\sin \\
\mathrm{k}\end{array}$ & $\begin{array}{l}\text { ) } \\
\mathrm{T}\end{array}$ & source & HX & $\begin{array}{l}\text { ) } \\
\mathrm{T}\end{array}$ & HX & $\begin{array}{c}\sin \\
\mathrm{k}\end{array}$ & $\begin{array}{l}\text { ) } \\
\mathrm{T}\end{array}$ & source & HX & $\begin{array}{l}\text { ) } \\
\mathrm{T}\end{array}$ & HX & $\begin{array}{c}\sin \\
\mathrm{k}\end{array}$ & $\begin{array}{l}\text { ) } \\
\mathrm{T}\end{array}$ \\
\hline $\begin{array}{l}\text { Gas Furnace / } \\
\text { Electric Air } \\
\text { Conditioner }\end{array}$ & 0.80 & & & & & & & & & & & & & 80 & 49 & 31 & 105 & 82 & 23 & 80 & 49 & 31 & 120 & 95 & 25 \\
\hline $\begin{array}{l}\text { Diesel Engine } \\
\text { Driven }\end{array}$ & 0.35 & 47 & 29 & 18 & 100 & 68 & 32 & 17 & -14 & 31 & 85 & 68 & 17 & 80 & 49 & 31 & 120 & 82 & 38 & 80 & 49 & 31 & 135 & 95 & 40 \\
\hline $\begin{array}{l}\text { IC Engine Driven } \\
\text { HP }\end{array}$ & 0.30 & 47 & 29 & 18 & 100 & 68 & 32 & 17 & -14 & 31 & 85 & 68 & 17 & 80 & 49 & 31 & 120 & 82 & 38 & 80 & 49 & 31 & 135 & 95 & 40 \\
\hline $\begin{array}{l}\text { Stirling Engine } \\
\text { Driven }\end{array}$ & 0.28 & 47 & 29 & 18 & 100 & 68 & 32 & 17 & -14 & 31 & 85 & 68 & 17 & 80 & 49 & 31 & 120 & 82 & 38 & 80 & 49 & 31 & 135 & 95 & 40 \\
\hline $\begin{array}{l}\text { Brayton Engine } \\
\text { Driven }\end{array}$ & 0.27 & 47 & 29 & 18 & 100 & 68 & 32 & 17 & -14 & 31 & 85 & 68 & 17 & 80 & 49 & 31 & 120 & 82 & 38 & 80 & 49 & 31 & 135 & 95 & 40 \\
\hline $\begin{array}{l}\text { Rankine Engine } \\
\text { Driven }\end{array}$ & 0.24 & 47 & 29 & 18 & 100 & 68 & 32 & 17 & -14 & 31 & 85 & 68 & 17 & 80 & 49 & 31 & 120 & 82 & 38 & 80 & 49 & 31 & 135 & 95 & 40 \\
\hline $\begin{array}{l}\text { Fuel Cell Powered } \\
\text { HP }\end{array}$ & 0.40 & 47 & 29 & 18 & 100 & 68 & 32 & 17 & -14 & 31 & 85 & 68 & 17 & 80 & 49 & 31 & 105 & 82 & 23 & 80 & 49 & 31 & 120 & 95 & 25 \\
\hline $\begin{array}{l}\text { Vuilleumier Cycle } \\
\text { HP }\end{array}$ & 0.80 & 47 & 29 & 18 & 102 & 68 & 34 & 17 & 10 & 7 & 72 & 68 & 4 & 80 & 49 & 31 & 137 & 82 & 55 & 80 & 49 & 31 & 150 & 95 & 55 \\
\hline $\begin{array}{r}\text { Absorption Cycle } \\
\text { single-effect } \\
\text { double-effect } \\
\text { GAX }\end{array}$ & $\begin{array}{l}0.80 \\
0.80 \\
0.80\end{array}$ & $\begin{array}{l}47 \\
47 \\
47\end{array}$ & $\begin{array}{l}29 \\
29 \\
29\end{array}$ & $\begin{array}{l}18 \\
18 \\
18\end{array}$ & $\begin{array}{l}100 \\
100 \\
100\end{array}$ & $\begin{array}{l}68 \\
68 \\
68\end{array}$ & $\begin{array}{l}32 \\
32 \\
32\end{array}$ & $\begin{array}{l}17 \\
17 \\
17\end{array}$ & $\begin{array}{l}10 \\
10 \\
10\end{array}$ & $\begin{array}{l}7 \\
7 \\
7\end{array}$ & $\begin{array}{l}85 \\
85 \\
85\end{array}$ & $\begin{array}{l}68 \\
68 \\
68\end{array}$ & $\begin{array}{l}17 \\
17 \\
17\end{array}$ & $\begin{array}{l}80 \\
80 \\
80\end{array}$ & $\begin{array}{l}49 \\
49 \\
49\end{array}$ & $\begin{array}{l}31 \\
31 \\
31\end{array}$ & $\begin{array}{l}105 \\
105 \\
105\end{array}$ & $\begin{array}{l}82 \\
82 \\
82\end{array}$ & $\begin{array}{l}23 \\
23 \\
23\end{array}$ & $\begin{array}{l}80 \\
80 \\
40\end{array}$ & $\begin{array}{l}49 \\
49 \\
49\end{array}$ & $\begin{array}{l}31 \\
31 \\
31\end{array}$ & $\begin{array}{l}120 \\
120 \\
120\end{array}$ & $\begin{array}{l}95 \\
95 \\
95\end{array}$ & $\begin{array}{l}25 \\
25 \\
25\end{array}$ \\
\hline Duplex Stirling & 0.28 & 47 & 29 & 18 & 100 & 68 & 32 & 17 & -14 & 31 & 85 & 68 & 17 & 80 & 49 & 31 & 120 & 82 & 38 & 80 & 49 & 31 & 135 & 95 & 40 \\
\hline $\begin{array}{l}\text { Ejector Heat } \\
\text { Pump }\end{array}$ & 0.80 & 47 & 29 & 18 & 101 & 68 & 33 & 17 & -14 & 31 & 101 & 68 & 33 & 80 & 49 & 31 & 105 & 82 & 23 & 80 & 49 & 31 & 120 & 95 & 25 \\
\hline
\end{tabular}


B - 4 
APPENDIX C: MODELED, OBSERVED, AND REPORTED EFFICIENCIES (REALITY CHECK)

C -1 
C - 2 
Table 40. Comparison of Modeled and Reported COPs and Efficiencies.

\begin{tabular}{|c|c|c|c|c|}
\hline Technology & $\begin{array}{l}\text { Temperature } \\
\text { Condition }\end{array}$ & $\begin{array}{l}\text { Modeled } \\
\text { Value }\end{array}$ & $\begin{array}{l}\text { Observed } \\
\text { Value }\end{array}$ & Source \\
\hline $\begin{array}{l}\text { Thermoacoustic } \\
\text { Cooling }\end{array}$ & $\begin{array}{l}95 \mathrm{EF} \\
95 \mathrm{EF}\end{array}$ & $\begin{array}{l}0.39 \\
0.39\end{array}$ & $\begin{array}{l}2.3 \text { to } 2.5 \\
1.7 \text { to } 2.0\end{array}$ & $\begin{array}{l}\text { Steve Garrett, personal communication } \\
\text { Greg Swift, personal communication }\end{array}$ \\
\hline $\begin{array}{l}\text { IC-Engine Driven } \\
\text { HP }\end{array}$ & $\begin{array}{l}\text { gCOP(heat) } \\
\text { gCOP(heat) } \\
\text { gCOP(cool) } \\
95 E F \\
\text { IPLV } \\
\text { gCOP(cool) }\end{array}$ & $\begin{array}{l}1.45 \\
1.45 \\
0.89 \\
0.88 \\
0.89\end{array}$ & $\begin{array}{c}1.3 \\
1.27 \\
1.1 \\
0.9 \\
0.77 \\
0.72\end{array}$ & $\begin{array}{l}\text { Nowakowski 1996, p. } 46 \\
\text { Nowakowski 1995, p. } 1386 \\
\text { Nowakowski 1996, p. } 46 \\
\text { Nowakowski 1995, p. } 1384 \\
\text { ThermoKing Brochure, p. } 25 \\
\text { Aisin Brochure, back cover }\end{array}$ \\
\hline $\begin{array}{l}\text { Diesel Engine } \\
\text { Driven HP }\end{array}$ & $\begin{array}{l}\mathrm{gCOP}(\text { heat }) \\
\mathrm{gCOP}(\text { cool })\end{array}$ & $\begin{array}{l}1.57 \\
1.05\end{array}$ & $\begin{array}{l}1.3 \\
0.9\end{array}$ & $\begin{array}{l}\text { Yanmar Brochure (Y4GPB-PRC) } \\
\text { Yanmar Brochure (Y4GPB-PRC) }\end{array}$ \\
\hline $\begin{array}{l}\text { Stirling Engine } \\
\text { Driven HP }\end{array}$ & $\begin{array}{l}47 \mathrm{EF} \\
47 \mathrm{EF} \\
47 \mathrm{EF} \\
47 \mathrm{EF} \\
15 \mathrm{EF} \\
95 \mathrm{EF} \\
95 \mathrm{EF} \\
95 \mathrm{EF} \\
85 \mathrm{EF}\end{array}$ & $\begin{array}{l}1.63 \\
1.63 \\
1.63 \\
1.63 \\
1.56 \\
0.70 \\
0.70 \\
0.70 \\
0.88\end{array}$ & $\begin{array}{l}1.09 \\
1.57 \\
1.80 \\
1.36 \\
1.08 \\
0.91 \\
1.10 \\
0.42 \\
1.0\end{array}$ & $\begin{array}{l}\text { Aisin Seiki } \\
\text { Aisin Seiki (70\% heat recovery) } \\
\text { SPS } \\
\text { Sunpower (90\% heat recovery) } \\
\text { Sunpower (90\% heat recovery) } \\
\text { Aisin Seiki } \\
\text { SPS } \\
\text { Sunpower } \\
\text { Sunpower }\end{array}$ \\
\hline $\begin{array}{l}\text { Brayton Engine } \\
\text { Driven HP }\end{array}$ & $\begin{array}{l}47 \mathrm{EF} \\
95 \mathrm{EF}\end{array}$ & $\begin{array}{l}1.59 \\
0.68\end{array}$ & $\begin{array}{l}1.2 \text { to } 1.4 \\
1.0\end{array}$ & $\begin{array}{l}\text { GRI/DOE } \\
\text { GRI/DOE }\end{array}$ \\
\hline $\begin{array}{l}\text { Single-Effect } \\
\text { Absorption }\end{array}$ & $\begin{array}{l}\text { heating } \\
\text { cooling } \\
\text { cooling }\end{array}$ & $\begin{array}{l}1.30 \\
0.56 \\
0.56\end{array}$ & $\begin{array}{l}0.81 \\
0.5 \text { to } 0.6 \\
0.62\end{array}$ & $\begin{array}{l}\text { Servel } \\
\text { Servel } \\
\text { DeVault }\end{array}$ \\
\hline $\begin{array}{l}\text { Double-Effect } \\
\text { Absorption }\end{array}$ & IPLV & 0.94 & 0.96 & DeVault \\
\hline $\begin{array}{l}\text { Adsorption: } \\
\text { Complex } \\
\text { Compounds }\end{array}$ & $\begin{array}{c}30 \mathrm{EF} \\
\mathrm{gCOP}(\text { cool }) \\
\mathrm{gCOP}(\text { heat }) \\
\mathrm{gCOP}(\text { cool })\end{array}$ & & $\begin{array}{l}1.7 \\
1.0 \\
1.5 \\
1.0\end{array}$ & $\begin{array}{l}\text { Rockenfeller } 1992 \\
\text { Rockenfeller } 1992 \\
\text { Bill Ryan } 1992 \\
\text { Bill Ryan } 1992\end{array}$ \\
\hline $\begin{array}{l}\text { Adsorption: } \\
\text { Ammoniated } \\
\text { Carbon }\end{array}$ & $\begin{array}{c}\text { gCOP(heat) } \\
\text { gCOP(cool) } \\
47 E F \\
95 E F \\
17 E F \\
82 E F\end{array}$ & & $\begin{array}{c}1.30 \\
1.00 \\
1.9 \text { to } 2.4 \\
1.0 \text { to } 1.7 \\
1.5 \text { to } 1.8 \\
1.3 \text { to } 1.6\end{array}$ & $\begin{array}{l}\text { WaveAir } \\
\text { WaveAir } \\
\text { JPL } \\
\text { JPL } \\
\text { JPL } \\
\text { JPL }\end{array}$ \\
\hline $\begin{array}{l}\text { Adsorption: Water } \\
\text { Zeolite }\end{array}$ & $\begin{array}{l}\text { gCOP(heat }) \\
\text { gCOP(cool })\end{array}$ & & $\begin{array}{l}1.8 \\
1.2\end{array}$ & $\begin{array}{l}\text { Tchernev } 1988 \\
\text { Tchernev } 1988\end{array}$ \\
\hline
\end{tabular}


Table 41. Comparison of Modeled and Reported COPs and Efficiencies (cont).

\begin{tabular}{|c|c|c|c|c|}
\hline Technology & $\begin{array}{c}\text { Temperature } \\
\text { Condition }\end{array}$ & $\begin{array}{l}\text { Modeled } \\
\text { Value }\end{array}$ & $\begin{array}{l}\text { Observed } \\
\text { Value }\end{array}$ & Source \\
\hline $\begin{array}{l}\text { Adsorption: Water / } \\
\text { Zeolite }\end{array}$ & $\begin{array}{l}\text { gCOP }(\text { cool }) \\
\text { gCOP }(\text { cool }) \\
\text { gCOP(heat })\end{array}$ & & $\begin{array}{c}0.4 \text { to } 0.5 \\
1.2 \\
1.8\end{array}$ & $\begin{array}{l}\text { Tchernev } 1988 \text { (w/o regeneration) } \\
\text { Tchernev } 1988(\mathrm{w} / \text { regeneration }) \\
\text { Tchernev } 1988(\mathrm{w} / \text { regeneration })\end{array}$ \\
\hline Electric Heat Pump & $\begin{array}{l}47 E F \\
17 E F \\
95 E F \\
82 E F \\
\text { HSPF } \\
\text { SEER }\end{array}$ & $\begin{array}{c}3.83 \\
2.60 \\
3.21 \\
4.02 \\
8.2 \\
11.9\end{array}$ & $\begin{array}{c}3.84 \\
2.60 \\
2.66 \\
\\
8.3 \\
12.0\end{array}$ & $\begin{array}{l}\text { Carrier Product literature } \\
\text { Carrier Product literature } \\
\text { Carrier Product literature } \\
\text { Carrier Product literature } \\
\text { Carrier Product literature }\end{array}$ \\
\hline $\begin{array}{l}\text { Geothermal Heat } \\
\text { Pumps }\end{array}$ & $\begin{array}{l}\text { HSPF } \\
\text { SEER }\end{array}$ & & $\begin{array}{l}2.7 \text { to } 3.6 \\
9.6 \text { to } 12.6\end{array}$ & $\begin{array}{l}\text { L'Ecuyer } 1993 \\
\text { L'Ecuyer } 1993\end{array}$ \\
\hline $\begin{array}{l}\text { Compressor Driven } \\
\text { Metal Hydride }\end{array}$ & $95 \mathrm{EF}$ & 3.12 & 3.22 & Kim 1997 \\
\hline Transcritical $\mathrm{CO}_{2}$ & $\begin{array}{l}47 \mathrm{EF} \\
95 \mathrm{EF}\end{array}$ & $\begin{array}{l}3.78 \\
2.32\end{array}$ & $\begin{array}{l}2.49 \\
2.27\end{array}$ & $\begin{array}{l}\text { Bullock } 1997 \\
\text { Bullock } 1997\end{array}$ \\
\hline Brayton Cycle & $\begin{array}{l}47 \mathrm{EF} \\
17 \mathrm{EF} \\
95 \mathrm{EF} \\
82 \mathrm{EF} \\
\mathrm{HSPF} \\
\text { SEER }\end{array}$ & $\begin{array}{c}1.73 \\
1,71 \\
0.92 \\
0.98 \\
5.0 \\
2.9\end{array}$ & & \\
\hline Stirling Cycle & $\begin{array}{l}47 \mathrm{EF} \\
17 \mathrm{EF} \\
95 \mathrm{EF} \\
82 \mathrm{EF} \\
\text { HSPF } \\
\text { SEER }\end{array}$ & $\begin{array}{c}1.67 \\
1.50 \\
0.86 \\
0.93 \\
4.7 \\
2.7\end{array}$ & & \\
\hline Thermoelectric & $\begin{array}{l}47 \mathrm{EF} \\
17 \mathrm{EF} \\
95 \mathrm{EF} \\
82 \mathrm{EF} \\
\mathrm{HSPF} \\
\text { SEER }\end{array}$ & $\begin{array}{c}1.40 \\
1.31 \\
0.62 \\
0.86 \\
4.4 \\
2.9\end{array}$ & & \\
\hline
\end{tabular}

C -4 


\section{APPENDIX D: TABULATED ASSUMPTIONS}

Average price of natural gas (\$ per $\left.1000 \mathrm{ft}^{3}\right)$ to residential customers in 1997 listed by state (Energy Information Agency (EIA) Form-176, “Annual Report of Natural Gas Supply and Disposition):

$\begin{array}{llllll}\text { Alabama } & \$ 8.35 & \text { Louisana } & \$ 7.16 & \text { Ohio } & \$ 6.75 \\ \text { Alaska } & \$ 3.77 & \text { Maine } & \$ 8.47 & \text { Oklahoma } & \$ 6.23 \\ \text { Arizona } & \$ 7.83 & \text { Maryland } & \$ 8.36 & \text { Oregon } & \$ 6.21 \\ \text { Arkansas } & \$ 6.67 & \text { Massachusetts } & \$ 9.43 & \text { Pennsylvania } & \$ 8.33 \\ \text { California } & \$ 6.81 & \text { Michigan } & \$ 5.20 & \text { Rhode Island } & \$ 9.61 \\ \text { Colorado } & \$ 4.81 & \text { Minnesota } & \$ 5.76 & \text { South Carolina } & \$ 8.37 \\ \text { Connecticut } & \$ 10.33 & \text { Mississippi } & \$ 6.35 & \text { South Dakota } & \$ 5.75 \\ \text { Delaware } & \$ 8.36 & \text { Missouri } & \$ 6.61 & \text { Tennessee } & \$ 6.91 \\ \text { Florida } & \$ 11.90 & \text { Montana } & \$ 5.05 & \text { Texas } & \$ 6.32 \\ \text { Georgia } & \$ 7.41 & \text { Nebraska } & \$ 5.69 & \text { Utah } & \$ 5.13 \\ \text { Hawaii } & \$ 21.74 & \text { Nevada } & \$ 6.27 & \text { Vermont } & \$ 6.41 \\ \text { Idaho } & \$ 5.12 & \text { New Hampshire } & \$ 8.48 & \text { Virginia } & \$ 8.60 \\ \text { Illinois } & \$ 5.95 & \text { New Jersey } & \$ 7.93 & \text { Washington } & \$ 5.64 \\ \text { Indiana } & \$ 6.37 & \text { New Mexico } & \$ 5.87 & \text { West Virginia } & \$ 6.81 \\ \text { Iowa } & \$ 6.17 & \text { New York } & \$ 9.73 & \text { Wisconsin } & \$ 6.43 \\ \text { Kansas } & \$ 6.42 & \text { North Carolina } & \$ 8.98 & \text { Wyoming } & \$ 4.58 \\ \text { Kentucky } & \$ 6.37 & \text { North Dakota } & \$ 4.99 & \text { U.S. Average } & \$ 6.94\end{array}$

Data taken from an electronic document located at:

ftp://ftp.eia.doe.gov/pub/oil_gas/natural_gas/data_publications/natural_gas_annual/current/pdf/table_02 4.pdf 
Estimated U.S. Electric Utility Revenue From Residential Consumers (c per kWh) for 1998 (Energy Information Administration, Form EIA-286, "Monthly Electric Utility Sales and Revenue Report with State Distribution).

$\begin{array}{llllll}\text { Alabama } & 7.0 & \text { Louisiana } & 7.1 & \text { Ohio } & 8.7 \\ \text { Alaska } & 11.6 & \text { Maine } & 12.8 & \text { Oklahoma } & 6.7 \\ \text { Arizona } & 8.8 & \text { Maryland } & 8.6 & \text { Oregon } & 5.9 \\ \text { Arkansas } & 7.3 & \text { Massachusetts } & 10.5 & \text { Pennsylvania } & 10.0 \\ \text { California } & 10.5 & \text { Michigan } & 8.8 & \text { Rhode Island } & 11.2 \\ \text { Colorado } & 7.4 & \text { Minnesota } & 7.4 & \text { South Carolina } & 7.5 \\ \text { Connecticut } & 12.0 & \text { Mississippi } & 7.0 & \text { South Dakota } & 7.2 \\ \text { Delaware } & 9.2 & \text { Missouri } & 7.2 & \text { Tennessee } & 6.3 \\ \text { Florida } & 7.9 & \text { Montana } & 6.6 & \text { Texas } & 7.7 \\ \text { Georgia } & 7.7 & \text { Nebraska } & 6.6 & \text { Utah } & 6.9 \\ \text { Hawaii } & 13.9 & \text { Nevada } & 7.0 & \text { Vermont } & 11.5 \\ \text { Idaho } & 5.3 & \text { New York } & 14.1 & \text { Virginia } & 7.7 \\ \text { Illinois } & 10.0 & \text { New Jersey } & 11.7 & \text { Washington } & 5.0 \\ \text { Indiana } & 7.1 & \text { New Mexico } & 9.0 & \text { West Virginia } & 6.3 \\ \text { Iowa } & 8.6 & \text { New Hampshire } & 13.6 & \text { Wisconsin } & 7.2 \\ \text { Kansas } & 7.7 & \text { North Dakota } & 6.5 & \text { Wyoming } & 6.4 \\ \text { Kentucky } & 5.7 & \text { North Carolina } & 8.1 & \text { U.S. Average } & 8.31\end{array}$

Electricity costs for residential cosumers was taken from an electronic document located at http://www.eia.doe.gov/cneaf/electricity/epm/epmt55.txt

Energy cost ratios by state (1000 Btu natural gas per \$ / 1000 Btu electric per \$):

$\begin{array}{llllll}\text { Alabama } & 2.52 & \text { Indiana } & 3.35 & \text { Nebraska } & 3.48 \\ \text { Alaska } & 9.24 & \text { Iowa } & 4.19 & \text { Nevada } & 3.35 \\ \text { Arizona } & 3.38 & \text { Kansas } & 3.60 & \text { New Hampshire } & 4.82 \\ \text { Arkansas } & 3.29 & \text { Kentucky } & 2.69 & \text { New Jersey } & 4.43 \\ \text { California } & 4.63 & \text { Louisiana } & 2.98 & \text { New Mexico } & 4.60 \\ \text { Colorado } & 4.62 & \text { Maine } & 4.54 & \text { New York } & 4.35 \\ \text { Connecticut } & 3.49 & \text { Maryland } & 2.98 & \text { North Carolina } & 2.71 \\ \text { Delaware } & 3.30 & \text { Massachusetts } & 3.34 & \text { North Dakota } & 3.91 \\ \text { Florida } & 1.99 & \text { Michigan } & 5.08 & \text { Ohio } & 3.87 \\ \text { Georgia } & 3.12 & \text { Minnesota } & 3.86 & \text { Oklahoma } & 3.23 \\ \text { Hawaii } & 1.92 & \text { Mississippi } & 3.31 & \text { Oregon } & 2.85 \\ \text { Idaho } & 3.11 & \text { Missouri } & 3.27 & \text { Pennsylvania } & 3.61 \\ \text { Illinois } & 5.05 & \text { Montana } & 3.93 & \text { Rhode Island } & 3.50\end{array}$

D - 2 
South Carolina $\quad 2.69$

South Dakota $\quad 3.76$

Tennessee $\quad 2.74$

Texas $\quad 3.66$

Utah 4.04

Vermont $\quad 5.39$

Virginia $\quad 2.69$

Washington $\quad 2.66$

West Virginia $\quad 2.78$

Wisconsin $\quad 3.36$

Wyoming $\quad 4.20$

U.S. Average $\quad 3.60$

D - 3 


\section{APPENDIX E: ECONOMIC ANALYSIS}

Seasonal performance factors and economic analyses are performed for the following 117 cities using typical weather year data and state-wide averages for gas and electric rates. The distribution of these cities across the U.S. is shown in Fig. 52. Building loads are computed for a two-story, 2000 $\mathrm{ft}^{2}$ home with "typical" insulation (using binned temperature data from the Air Force Weather Manual for each of the following cities:

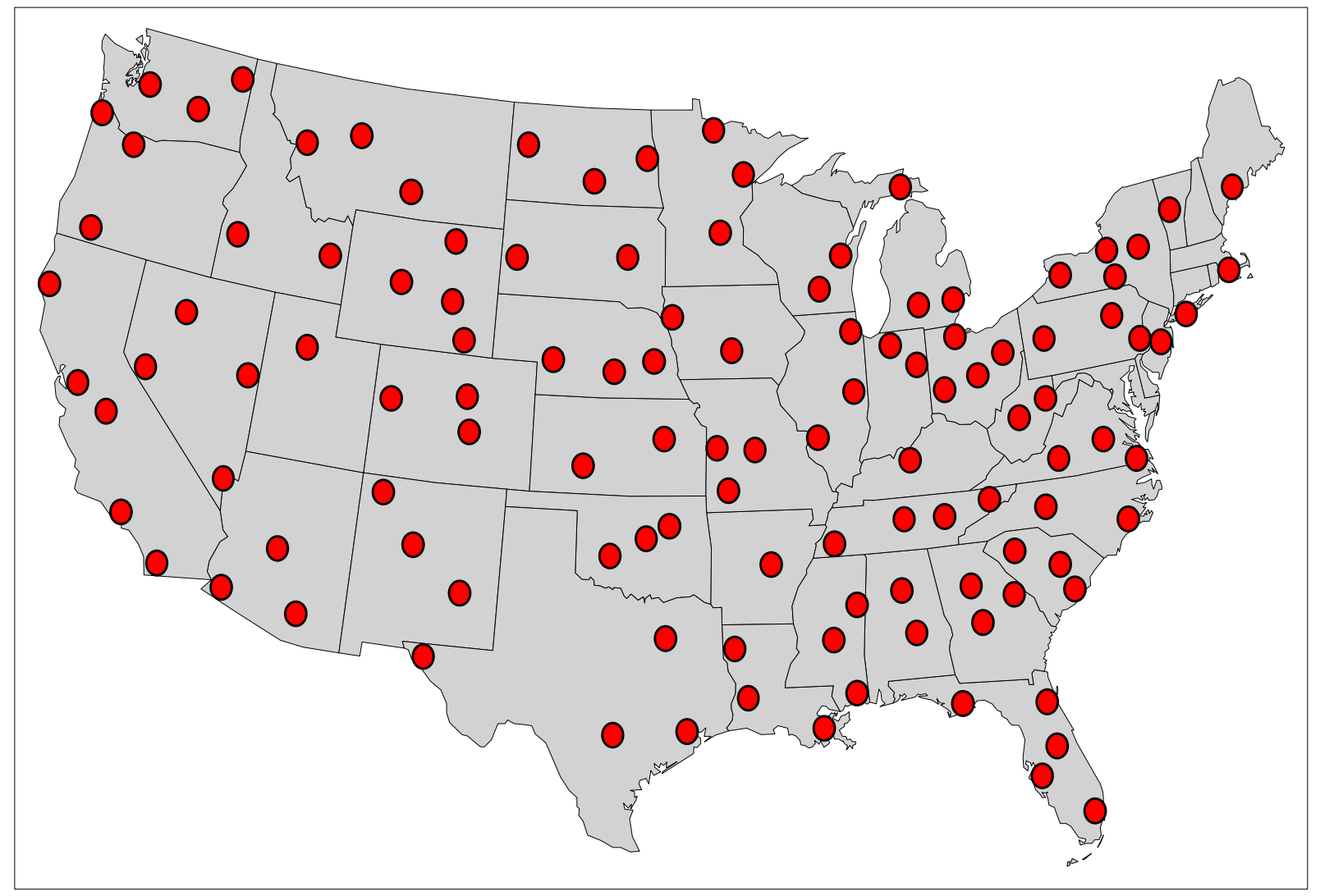

Fig. 52. Distribution of weather data across the U.S. for heating and cooling calculations.

Birmingham, Alabama

Montgomery, Alabama

Phoenix, Arizona

Tucson, Arizona

Yuma, Arizona

Little Rock, Arkansas

Arcata, California

Los Angeles, California
Merced, California

Oakland, California

San Diego, California

Colorado Springs, Colorado

Denver, Colorado

Grand Junction, Colorado

Appalachicola, Florida
Jacksonville, Florida

Miami, Florida

Orlando, Florida

Tampa, Florida

Atlanta, Georgia

Augusta, Georgia

Macon, Georgia

Des Moines, Iowa 
Sioux City, Iowa

Boise, Idaho

Idaho Falls, Idaho

Champaigne-Urbana, Illinois

Chicago, Illinois

East St. Louis, Illinois

Fort Wayne, Indiana

South Bend, Indiana

Dodge City, Kansas

Topeka, Kansas

Louisville, Kentucky

Lake Charles, Louisiana

New Orleans, Louisiana

Shreveport, Louisiana

Portland, Maine

Falmouth, Massachusetts

Battle Creek, Michigan

Detroit, Michigan

Sault Ste Marie, Michigan

Duluth, Minnesota

International Falls,

Minnesota

Minneapolis, Minnesota

Biloxi, Mississippi

Columbus, Mississippi

Jackson, Mississippi

Columbia, Missouri

Kansas City, Missouri

Springfield, Missouri

Billings, Montana

Great Falls, Montana

Missoula, Montana
Grand Island, Nebraska

Lincoln, Nebraska

North Platte, Nebraska

Ely, Nevada

Las Vegas, Nevada

Reno, Nevada

Winnemucca, Nevada

Trenton, New Jersey

Albuquerque, New Mexico

Farmington, New Mexico

Roswell, New Mexico

Albany, New York

Binghamton, New York

Niagara Falls, New York

Syracuse, New York

Westhampton Beach, New

York

Greensboro, North Carolina

New Bern, North Carolina

Bismarck, North Dakota

Grand Forks, North Dakota

Williston, North Dakota

Akron, Ohio

Columbus, Ohio

Dayton, Ohio

Toledo, Ohio

Altus, Oklahoma

Oklahoma City, Oklahoma

Tulsa, Oklahoma

Astoria, Oregon

Medford, Oregon

Portland, Oregon
Philadelphia, Pennsylvania

Pittsburgh, Pennsylvania

Wilkes-Barre, Pennsylvania

Charleston, South Carolina

Greenville, South Carolina

Sumter, South Carolina

Huron, South Dakota

Rapid City, South Dakota

Bristol, Tennessee

Knoxville, Tennessee

Memphis, Tennessee

Nashville, Tennessee

El Paso, Texas

Fort Worth, Texas

Houston, Texas

San Antonio, Texas

Salt Lake City, Utah

Burlington, Vermont

Norfolk, Virginia

Richmond, Virginia

Roanoke, Virginia

Moses Lake, Washington

Seattle, Washington

Spokane, Washington

Charleston, West Virginia

Elkins, West Virginia

Green Bay, Wisconsin

Madison, Wisconsin

Casper, Wyoming

Cheyenne, Wyoming

Lander, Wyoming

Sheridan, Wyoming

The results for economic comparisons depend on system efficiencies for the baseline and alternative technologies, heating and cooling loads and climate variables, energy costs, and the relative costs of gas and electricity. Appendix D tabulates the average costs of gas and electricity in each state in the U.S. and the ratio of energy costs (i.e. Btus that can be purchased for $\$ 1.00$ spent on natural gas divided by the number of Btus that can be purchased for a $\$ 1.00$ spent on electricity). In general, gasfired systems compare more favorably with the electric heat pump baseline in the cities where the "heat content" of a dollar of natural gas is high compared to the "heat content" of a dollar of electricity. Burlington, Vermont; Albuquerque, Roswell, and Farmington, New Mexico; Albany, Binghamton,

E - 2 
Niagara Falls, Syracuse, and Westhampton Beach, New York; and Portland, Maine are good locations for efficient gas-fired equipment based on the gas and electric rates. 


\section{APPENDIX F: MAINTENANCE COST ASSUMPTIONS}

\section{Electric-Driven Heat Pumps}

1. Reverse Rankein Cycle Heat Pump
a) R-22
$\$ 100$
b) Propane
$\$ 100$
c) Transcritical $\mathrm{CO}_{2}$
$\$ 100$

2. Brayton Cycle

$\$ 100$

3. Stirling Cycle

$\$ 100$

4. Thermoelectric Cooling \$25

5. Thermionic Cooling \$25

6. Thermoacoustic Cooling $\$ 100$

7. Pulse Tube Refrigeration $\$ 100$

8. Magnetic Refrigeration $\$ 125$

9. Compressor Driven Metal Hydride Heat Pump

$\$ 110$

\section{Gas-Fired Heat Pumps}

10. Gas Furnace and Electric

Air Conditioner

$\$ 100$

11. Engine Driven Rankine

Cycle Heat Pumps
a) IC engine
$\$ 125$
b) Diesel Engine
$\$ 125$
c) Stirling Engine
$\$ 125$
d) Brayton Engine
$\$ 125$
e) Rankine Engine
$\$ 125$

12. Fuel Cell Powered Rankine Cycle Heat Pump $\$ 200$

13. Absorption Cycles
a) Single Effect
$\$ 100$
b) GAX Cycle
$\$ 100$
c) Double Effect
$\$ 100$

14. Vuilleumier Cycle Heat Pump $\$ 75$

15. Duplex Stirling Heat Pump \$125 


\section{APPENDIX G: BUILDING LOAD CALCULATIONS}

Heating and cooling loads are computed using the ORNL APF / Loads Model with binned weather data from the Air Force Weather Manual ${ }^{1}$. The ORNL APF / Loads Model is documented in an unpublished draft report by C. K. Rice and S. K. Fischer in the Building Equipment Research Program of the Energy Division at Oak Ridge National Laboratory. The APF / Loads Model was written to compute seasonal and annual performance factors for single- and variable-speed electric heat pumps. It incorporated FORTRAN subroutines to compute building heating and cooling loads from the MAD ${ }^{2}$ program for the design of Annual Cycle Energy Systems; MAD in turn used subroutines from the NBSLD $^{3}$ program from the National Bureau of Standards. The loads calculation from NBSLD is treated as a black box and is taken as sufficiently accurate for the comparisons of annual energy use performed in the current project.

Building specification data are used for a two-story, $2000 \mathrm{ft}^{2}$ home with typical levels of insulation, window glazing, and air infiltration. The walls are assumed to be of frame construction with R-11 fiberglass batt insulation and $1 / 2$ in. polyurethane sheathing; the overall roof R-value is 20 ; the floor $\mathrm{R}$-value is 10; there are single pane windows; and one air change per hour. The average monthly internal sensible heat source rates are set at $4300 \mathrm{Btu} / \mathrm{h}$. The building walls are defined as:

! North - $426 \mathrm{ft}^{2}$ including $54 \mathrm{ft}^{2}$ of windows;

! East - $204 \mathrm{ft}^{2}$ including $36 \mathrm{ft}^{2}$ of windows;

! South - $426 \mathrm{ft}^{2}$ including $54 \mathrm{ft}^{2}$ of windows;

! West - $204 \mathrm{ft}^{2}$ including $36 \mathrm{ft}^{2}$ of windows;

The summer and winter thermostat settings are assumed to be $78 \mathrm{E}$ and $70 \mathrm{E}$, respectively, and the design wet bulb temperature is 66EF.

The main program from the APF model was modified to loop through a list of weather data files, store the name of each city, the corresponding design heating and cooling loads, and the annual binned temperatures and hours. These data are written into an ASCII data file that can be imported into EXCEL for analysis; each column of the data file corresponds to the binned loads and temperatures for a single city. The data were organized to group cities by DOE climate region. This appeared to be a meaningful way to structure the economic analysis which turned out to be less useful than expected. FORTRAN programs used in this analysis are stored in the file folder "C:INIK Technologies\APF \& Loads CalculationslSource." The main program is in file "LDSCAL2.FOR" and the list of subroutines needed to compile and like the program are in "LODFILES.FOR." The latter file also contains the

${ }^{1}$ Engineering Weather Data, Departments of the Air Force, the Army, and the Navy, AFM 88-29, TM 5-785, NAVFAC P-89, July 1978.

${ }^{2}$ MAD: A Computer Program for ACES Design Using Monthly Thermal Loads, M. L. Ballou, E. A. Nephew, and L. A. Abbatiello, ORNL/CON-51, March 1981.

${ }^{3}$ NBSLD: The Computer Program for Heating and Cooling Loads in Buildings, T. Kusuda, NBS Building Science Series 69, July 1976. 
control specification to compile and load the program using the SVS FORTRAN compiler. All of the FORTRAN subroutines for this program use "INCLUDE" statements to incorporate COMMON blocks; these statements point to the included files using subdirectory or folder names that need to be changed to correspond to how the files are stored.

G - 2 


\section{APPENDIX H: THERMIONIC CONVERTERS}

\section{Theory of a Thermionic Converter}

Labinov assembled a derivation of the theoretical efficiency of thermionic converters from multiple sources. Heat is transfered by the current flowing between the electrodes and the current density is given by Richardson's formula:

$$
\mathrm{J}^{\prime} \mathrm{AT} \mathrm{e}^{\mathrm{*} 0^{-}}
$$

where $\mathrm{A}$ is the thermionic constant $\left(120 \mathrm{~A} / \mathrm{cm}^{2} \cdot \mathrm{K}^{2}\right), \mathrm{T}$ is the absolute temperature of the electrode $(\mathrm{K})$, $\mathrm{K}$ is the Boltzmann constant $\left(1.3806 \times 10^{-23} \mathrm{~W} / \mathrm{K} \mathrm{sec}\right)$, and $\mathrm{N}_{0}$ is the work function of an electron $(\mathrm{eV})$. The heat transfered is then given by:

$$
\mathrm{Q} \cdot \frac{\mathrm{N} \% 2 \mathrm{KT}}{\mathrm{e}} \mathrm{J}
$$

where $\mathrm{e}_{0}$ is the charge of an electron $\left(1.602 \times 10^{-13}\right.$ Coulomb). It follows that both the current, J, and heat transfer, Q, increase as the temperature, $\mathrm{T}$, increases. The net current between two electrodes is the difference between the current from the hot electrode to the cold electrode and the current in the opposite direction:

$$
\mathrm{J} \quad \mathrm{J} \& \mathrm{~J}
$$

where $J_{h-c}$ is the current from the hot electrode to the cold electrode and $J_{c-h}$ is the current in the opposite direction.

If $\mathrm{N}_{0}$ is the same for both electrodes, then other things being equal the electrons will move from the hot electrode to the cold electrode and the thermionic converter will operate as an electrogenerator. At least two conditions must be met to make a thermionic converter operate as a refrigeration device: ! the current specific density must be great enough to provide the necessary heat transfer. Figure 53 shows the relationship of $\mathrm{N}_{0}$ and $\mathrm{T}$ assuming that a current specific density of $1 \mathrm{~A} / \mathrm{cm}^{2}$ is the minimum acceptable value for practical purposes. This dependence is practically linear and $\mathrm{N}_{0}$ should be $0.3 \mathrm{eV}$ to provide the specified current density at a temperature below $250 \mathrm{~K}$ ($10 \mathrm{EF})$.

! when electrons move in the interelectrode space, a space charge is formed of the voltage ) $\mathrm{V}_{1}$. The voltage ) $\mathrm{V}_{1}$ applied to the electrodes must overcome that charge and also the potential barrier of the hot electrode (collector) surface, then: 


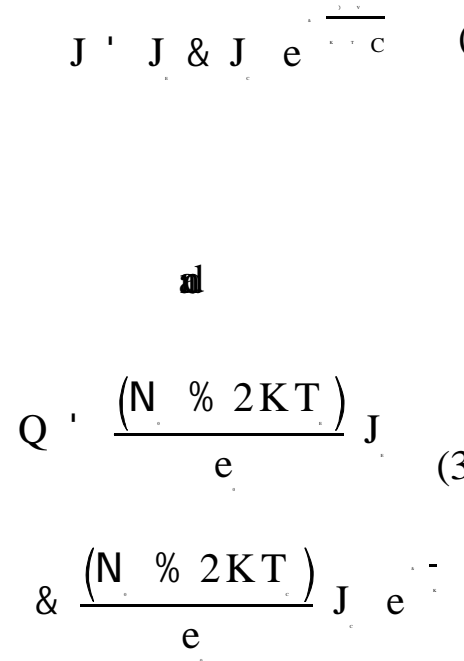

$\& \frac{(\mathrm{N} \% 2 \mathrm{KT})}{\mathrm{e}} \mathrm{J} \mathrm{e}^{-}$

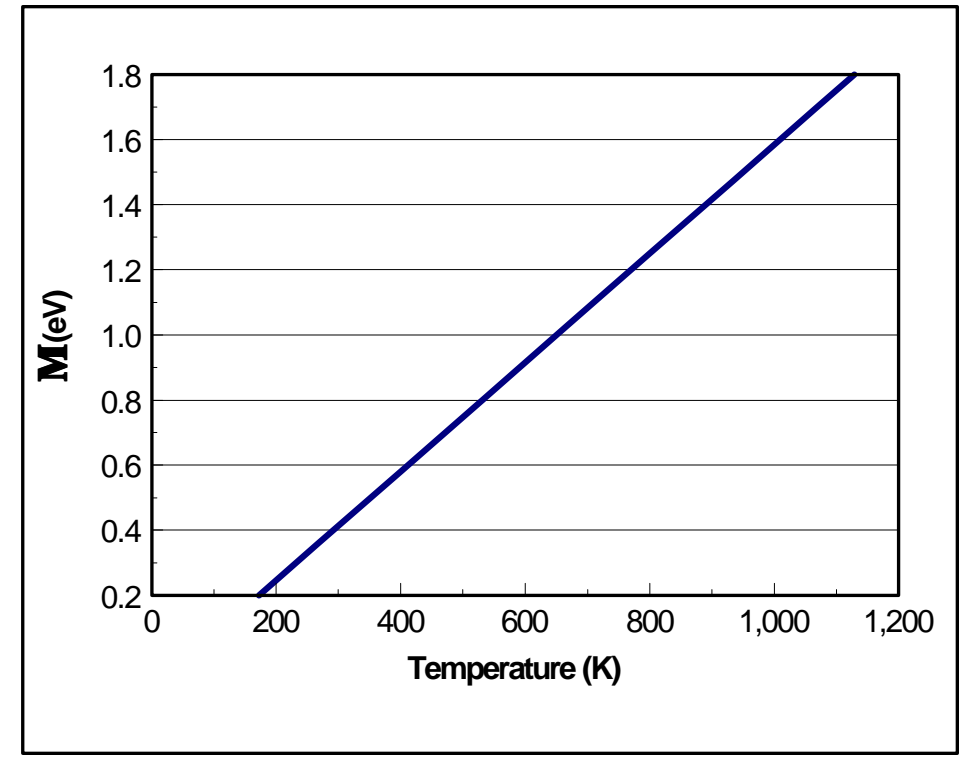

Fig. 53. Relationship between the work function and electrode temperature for a Richardson current of 1 $\mathrm{amp} / \mathrm{cm}^{2}$.

So the total voltage applied to a thermionic refrigerator should consist of two parts:

$$
\mathrm{V}, \text { ) } \mathrm{V} \%) \mathrm{V}
$$

where ) $V_{1}$ is the voltage drop across the interelectrode space and ) $V_{2}$ is the voltage drop of an external circuit. Not only the value of current may change depending on the value of the electric field voltage of the interelectrode space, but the direction of current and heat transfer may change as well.

The preceding equations show that for fixed temperatures $T_{C}$ and $T_{E}$, the efficiency depends on $\mathrm{N}_{0}$ and ) V. Current strength grows as $\mathrm{N}_{0}$ decreases, but $\mathrm{Q}$ is decreasing at the same time as $\mathrm{N}_{0}$ »KT. The total current increases as ) V increases, but the energy consumption of the process increases at the same time.

\section{Model of a Thermionic Converter}

Figure 54 illustrates the components and electron flow of an operating thermionic cooling device using ballistic electrons (Edelson) or the tunneling effect (Mahan). Electrical energy is required so the heat flow going from an external source to the cathode can be transferred from the electrode at a lower temperature (the emitter) to the electrode at a higher temperature (collector) where it can be rejected to the ambient. The electron cooling rate (Watts) is given by:

H - 2 


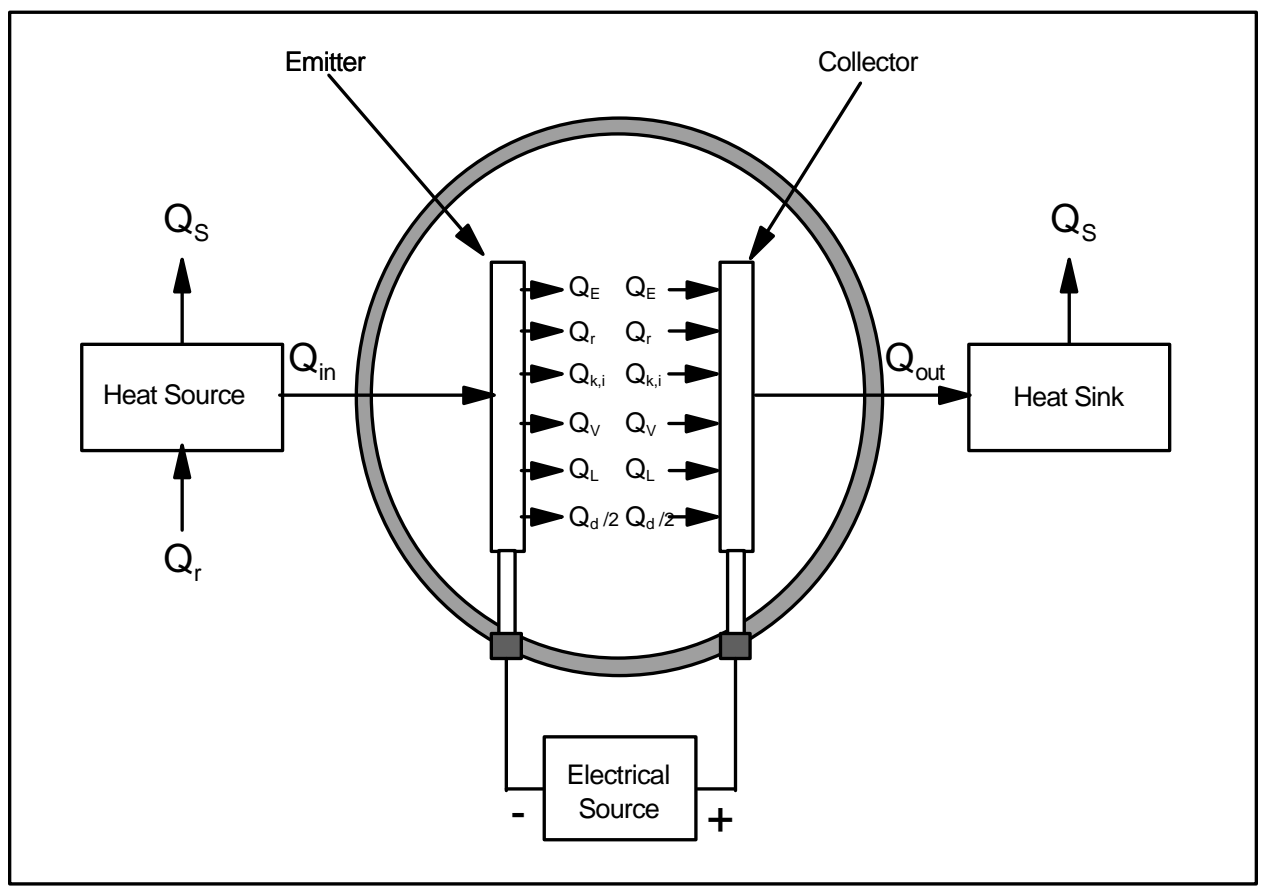

Fig. 54. Energy transfer rates in a thermionic refrigerator.

$$
\text { Q , SJ } \frac{\mathrm{N} \% 2 \mathrm{KT}}{\mathrm{e}} \& \mathrm{SJ} \frac{\mathrm{N} \% 2 \mathrm{KT}}{\mathrm{e}} \mathrm{e}^{\frac{\mathrm{c}}{\cdots}}
$$

where:

$\mathrm{S} \quad$ is the emitter surface area $\left(\mathrm{cm}^{2}\right)$,

$\mathrm{T}_{\mathrm{E}} \quad$ is the emitter temperature $(\mathrm{K})$,

$\mathrm{T}_{\mathrm{C}} \quad$ is the collector temperature $(\mathrm{K})$,

$\mathrm{J}_{\mathrm{E}} \quad$ is the current formed by the electrons emitted by the cathode at temperature $T_{\mathrm{E}}\left(\mathrm{A} / \mathrm{sec} \cdot \mathrm{cm}^{2}\right)$, and $\mathrm{J}_{\mathrm{C}} \quad$ is the current formed by the electrons emitted by the anode at temperature $T_{C}\left(\mathrm{~A} / \mathrm{sec} \cdot \mathrm{cm}^{2}\right)$.

The rate of interelectrode thermal radiation is given by:

$$
\mathrm{Q}, \mathrm{SF},(\mathrm{T} \& \mathrm{~T})
$$

where:

$\mathrm{F}_{0} \quad$ is the Stephan-Boltzmann radiation constant $\left(5.67 \times 10-12 \mathrm{~W} / \mathrm{cm}^{2} \cdot \mathrm{K}^{4}\right)$, and , is the net effective thermal emissivity (, \#1).

This expression for $Q_{r}$ does not include any thermal radiation energy transfer through surface areas of electrodes other than those facing the interelectrode space. The value of , may be used to account for 
the influence of a thin layer of a dielectric placed between the two electrodes. Nobody has examined how a superthin film which is easily penetrated by electrons affects radiant heat flow.

The heat conduction rate through the electrical leads associated with the emitter consists of the sum of two terms: $Q_{L}+1 / 2 Q_{d}$. The first term, $Q_{L}$, is the rate heat would be conducted through the lead when there is no current flow. This is given by:

$$
\mathrm{Q} \quad \mathrm{K} \frac{\mathrm{S}}{1}(\mathrm{~T} \quad \& \mathrm{~T})
$$

where:

$\mathrm{K}_{\mathrm{L}} \quad$ is the lead thermal conductivity,

$\mathrm{S}_{\mathrm{L}} \quad$ is the lead cross-sectional area, and

$1_{\mathrm{L}} \quad$ is the length of the electrical leads.

The second term in the conduction heat transfer arises because half of the Joule heat rate, $Q_{d}$, generated in the electrical leads is transfered back to the collector. This term is given by the relationship:

$$
\frac{1}{2} Q \cdot \frac{1}{2} S J V \cdot \frac{1}{2} S \cdot D \cdot \frac{1}{S}
$$

where:

$\mathrm{VL}$ is the voltage drop across the leads and

D is the electrical resistivity of the leads.

If the heat conduction rate through the structural components connected to the collector are designated as $\mathrm{Q}_{\mathrm{k}, \mathrm{i}}$ and the heat conduction rate through the interelectrode space as $\mathrm{Q}_{\mathrm{v}}$ (when there is a semiconductor film between the electrodes), then:

$$
\mathrm{Q} \quad \mathrm{Q} \quad \% \mathrm{Q} \quad \mathrm{g}(\mathrm{T} \& \mathrm{~T})
$$

where $\mathrm{g}_{\mathrm{k}}$ is the sum of the thermal conductivities, $\mathrm{g}_{\mathrm{i}}$, of the interelectrode space and the structural materials connected to the emitter. The total heat transferred to the anode (collector) should be equal to the total quantity of heat transfered to the external source $\left(\mathrm{Q}_{0}\right)$, that is:

$$
\text { Q ' Q \% Q \% } \% \frac{1}{2} \mathrm{Q} \% \mathrm{Q}
$$

and the electrical energy suppled to transfer the heat is:

$$
\text { W ' S (D) }
$$

$\mathrm{H}-4$ 
where $\mathrm{V}=\mathrm{V}_{\mathrm{T}}+\mathrm{V}_{\mathrm{L}}$ and

$\mathrm{V}_{\mathrm{T}} \quad$ is the space charge voltage drop across the interelectrode space and

$\mathrm{V}_{\mathrm{L}} \quad$ is the voltage drop across the external circuit.

The efficiency of the thermionic converter is then:

$$
0 \cdot \frac{\mathrm{Q}}{\mathrm{W}} \cdot \frac{\mathrm{Q} \% \mathrm{Q} \% \mathrm{Q} \% \frac{1}{2} \mathrm{Q} \% \mathrm{Q}}{\mathrm{S} \text { (b) }}
$$

Defining the "electronic efficiency" as the maximum possible efficiency associated with strictly electronic processes under ideal conditions of transport in the interelectrode space:

$$
\boldsymbol{\theta}, \frac{\mathrm{Q}}{\mathrm{S} \text { (D) }}
$$

Figure 55 shows the calculated efficiency for $\mathrm{T}_{\mathrm{E}}=500 \mathrm{~K}, \mathrm{~T}_{\mathrm{C}}=700 \mathrm{~K}$, and $\mathrm{N} 0=0.7 \mathrm{eV}$ for both electrodes. The changes in efficiency The change in efficiency is shown against the change of voltage applied between the electrodes () $\left.\mathrm{V}_{1}\right)$. The figure also shows that the direction of heat flow changes at the critical value of ) $\mathrm{V}=0.323 \mathrm{~V}$, and the process of heat transfer from the cold electrode (emitter) to the hot electrode (collector) begins. The maximum value of calculated COP is 2.08 while the theoretical value is 2.5 in this case. Under these circumstances, the specific density of the transfered heat is $1 \mathrm{~W} / \mathrm{cm}^{2}$. The maximum efficiency of the thermionic converter is $80 \%$ of that of the Carnot cycle.

The practical value of COP is much lower than that shown in Fig. 55 because of the losses in a real device. It is clear from the relations above that these losses will be reduced for a lower temperature drop in the electrodes and for a smaller interelectrode space. The relative efficiency is given by:

$$
0 \cdot \frac{0}{0}
$$

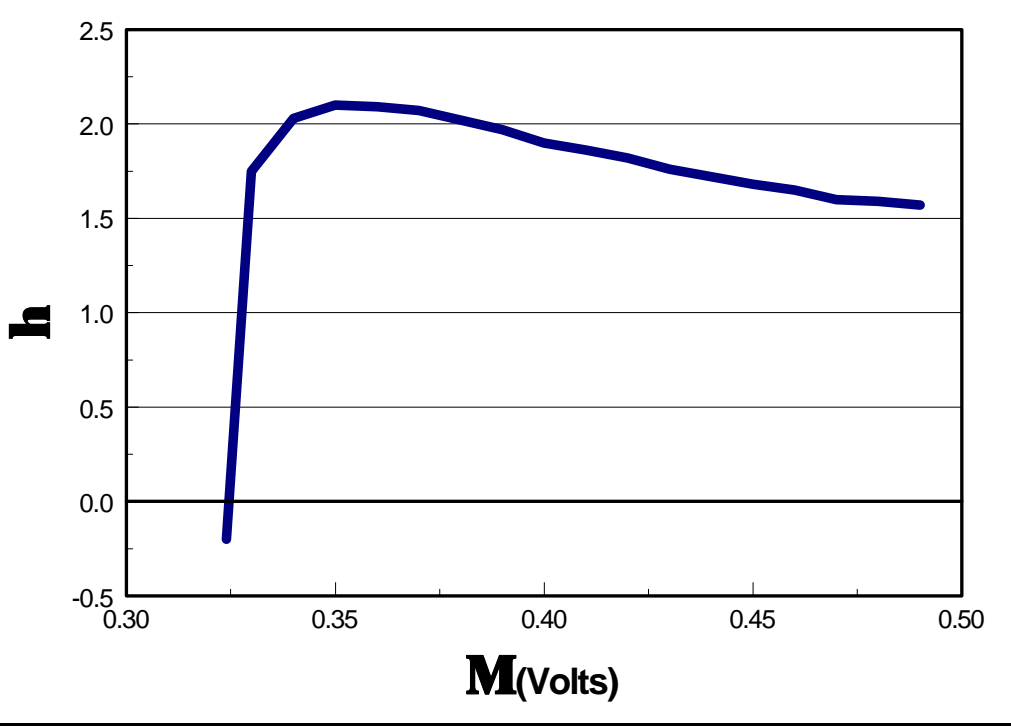

Fig. 55. Theoretical efficiency of a thermionic converter. 
where

$0_{\mathrm{r}} \quad$ is the real value of a thermionic converter efficiency including heat losses and

$0_{c} \quad$ is the Carnot efficiency at the same temperatures.

Figure 56 shows the relative efficiency against the integral factor that characterizes the thermal resistance of the thermionic converter. It is clear that the real efficiency decreases with the thermal resistance $\mathrm{N}$ and approaches 5 to $10 \%$ of Carnot efficiency.

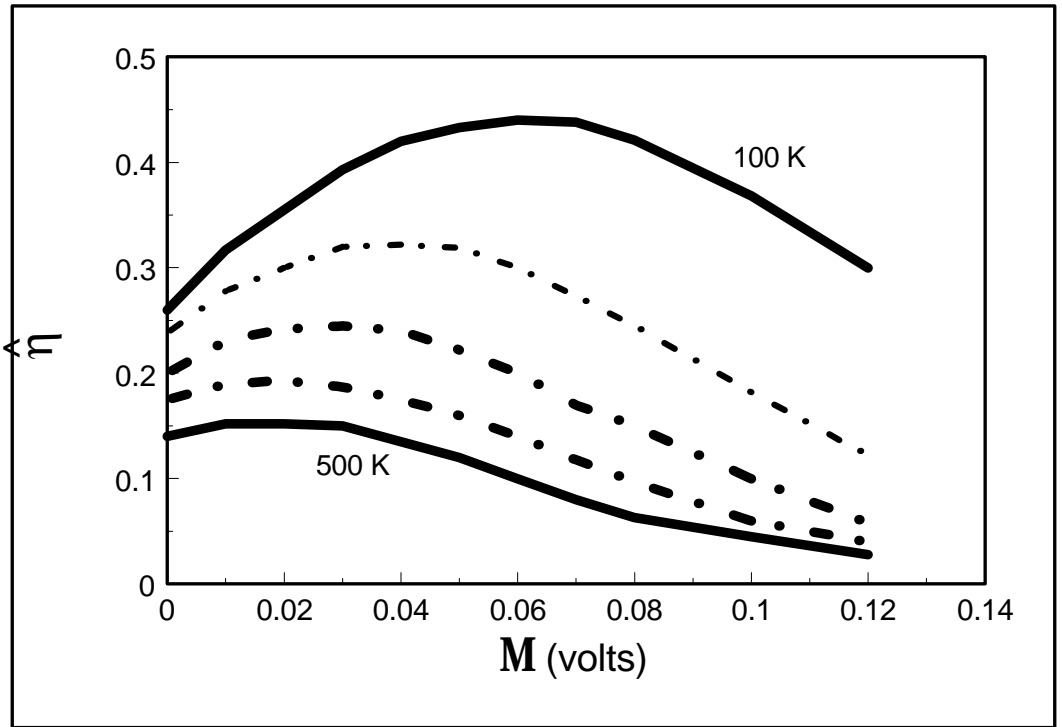

Fig. 56. Reduction in real efficiency for a thermionic converter. 


\section{APPENDIX I: MALONE REFRIGERATION}

An examination of the thermodynamic relationships provides some insights into the Malone cycle. First, the first and second laws of thermodynamics give:

$$
\mathrm{Td} \cdot \mathbb{U} \% \mathrm{pd}
$$

and for adiabatic compression $(\mathrm{Td} S=0)$, this becomes:

As $\mathrm{V}=\mathrm{f}(\mathrm{p}, \mathrm{T})$, then:

$$
\begin{aligned}
& \mathbb{W} \quad \& p d \\
& d \cdot\left(\frac{M N}{M}\right) \phi \quad \%\left(\frac{M N}{M}\right) d
\end{aligned}
$$

where

$$
\left(\frac{M N}{M}\right), K
$$

is the coefficient of isothermic compression and

$$
\left(\frac{M N}{M}\right), \$
$$

is the coefficient of isobaric compression. Substitution of the ideal gas equation ( $\mathrm{pV}=\mathrm{RT}$ ) gives $\mathrm{K}_{\mathrm{p}}=\mathrm{RT} / \mathrm{p}^{2}$ and $\$_{\mathrm{T}}=\mathrm{R} / \mathrm{p}$. So, $\mathrm{K}_{\mathrm{p}}$ depends on the absolute value of the pressure than $\$_{\mathrm{T}}$ does. This principal depends holds for gases as well as liquids, although the total pressure includes internal and external pressures. The external pressures are similar for liquids and gases, but the internal pressures of a liquid is caused by surface tension and depends on its temperature and chemical composition; the liquid internal pressure can be hundreds or thousands of atmospheres of pressure. So the values of $\mathrm{K}_{\mathrm{p}}$ and $\$_{\mathrm{T}}$ are much lower for a liquid than a gas; a liquid is practically incompressible. As a result, the adiabatic compression of a gas requires considerably greater work than the adiabatic compression of a 
liquid under the same pressure drop. On the contrary, a considerably larger amount of power is released with gas expansion than with liquid expansion.

Heat transfer in an isobaric process (the Brayton cycle) is given by:

$$
\begin{array}{cc}
\mathbb{Q} & \mathrm{T} \boldsymbol{\Phi} \% \mathrm{pd} \\
\mathrm{T} \Phi & \mathrm{C} \text { d } \% \mathrm{pd} \\
\mathrm{T}\left(\frac{\mathrm{M}}{\mathrm{M}}\right), & \mathrm{C} \% \mathrm{p}\left(\frac{\mathrm{M}}{\mathrm{M}}\right)
\end{array}
$$

and

$$
\begin{gathered}
Q, C \int \mathrm{d} \% \mathrm{p} \int\left(\frac{\mathrm{M}}{\mathrm{M}}\right) \mathrm{d} \\
\mathrm{Q}{ }^{\prime} \mathrm{C}(\mathrm{T} \& \mathrm{~T}) \% \mathrm{p} \$(\mathrm{~T} \& \mathrm{~T})
\end{gathered}
$$

So the heat transfer for the isobaric process in the Brayton cycle Malone system depends on $\$_{\mathrm{T}}$ but not on $\mathrm{K}_{\mathrm{p}}$. It can also be shown that heat transfer for the Stirling cycle process depends on the coefficient of isobaric compression, $\$$, but not on the coefficient of isothermic compression, $\mathrm{K}_{\mathrm{p}}$. Figure 57 shows lines of constant isothermic (dashed) and isobaric (solid) compression coefficients for carbon dioxide; the labels on the lines show how $\mathrm{K}_{\mathrm{p}}$ changes slowly from 0.01 to 0.02 away from the critical point on the left of the drawing, but rapidly from 0.20 to 1.0 near the critical point on the right. Similar changes can be seen for $\$_{\mathrm{T}}$.

Under normal conditions, $\$_{\mathrm{T}}$ is much smaller for a liquid than it is for a gas because of the exclusively strong compression resulting from surface tension forces. As the critical point is approached, however, the density of the liquid and the density of the equilibrium gas approach each other very quickly and the surface tension forces begin to decrease and become zero at the critical point. As a result, $\$_{\mathrm{T}}$ and $\mathrm{K}_{\mathrm{p}}$ increase as the critical point is approached from the liquid side. 


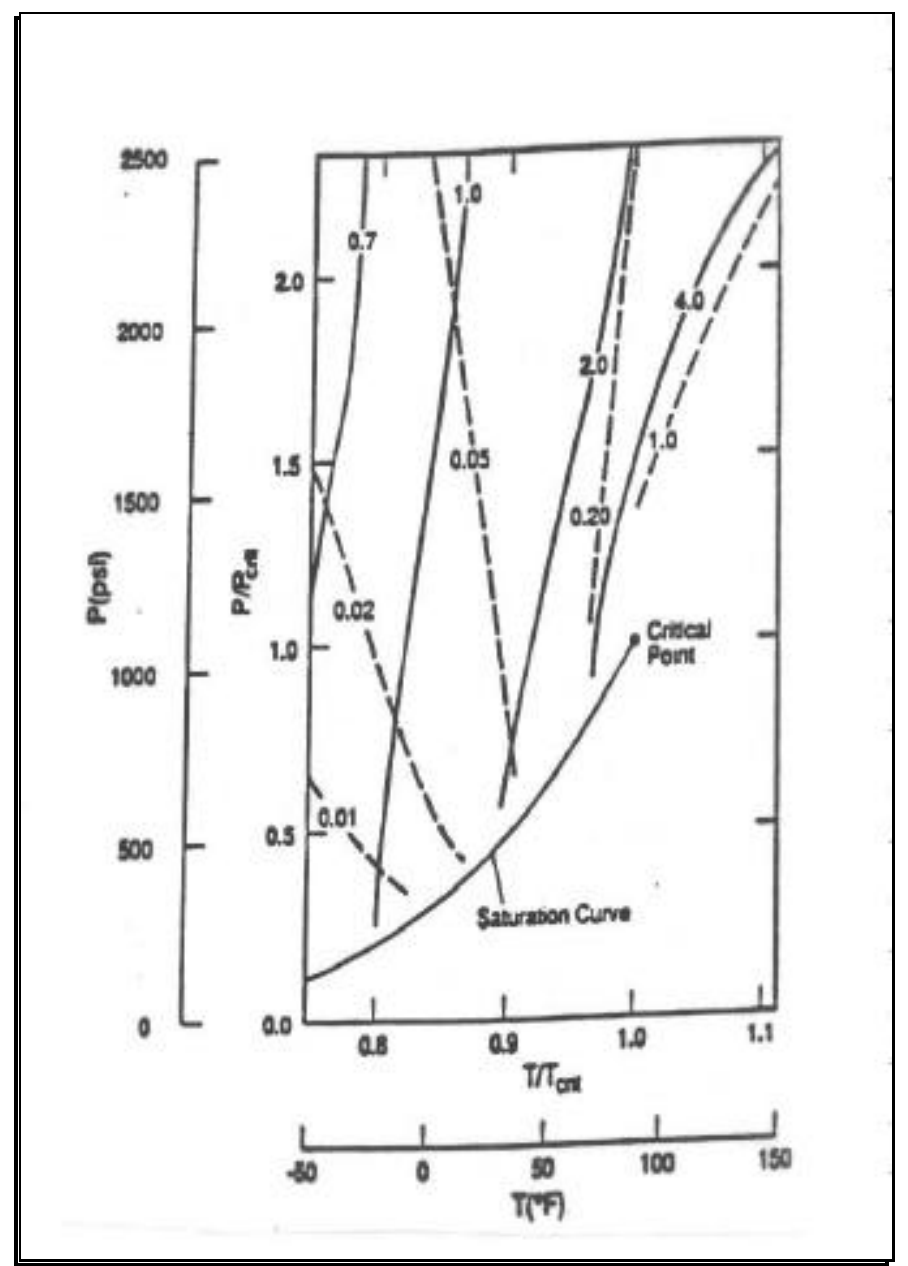

Fig. 57. $\mathrm{K}_{\mathrm{p}}$ (dashed lines) and $\$_{\mathrm{T}}$ (solid lines) near the critical point of $\mathrm{CO}_{2}$. 
APPENDIX J: GAS AND ELECTRICAL CONSUMPTION FOR EACH TECHNOLOGY

$\mathrm{J}-1$ 


\begin{tabular}{|c|c|c|c|c|c|c|c|c|}
\hline \multirow[b]{2}{*}{ State and City } & \multicolumn{2}{|c|}{ Electric Heat Pump } & \multicolumn{2}{|c|}{ Gas Furnace/Electric AC } & \multicolumn{2}{|c|}{ Hydrocarbon Heat Pump } & \multicolumn{2}{|c|}{ Transcritical $\mathrm{CO}_{2}$ Heat Pump } \\
\hline & $(\mathrm{kWh} / \mathrm{y})$ & (therms/y) & $(\mathrm{kWh} / \mathrm{y})$ & (therms/y) & $(\mathrm{kWh} / \mathrm{y})$ & (therms/y) & $(\mathrm{kWh} / \mathrm{y})$ & (therms/y) \\
\hline $\begin{array}{l}\text { Alabama } \\
\text { Birmingham } \\
\text { Montgomery }\end{array}$ & $\begin{array}{l}7,294 \\
7,095\end{array}$ & $\begin{array}{l}0 \\
0\end{array}$ & $\begin{array}{l}3,870 \\
4,597\end{array}$ & $\begin{array}{l}463 \\
362\end{array}$ & $\begin{array}{l}7,316 \\
7,118\end{array}$ & $\begin{array}{l}0 \\
0\end{array}$ & $\begin{array}{l}8,364 \\
8,318\end{array}$ & $\begin{array}{l}0 \\
0\end{array}$ \\
\hline $\begin{array}{l}\text { Arizona } \\
\text { Phoenix } \\
\text { Tucson } \\
\text { Yuma }\end{array}$ & $\begin{array}{l}9,261 \\
7,787 \\
9,399\end{array}$ & $\begin{array}{l}0 \\
0 \\
0\end{array}$ & $\begin{array}{l}7,688 \\
5,998 \\
8,408\end{array}$ & $\begin{array}{l}253 \\
280 \\
169\end{array}$ & $\begin{array}{l}9,300 \\
7,815 \\
9,443\end{array}$ & $\begin{array}{l}0 \\
0 \\
0\end{array}$ & $\begin{array}{r}11,939 \\
9,572 \\
12,433\end{array}$ & $\begin{array}{l}0 \\
0 \\
0\end{array}$ \\
\hline $\begin{array}{l}\text { Arkansas } \\
\text { Little Rock }\end{array}$ & 7,763 & 0 & 4,205 & 501 & 7,788 & 0 & 9,006 & 0 \\
\hline $\begin{array}{l}\text { California } \\
\text { Arcata } \\
\text { Los Angeles } \\
\text { Merced } \\
\text { Oakland } \\
\text { San Diego }\end{array}$ & $\begin{array}{l}5,627 \\
3,629 \\
6,627 \\
4,189 \\
2,949\end{array}$ & $\begin{array}{l}0 \\
0 \\
0 \\
0 \\
0\end{array}$ & $\begin{array}{r}518 \\
2,254 \\
3,856 \\
1,473 \\
1,806\end{array}$ & $\begin{array}{l}729 \\
226 \\
428 \\
438 \\
197\end{array}$ & $\begin{array}{l}5,615 \\
3,628 \\
6,640 \\
4,179 \\
2,947\end{array}$ & $\begin{array}{l}0 \\
0 \\
0 \\
0 \\
0\end{array}$ & $\begin{array}{l}5,700 \\
3,824 \\
7,680 \\
4,284 \\
3,062\end{array}$ & $\begin{array}{l}0 \\
0 \\
0 \\
0 \\
0\end{array}$ \\
\hline $\begin{array}{l}\text { Colorado } \\
\text { Colorado Springs } \\
\text { Denver } \\
\text { Grand Junction }\end{array}$ & $\begin{array}{l}14,585 \\
14,454 \\
11,278\end{array}$ & $\begin{array}{l}0 \\
0 \\
0\end{array}$ & $\begin{array}{l}2,000 \\
1,990 \\
2,991\end{array}$ & $\begin{array}{r}1,154 \\
1,137 \\
945\end{array}$ & $\begin{array}{l}14,620 \\
14,487 \\
11,319\end{array}$ & $\begin{array}{l}0 \\
0 \\
0\end{array}$ & $\begin{array}{l}15,335 \\
15,223 \\
12,353\end{array}$ & $\begin{array}{l}0 \\
0 \\
0\end{array}$ \\
\hline $\begin{array}{l}\text { Florida } \\
\text { Appalachicola } \\
\text { Jacksonville } \\
\text { Miami } \\
\text { Orlando } \\
\text { Tampa }\end{array}$ & $\begin{array}{l}6,461 \\
6,481 \\
7,128 \\
6,227 \\
6,689 \\
\end{array}$ & $\begin{array}{l}0 \\
0 \\
0 \\
0 \\
0\end{array}$ & $\begin{array}{l}5,221 \\
5,190 \\
6,982 \\
5,462 \\
6,151\end{array}$ & $\begin{array}{r}191 \\
199 \\
23 \\
119 \\
84\end{array}$ & $\begin{array}{l}6,483 \\
6,504 \\
7,161 \\
6,250 \\
6,716\end{array}$ & $\begin{array}{l}0 \\
0 \\
0 \\
0 \\
0\end{array}$ & $\begin{array}{l}7,659 \\
7,753 \\
8,739 \\
7,470 \\
8,162 \\
\end{array}$ & $\begin{array}{l}0 \\
0 \\
0 \\
0 \\
0\end{array}$ \\
\hline $\begin{array}{l}\text { Georgia } \\
\text { Atlanta } \\
\text { Augusta } \\
\text { Macon } \\
\end{array}$ & $\begin{array}{l}7,475 \\
7,174 \\
6,948 \\
\end{array}$ & $\begin{array}{l}0 \\
0 \\
0\end{array}$ & $\begin{array}{l}3,128 \\
4,149 \\
4,384 \\
\end{array}$ & $\begin{array}{l}562 \\
428 \\
374 \\
\end{array}$ & $\begin{array}{l}7,495 \\
7,197 \\
6,970\end{array}$ & $\begin{array}{l}0 \\
0 \\
0\end{array}$ & $\begin{array}{l}8,301 \\
8,314 \\
8,102 \\
\end{array}$ & $\begin{array}{l}0 \\
0 \\
0\end{array}$ \\
\hline $\begin{array}{l}\text { Idaho } \\
\text { Boise } \\
\text { Idaho Falls }\end{array}$ & $\begin{array}{l}11,150 \\
18,976\end{array}$ & $\begin{array}{l}0 \\
0\end{array}$ & $\begin{array}{l}2,395 \\
1,750\end{array}$ & $\begin{array}{l}1,054 \\
1,475\end{array}$ & $\begin{array}{l}11,184 \\
19,019\end{array}$ & $\begin{array}{l}0 \\
0\end{array}$ & $\begin{array}{l}12,046 \\
19,761\end{array}$ & $\begin{array}{l}0 \\
0\end{array}$ \\
\hline $\begin{array}{l}\text { Illinois } \\
\text { Champaigne-Urbana } \\
\text { Chicago } \\
\text { East St. Louis }\end{array}$ & $\begin{array}{l}15,043 \\
15,297 \\
11,435\end{array}$ & $\begin{array}{l}0 \\
0 \\
0\end{array}$ & $\begin{array}{l}2,530 \\
1,924 \\
3,188\end{array}$ & $\begin{array}{r}1,177 \\
1,265 \\
905\end{array}$ & $\begin{array}{l}15,087 \\
15,336 \\
11,474\end{array}$ & $\begin{array}{l}0 \\
0 \\
0\end{array}$ & $\begin{array}{l}15,985 \\
16,106 \\
12,495\end{array}$ & $\begin{array}{l}0 \\
0 \\
0\end{array}$ \\
\hline $\begin{array}{l}\text { Indiana } \\
\text { Fort Wayne } \\
\text { South Bend }\end{array}$ & $\begin{array}{l}13,586 \\
14,537\end{array}$ & $\begin{array}{l}0 \\
0\end{array}$ & $\begin{array}{l}2,204 \\
2,091\end{array}$ & $\begin{array}{l}1,140 \\
1,205\end{array}$ & $\begin{array}{l}13,626 \\
14,578\end{array}$ & $\begin{array}{l}0 \\
0\end{array}$ & $\begin{array}{l}14,445 \\
15,373\end{array}$ & $\begin{array}{l}0 \\
0\end{array}$ \\
\hline $\begin{array}{l}\text { Iowa } \\
\text { Des Moines } \\
\text { Sioux City }\end{array}$ & $\begin{array}{l}17,312 \\
18,402\end{array}$ & $\begin{array}{l}0 \\
0\end{array}$ & $\begin{array}{l}2,360 \\
2,663\end{array}$ & $\begin{array}{l}1,250 \\
1,306\end{array}$ & $\begin{array}{l}17,355 \\
18,454\end{array}$ & $\begin{array}{l}0 \\
0\end{array}$ & $\begin{array}{l}18,239 \\
19,476\end{array}$ & $\begin{array}{l}0 \\
0\end{array}$ \\
\hline $\begin{array}{l}\text { Kansas } \\
\text { Dodge City } \\
\text { Topeka }\end{array}$ & $\begin{array}{l}12,086 \\
12,933\end{array}$ & $\begin{array}{l}0 \\
0\end{array}$ & $\begin{array}{l}3,284 \\
3,205\end{array}$ & $\begin{array}{l}926 \\
985\end{array}$ & $\begin{array}{l}12,128 \\
12,977\end{array}$ & $\begin{array}{l}0 \\
0\end{array}$ & $\begin{array}{l}13,299 \\
14,066\end{array}$ & $\begin{array}{l}0 \\
0\end{array}$ \\
\hline $\begin{array}{l}\text { Kentucky } \\
\text { Louisville }\end{array}$ & 9,640 & 0 & 3,278 & 767 & 9,672 & 0 & 10,647 & 0 \\
\hline $\begin{array}{l}\text { Louisiana } \\
\text { Lake Charles } \\
\text { New Orleans } \\
\text { Shreveport }\end{array}$ & $\begin{array}{l}6,676 \\
6,126 \\
7,526\end{array}$ & $\begin{array}{l}0 \\
0 \\
0\end{array}$ & $\begin{array}{l}5,047 \\
4,812 \\
4,623\end{array}$ & $\begin{array}{l}246 \\
201 \\
410\end{array}$ & $\begin{array}{l}6,697 \\
6,146 \\
7,550\end{array}$ & $\begin{array}{l}0 \\
0 \\
0\end{array}$ & $\begin{array}{l}7,936 \\
7,278 \\
8,816\end{array}$ & $\begin{array}{l}0 \\
0 \\
0\end{array}$ \\
\hline
\end{tabular}

J - 2 


\begin{tabular}{|c|c|c|c|c|c|c|c|c|}
\hline \multirow[b]{2}{*}{ State and City } & \multicolumn{2}{|c|}{ Electric Heat Pump } & \multicolumn{2}{|c|}{ Gas Furnace/Electric AC } & \multicolumn{2}{|c|}{ Hydrocarbon Heat Pump } & \multicolumn{2}{|c|}{ Transcritical $\mathrm{CO}_{2}$ Heat Pump } \\
\hline & $(\mathrm{kWh} / \mathrm{y})$ & (therms/y) & $(\mathrm{kWh} / \mathrm{y})$ & (therms/y) & $(\mathrm{kWh} / \mathrm{y})$ & (therms/y) & $(\mathrm{kWh} / \mathrm{y})$ & (therms/y) \\
\hline $\begin{array}{l}\text { Maine } \\
\text { Portland }\end{array}$ & 16,743 & 0 & 1,490 & 1,349 & 16,778 & 0 & 17,379 & 0 \\
\hline $\begin{array}{l}\text { Massachusetts } \\
\text { Falmouth }\end{array}$ & 12,390 & 0 & 1,386 & 1,087 & 12,411 & 0 & 12,861 & 0 \\
\hline $\begin{array}{l}\text { Michigan } \\
\text { Battle Creek } \\
\text { Detroit } \\
\text { Sault Ste Marie }\end{array}$ & $\begin{array}{l}14,437 \\
15,483 \\
26,637\end{array}$ & $\begin{array}{l}0 \\
0 \\
0\end{array}$ & $\begin{array}{l}2,027 \\
1,994 \\
1,215\end{array}$ & $\begin{array}{l}1,230 \\
1,273 \\
1,777\end{array}$ & $\begin{array}{l}14,482 \\
15,527 \\
26,676\end{array}$ & $\begin{array}{l}0 \\
0 \\
0\end{array}$ & $\begin{array}{l}15,285 \\
16,286 \\
27,263\end{array}$ & $\begin{array}{l}0 \\
0 \\
0\end{array}$ \\
\hline $\begin{array}{l}\text { Minnesota } \\
\text { Duluth } \\
\text { International Falls } \\
\text { Minneapolis }\end{array}$ & $\begin{array}{l}31,461 \\
34,783 \\
22,354\end{array}$ & $\begin{array}{l}0 \\
0 \\
0\end{array}$ & $\begin{array}{l}1,174 \\
1,178 \\
1,981\end{array}$ & $\begin{array}{l}1,949 \\
2,040 \\
1,513\end{array}$ & $\begin{array}{l}31,499 \\
34,820 \\
22,402\end{array}$ & $\begin{array}{l}0 \\
0 \\
0\end{array}$ & $\begin{array}{l}32,065 \\
35,372 \\
23,218\end{array}$ & $\begin{array}{l}0 \\
0 \\
0\end{array}$ \\
\hline $\begin{array}{l}\text { Mississippi } \\
\text { Biloxi } \\
\text { Columbus } \\
\text { Jackson }\end{array}$ & $\begin{array}{l}6,537 \\
7,795 \\
7,255\end{array}$ & $\begin{array}{l}0 \\
0 \\
0\end{array}$ & $\begin{array}{l}4,949 \\
4,138 \\
4,480\end{array}$ & $\begin{array}{l}240 \\
495 \\
400\end{array}$ & $\begin{array}{l}6,559 \\
7,820 \\
7,277\end{array}$ & $\begin{array}{l}0 \\
0 \\
0\end{array}$ & $\begin{array}{l}7,769 \\
8,979 \\
8,471\end{array}$ & $\begin{array}{l}0 \\
0 \\
0\end{array}$ \\
\hline $\begin{array}{l}\text { Missouri } \\
\text { Columbia } \\
\text { Kansas City } \\
\text { Springfield }\end{array}$ & $\begin{array}{l}11,678 \\
11,275 \\
11,049\end{array}$ & $\begin{array}{l}0 \\
0 \\
0\end{array}$ & $\begin{array}{l}3,137 \\
3,518 \\
3,141\end{array}$ & $\begin{array}{l}908 \\
854 \\
864\end{array}$ & $\begin{array}{l}11,715 \\
11,316 \\
11,084\end{array}$ & $\begin{array}{l}0 \\
0 \\
0\end{array}$ & $\begin{array}{l}12,749 \\
12,487 \\
12,073\end{array}$ & $\begin{array}{l}0 \\
0 \\
0\end{array}$ \\
\hline $\begin{array}{l}\text { Montana } \\
\text { Billings } \\
\text { Great Falls } \\
\text { Missoula }\end{array}$ & $\begin{array}{l}16,638 \\
20,870 \\
16,856\end{array}$ & $\begin{array}{l}0 \\
0 \\
0\end{array}$ & $\begin{array}{l}2,009 \\
1,700 \\
1,505\end{array}$ & $\begin{array}{l}1,277 \\
1,476 \\
1,417\end{array}$ & $\begin{array}{l}16,673 \\
20,899 \\
16,895\end{array}$ & $\begin{array}{l}0 \\
0 \\
0\end{array}$ & $\begin{array}{l}17,439 \\
21,526 \\
17,601\end{array}$ & $\begin{array}{l}0 \\
0 \\
0\end{array}$ \\
\hline $\begin{array}{l}\text { Nebraska } \\
\text { Grand Island } \\
\text { Lincoln } \\
\text { North Platte }\end{array}$ & $\begin{array}{l}16,601 \\
16,520 \\
16,699\end{array}$ & $\begin{array}{l}0 \\
0 \\
0\end{array}$ & $\begin{array}{l}2,672 \\
2,489 \\
2,403\end{array}$ & $\begin{array}{l}1,232 \\
1,209 \\
1,281\end{array}$ & $\begin{array}{l}16,650 \\
16,566 \\
16,750\end{array}$ & $\begin{array}{l}0 \\
0 \\
0\end{array}$ & $\begin{array}{l}17,680 \\
17,495 \\
17,744\end{array}$ & $\begin{array}{l}0 \\
0 \\
0\end{array}$ \\
\hline $\begin{array}{l}\text { Nevada } \\
\text { Ely } \\
\text { Las Vegas } \\
\text { Reno } \\
\text { Winnemucca }\end{array}$ & $\begin{array}{r}18,865 \\
9,367 \\
12,163 \\
14,029\end{array}$ & $\begin{array}{l}0 \\
0 \\
0 \\
0\end{array}$ & $\begin{array}{l}2,091 \\
6,709 \\
2,426 \\
2,762\end{array}$ & $\begin{array}{r}1,460 \\
400 \\
1,125 \\
1,161\end{array}$ & $\begin{array}{r}18,913 \\
9,405 \\
12,203 \\
14,072\end{array}$ & $\begin{array}{l}0 \\
0 \\
0 \\
0\end{array}$ & $\begin{array}{l}19,781 \\
11,766 \\
13,015 \\
15,109\end{array}$ & $\begin{array}{l}0 \\
0 \\
0 \\
0\end{array}$ \\
\hline $\begin{array}{l}\text { New Jersey } \\
\text { Trenton }\end{array}$ & 10,754 & 0 & 2,221 & 937 & 10,781 & 0 & 11,460 & 0 \\
\hline $\begin{array}{l}\text { New Mexico } \\
\text { Albuquerque } \\
\text { Farmington } \\
\text { Roswell }\end{array}$ & $\begin{array}{r}8,654 \\
11,886 \\
8,625\end{array}$ & $\begin{array}{l}0 \\
0 \\
0\end{array}$ & $\begin{array}{l}3,261 \\
2,977 \\
4,143\end{array}$ & $\begin{array}{l}703 \\
965 \\
585\end{array}$ & $\begin{array}{r}8,682 \\
11,927 \\
8,656\end{array}$ & $\begin{array}{l}0 \\
0 \\
0\end{array}$ & $\begin{array}{r}9,648 \\
12,908 \\
9,961\end{array}$ & $\begin{array}{l}0 \\
0 \\
0\end{array}$ \\
\hline $\begin{array}{l}\text { New York } \\
\text { Albany } \\
\text { Binghamton } \\
\text { Niagara Falls } \\
\text { Syracuse } \\
\text { Westhampton Beach }\end{array}$ & $\begin{array}{l}16,312 \\
19,084 \\
16,228 \\
15,864 \\
10,781\end{array}$ & $\begin{array}{l}0 \\
0 \\
0 \\
0 \\
0\end{array}$ & $\begin{array}{l}1,668 \\
1,435 \\
1,722 \\
1,748 \\
1,672\end{array}$ & $\begin{array}{c}1,276 \\
1,413 \\
1,323 \\
1,258 \\
989\end{array}$ & $\begin{array}{l}16,349 \\
19,119 \\
16,266 \\
15,900 \\
10,805\end{array}$ & $\begin{array}{l}0 \\
0 \\
0 \\
0 \\
0\end{array}$ & $\begin{array}{l}17,028 \\
19,697 \\
16,936 \\
16,579 \\
11,305\end{array}$ & $\begin{array}{l}0 \\
0 \\
0 \\
0 \\
0\end{array}$ \\
\hline $\begin{array}{l}\text { North Carolina } \\
\text { Greensboro } \\
\text { New Bern }\end{array}$ & $\begin{array}{l}7,990 \\
6,918\end{array}$ & $\begin{array}{l}0 \\
0\end{array}$ & $\begin{array}{l}2,940 \\
4,201\end{array}$ & $\begin{array}{l}641 \\
396\end{array}$ & $\begin{array}{l}8,013 \\
6,937\end{array}$ & $\begin{array}{l}0 \\
0\end{array}$ & $\begin{array}{l}8,821 \\
7,909\end{array}$ & $\begin{array}{l}0 \\
0\end{array}$ \\
\hline
\end{tabular}




\begin{tabular}{|c|c|c|c|c|c|c|c|c|}
\hline \multirow[b]{2}{*}{ State and City } & \multicolumn{2}{|c|}{ Electric Heat Pump } & \multicolumn{2}{|c|}{ Gas Furnace/Electric AC } & \multicolumn{2}{|c|}{ Hydrocarbon Heat Pump } & \multicolumn{2}{|c|}{ Transcritical $\mathrm{CO}_{2}$ Heat Pump } \\
\hline & $(\mathrm{kWh} / \mathrm{y})$ & (therms/y) & $(\mathrm{kWh} / \mathrm{y})$ & (therms/y) & $(\mathrm{kWh} / \mathrm{y})$ & (therms/y) & $(\mathrm{kWh} / \mathrm{y})$ & (therms/y) \\
\hline $\begin{array}{l}\text { North Dakota } \\
\text { Bismarck } \\
\text { Grand Forks } \\
\text { Williston }\end{array}$ & $\begin{array}{l}28,116 \\
33,185 \\
24,514\end{array}$ & $\begin{array}{l}0 \\
0 \\
0\end{array}$ & $\begin{array}{l}2,027 \\
1,818 \\
1,946\end{array}$ & $\begin{array}{l}1,750 \\
1,960 \\
1,584\end{array}$ & $\begin{array}{l}28,162 \\
33,231 \\
24,562\end{array}$ & $\begin{array}{l}0 \\
0 \\
0\end{array}$ & $\begin{array}{l}28,985 \\
33,967 \\
25,370\end{array}$ & $\begin{array}{l}0 \\
0 \\
0\end{array}$ \\
\hline $\begin{array}{l}\text { Ohio } \\
\text { Akron } \\
\text { Columbus } \\
\text { Dayton } \\
\text { Toledo }\end{array}$ & $\begin{array}{l}14,144 \\
10,854 \\
11,849 \\
15,612\end{array}$ & $\begin{array}{l}0 \\
0 \\
0 \\
0\end{array}$ & $\begin{array}{l}1,834 \\
2,295 \\
2,610 \\
2,065\end{array}$ & $\begin{array}{c}1,180 \\
968 \\
967 \\
1,256\end{array}$ & $\begin{array}{l}14,178 \\
10,886 \\
11,883 \\
15,654\end{array}$ & $\begin{array}{l}0 \\
0 \\
0 \\
0\end{array}$ & $\begin{array}{l}14,850 \\
11,656 \\
12,727 \\
16,448\end{array}$ & $\begin{array}{l}0 \\
0 \\
0 \\
0\end{array}$ \\
\hline $\begin{array}{l}\text { Oklahoma } \\
\text { Altus } \\
\text { Oklahoma City } \\
\text { Tulsa }\end{array}$ & $\begin{array}{l}9,230 \\
9,438 \\
9,438\end{array}$ & $\begin{array}{l}0 \\
0\end{array}$ & $\begin{array}{l}4,551 \\
4,037 \\
4,176\end{array}$ & $\begin{array}{l}605 \\
660 \\
645\end{array}$ & $\begin{array}{l}9,265 \\
9,471 \\
9,472\end{array}$ & $\begin{array}{l}0 \\
0\end{array}$ & $\begin{array}{l}10,767 \\
10,718 \\
10,785\end{array}$ & $\begin{array}{l}0 \\
0\end{array}$ \\
\hline $\begin{array}{l}\text { Oregon } \\
\text { Astoria } \\
\text { Medford } \\
\text { Portland }\end{array}$ & $\begin{array}{l}7,220 \\
8,404 \\
7,152\end{array}$ & $\begin{array}{l}0 \\
0 \\
0\end{array}$ & $\begin{array}{r}704 \\
2,567 \\
1,545\end{array}$ & $\begin{array}{l}832 \\
836 \\
806\end{array}$ & $\begin{array}{l}7,212 \\
8,422 \\
7,153\end{array}$ & $\begin{array}{l}0 \\
0 \\
0\end{array}$ & $\begin{array}{l}7,333 \\
9,129 \\
7,468\end{array}$ & $\begin{array}{l}0 \\
0 \\
0\end{array}$ \\
\hline $\begin{array}{l}\text { Pennsylvania } \\
\text { Philadelphia } \\
\text { Pittsburgh } \\
\text { Wilkes-Barre }\end{array}$ & $\begin{array}{l}10,266 \\
13,990 \\
13,310\end{array}$ & $\begin{array}{l}0 \\
0 \\
0\end{array}$ & $\begin{array}{l}2,052 \\
1,798 \\
1,755\end{array}$ & $\begin{array}{r}925 \\
1,154 \\
1,130\end{array}$ & $\begin{array}{l}10,292 \\
14,022 \\
13,343\end{array}$ & $\begin{array}{l}0 \\
0 \\
0\end{array}$ & $\begin{array}{l}10,918 \\
14,666 \\
13,993\end{array}$ & $\begin{array}{l}0 \\
0 \\
0\end{array}$ \\
\hline $\begin{array}{l}\text { South Carolina } \\
\text { Charleston } \\
\text { Greenville } \\
\text { Sumter }\end{array}$ & $\begin{array}{l}6,664 \\
6,930 \\
6,712\end{array}$ & $\begin{array}{l}0 \\
0\end{array}$ & $\begin{array}{l}4,057 \\
3,208 \\
3,914\end{array}$ & $\begin{array}{l}382 \\
518 \\
405\end{array}$ & $\begin{array}{l}6,683 \\
6,949 \\
6,731\end{array}$ & $\begin{array}{l}0 \\
0\end{array}$ & $\begin{array}{l}7,626 \\
7,799 \\
7,702\end{array}$ & $\begin{array}{l}0 \\
0\end{array}$ \\
\hline $\begin{array}{l}\text { South Dakota } \\
\text { Huron } \\
\text { Rapid City }\end{array}$ & $\begin{array}{l}23,699 \\
18,167\end{array}$ & $\begin{array}{l}0 \\
0\end{array}$ & $\begin{array}{l}2,383 \\
2,157\end{array}$ & $\begin{array}{l}1,579 \\
1,305\end{array}$ & $\begin{array}{l}23,755 \\
18,207\end{array}$ & $\begin{array}{l}0 \\
0\end{array}$ & $\begin{array}{l}24,768 \\
19,028\end{array}$ & $\begin{array}{l}0 \\
0\end{array}$ \\
\hline $\begin{array}{l}\text { Teennessee } \\
\text { Bristol } \\
\text { Knoxville } \\
\text { Memphis } \\
\text { Nashville }\end{array}$ & $\begin{array}{l}8,400 \\
7,798 \\
8,333 \\
9,004\end{array}$ & $\begin{array}{l}0 \\
0 \\
0 \\
0\end{array}$ & $\begin{array}{l}2,625 \\
2,835 \\
4,038 \\
3,292\end{array}$ & $\begin{array}{l}700 \\
634 \\
569 \\
686\end{array}$ & $\begin{array}{l}8,423 \\
7,818 \\
8,360 \\
9,032\end{array}$ & $\begin{array}{l}0 \\
0 \\
0 \\
0\end{array}$ & $\begin{array}{l}9,147 \\
8,545 \\
9,516 \\
9,993\end{array}$ & $\begin{array}{l}0 \\
0 \\
0 \\
0\end{array}$ \\
\hline $\begin{array}{l}\text { Texas } \\
\text { El Paso } \\
\text { Fort Worth } \\
\text { Houston } \\
\text { San Antonio }\end{array}$ & $\begin{array}{l}7,716 \\
8,417 \\
7,052 \\
7,286\end{array}$ & $\begin{array}{l}0 \\
0 \\
0 \\
0\end{array}$ & $\begin{array}{l}4,567 \\
5,408 \\
5,551 \\
6,006\end{array}$ & $\begin{array}{l}442 \\
423 \\
228 \\
196\end{array}$ & $\begin{array}{l}7,742 \\
8,447 \\
7,077 \\
7,314\end{array}$ & $\begin{array}{l}0 \\
0 \\
0 \\
0\end{array}$ & $\begin{array}{r}9,038 \\
10,080 \\
8,479 \\
8,993\end{array}$ & $\begin{array}{l}0 \\
0 \\
0 \\
0\end{array}$ \\
\hline $\begin{array}{l}\text { Utah } \\
\text { Salt Lake City }\end{array}$ & 11,880 & 0 & 2,328 & 1,065 & 11,917 & 0 & 12,761 & 0 \\
\hline $\begin{array}{l}\text { Vermont } \\
\text { Burlington }\end{array}$ & 21,493 & 0 & 1,512 & 1,524 & 21,534 & 0 & 22,183 & 0 \\
\hline $\begin{array}{l}\text { Virginia } \\
\text { Norfolk } \\
\text { Richmond } \\
\text { Roanoke }\end{array}$ & $\begin{array}{l}7,640 \\
7,822 \\
8,527\end{array}$ & $\begin{array}{l}0 \\
0 \\
0\end{array}$ & $\begin{array}{l}3,187 \\
3,083 \\
2,705\end{array}$ & $\begin{array}{l}616 \\
635 \\
734\end{array}$ & $\begin{array}{l}7,661 \\
7,844 \\
8,549\end{array}$ & $\begin{array}{l}0 \\
0 \\
0\end{array}$ & $\begin{array}{l}8,450 \\
8,675 \\
9,319\end{array}$ & $\begin{array}{l}0 \\
0 \\
0\end{array}$ \\
\hline $\begin{array}{l}\text { Washington } \\
\text { Moses Lake } \\
\text { Seattle } \\
\text { Spokane }\end{array}$ & $\begin{array}{r}11,411 \\
7,903 \\
13,311\end{array}$ & $\begin{array}{l}0 \\
0 \\
0\end{array}$ & $\begin{array}{l}2,563 \\
1,270 \\
1,764\end{array}$ & $\begin{array}{r}1,036 \\
913 \\
1,253\end{array}$ & $\begin{array}{r}11,446 \\
7,904 \\
13,347\end{array}$ & $\begin{array}{l}0 \\
0 \\
0\end{array}$ & $\begin{array}{r}12,330 \\
8,179 \\
14,038\end{array}$ & $\begin{array}{l}0 \\
0 \\
0\end{array}$ \\
\hline
\end{tabular}




\begin{tabular}{|c|c|c|c|c|c|c|c|c|}
\hline \multirow[b]{2}{*}{ State and City } & \multicolumn{2}{|c|}{ Electric Heat Pump } & \multicolumn{2}{|c|}{ Gas Furnace/Electric AC } & \multicolumn{2}{|c|}{ Hydrocarbon Heat Pump } & \multicolumn{2}{|c|}{ Transcritical $\mathrm{CO}_{2}$ Heat Pump } \\
\hline & $(\mathrm{kWh} / \mathrm{y})$ & (therms/y) & $(\mathrm{kWh} / \mathrm{y})$ & (therms/y) & $(\mathrm{kWh} / \mathrm{y})$ & (therms/y) & $(\mathrm{kWh} / \mathrm{y})$ & (therms/y) \\
\hline $\begin{array}{l}\text { West Virginia } \\
\text { Charleston } \\
\text { Elkins }\end{array}$ & $\begin{array}{r}9,252 \\
12,910\end{array}$ & $\begin{array}{l}0 \\
0\end{array}$ & $\begin{array}{l}2,611 \\
1,640\end{array}$ & $\begin{array}{r}779 \\
1,061\end{array}$ & $\begin{array}{r}9,278 \\
12,935\end{array}$ & $\begin{array}{l}0 \\
0\end{array}$ & $\begin{array}{l}10,054 \\
13,484\end{array}$ & $\begin{array}{l}0 \\
0\end{array}$ \\
\hline $\begin{array}{l}\text { Wisconsin } \\
\text { Green Bay } \\
\text { Madison }\end{array}$ & $\begin{array}{l}21,208 \\
19,252\end{array}$ & $\begin{array}{l}0 \\
0\end{array}$ & $\begin{array}{l}1,632 \\
1,901\end{array}$ & $\begin{array}{l}1,526 \\
1,398\end{array}$ & $\begin{array}{l}21,253 \\
19,295\end{array}$ & $\begin{array}{l}0 \\
0\end{array}$ & $\begin{array}{l}21,957 \\
20,066\end{array}$ & $\begin{array}{l}0 \\
0\end{array}$ \\
\hline $\begin{array}{l}\text { Wyoming } \\
\text { Casper } \\
\text { Cheyenne } \\
\text { Lander } \\
\text { Sheridan }\end{array}$ & $\begin{array}{l}17,654 \\
17,521 \\
17,700 \\
18,088\end{array}$ & $\begin{array}{l}0 \\
0 \\
0 \\
0\end{array}$ & $\begin{array}{l}2,039 \\
1,685 \\
1,736 \\
2,053\end{array}$ & $\begin{array}{l}1,394 \\
1,388 \\
1,360 \\
1,381\end{array}$ & $\begin{array}{l}17,701 \\
17,558 \\
17,750 \\
18,134\end{array}$ & $\begin{array}{l}0 \\
0 \\
0 \\
0\end{array}$ & $\begin{array}{l}18,581 \\
18,244 \\
18,516 \\
19,002\end{array}$ & $\begin{array}{l}0 \\
0 \\
0 \\
0\end{array}$ \\
\hline
\end{tabular}




\begin{tabular}{|c|c|c|c|c|c|c|c|c|}
\hline \multirow[b]{2}{*}{ State and City } & \multicolumn{2}{|c|}{ Brayton Cycle Heat Pump } & \multicolumn{2}{|c|}{ Stirling Cycle Heat Pump } & \multicolumn{2}{|c|}{$\begin{array}{l}\text { Thermoelectric Heat Pump } \\
(\max Z \mathrm{ZT})\end{array}$} & \multicolumn{2}{|c|}{ Thermoacoustic Heat Pump } \\
\hline & $(\mathrm{kWh} / \mathrm{y})$ & (therms/y) & $(\mathrm{kWh} / \mathrm{y})$ & (therms/y) & $(\mathrm{kWh} / \mathrm{y})$ & (therms/y) & $(\mathrm{kWh} / \mathrm{y})$ & (therms/y) \\
\hline $\begin{array}{l}\text { Alabama } \\
\text { Birmingham } \\
\text { Montgomery }\end{array}$ & $\begin{array}{l}19,510 \\
20,655\end{array}$ & $\begin{array}{l}0 \\
0\end{array}$ & $\begin{array}{l}13,006 \\
13,116\end{array}$ & $\begin{array}{l}0 \\
0\end{array}$ & $\begin{array}{l}11,006 \\
10,717\end{array}$ & $\begin{array}{l}0 \\
0\end{array}$ & $\begin{array}{l}9,575 \\
9,269\end{array}$ & $\begin{array}{l}0 \\
0\end{array}$ \\
\hline $\begin{array}{l}\text { Arizona } \\
\text { Phoenix } \\
\text { Tucson } \\
\text { Yuma }\end{array}$ & $\begin{array}{l}27,562 \\
23,649 \\
28,508\end{array}$ & $\begin{array}{l}0 \\
0 \\
0\end{array}$ & $\begin{array}{l}16,001 \\
14,234 \\
16,003\end{array}$ & $\begin{array}{l}0 \\
0 \\
0\end{array}$ & $\begin{array}{l}13,262 \\
11,494 \\
13,211\end{array}$ & $\begin{array}{l}0 \\
0 \\
0\end{array}$ & $\begin{array}{l}12,154 \\
10,135 \\
12,308\end{array}$ & $\begin{array}{l}0 \\
0 \\
0\end{array}$ \\
\hline $\begin{array}{l}\text { Arkansas } \\
\text { Little Rock }\end{array}$ & 20,753 & 0 & 13,805 & 0 & 11,800 & 0 & 10,230 & 0 \\
\hline $\begin{array}{l}\text { California } \\
\text { Arcata } \\
\text { Los Angeles } \\
\text { Merced } \\
\text { Oakland } \\
\text { San Diego }\end{array}$ & $\begin{array}{r}11,287 \\
11,884 \\
18,337 \\
11,326 \\
9,658 \\
\end{array}$ & $\begin{array}{l}0 \\
0 \\
0 \\
0 \\
0\end{array}$ & $\begin{array}{r}9,868 \\
7,868 \\
12,175 \\
8,563 \\
6,475 \\
\end{array}$ & $\begin{array}{l}0 \\
0 \\
0 \\
0 \\
0\end{array}$ & $\begin{array}{r}8,930 \\
5,852 \\
10,184 \\
6,944 \\
4,799\end{array}$ & $\begin{array}{l}0 \\
0 \\
0 \\
0 \\
0\end{array}$ & $\begin{array}{l}7,332 \\
4,568 \\
8,636 \\
5,367 \\
3,690\end{array}$ & $\begin{array}{l}0 \\
0 \\
0 \\
0 \\
0\end{array}$ \\
\hline $\begin{array}{l}\text { Colorado } \\
\text { Colorado Springs } \\
\text { Denver } \\
\text { Grand Junction }\end{array}$ & $\begin{array}{l}24,223 \\
23,848 \\
22,950\end{array}$ & $\begin{array}{l}0 \\
0 \\
0\end{array}$ & $\begin{array}{l}20,212 \\
19,916 \\
17,525\end{array}$ & $\begin{array}{l}0 \\
0 \\
0\end{array}$ & $\begin{array}{l}19,420 \\
19,171 \\
16,432\end{array}$ & $\begin{array}{l}0 \\
0 \\
0\end{array}$ & $\begin{array}{l}17,861 \\
17,661 \\
14,655\end{array}$ & $\begin{array}{l}0 \\
0 \\
0\end{array}$ \\
\hline $\begin{array}{l}\text { Florida } \\
\text { Appalachicola } \\
\text { Jacksonville } \\
\text { Miami } \\
\text { Orlando } \\
\text { Tampa }\end{array}$ & $\begin{array}{l}21,404 \\
21,074 \\
25,947 \\
21,518 \\
23,400\end{array}$ & $\begin{array}{l}0 \\
0 \\
0 \\
0 \\
0\end{array}$ & $\begin{array}{l}12,745 \\
12,551 \\
14,392 \\
12,456 \\
13,280\end{array}$ & $\begin{array}{l}0 \\
0 \\
0 \\
0 \\
0\end{array}$ & $\begin{array}{r}9,696 \\
9,677 \\
10,408 \\
9,259 \\
9,830\end{array}$ & $\begin{array}{l}0 \\
0 \\
0 \\
0 \\
0\end{array}$ & $\begin{array}{l}8,410 \\
8,482 \\
9,280 \\
8,087 \\
8,726\end{array}$ & $\begin{array}{l}0 \\
0 \\
0 \\
0 \\
0\end{array}$ \\
\hline $\begin{array}{l}\text { Georgia } \\
\text { Atlanta } \\
\text { Augusta } \\
\text { Macon }\end{array}$ & $\begin{array}{l}18,454 \\
19,922 \\
20,070\end{array}$ & $\begin{array}{l}0 \\
0 \\
0\end{array}$ & $\begin{array}{l}12,998 \\
13,020 \\
12,857\end{array}$ & $\begin{array}{l}0 \\
0 \\
0\end{array}$ & $\begin{array}{l}11,261 \\
10,876 \\
10,546\end{array}$ & $\begin{array}{l}0 \\
0 \\
0\end{array}$ & $\begin{array}{l}9,780 \\
9,473 \\
9,075\end{array}$ & $\begin{array}{l}0 \\
0 \\
0\end{array}$ \\
\hline $\begin{array}{l}\text { Idaho } \\
\text { Boise } \\
\text { Idaho Falls }\end{array}$ & $\begin{array}{l}22,070 \\
28,770\end{array}$ & $\begin{array}{l}0 \\
0\end{array}$ & $\begin{array}{l}17,511 \\
24,992\end{array}$ & $\begin{array}{l}0 \\
0\end{array}$ & $\begin{array}{l}16,584 \\
24,508\end{array}$ & $\begin{array}{l}0 \\
0\end{array}$ & $\begin{array}{l}14,570 \\
22,822\end{array}$ & $\begin{array}{l}0 \\
0\end{array}$ \\
\hline $\begin{array}{l}\text { Illinois } \\
\text { Champaigne-Urbana } \\
\text { Chicago } \\
\text { East St. Louis }\end{array}$ & $\begin{array}{l}25,840 \\
25,039 \\
23,363\end{array}$ & $\begin{array}{l}0 \\
0 \\
0\end{array}$ & $\begin{array}{l}21,104 \\
21,142 \\
17,712\end{array}$ & $\begin{array}{l}0 \\
0 \\
0\end{array}$ & $\begin{array}{l}20,283 \\
20,557 \\
16,441\end{array}$ & $\begin{array}{l}0 \\
0 \\
0\end{array}$ & $\begin{array}{l}18,606 \\
18,874 \\
14,637\end{array}$ & $\begin{array}{l}0 \\
0 \\
0\end{array}$ \\
\hline $\begin{array}{l}\text { Indiana } \\
\text { Fort Wayne } \\
\text { South Bend }\end{array}$ & $\begin{array}{l}23,807 \\
24,590\end{array}$ & $\begin{array}{l}0 \\
0\end{array}$ & $\begin{array}{l}19,487 \\
20,440\end{array}$ & $\begin{array}{l}0 \\
0\end{array}$ & $\begin{array}{l}18,736 \\
19,770\end{array}$ & $\begin{array}{l}0 \\
0\end{array}$ & $\begin{array}{l}17,075 \\
18,091\end{array}$ & $\begin{array}{l}0 \\
0\end{array}$ \\
\hline $\begin{array}{l}\text { Iowa } \\
\text { Des Moines } \\
\text { Sioux City }\end{array}$ & $\begin{array}{l}27,451 \\
29,213\end{array}$ & $\begin{array}{l}0 \\
0\end{array}$ & $\begin{array}{l}22,975 \\
24,319\end{array}$ & $\begin{array}{l}0 \\
0\end{array}$ & $\begin{array}{l}22,265 \\
23,667\end{array}$ & $\begin{array}{l}0 \\
0\end{array}$ & $\begin{array}{l}20,798 \\
22,144\end{array}$ & $\begin{array}{l}0 \\
0\end{array}$ \\
\hline $\begin{array}{l}\text { Kansas } \\
\text { Dodge City } \\
\text { Topeka }\end{array}$ & $\begin{array}{l}23,928 \\
24,815\end{array}$ & $\begin{array}{l}0 \\
0\end{array}$ & $\begin{array}{l}18,155 \\
19,154\end{array}$ & $\begin{array}{l}0 \\
0\end{array}$ & $\begin{array}{l}17,034 \\
18,035\end{array}$ & $\begin{array}{l}0 \\
0\end{array}$ & $\begin{array}{l}15,451 \\
16,311\end{array}$ & $\begin{array}{l}0 \\
0\end{array}$ \\
\hline $\begin{array}{l}\text { Kentucky } \\
\text { Louisville }\end{array}$ & 21,641 & 0 & 15,831 & 0 & 14,291 & 0 & 12,576 & 0 \\
\hline
\end{tabular}




\begin{tabular}{|c|c|c|c|c|c|c|c|c|}
\hline \multirow[b]{2}{*}{ State and City } & \multicolumn{2}{|c|}{ Brayton Cycle Heat Pump } & \multicolumn{2}{|c|}{ Stirling Cycle Heat Pump } & \multicolumn{2}{|c|}{$\begin{array}{l}\text { Thermoelectric Heat Pump } \\
(\max Z \mathrm{ZT})\end{array}$} & \multicolumn{2}{|c|}{ Thermoacoustic Heat Pump } \\
\hline & $(\mathrm{kWh} / \mathrm{y})$ & (therms/y) & $(\mathrm{kWh} / \mathrm{y})$ & (therms/y) & $(\mathrm{kWh} / \mathrm{y})$ & (therms/y) & $(\mathrm{kWh} / \mathrm{y})$ & (therms/y) \\
\hline $\begin{array}{l}\text { Louisiana } \\
\text { Lake Charles } \\
\text { New Orleans } \\
\text { Shreveport }\end{array}$ & $\begin{array}{l}21,114 \\
19,843 \\
21,240\end{array}$ & $\begin{array}{l}0 \\
0 \\
0\end{array}$ & $\begin{array}{l}12,809 \\
11,915 \\
13,655\end{array}$ & $\begin{array}{l}0 \\
0 \\
0\end{array}$ & $\begin{array}{r}10,017 \\
9,185 \\
11,342\end{array}$ & $\begin{array}{l}0 \\
0 \\
0\end{array}$ & $\begin{array}{l}8,742 \\
7,960 \\
9,869\end{array}$ & $\begin{array}{l}0 \\
0 \\
0\end{array}$ \\
\hline $\begin{array}{l}\text { Maine } \\
\text { Portland }\end{array}$ & 25,731 & 0 & 22,423 & 0 & 21,893 & 0 & 20,189 & 0 \\
\hline $\begin{array}{l}\text { Massachusetts } \\
\text { Falmouth }\end{array}$ & 20,691 & 0 & 17,655 & 0 & 16,879 & 0 & 15,273 & 0 \\
\hline $\begin{array}{l}\text { Michigan } \\
\text { Battle Creek } \\
\text { Detroit } \\
\text { Sault Ste Marie }\end{array}$ & $\begin{array}{l}24,284 \\
25,274 \\
34,486\end{array}$ & $\begin{array}{l}0 \\
0 \\
0\end{array}$ & $\begin{array}{l}20,287 \\
21,348 \\
31,720\end{array}$ & $\begin{array}{l}0 \\
0 \\
0\end{array}$ & $\begin{array}{l}19,786 \\
20,802 \\
31,540\end{array}$ & $\begin{array}{l}0 \\
0 \\
0\end{array}$ & $\begin{array}{l}18,114 \\
19,112 \\
30,187\end{array}$ & $\begin{array}{l}0 \\
0 \\
0\end{array}$ \\
\hline $\begin{array}{l}\text { Minnesota } \\
\text { Duluth } \\
\text { International Falls } \\
\text { Minneapolis }\end{array}$ & $\begin{array}{l}38,930 \\
41,829 \\
31,641\end{array}$ & $\begin{array}{l}0 \\
0 \\
0\end{array}$ & $\begin{array}{l}36,289 \\
39,277 \\
27,758\end{array}$ & $\begin{array}{l}0 \\
0 \\
0\end{array}$ & $\begin{array}{l}36,124 \\
39,127 \\
27,373\end{array}$ & $\begin{array}{l}0 \\
0 \\
0\end{array}$ & $\begin{array}{l}34,895 \\
38,063 \\
26,000\end{array}$ & $\begin{array}{l}0 \\
0 \\
0\end{array}$ \\
\hline $\begin{array}{l}\text { Mississippi } \\
\text { Biloxi } \\
\text { Columbus } \\
\text { Jackson }\end{array}$ & $\begin{array}{l}20,610 \\
20,693 \\
20,592\end{array}$ & $\begin{array}{l}0 \\
0 \\
0\end{array}$ & $\begin{array}{l}12,501 \\
13,784 \\
13,260\end{array}$ & $\begin{array}{l}0 \\
0 \\
0\end{array}$ & $\begin{array}{r}9,791 \\
11,725 \\
10,970\end{array}$ & $\begin{array}{l}0 \\
0 \\
0\end{array}$ & $\begin{array}{r}8,539 \\
10,286 \\
9,501\end{array}$ & $\begin{array}{l}0 \\
0 \\
0\end{array}$ \\
\hline $\begin{array}{l}\text { Missouri } \\
\text { Columbia } \\
\text { Kansas City } \\
\text { Springfield }\end{array}$ & $\begin{array}{l}23,443 \\
23,595 \\
22,740\end{array}$ & $\begin{array}{l}0 \\
0 \\
0\end{array}$ & $\begin{array}{l}17,827 \\
17,511 \\
17,143\end{array}$ & $\begin{array}{l}0 \\
0 \\
0\end{array}$ & $\begin{array}{l}16,566 \\
16,192 \\
15,807\end{array}$ & $\begin{array}{l}0 \\
0 \\
0\end{array}$ & $\begin{array}{l}14,895 \\
14,462 \\
14,175\end{array}$ & $\begin{array}{l}0 \\
0 \\
0\end{array}$ \\
\hline $\begin{array}{l}\text { Montana } \\
\text { Billings } \\
\text { Great Falls } \\
\text { Missoula }\end{array}$ & $\begin{array}{l}26,478 \\
30,134 \\
26,642\end{array}$ & $\begin{array}{l}0 \\
0 \\
0\end{array}$ & $\begin{array}{l}22,458 \\
26,564 \\
23,010\end{array}$ & $\begin{array}{l}0 \\
0 \\
0\end{array}$ & $\begin{array}{l}21,735 \\
25,800 \\
22,493\end{array}$ & $\begin{array}{l}0 \\
0 \\
0\end{array}$ & $\begin{array}{l}20,039 \\
24,182 \\
20,665\end{array}$ & $\begin{array}{l}0 \\
0 \\
0\end{array}$ \\
\hline $\begin{array}{l}\text { Nebraska } \\
\text { Grand Island } \\
\text { Lincoln } \\
\text { North Platte }\end{array}$ & $\begin{array}{l}27,446 \\
26,710 \\
27,059\end{array}$ & $\begin{array}{l}0 \\
0 \\
0\end{array}$ & $\begin{array}{l}22,547 \\
22,174 \\
22,551\end{array}$ & $\begin{array}{l}0 \\
0 \\
0\end{array}$ & $\begin{array}{l}21,866 \\
21,515 \\
22,075\end{array}$ & $\begin{array}{l}0 \\
0 \\
0\end{array}$ & $\begin{array}{l}20,297 \\
19,996 \\
20,482\end{array}$ & $\begin{array}{l}0 \\
0 \\
0\end{array}$ \\
\hline $\begin{array}{l}\text { Nevada } \\
\text { Ely } \\
\text { Las Vegas } \\
\text { Reno } \\
\text { Winnemucca }\end{array}$ & $\begin{array}{l}29,360 \\
26,060 \\
23,261 \\
25,575\end{array}$ & $\begin{array}{l}0 \\
0 \\
0 \\
0\end{array}$ & $\begin{array}{l}25,122 \\
15,937 \\
18,747 \\
20,488\end{array}$ & $\begin{array}{l}0 \\
0 \\
0 \\
0\end{array}$ & $\begin{array}{l}24,606 \\
13,661 \\
17,883 \\
19,616\end{array}$ & $\begin{array}{l}0 \\
0 \\
0 \\
0\end{array}$ & $\begin{array}{l}22,835 \\
12,355 \\
15,679 \\
17,748\end{array}$ & $\begin{array}{l}0 \\
0 \\
0 \\
0\end{array}$ \\
\hline $\begin{array}{l}\text { New Jersey } \\
\text { Trenton }\end{array}$ & 20,581 & 0 & 16,382 & 0 & 15,329 & 0 & 13,729 & 0 \\
\hline $\begin{array}{l}\text { New Mexico } \\
\text { Albuquerque } \\
\text { Farmington } \\
\text { Roswell }\end{array}$ & $\begin{array}{l}20,334 \\
23,491 \\
21,472\end{array}$ & $\begin{array}{l}0 \\
0 \\
0\end{array}$ & $\begin{array}{l}14,658 \\
18,120 \\
14,636\end{array}$ & $\begin{array}{l}0 \\
0 \\
0\end{array}$ & $\begin{array}{l}13,125 \\
16,999 \\
12,890\end{array}$ & $\begin{array}{l}0 \\
0 \\
0\end{array}$ & $\begin{array}{l}11,426 \\
15,220 \\
11,351\end{array}$ & $\begin{array}{l}0 \\
0 \\
0\end{array}$ \\
\hline $\begin{array}{l}\text { New York } \\
\text { Albany } \\
\text { Binghamton } \\
\text { Niagara Falls } \\
\text { Syracuse } \\
\text { Westhampton Beach }\end{array}$ & $\begin{array}{l}25,149 \\
27,349 \\
25,448 \\
24,961 \\
19,814\end{array}$ & $\begin{array}{l}0 \\
0 \\
0 \\
0 \\
0\end{array}$ & $\begin{array}{l}21,676 \\
24,270 \\
21,910 \\
21,359 \\
16,312\end{array}$ & $\begin{array}{l}0 \\
0 \\
0 \\
0 \\
0\end{array}$ & $\begin{array}{l}21,173 \\
23,839 \\
21,386 \\
20,782 \\
15,393\end{array}$ & $\begin{array}{l}0 \\
0 \\
0 \\
0 \\
0\end{array}$ & $\begin{array}{l}19,671 \\
22,409 \\
19,785 \\
19,245 \\
13,658\end{array}$ & $\begin{array}{l}0 \\
0 \\
0 \\
0 \\
0\end{array}$ \\
\hline
\end{tabular}




\begin{tabular}{|c|c|c|c|c|c|c|c|c|}
\hline \multirow[b]{2}{*}{ State and City } & \multicolumn{2}{|c|}{ Brayton Cycle Heat Pump } & \multicolumn{2}{|c|}{ Stirling Cycle Heat Pump } & \multicolumn{2}{|c|}{$\begin{array}{l}\text { Thermoelectric Heat Pump } \\
(\max Z \mathrm{ZT})\end{array}$} & \multicolumn{2}{|c|}{ Thermoacoustic Heat Pump } \\
\hline & $(\mathrm{kWh} / \mathrm{y})$ & (therms/y) & $(\mathrm{kWh} / \mathrm{y})$ & (therms/y) & $(\mathrm{kWh} / \mathrm{y})$ & (therms/y) & $(\mathrm{kWh} / \mathrm{y})$ & (therms/y) \\
\hline $\begin{array}{l}\text { North Carolina } \\
\text { Greensboro } \\
\text { New Bern }\end{array}$ & $\begin{array}{l}18,785 \\
20,187\end{array}$ & $\begin{array}{l}0 \\
0\end{array}$ & $\begin{array}{l}13,568 \\
13,094\end{array}$ & $\begin{array}{l}0 \\
0\end{array}$ & $\begin{array}{l}12,019 \\
10,628\end{array}$ & $\begin{array}{l}0 \\
0\end{array}$ & $\begin{array}{r}10,488 \\
9,032\end{array}$ & $\begin{array}{l}0 \\
0\end{array}$ \\
\hline $\begin{array}{l}\text { North Dakota } \\
\text { Bismarck } \\
\text { Grand Forks } \\
\text { Williston }\end{array}$ & $\begin{array}{l}37,323 \\
41,658 \\
33,579\end{array}$ & $\begin{array}{l}0 \\
0 \\
0\end{array}$ & $\begin{array}{l}33,469 \\
38,213 \\
29,767\end{array}$ & $\begin{array}{l}0 \\
0 \\
0\end{array}$ & $\begin{array}{l}33,070 \\
37,945 \\
29,410\end{array}$ & $\begin{array}{l}0 \\
0 \\
0\end{array}$ & $\begin{array}{l}31,787 \\
36,813 \\
28,091\end{array}$ & $\begin{array}{l}0 \\
0 \\
0\end{array}$ \\
\hline $\begin{array}{l}\text { Ohio } \\
\text { Akron } \\
\text { Columbus } \\
\text { Dayton } \\
\text { Toledo }\end{array}$ & $\begin{array}{l}23,451 \\
21,193 \\
22,700 \\
25,546\end{array}$ & $\begin{array}{l}0 \\
0 \\
0 \\
0\end{array}$ & $\begin{array}{l}19,741 \\
16,746 \\
17,807 \\
21,462\end{array}$ & $\begin{array}{l}0 \\
0 \\
0 \\
0\end{array}$ & $\begin{array}{l}19,071 \\
15,734 \\
16,668 \\
20,849\end{array}$ & $\begin{array}{l}0 \\
0 \\
0 \\
0\end{array}$ & $\begin{array}{l}17,495 \\
14,016 \\
15,020 \\
19,203\end{array}$ & $\begin{array}{l}0 \\
0 \\
0 \\
0\end{array}$ \\
\hline $\begin{array}{l}\text { Oklahoma } \\
\text { Altus } \\
\text { Oklahoma City } \\
\text { Tulsa }\end{array}$ & $\begin{array}{l}22,864 \\
22,423 \\
22,626\end{array}$ & $\begin{array}{l}0 \\
0\end{array}$ & $\begin{array}{l}15,456 \\
15,651 \\
15,666\end{array}$ & $\begin{array}{l}0 \\
0\end{array}$ & $\begin{array}{l}13,685 \\
13,917 \\
13,914\end{array}$ & $\begin{array}{l}0 \\
0\end{array}$ & $\begin{array}{l}12,176 \\
12,312 \\
12,328\end{array}$ & $\begin{array}{l}0 \\
0\end{array}$ \\
\hline $\begin{array}{l}\text { Oregon } \\
\text { Astoria } \\
\text { Medford } \\
\text { Portland }\end{array}$ & $\begin{array}{l}13,814 \\
19,246 \\
16,005\end{array}$ & $\begin{array}{l}0 \\
0 \\
0\end{array}$ & $\begin{array}{l}11,935 \\
14,672 \\
12,859\end{array}$ & $\begin{array}{l}0 \\
0 \\
0\end{array}$ & $\begin{array}{l}10,886 \\
13,277 \\
11,516\end{array}$ & $\begin{array}{l}0 \\
0 \\
0\end{array}$ & $\begin{array}{r}9,238 \\
11,165 \\
9,380\end{array}$ & $\begin{array}{l}0 \\
0 \\
0\end{array}$ \\
\hline $\begin{array}{l}\text { Pennsylvania } \\
\text { Philadelphia } \\
\text { Pittsburgh } \\
\text { Wilkes-Barre }\end{array}$ & $\begin{array}{l}19,805 \\
23,062 \\
22,349\end{array}$ & $\begin{array}{l}0 \\
0 \\
0\end{array}$ & $\begin{array}{l}15,805 \\
19,448 \\
18,769\end{array}$ & $\begin{array}{l}0 \\
0 \\
0\end{array}$ & $\begin{array}{l}14,791 \\
18,753 \\
18,122\end{array}$ & $\begin{array}{l}0 \\
0 \\
0\end{array}$ & $\begin{array}{l}13,168 \\
17,209 \\
16,533\end{array}$ & $\begin{array}{l}0 \\
0 \\
0\end{array}$ \\
\hline $\begin{array}{l}\text { South Carolina } \\
\text { Charleston } \\
\text { Greenville } \\
\text { Sumter }\end{array}$ & $\begin{array}{l}19,423 \\
17,789 \\
19,004\end{array}$ & $\begin{array}{l}0 \\
0\end{array}$ & $\begin{array}{l}12,580 \\
12,338 \\
12,447\end{array}$ & $\begin{array}{l}0 \\
0\end{array}$ & $\begin{array}{l}10,213 \\
10,628 \\
10,271\end{array}$ & $\begin{array}{l}0 \\
0\end{array}$ & $\begin{array}{l}8,754 \\
9,114 \\
8,806\end{array}$ & $\begin{array}{l}0 \\
0\end{array}$ \\
\hline $\begin{array}{l}\text { South Dakota } \\
\text { Huron } \\
\text { Rapid City }\end{array}$ & $\begin{array}{l}33,850 \\
27,914\end{array}$ & $\begin{array}{l}0 \\
0\end{array}$ & $\begin{array}{l}29,400 \\
23,770\end{array}$ & $\begin{array}{l}0 \\
0\end{array}$ & $\begin{array}{l}29,056 \\
23,120\end{array}$ & $\begin{array}{l}0 \\
0\end{array}$ & $\begin{array}{l}27,664 \\
21,594\end{array}$ & $\begin{array}{l}0 \\
0\end{array}$ \\
\hline $\begin{array}{l}\text { Teennessee } \\
\text { Bristol } \\
\text { Knoxville } \\
\text { Memphis } \\
\text { Nashville }\end{array}$ & $\begin{array}{l}18,686 \\
18,506 \\
21,280 \\
20,586\end{array}$ & $\begin{array}{l}0 \\
0 \\
0 \\
0\end{array}$ & $\begin{array}{l}13,895 \\
13,414 \\
14,503 \\
14,861\end{array}$ & $\begin{array}{l}0 \\
0 \\
0 \\
0\end{array}$ & $\begin{array}{l}12,500 \\
11,795 \\
12,562 \\
13,289\end{array}$ & $\begin{array}{l}0 \\
0 \\
0 \\
0\end{array}$ & $\begin{array}{l}10,917 \\
10,137 \\
10,924 \\
11,693\end{array}$ & $\begin{array}{l}0 \\
0 \\
0 \\
0\end{array}$ \\
\hline $\begin{array}{l}\text { Texas } \\
\text { El Paso } \\
\text { Fort Worth } \\
\text { Houston } \\
\text { San Antonio }\end{array}$ & $\begin{array}{l}21,268 \\
23,641 \\
22,495 \\
23,187\end{array}$ & $\begin{array}{l}0 \\
0 \\
0 \\
0\end{array}$ & $\begin{array}{l}13,812 \\
14,958 \\
13,451 \\
13,585\end{array}$ & $\begin{array}{l}0 \\
0 \\
0 \\
0\end{array}$ & $\begin{array}{l}11,612 \\
12,544 \\
10,495 \\
10,684\end{array}$ & $\begin{array}{l}0 \\
0 \\
0 \\
0\end{array}$ & $\begin{array}{r}10,110 \\
11,024 \\
9,284 \\
9,626\end{array}$ & $\begin{array}{l}0 \\
0 \\
0 \\
0\end{array}$ \\
\hline $\begin{array}{l}\text { Utah } \\
\text { Salt Lake City }\end{array}$ & 22,488 & 0 & 17,995 & 0 & 17,128 & 0 & 15,313 & 0 \\
\hline $\begin{array}{l}\text { Vermont } \\
\text { Burlington }\end{array}$ & 30,023 & 0 & 26,786 & 0 & 26,444 & 0 & 25,000 & 0 \\
\hline $\begin{array}{l}\text { Virginia } \\
\text { Norfolk } \\
\text { Richmond } \\
\text { Roanoke }\end{array}$ & $\begin{array}{l}19,112 \\
18,945 \\
19,094\end{array}$ & $\begin{array}{l}0 \\
0 \\
0\end{array}$ & $\begin{array}{l}13,574 \\
13,579 \\
14,220\end{array}$ & $\begin{array}{l}0 \\
0 \\
0\end{array}$ & $\begin{array}{l}11,793 \\
11,963 \\
12,813\end{array}$ & $\begin{array}{l}0 \\
0 \\
0\end{array}$ & $\begin{array}{l}10,060 \\
10,303 \\
11,161\end{array}$ & $\begin{array}{l}0 \\
0 \\
0\end{array}$ \\
\hline
\end{tabular}




\begin{tabular}{|c|c|c|c|c|c|c|c|c|}
\hline \multirow[b]{2}{*}{ State and City } & \multicolumn{2}{|c|}{ Brayton Cycle Heat Pump } & \multicolumn{2}{|c|}{ Stirling Cycle Heat Pump } & \multicolumn{2}{|c|}{$\begin{array}{l}\text { Thermoelectric Heat Pump } \\
(\max Z \mathrm{ZT})\end{array}$} & \multicolumn{2}{|c|}{ Thermoacoustic Heat Pump } \\
\hline & $(\mathrm{kWh} / \mathrm{y})$ & (therms/y) & $(\mathrm{kWh} / \mathrm{y})$ & (therms/y) & $(\mathrm{kWh} / \mathrm{y})$ & (therms/y) & $(\mathrm{kWh} / \mathrm{y})$ & (therms/y) \\
\hline $\begin{array}{l}\text { Washington } \\
\text { Moses Lake } \\
\text { Seattle } \\
\text { Spokane }\end{array}$ & $\begin{array}{l}22,584 \\
16,256 \\
23,567\end{array}$ & $\begin{array}{l}0 \\
0 \\
0\end{array}$ & $\begin{array}{l}17,829 \\
13,525 \\
19,714\end{array}$ & $\begin{array}{l}0 \\
0 \\
0\end{array}$ & $\begin{array}{l}16,844 \\
12,353 \\
19,016\end{array}$ & $\begin{array}{l}0 \\
0 \\
0\end{array}$ & $\begin{array}{l}14,756 \\
10,368 \\
16,992\end{array}$ & $\begin{array}{l}0 \\
0 \\
0\end{array}$ \\
\hline $\begin{array}{l}\text { West Virginia } \\
\text { Charleston } \\
\text { Elkins }\end{array}$ & $\begin{array}{l}19,700 \\
21,527\end{array}$ & $\begin{array}{l}0 \\
0\end{array}$ & $\begin{array}{l}14,893 \\
18,113\end{array}$ & $\begin{array}{l}0 \\
0\end{array}$ & $\begin{array}{l}13,601 \\
17,306\end{array}$ & $\begin{array}{l}0 \\
0\end{array}$ & $\begin{array}{l}11,993 \\
15,825\end{array}$ & $\begin{array}{l}0 \\
0\end{array}$ \\
\hline $\begin{array}{l}\text { Wisconsin } \\
\text { Green Bay } \\
\text { Madison }\end{array}$ & $\begin{array}{l}30,141 \\
28,577\end{array}$ & $\begin{array}{l}0 \\
0\end{array}$ & $\begin{array}{l}26,670 \\
24,744\end{array}$ & $\begin{array}{l}0 \\
0\end{array}$ & $\begin{array}{l}26,327 \\
24,249\end{array}$ & $\begin{array}{l}0 \\
0\end{array}$ & $\begin{array}{l}24,887 \\
22,840\end{array}$ & $\begin{array}{l}0 \\
0\end{array}$ \\
\hline $\begin{array}{l}\text { Wyoming } \\
\text { Casper } \\
\text { Cheyenne } \\
\text { Lander } \\
\text { Sheridan }\end{array}$ & $\begin{array}{l}27,757 \\
27,050 \\
27,004 \\
28,091\end{array}$ & $\begin{array}{l}0 \\
0 \\
0 \\
0\end{array}$ & $\begin{array}{l}23,653 \\
23,409 \\
23,293 \\
23,973\end{array}$ & $\begin{array}{l}0 \\
0 \\
0 \\
0\end{array}$ & $\begin{array}{l}23,210 \\
22,827 \\
22,971 \\
23,483\end{array}$ & $\begin{array}{l}0 \\
0 \\
0 \\
0\end{array}$ & $\begin{array}{l}21,534 \\
21,125 \\
21,382 \\
21,860\end{array}$ & $\begin{array}{l}0 \\
0 \\
0 \\
0\end{array}$ \\
\hline
\end{tabular}




\begin{tabular}{|c|c|c|c|c|c|c|c|c|}
\hline \multirow[b]{2}{*}{ State and City } & \multicolumn{2}{|c|}{ Pulse Tube Heat Pump } & \multicolumn{2}{|c|}{$\begin{array}{l}\text { Magnetic Heat Pump } \\
\text { (1/4 HP Pump) }\end{array}$} & \multicolumn{2}{|c|}{$\begin{array}{c}\text { Compressor Driven Metal } \\
\text { Hydride HP }\end{array}$} & \multicolumn{2}{|c|}{$\begin{array}{c}\text { Diesel Engine Driven Heat } \\
\text { Pump }\end{array}$} \\
\hline & $(\mathrm{kWh} / \mathrm{y})$ & (therms/y) & $(\mathrm{kWh} / \mathrm{y})$ & (therms/y) & $(\mathrm{kWh} / \mathrm{y})$ & (therms/y) & $(\mathrm{kWh} / \mathrm{y})$ & (therms/y) \\
\hline $\begin{array}{l}\text { Alabama } \\
\text { Birmingham } \\
\text { Montgomery }\end{array}$ & $\begin{array}{l}46,377 \\
50,777\end{array}$ & $\begin{array}{l}0 \\
0\end{array}$ & $\begin{array}{l}6,446 \\
6,322\end{array}$ & $\begin{array}{l}0 \\
0\end{array}$ & $\begin{array}{l}8,361 \\
7,728\end{array}$ & $\begin{array}{l}0 \\
0\end{array}$ & $\begin{array}{l}917 \\
958\end{array}$ & $\begin{array}{l}546 \\
563\end{array}$ \\
\hline $\begin{array}{l}\text { Arizona } \\
\text { Phoenix } \\
\text { Tucson } \\
\text { Yuma }\end{array}$ & $\begin{array}{l}68,022 \\
58,805 \\
70,980\end{array}$ & $\begin{array}{l}0 \\
0 \\
0\end{array}$ & $\begin{array}{l}8,777 \\
7,165 \\
9,014\end{array}$ & $\begin{array}{l}0 \\
0 \\
0\end{array}$ & $\begin{array}{l}9,468 \\
8,022 \\
9,385\end{array}$ & $\begin{array}{l}0 \\
0 \\
0\end{array}$ & $\begin{array}{l}1,314 \\
1,099 \\
1,357\end{array}$ & $\begin{array}{l}827 \\
660 \\
865\end{array}$ \\
\hline $\begin{array}{l}\text { Arkansas } \\
\text { Little Rock }\end{array}$ & 48,795 & 0 & 6,832 & 0 & 8,882 & 0 & 981 & 593 \\
\hline $\begin{array}{l}\text { California } \\
\text { Arcata } \\
\text { Los Angeles } \\
\text { Merced } \\
\text { Oakland } \\
\text { San Diego }\end{array}$ & $\begin{array}{l}20,119 \\
29,583 \\
42,765 \\
24,641 \\
23,773\end{array}$ & $\begin{array}{l}0 \\
0 \\
0 \\
0 \\
0\end{array}$ & $\begin{array}{l}5,226 \\
3,173 \\
5,962 \\
3,768 \\
2,574\end{array}$ & $\begin{array}{l}0 \\
0 \\
0 \\
0 \\
0\end{array}$ & $\begin{array}{l}6,789 \\
3,644 \\
7,185 \\
4,517 \\
2,935\end{array}$ & $\begin{array}{l}0 \\
0 \\
0 \\
0 \\
0\end{array}$ & $\begin{array}{l}560 \\
513 \\
860 \\
518 \\
413\end{array}$ & $\begin{array}{l}305 \\
266 \\
495 \\
284 \\
227\end{array}$ \\
\hline $\begin{array}{l}\text { Colorado } \\
\text { Colorado Springs } \\
\text { Denver } \\
\text { Grand Junction }\end{array}$ & $\begin{array}{l}44,685 \\
43,624 \\
47,630\end{array}$ & $\begin{array}{l}0 \\
0 \\
0\end{array}$ & $\begin{array}{r}13,063 \\
12,997 \\
9,611\end{array}$ & $\begin{array}{l}0 \\
0 \\
0\end{array}$ & $\begin{array}{l}17,896 \\
17,647 \\
14,331\end{array}$ & $\begin{array}{l}0 \\
0 \\
0\end{array}$ & $\begin{array}{l}1,094 \\
1,074 \\
1,091\end{array}$ & $\begin{array}{l}754 \\
750 \\
685\end{array}$ \\
\hline $\begin{array}{l}\text { Florida } \\
\text { Appalachicola } \\
\text { Jacksonville } \\
\text { Miami } \\
\text { Orlando } \\
\text { Tampa }\end{array}$ & $\begin{array}{l}56,381 \\
55,196 \\
72,050 \\
57,866 \\
63,641\end{array}$ & $\begin{array}{l}0 \\
0 \\
0 \\
0 \\
0\end{array}$ & $\begin{array}{l}5,839 \\
5,894 \\
6,506 \\
5,654 \\
6,140\end{array}$ & $\begin{array}{l}0 \\
0 \\
0 \\
0 \\
0\end{array}$ & $\begin{array}{l}6,640 \\
6,737 \\
7,020 \\
6,250 \\
6,680\end{array}$ & $\begin{array}{l}0 \\
0 \\
0 \\
0 \\
0\end{array}$ & $\begin{array}{r}974 \\
970 \\
1,170 \\
973 \\
1,066\end{array}$ & $\begin{array}{l}554 \\
557 \\
658 \\
550 \\
604\end{array}$ \\
\hline $\begin{array}{l}\text { Georgia } \\
\text { Atlanta } \\
\text { Augusta } \\
\text { Macon }\end{array}$ & $\begin{array}{l}42,288 \\
48,249 \\
48,978\end{array}$ & $\begin{array}{l}0 \\
0 \\
0\end{array}$ & $\begin{array}{l}6,567 \\
6,389 \\
6,150\end{array}$ & $\begin{array}{l}0 \\
0 \\
0\end{array}$ & $\begin{array}{l}8,868 \\
8,136 \\
7,613\end{array}$ & $\begin{array}{l}0 \\
0 \\
0\end{array}$ & $\begin{array}{l}871 \\
941 \\
928\end{array}$ & $\begin{array}{l}525 \\
556 \\
547\end{array}$ \\
\hline $\begin{array}{l}\text { Idaho } \\
\text { Boise } \\
\text { Idaho Falls }\end{array}$ & $\begin{array}{l}43,837 \\
49,338\end{array}$ & $\begin{array}{l}0 \\
0\end{array}$ & $\begin{array}{r}9,488 \\
17,089\end{array}$ & $\begin{array}{l}0 \\
0\end{array}$ & $\begin{array}{l}14,307 \\
23,189\end{array}$ & $\begin{array}{l}0 \\
0\end{array}$ & $\begin{array}{l}1,061 \\
1,268\end{array}$ & $\begin{array}{l}669 \\
918\end{array}$ \\
\hline $\begin{array}{l}\text { Illinois } \\
\text { Champaigne-Urbana } \\
\text { Chicago } \\
\text { East St. Louis }\end{array}$ & $\begin{array}{l}48,769 \\
45,141 \\
48,537\end{array}$ & $\begin{array}{l}0 \\
0 \\
0\end{array}$ & $\begin{array}{r}13,240 \\
13,577 \\
9,813\end{array}$ & $\begin{array}{l}0 \\
0 \\
0\end{array}$ & $\begin{array}{l}18,612 \\
19,025 \\
14,157\end{array}$ & $\begin{array}{l}0 \\
0 \\
0\end{array}$ & $\begin{array}{l}1,173 \\
1,142 \\
1,087\end{array}$ & $\begin{array}{l}802 \\
790 \\
718\end{array}$ \\
\hline $\begin{array}{l}\text { Indiana } \\
\text { Fort Wayne } \\
\text { South Bend }\end{array}$ & $\begin{array}{l}45,336 \\
45,657\end{array}$ & $\begin{array}{l}0 \\
0\end{array}$ & $\begin{array}{l}11,914 \\
12,795\end{array}$ & $\begin{array}{l}0 \\
0\end{array}$ & $\begin{array}{l}17,119 \\
18,230\end{array}$ & $\begin{array}{l}0 \\
0\end{array}$ & $\begin{array}{l}1,107 \\
1,131\end{array}$ & $\begin{array}{l}733 \\
761\end{array}$ \\
\hline $\begin{array}{l}\text { Iowa } \\
\text { Des Moines } \\
\text { Sioux City }\end{array}$ & $\begin{array}{l}49,306 \\
52,568\end{array}$ & $\begin{array}{l}0 \\
0\end{array}$ & $\begin{array}{l}15,617 \\
16,469\end{array}$ & $\begin{array}{l}0 \\
0\end{array}$ & $\begin{array}{l}20,854 \\
22,242\end{array}$ & $\begin{array}{l}0 \\
0\end{array}$ & $\begin{array}{l}1,206 \\
1,283\end{array}$ & $\begin{array}{l}871 \\
929\end{array}$ \\
\hline $\begin{array}{l}\text { Kansas } \\
\text { Dodge City } \\
\text { Topeka }\end{array}$ & $\begin{array}{l}49,381 \\
50,082\end{array}$ & $\begin{array}{l}0 \\
0\end{array}$ & $\begin{array}{l}10,546 \\
11,205\end{array}$ & $\begin{array}{l}0 \\
0\end{array}$ & $\begin{array}{l}15,009 \\
15,962\end{array}$ & $\begin{array}{l}0 \\
0\end{array}$ & $\begin{array}{l}1,126 \\
1,142\end{array}$ & $\begin{array}{l}751 \\
736\end{array}$ \\
\hline $\begin{array}{l}\text { Kentucky } \\
\text { Louisville }\end{array}$ & 47,336 & 0 & 8,328 & 0 & 11,848 & 0 & 1,025 & 622 \\
\hline
\end{tabular}




\begin{tabular}{|c|c|c|c|c|c|c|c|c|}
\hline \multirow[b]{2}{*}{ State and City } & \multicolumn{2}{|c|}{ Pulse Tube Heat Pump } & \multicolumn{2}{|c|}{$\begin{array}{l}\text { Magnetic Heat Pump } \\
\text { (1/4 HP Pump) }\end{array}$} & \multicolumn{2}{|c|}{$\begin{array}{c}\text { Compressor Driven Metal } \\
\text { Hydride HP }\end{array}$} & \multicolumn{2}{|c|}{$\begin{array}{c}\text { Diesel Engine Driven Heat } \\
\text { Pump }\end{array}$} \\
\hline & $(\mathrm{kWh} / \mathrm{y})$ & (therms/y) & $(\mathrm{kWh} / \mathrm{y})$ & (therms/y) & $(\mathrm{kWh} / \mathrm{y})$ & (therms/y) & $(\mathrm{kWh} / \mathrm{y})$ & (therms/y) \\
\hline $\begin{array}{l}\text { Louisiana } \\
\text { Lake Charles } \\
\text { New Orleans } \\
\text { Shreveport }\end{array}$ & $\begin{array}{l}54,476 \\
51,539 \\
51,589\end{array}$ & $\begin{array}{l}0 \\
0 \\
0\end{array}$ & $\begin{array}{l}6,070 \\
5,539 \\
6,698\end{array}$ & $\begin{array}{l}0 \\
0 \\
0\end{array}$ & $\begin{array}{l}7,012 \\
6,310 \\
8,354\end{array}$ & $\begin{array}{l}0 \\
0 \\
0\end{array}$ & $\begin{array}{l}977 \\
905 \\
993\end{array}$ & $\begin{array}{l}562 \\
518 \\
589\end{array}$ \\
\hline $\begin{array}{l}\text { Maine } \\
\text { Portland }\end{array}$ & 43,950 & 0 & 15,056 & 0 & 20,442 & 0 & 1,136 & 822 \\
\hline $\begin{array}{l}\text { Massachusetts } \\
\text { Falmouth }\end{array}$ & 37,355 & 0 & 11,154 & 0 & 15,251 & 0 & 946 & 616 \\
\hline $\begin{array}{l}\text { Michigan } \\
\text { Battle Creek } \\
\text { Detroit } \\
\text { Sault Ste Marie }\end{array}$ & $\begin{array}{l}44,951 \\
45,708 \\
50,869\end{array}$ & $\begin{array}{l}0 \\
0 \\
0\end{array}$ & $\begin{array}{l}12,560 \\
13,628 \\
24,922\end{array}$ & $\begin{array}{l}0 \\
0 \\
0\end{array}$ & $\begin{array}{l}18,447 \\
19,408 \\
30,706\end{array}$ & $\begin{array}{l}0 \\
0 \\
0\end{array}$ & $\begin{array}{l}1,127 \\
1,151 \\
1,333\end{array}$ & $\begin{array}{r}772 \\
806 \\
1,153\end{array}$ \\
\hline $\begin{array}{l}\text { Minnesota } \\
\text { Duluth } \\
\text { International Falls } \\
\text { Minneapolis }\end{array}$ & $\begin{array}{l}54,558 \\
56,775 \\
51,641\end{array}$ & $\begin{array}{l}0 \\
0 \\
0\end{array}$ & $\begin{array}{l}29,814 \\
33,226 \\
20,463\end{array}$ & $\begin{array}{l}0 \\
0 \\
0\end{array}$ & $\begin{array}{l}35,344 \\
38,423 \\
26,345\end{array}$ & $\begin{array}{l}0 \\
0 \\
0\end{array}$ & $\begin{array}{l}1,391 \\
1,415 \\
1,315\end{array}$ & $\begin{array}{l}1,346 \\
1,497 \\
1,081\end{array}$ \\
\hline $\begin{array}{l}\text { Mississippi } \\
\text { Biloxi } \\
\text { Columbus } \\
\text { Jackson }\end{array}$ & $\begin{array}{l}53,072 \\
49,276 \\
50,017\end{array}$ & $\begin{array}{l}0 \\
0 \\
0\end{array}$ & $\begin{array}{l}5,917 \\
6,936 \\
6,456\end{array}$ & $\begin{array}{l}0 \\
0 \\
0\end{array}$ & $\begin{array}{l}6,868 \\
9,005 \\
8,015\end{array}$ & $\begin{array}{l}0 \\
0 \\
0\end{array}$ & $\begin{array}{l}949 \\
984 \\
961\end{array}$ & $\begin{array}{l}547 \\
587 \\
568\end{array}$ \\
\hline $\begin{array}{l}\text { Missouri } \\
\text { Columbia } \\
\text { Kansas City } \\
\text { Springfield }\end{array}$ & $\begin{array}{l}48,615 \\
49,697 \\
47,967\end{array}$ & $\begin{array}{l}0 \\
0 \\
0\end{array}$ & $\begin{array}{r}10,178 \\
9,713 \\
9,625\end{array}$ & $\begin{array}{l}0 \\
0 \\
0\end{array}$ & $\begin{array}{l}14,410 \\
13,845 \\
13,665\end{array}$ & $\begin{array}{l}0 \\
0 \\
0\end{array}$ & $\begin{array}{l}1,096 \\
1,100 \\
1,068\end{array}$ & $\begin{array}{l}724 \\
725 \\
695\end{array}$ \\
\hline $\begin{array}{l}\text { Montana } \\
\text { Billings } \\
\text { Great Falls } \\
\text { Missoula }\end{array}$ & $\begin{array}{l}46,578 \\
48,942 \\
46,496\end{array}$ & $\begin{array}{l}0 \\
0 \\
0\end{array}$ & $\begin{array}{l}15,018 \\
19,437 \\
15,051\end{array}$ & $\begin{array}{l}0 \\
0 \\
0\end{array}$ & $\begin{array}{l}19,959 \\
24,062 \\
20,911\end{array}$ & $\begin{array}{l}0 \\
0 \\
0\end{array}$ & $\begin{array}{l}1,165 \\
1,227 \\
1,206\end{array}$ & $\begin{array}{r}849 \\
1,001 \\
861\end{array}$ \\
\hline $\begin{array}{l}\text { Nebraska } \\
\text { Grand Island } \\
\text { Lincoln } \\
\text { North Platte }\end{array}$ & $\begin{array}{l}50,678 \\
48,380 \\
49,002\end{array}$ & $\begin{array}{l}0 \\
0 \\
0\end{array}$ & $\begin{array}{l}14,730 \\
14,732 \\
14,721\end{array}$ & $\begin{array}{l}0 \\
0 \\
0\end{array}$ & $\begin{array}{l}20,348 \\
20,043 \\
20,721\end{array}$ & $\begin{array}{l}0 \\
0 \\
0\end{array}$ & $\begin{array}{l}1,233 \\
1,183 \\
1,220\end{array}$ & $\begin{array}{l}863 \\
840 \\
858\end{array}$ \\
\hline $\begin{array}{l}\text { Nevada } \\
\text { Ely } \\
\text { Las Vegas } \\
\text { Reno } \\
\text { Winnemucca }\end{array}$ & $\begin{array}{l}51,402 \\
62,071 \\
45,201 \\
49,551\end{array}$ & $\begin{array}{l}0 \\
0 \\
0 \\
0\end{array}$ & $\begin{array}{r}16,857 \\
8,683 \\
10,181 \\
12,224\end{array}$ & $\begin{array}{l}0 \\
0 \\
0 \\
0\end{array}$ & $\begin{array}{l}23,127 \\
10,066 \\
15,594 \\
17,569\end{array}$ & $\begin{array}{l}0 \\
0 \\
0 \\
0\end{array}$ & $\begin{array}{l}1,305 \\
1,254 \\
1,093 \\
1,197\end{array}$ & $\begin{array}{l}935 \\
797 \\
694 \\
787\end{array}$ \\
\hline $\begin{array}{l}\text { New Jersey } \\
\text { Trenton }\end{array}$ & 41,279 & 0 & 9,460 & 0 & 13,488 & 0 & 973 & 606 \\
\hline $\begin{array}{l}\text { New Mexico } \\
\text { Albuquerque } \\
\text { Farmington } \\
\text { Roswell }\end{array}$ & $\begin{array}{l}45,087 \\
48,114 \\
49,148\end{array}$ & $\begin{array}{l}0 \\
0 \\
0\end{array}$ & $\begin{array}{r}7,442 \\
10,183 \\
7,549\end{array}$ & $\begin{array}{l}0 \\
0 \\
0\end{array}$ & $\begin{array}{l}10,620 \\
14,939 \\
10,179\end{array}$ & $\begin{array}{l}0 \\
0 \\
0\end{array}$ & $\begin{array}{r}972 \\
1,097 \\
1,022\end{array}$ & $\begin{array}{l}581 \\
698 \\
635\end{array}$ \\
\hline $\begin{array}{l}\text { New York } \\
\text { Albany } \\
\text { Binghamton } \\
\text { Niagara Falls } \\
\text { Syracuse } \\
\text { Westhampton Beach }\end{array}$ & $\begin{array}{l}43,547 \\
44,680 \\
44,692 \\
43,986 \\
38,022\end{array}$ & $\begin{array}{l}0 \\
0 \\
0 \\
0 \\
0\end{array}$ & $\begin{array}{r}14,723 \\
17,531 \\
14,549 \\
14,268 \\
9,407\end{array}$ & $\begin{array}{l}0 \\
0 \\
0 \\
0 \\
0\end{array}$ & $\begin{array}{l}19,895 \\
22,776 \\
20,106 \\
19,450 \\
13,565\end{array}$ & $\begin{array}{l}0 \\
0 \\
0 \\
0 \\
0\end{array}$ & $\begin{array}{r}1,113 \\
1,155 \\
1,147 \\
1,115 \\
924\end{array}$ & $\begin{array}{l}807 \\
847 \\
796 \\
792 \\
584\end{array}$ \\
\hline
\end{tabular}




\begin{tabular}{|c|c|c|c|c|c|c|c|c|}
\hline \multirow[b]{2}{*}{ State and City } & \multicolumn{2}{|c|}{ Pulse Tube Heat Pump } & \multicolumn{2}{|c|}{$\begin{array}{l}\text { Magnetic Heat Pump } \\
\text { (1/4 HP Pump) }\end{array}$} & \multicolumn{2}{|c|}{$\begin{array}{c}\text { Compressor Driven Metal } \\
\text { Hydride HP }\end{array}$} & \multicolumn{2}{|c|}{$\begin{array}{c}\text { Diesel Engine Driven Heat } \\
\text { Pump }\end{array}$} \\
\hline & $(\mathrm{kWh} / \mathrm{y})$ & (therms/y) & $(\mathrm{kWh} / \mathrm{y})$ & (therms/y) & $(\mathrm{kWh} / \mathrm{y})$ & (therms/y) & $(\mathrm{kWh} / \mathrm{y})$ & (therms/y) \\
\hline $\begin{array}{l}\text { North Carolina } \\
\text { Greensboro } \\
\text { New Bern }\end{array}$ & $\begin{array}{l}42,002 \\
49,530\end{array}$ & $\begin{array}{l}0 \\
0\end{array}$ & $\begin{array}{l}6,957 \\
6,090\end{array}$ & $\begin{array}{l}0 \\
0\end{array}$ & $\begin{array}{l}9,730 \\
7,599\end{array}$ & $\begin{array}{l}0 \\
0\end{array}$ & $\begin{array}{l}894 \\
930\end{array}$ & $\begin{array}{l}545 \\
543\end{array}$ \\
\hline $\begin{array}{l}\text { North Dakota } \\
\text { Bismarck } \\
\text { Grand Forks } \\
\text { Williston }\end{array}$ & $\begin{array}{l}57,074 \\
59,997 \\
52,994\end{array}$ & $\begin{array}{l}0 \\
0 \\
0\end{array}$ & $\begin{array}{l}26,296 \\
31,339 \\
22,627\end{array}$ & $\begin{array}{l}0 \\
0 \\
0\end{array}$ & $\begin{array}{l}31,962 \\
37,081 \\
28,371\end{array}$ & $\begin{array}{l}0 \\
0 \\
0\end{array}$ & $\begin{array}{l}1,462 \\
1,545 \\
1,352\end{array}$ & $\begin{array}{l}1,328 \\
1,524 \\
1,178\end{array}$ \\
\hline $\begin{array}{l}\text { Ohio } \\
\text { Akron } \\
\text { Columbus } \\
\text { Dayton } \\
\text { Toledo }\end{array}$ & $\begin{array}{l}42,980 \\
42,717 \\
45,810 \\
46,430\end{array}$ & $\begin{array}{l}0 \\
0 \\
0 \\
0\end{array}$ & $\begin{array}{r}12,591 \\
9,400 \\
10,399 \\
13,835\end{array}$ & $\begin{array}{l}0 \\
0 \\
0 \\
0\end{array}$ & $\begin{array}{l}17,654 \\
13,784 \\
14,718 \\
19,402\end{array}$ & $\begin{array}{l}0 \\
0 \\
0 \\
0\end{array}$ & $\begin{array}{l}1,075 \\
1,008 \\
1,059 \\
1,159\end{array}$ & $\begin{array}{l}717 \\
634 \\
674 \\
797\end{array}$ \\
\hline $\begin{array}{l}\text { Oklahoma } \\
\text { Altus } \\
\text { Oklahoma City } \\
\text { Tulsa }\end{array}$ & $\begin{array}{l}52,402 \\
50,508 \\
51,188\end{array}$ & $\begin{array}{l}0 \\
0 \\
0\end{array}$ & $\begin{array}{l}8,135 \\
8,228 \\
8,246\end{array}$ & $\begin{array}{l}0 \\
0 \\
0\end{array}$ & $\begin{array}{l}10,911 \\
11,281 \\
11,238\end{array}$ & $\begin{array}{l}0 \\
0\end{array}$ & $\begin{array}{l}1,096 \\
1,059 \\
1,071\end{array}$ & $\begin{array}{l}687 \\
665 \\
673\end{array}$ \\
\hline $\begin{array}{l}\text { Oregon } \\
\text { Astoria } \\
\text { Medford } \\
\text { Portland }\end{array}$ & $\begin{array}{l}25,228 \\
40,244 \\
31,705\end{array}$ & $\begin{array}{l}0 \\
0 \\
0\end{array}$ & $\begin{array}{l}6,703 \\
7,173 \\
6,188\end{array}$ & $\begin{array}{l}0 \\
0 \\
0\end{array}$ & $\begin{array}{r}8,732 \\
10,370 \\
8,649\end{array}$ & $\begin{array}{l}0 \\
0 \\
0\end{array}$ & $\begin{array}{l}670 \\
929 \\
764\end{array}$ & $\begin{array}{l}354 \\
362 \\
453\end{array}$ \\
\hline $\begin{array}{l}\text { Pennsylvania } \\
\text { Philadelphia } \\
\text { Pittsburgh } \\
\text { Wilkes-Barre }\end{array}$ & $\begin{array}{l}39,607 \\
41,978 \\
41,041\end{array}$ & $\begin{array}{l}0 \\
0 \\
0\end{array}$ & $\begin{array}{r}8,956 \\
12,520 \\
11,787\end{array}$ & $\begin{array}{l}0 \\
0 \\
0\end{array}$ & $\begin{array}{l}12,981 \\
17,305 \\
16,647\end{array}$ & $\begin{array}{l}0 \\
0 \\
0\end{array}$ & $\begin{array}{r}935 \\
1,050 \\
1,029\end{array}$ & $\begin{array}{l}576 \\
717 \\
685\end{array}$ \\
\hline $\begin{array}{l}\text { South Carolina } \\
\text { Charleston } \\
\text { Greenville } \\
\text { Sumter }\end{array}$ & $\begin{array}{l}48,011 \\
40,891 \\
46,062\end{array}$ & $\begin{array}{l}0 \\
0\end{array}$ & $\begin{array}{l}5,902 \\
6,052 \\
5,931\end{array}$ & $\begin{array}{l}0 \\
0\end{array}$ & $\begin{array}{l}7,406 \\
8,102 \\
7,501\end{array}$ & $\begin{array}{l}0 \\
0\end{array}$ & $\begin{array}{l}902 \\
840 \\
885\end{array}$ & $\begin{array}{l}522 \\
505 \\
518\end{array}$ \\
\hline $\begin{array}{l}\text { South Dakota } \\
\text { Huron } \\
\text { Rapid City }\end{array}$ & $\begin{array}{l}55,840 \\
48,409\end{array}$ & $\begin{array}{l}0 \\
0\end{array}$ & $\begin{array}{l}21,622 \\
16,476\end{array}$ & $\begin{array}{l}0 \\
0\end{array}$ & $\begin{array}{l}27,979 \\
21,628\end{array}$ & $\begin{array}{l}0 \\
0\end{array}$ & $\begin{array}{l}1,419 \\
1,207\end{array}$ & $\begin{array}{c}1,180 \\
897\end{array}$ \\
\hline $\begin{array}{l}\text { Teennessee } \\
\text { Bristol } \\
\text { Knoxville } \\
\text { Memphis } \\
\text { Nashville }\end{array}$ & $\begin{array}{l}40,467 \\
40,919 \\
49,213 \\
45,457\end{array}$ & $\begin{array}{l}0 \\
0 \\
0 \\
0\end{array}$ & $\begin{array}{l}7,259 \\
6,742 \\
7,271 \\
7,832\end{array}$ & $\begin{array}{l}0 \\
0 \\
0 \\
0\end{array}$ & $\begin{array}{r}10,328 \\
9,337 \\
9,721 \\
10,897\end{array}$ & $\begin{array}{l}0 \\
0 \\
0 \\
0\end{array}$ & $\begin{array}{r}880 \\
862 \\
1,002 \\
969\end{array}$ & $\begin{array}{l}529 \\
507 \\
612 \\
607\end{array}$ \\
\hline $\begin{array}{l}\text { Texas } \\
\text { El Paso } \\
\text { Fort Worth } \\
\text { Houston } \\
\text { San Antonio }\end{array}$ & $\begin{array}{l}50,847 \\
57,009 \\
58,702 \\
60,432\end{array}$ & $\begin{array}{l}0 \\
0 \\
0 \\
0\end{array}$ & $\begin{array}{l}6,855 \\
7,548 \\
6,469 \\
6,797\end{array}$ & $\begin{array}{l}0 \\
0 \\
0 \\
0\end{array}$ & $\begin{array}{l}8,626 \\
9,234 \\
7,418 \\
7,591\end{array}$ & $\begin{array}{l}0 \\
0 \\
0 \\
0\end{array}$ & $\begin{array}{r}996 \\
1,109 \\
1,050 \\
1,094\end{array}$ & $\begin{array}{l}602 \\
670 \\
605 \\
641\end{array}$ \\
\hline $\begin{array}{l}\text { Utah } \\
\text { Salt Lake City }\end{array}$ & 44,362 & 0 & 10,230 & 0 & 15,207 & 0 & 1,070 & 681 \\
\hline $\begin{array}{l}\text { Vermont } \\
\text { Burlington }\end{array}$ & 47,855 & 0 & 19,748 & 0 & 25,391 & 0 & 1,243 & 1,001 \\
\hline $\begin{array}{l}\text { Virginia } \\
\text { Norfolk } \\
\text { Richmond } \\
\text { Roanoke }\end{array}$ & $\begin{array}{l}43,356 \\
42,424 \\
41,219\end{array}$ & $\begin{array}{l}0 \\
0 \\
0\end{array}$ & $\begin{array}{l}6,567 \\
6,746 \\
7,405\end{array}$ & $\begin{array}{l}0 \\
0 \\
0\end{array}$ & $\begin{array}{r}9,143 \\
9,455 \\
10,504\end{array}$ & $\begin{array}{l}0 \\
0 \\
0\end{array}$ & $\begin{array}{l}899 \\
898 \\
910\end{array}$ & $\begin{array}{l}541 \\
529 \\
544\end{array}$ \\
\hline
\end{tabular}




\begin{tabular}{|c|c|c|c|c|c|c|c|c|}
\hline \multirow[b]{2}{*}{ State and City } & \multicolumn{2}{|c|}{ Pulse Tube Heat Pump } & \multicolumn{2}{|c|}{$\begin{array}{l}\text { Magnetic Heat Pump } \\
\text { (1/4 HP Pump) }\end{array}$} & \multicolumn{2}{|c|}{$\begin{array}{c}\text { Compressor Driven Metal } \\
\text { Hydride HP }\end{array}$} & \multicolumn{2}{|c|}{$\begin{array}{l}\text { Diesel Engine Driven Hea } \\
\text { Pump }\end{array}$} \\
\hline & $(\mathrm{kWh} / \mathrm{y})$ & (therms/y) & $(\mathrm{kWh} / \mathrm{y})$ & (therms/y) & $(\mathrm{kWh} / \mathrm{y})$ & (therms/y) & $(\mathrm{kWh} / \mathrm{y})$ & (therms/y) \\
\hline $\begin{array}{l}\text { Washington } \\
\text { Moses Lake } \\
\text { Seattle } \\
\text { Spokane }\end{array}$ & $\begin{array}{l}44,743 \\
31,214 \\
43,946\end{array}$ & $\begin{array}{l}0 \\
0 \\
0\end{array}$ & $\begin{array}{r}9,664 \\
7,029 \\
11,513\end{array}$ & $\begin{array}{l}0 \\
0 \\
0\end{array}$ & $\begin{array}{r}14,421 \\
9,812 \\
17,075\end{array}$ & $\begin{array}{l}0 \\
0 \\
0\end{array}$ & $\begin{array}{r}1,067 \\
793 \\
1,115\end{array}$ & $\begin{array}{l}702 \\
471 \\
745\end{array}$ \\
\hline $\begin{array}{l}\text { West Virginia } \\
\text { Charleston } \\
\text { Elkins }\end{array}$ & $\begin{array}{l}41,811 \\
39,579\end{array}$ & $\begin{array}{l}0 \\
0\end{array}$ & $\begin{array}{r}8,017 \\
11,647\end{array}$ & $\begin{array}{l}0 \\
0\end{array}$ & $\begin{array}{l}11,494 \\
15,803\end{array}$ & $\begin{array}{l}0 \\
0\end{array}$ & $\begin{array}{l}932 \\
977\end{array}$ & $\begin{array}{l}568 \\
644\end{array}$ \\
\hline $\begin{array}{l}\text { Wisconsin } \\
\text { Green Bay } \\
\text { Madison }\end{array}$ & $\begin{array}{l}49,203 \\
48,704\end{array}$ & $\begin{array}{l}0 \\
0\end{array}$ & $\begin{array}{l}19,390 \\
17,552\end{array}$ & $\begin{array}{l}0 \\
0\end{array}$ & $\begin{array}{l}25,347 \\
23,137\end{array}$ & $\begin{array}{l}0 \\
0\end{array}$ & $\begin{array}{l}1,270 \\
1,230\end{array}$ & $\begin{array}{l}997 \\
933\end{array}$ \\
\hline $\begin{array}{l}\text { Wyoming } \\
\text { Casper } \\
\text { Cheyenne } \\
\text { Lander } \\
\text { Sheridan }\end{array}$ & $\begin{array}{l}48,951 \\
46,699 \\
46,636 \\
49,095\end{array}$ & $\begin{array}{l}0 \\
0 \\
0 \\
0\end{array}$ & $\begin{array}{l}15,739 \\
15,816 \\
15,671 \\
16,219\end{array}$ & $\begin{array}{l}0 \\
0 \\
0 \\
0\end{array}$ & $\begin{array}{l}21,824 \\
21,346 \\
21,870 \\
22,080\end{array}$ & $\begin{array}{l}0 \\
0 \\
0 \\
0\end{array}$ & $\begin{array}{l}1,249 \\
1,195 \\
1,190 \\
1,246\end{array}$ & $\begin{array}{l}904 \\
860 \\
897 \\
905\end{array}$ \\
\hline
\end{tabular}




\begin{tabular}{|c|c|c|c|c|c|c|c|c|}
\hline \multirow[b]{2}{*}{ State and City } & \multicolumn{2}{|c|}{$\begin{array}{l}\text { IC Engine-Driven Heat } \\
\text { Pump }\end{array}$} & \multicolumn{2}{|c|}{$\begin{array}{l}\text { Stirling Engine-Driven Heat } \\
\text { Pump }\end{array}$} & \multicolumn{2}{|c|}{$\begin{array}{l}\text { Brayton Engine Driven Heat } \\
\text { Pump }\end{array}$} & \multicolumn{2}{|c|}{$\begin{array}{c}\text { Rankine Engine Driven } \\
\text { Heat Pump }\end{array}$} \\
\hline & $(\mathrm{kWh} / \mathrm{y})$ & (therms/y) & $(\mathrm{kWh} / \mathrm{y})$ & (therms/y) & $(\mathrm{kWh} / \mathrm{y})$ & (therms/y) & $(\mathrm{kWh} / \mathrm{y})$ & (therms/y) \\
\hline $\begin{array}{l}\text { Alabama } \\
\text { Birmingham } \\
\text { Montgomery }\end{array}$ & $\begin{array}{l}965 \\
984\end{array}$ & $\begin{array}{l}625 \\
648\end{array}$ & $\begin{array}{l}917 \\
958\end{array}$ & $\begin{array}{l}665 \\
691\end{array}$ & $\begin{array}{l}917 \\
958\end{array}$ & $\begin{array}{l}688 \\
716\end{array}$ & $\begin{array}{l}917 \\
958\end{array}$ & $\begin{array}{l}760 \\
794\end{array}$ \\
\hline $\begin{array}{l}\text { Arizona } \\
\text { Phoenix } \\
\text { Tucson } \\
\text { Yuma }\end{array}$ & $\begin{array}{l}1,317 \\
1,104 \\
1,353\end{array}$ & $\begin{array}{r}960 \\
763 \\
1,006\end{array}$ & $\begin{array}{l}1,314 \\
1,099 \\
1,357\end{array}$ & $\begin{array}{r}1,026 \\
816 \\
1,076\end{array}$ & $\begin{array}{l}1,314 \\
1,099 \\
1,357\end{array}$ & $\begin{array}{r}1,063 \\
845 \\
1,115\end{array}$ & $\begin{array}{l}1,314 \\
1,099 \\
1,357\end{array}$ & $\begin{array}{r}1,190 \\
942 \\
1,251\end{array}$ \\
\hline $\begin{array}{l}\text { Arkansas } \\
\text { Little Rock }\end{array}$ & 1,032 & 678 & 981 & 723 & 981 & 747 & 981 & 826 \\
\hline $\begin{array}{l}\text { California } \\
\text { Arcata } \\
\text { Los Angeles } \\
\text { Merced } \\
\text { Oakland } \\
\text { San Diego }\end{array}$ & $\begin{array}{l}558 \\
497 \\
871 \\
495 \\
397\end{array}$ & $\begin{array}{l}342 \\
305 \\
568 \\
323 \\
260\end{array}$ & $\begin{array}{l}560 \\
513 \\
860 \\
518 \\
413 \\
\end{array}$ & $\begin{array}{l}359 \\
325 \\
605 \\
343 \\
277\end{array}$ & $\begin{array}{l}560 \\
513 \\
860 \\
518 \\
413\end{array}$ & $\begin{array}{l}370 \\
337 \\
626 \\
354 \\
287\end{array}$ & $\begin{array}{l}560 \\
513 \\
860 \\
518 \\
413\end{array}$ & $\begin{array}{l}400 \\
372 \\
693 \\
388 \\
317 \\
\end{array}$ \\
\hline $\begin{array}{l}\text { Colorado } \\
\text { Colorado Springs } \\
\text { Denver } \\
\text { Grand Junction }\end{array}$ & $\begin{array}{l}1,258 \\
1,232 \\
1,268\end{array}$ & $\begin{array}{l}845 \\
838 \\
776\end{array}$ & $\begin{array}{l}1,094 \\
1,074 \\
1,091\end{array}$ & $\begin{array}{l}872 \\
866 \\
812\end{array}$ & $\begin{array}{l}1,094 \\
1,074 \\
1,091\end{array}$ & $\begin{array}{l}894 \\
888 \\
836\end{array}$ & $\begin{array}{l}1,094 \\
1,074 \\
1,091\end{array}$ & $\begin{array}{l}964 \\
956 \\
912\end{array}$ \\
\hline $\begin{array}{l}\text { Florida } \\
\text { Appalachicola } \\
\text { Jacksonville } \\
\text { Miami } \\
\text { Orlando } \\
\text { Tampa }\end{array}$ & $\begin{array}{r}977 \\
976 \\
1,169 \\
971 \\
1,063\end{array}$ & $\begin{array}{l}640 \\
644 \\
766 \\
638 \\
702 \\
\end{array}$ & $\begin{array}{r}974 \\
970 \\
1,170 \\
973 \\
1,066\end{array}$ & $\begin{array}{l}686 \\
689 \\
822 \\
684 \\
753 \\
\end{array}$ & $\begin{array}{r}974 \\
970 \\
1,170 \\
973 \\
1,066\end{array}$ & $\begin{array}{l}711 \\
714 \\
854 \\
710 \\
782\end{array}$ & $\begin{array}{r}974 \\
970 \\
1,170 \\
973 \\
1,066\end{array}$ & $\begin{array}{l}792 \\
796 \\
954 \\
792 \\
873\end{array}$ \\
\hline $\begin{array}{l}\text { Georgia } \\
\text { Atlanta } \\
\text { Augusta } \\
\text { Macon }\end{array}$ & $\begin{array}{l}932 \\
981 \\
957\end{array}$ & $\begin{array}{l}597 \\
637 \\
628\end{array}$ & $\begin{array}{l}871 \\
941 \\
928\end{array}$ & $\begin{array}{l}634 \\
680 \\
670\end{array}$ & $\begin{array}{l}871 \\
941 \\
928\end{array}$ & $\begin{array}{l}654 \\
704 \\
694\end{array}$ & $\begin{array}{l}871 \\
941 \\
928\end{array}$ & $\begin{array}{l}719 \\
779 \\
769\end{array}$ \\
\hline $\begin{array}{l}\text { Idaho } \\
\text { Boise } \\
\text { Idaho Falls }\end{array}$ & $\begin{array}{l}1,229 \\
1,485\end{array}$ & $\begin{array}{r}752 \\
1,029\end{array}$ & $\begin{array}{l}1,061 \\
1,268\end{array}$ & $\begin{array}{r}790 \\
1,045\end{array}$ & $\begin{array}{l}1,061 \\
1,268\end{array}$ & $\begin{array}{r}813 \\
1,069\end{array}$ & $\begin{array}{l}1,061 \\
1,268\end{array}$ & $\begin{array}{r}885 \\
1,144\end{array}$ \\
\hline $\begin{array}{l}\text { Illinois } \\
\text { Champaigne-Urbana } \\
\text { Chicago } \\
\text { East St. Louis }\end{array}$ & $\begin{array}{l}1,386 \\
1,339 \\
1,254\end{array}$ & $\begin{array}{l}907 \\
886 \\
802\end{array}$ & $\begin{array}{l}1,173 \\
1,142 \\
1,087\end{array}$ & $\begin{array}{l}926 \\
910 \\
847\end{array}$ & $\begin{array}{l}1,173 \\
1,142 \\
1,087\end{array}$ & $\begin{array}{l}948 \\
932 \\
871\end{array}$ & $\begin{array}{l}1,173 \\
1,142 \\
1,087\end{array}$ & $\begin{array}{c}1,022 \\
1,002 \\
948\end{array}$ \\
\hline $\begin{array}{l}\text { Indiana } \\
\text { Fort Wayne } \\
\text { South Bend }\end{array}$ & $\begin{array}{l}1,298 \\
1,332\end{array}$ & $\begin{array}{l}826 \\
859\end{array}$ & $\begin{array}{l}1,107 \\
1,131\end{array}$ & $\begin{array}{l}854 \\
882\end{array}$ & $\begin{array}{l}1,107 \\
1,131\end{array}$ & $\begin{array}{l}876 \\
905\end{array}$ & $\begin{array}{l}1,107 \\
1,131\end{array}$ & $\begin{array}{l}948 \\
976\end{array}$ \\
\hline $\begin{array}{l}\text { Iowa } \\
\text { Des Moines } \\
\text { Sioux City }\end{array}$ & $\begin{array}{l}1,403 \\
1,539\end{array}$ & $\begin{array}{r}979 \\
1,052\end{array}$ & $\begin{array}{l}1,206 \\
1,283\end{array}$ & $\begin{array}{r}993 \\
1,058\end{array}$ & $\begin{array}{l}1,206 \\
1,283\end{array}$ & $\begin{array}{l}1,016 \\
1,082\end{array}$ & $\begin{array}{l}1,206 \\
1,283\end{array}$ & $\begin{array}{l}1,089 \\
1,159\end{array}$ \\
\hline $\begin{array}{l}\text { Kansas } \\
\text { Dodge City } \\
\text { Topeka }\end{array}$ & $\begin{array}{l}1,300 \\
1,340\end{array}$ & $\begin{array}{l}839 \\
849\end{array}$ & $\begin{array}{l}1,126 \\
1,142\end{array}$ & $\begin{array}{l}886 \\
865\end{array}$ & $\begin{array}{l}1,126 \\
1,142\end{array}$ & $\begin{array}{l}911 \\
889\end{array}$ & $\begin{array}{l}1,126 \\
1,142\end{array}$ & $\begin{array}{l}993 \\
966\end{array}$ \\
\hline $\begin{array}{l}\text { Kentucky } \\
\text { Louisville }\end{array}$ & 1,143 & 707 & 1,025 & 744 & 1,025 & 766 & 1,025 & 840 \\
\hline
\end{tabular}




\begin{tabular}{|c|c|c|c|c|c|c|c|c|}
\hline \multirow[b]{2}{*}{ State and City } & \multicolumn{2}{|c|}{$\begin{array}{l}\text { IC Engine-Driven Heat } \\
\text { Pump }\end{array}$} & \multicolumn{2}{|c|}{$\begin{array}{l}\text { Stirling Engine-Driven Heat } \\
\text { Pump }\end{array}$} & \multicolumn{2}{|c|}{$\begin{array}{l}\text { Brayton Engine Driven Heat } \\
\text { Pump }\end{array}$} & \multicolumn{2}{|c|}{$\begin{array}{l}\text { Rankine Engine Driven } \\
\text { Heat Pump }\end{array}$} \\
\hline & $(\mathrm{kWh} / \mathrm{y})$ & (therms/y) & $(\mathrm{kWh} / \mathrm{y})$ & (therms/y) & $(\mathrm{kWh} / \mathrm{y})$ & (therms/y) & $(\mathrm{kWh} / \mathrm{y})$ & (therms/y) \\
\hline $\begin{array}{l}\text { Louisiana } \\
\text { Lake Charles } \\
\text { New Orleans } \\
\text { Shreveport }\end{array}$ & $\begin{array}{r}985 \\
909 \\
1,030\end{array}$ & $\begin{array}{l}649 \\
599 \\
677\end{array}$ & $\begin{array}{l}977 \\
905 \\
993\end{array}$ & $\begin{array}{l}694 \\
641 \\
722\end{array}$ & $\begin{array}{l}977 \\
905 \\
993\end{array}$ & $\begin{array}{l}720 \\
665 \\
747\end{array}$ & $\begin{array}{l}977 \\
905 \\
993\end{array}$ & $\begin{array}{l}801 \\
740 \\
828\end{array}$ \\
\hline $\begin{array}{l}\text { Maine } \\
\text { Portland }\end{array}$ & 1,315 & 916 & 1,136 & 938 & 1,136 & 959 & 1,136 & 1,027 \\
\hline $\begin{array}{l}\text { Massachusetts } \\
\text { Falmouth }\end{array}$ & 1,060 & 703 & 946 & 719 & 946 & 738 & 946 & 798 \\
\hline $\begin{array}{l}\text { Michigan } \\
\text { Battle Creek } \\
\text { Detroit } \\
\text { Sault Ste Marie }\end{array}$ & $\begin{array}{l}1,352 \\
1,367 \\
1,490\end{array}$ & $\begin{array}{r}859 \\
897 \\
1,285\end{array}$ & $\begin{array}{l}1,127 \\
1,151 \\
1,333\end{array}$ & $\begin{array}{r}895 \\
929 \\
1,273\end{array}$ & $\begin{array}{l}1,127 \\
1,151 \\
1,333\end{array}$ & $\begin{array}{r}918 \\
952 \\
1,295\end{array}$ & $\begin{array}{l}1,127 \\
1,151 \\
1,333\end{array}$ & $\begin{array}{r}991 \\
1,024 \\
1,365\end{array}$ \\
\hline $\begin{array}{l}\text { Minnesota } \\
\text { Duluth } \\
\text { International Falls } \\
\text { Minneapolis }\end{array}$ & $\begin{array}{l}1,535 \\
1,553 \\
1,549\end{array}$ & $\begin{array}{l}1,479 \\
1,619 \\
1,176\end{array}$ & $\begin{array}{l}1,391 \\
1,415 \\
1,315\end{array}$ & $\begin{array}{l}1,462 \\
1,605 \\
1,203\end{array}$ & $\begin{array}{l}1,391 \\
1,415 \\
1,315\end{array}$ & $\begin{array}{l}1,483 \\
1,625 \\
1,225\end{array}$ & $\begin{array}{l}1,391 \\
1,415 \\
1,315\end{array}$ & $\begin{array}{l}1,551 \\
1,688 \\
1,297\end{array}$ \\
\hline $\begin{array}{l}\text { Mississippi } \\
\text { Biloxi } \\
\text { Columbus } \\
\text { Jackson }\end{array}$ & $\begin{array}{r}959 \\
1,036 \\
993\end{array}$ & $\begin{array}{l}632 \\
672 \\
652\end{array}$ & $\begin{array}{l}949 \\
984 \\
961\end{array}$ & $\begin{array}{l}676 \\
715 \\
696\end{array}$ & $\begin{array}{l}949 \\
984 \\
961\end{array}$ & $\begin{array}{l}700 \\
739 \\
720\end{array}$ & $\begin{array}{l}949 \\
984 \\
961\end{array}$ & $\begin{array}{l}779 \\
817 \\
798\end{array}$ \\
\hline $\begin{array}{l}\text { Missouri } \\
\text { Columbia } \\
\text { Kansas City } \\
\text { Springfield }\end{array}$ & $\begin{array}{l}1,254 \\
1,262 \\
1,213\end{array}$ & $\begin{array}{l}810 \\
812 \\
780\end{array}$ & $\begin{array}{l}1,096 \\
1,100 \\
1,068\end{array}$ & $\begin{array}{l}854 \\
859 \\
823 \\
\end{array}$ & $\begin{array}{l}1,096 \\
1,100 \\
1,068\end{array}$ & $\begin{array}{l}878 \\
884 \\
846\end{array}$ & $\begin{array}{l}1,096 \\
1,100 \\
1,068\end{array}$ & $\begin{array}{l}956 \\
965 \\
923\end{array}$ \\
\hline $\begin{array}{l}\text { Montana } \\
\text { Billings } \\
\text { Great Falls } \\
\text { Missoula }\end{array}$ & $\begin{array}{l}1,343 \\
1,362 \\
1,413\end{array}$ & $\begin{array}{r}947 \\
1,099 \\
954\end{array}$ & $\begin{array}{l}1,165 \\
1,227 \\
1,206\end{array}$ & $\begin{array}{r}966 \\
1,114 \\
986\end{array}$ & $\begin{array}{l}1,165 \\
1,227 \\
1,206\end{array}$ & $\begin{array}{r}987 \\
1,135 \\
1,009\end{array}$ & $\begin{array}{l}1,165 \\
1,227 \\
1,206\end{array}$ & $\begin{array}{l}1,056 \\
1,202 \\
1,083\end{array}$ \\
\hline $\begin{array}{l}\text { Nebraska } \\
\text { Grand Island } \\
\text { Lincoln } \\
\text { North Platte }\end{array}$ & $\begin{array}{l}1,471 \\
1,410 \\
1,478\end{array}$ & $\begin{array}{l}980 \\
955 \\
973\end{array}$ & $\begin{array}{l}1,233 \\
1,183 \\
1,220\end{array}$ & $\begin{array}{l}992 \\
961 \\
985\end{array}$ & $\begin{array}{l}1,233 \\
1,183 \\
1,220\end{array}$ & $\begin{array}{r}1,016 \\
983 \\
1,009\end{array}$ & $\begin{array}{l}1,233 \\
1,183 \\
1,220\end{array}$ & $\begin{array}{l}1,093 \\
1,054 \\
1,084\end{array}$ \\
\hline $\begin{array}{l}\text { Nevada } \\
\text { Ely } \\
\text { Las Vegas } \\
\text { Reno } \\
\text { Winnemucca }\end{array}$ & $\begin{array}{l}1,539 \\
1,283 \\
1,299 \\
1,403\end{array}$ & $\begin{array}{r}1,051 \\
920 \\
790 \\
894\end{array}$ & $\begin{array}{l}1,305 \\
1,254 \\
1,093 \\
1,197\end{array}$ & $\begin{array}{r}1,068 \\
982 \\
816 \\
921\end{array}$ & $\begin{array}{l}1,305 \\
1,254 \\
1,093 \\
1,197\end{array}$ & $\begin{array}{c}1,093 \\
1,016 \\
838 \\
945\end{array}$ & $\begin{array}{l}1,305 \\
1,254 \\
1,093 \\
1,197\end{array}$ & $\begin{array}{r}1,171 \\
1,133 \\
910 \\
1,025\end{array}$ \\
\hline $\begin{array}{l}\text { New Jersey } \\
\text { Trenton }\end{array}$ & 1,103 & 687 & 973 & 716 & 973 & 737 & 973 & 802 \\
\hline $\begin{array}{l}\text { New Mexico } \\
\text { Albuquerque } \\
\text { Farmington } \\
\text { Roswell }\end{array}$ & $\begin{array}{l}1,071 \\
1,281 \\
1,103\end{array}$ & $\begin{array}{l}659 \\
791 \\
723\end{array}$ & $\begin{array}{r}972 \\
1,097 \\
1,022\end{array}$ & $\begin{array}{l}698 \\
823 \\
769\end{array}$ & $\begin{array}{r}972 \\
1,097 \\
1,022\end{array}$ & $\begin{array}{l}721 \\
847 \\
794\end{array}$ & $\begin{array}{r}972 \\
1,097 \\
1,022\end{array}$ & $\begin{array}{l}791 \\
922 \\
876\end{array}$ \\
\hline $\begin{array}{l}\text { New York } \\
\text { Albany } \\
\text { Binghamton } \\
\text { Niagara Falls } \\
\text { Syracuse } \\
\text { Westhampton Beach }\end{array}$ & $\begin{array}{l}1,286 \\
1,302 \\
1,327 \\
1,288 \\
1,059\end{array}$ & $\begin{array}{l}901 \\
967 \\
899 \\
887 \\
658\end{array}$ & $\begin{array}{r}1,113 \\
1,155 \\
1,147 \\
1,115 \\
924\end{array}$ & $\begin{array}{l}922 \\
964 \\
917 \\
909 \\
684\end{array}$ & $\begin{array}{r}1,113 \\
1,155 \\
1,147 \\
1,115 \\
924\end{array}$ & $\begin{array}{l}943 \\
985 \\
940 \\
930 \\
703\end{array}$ & $\begin{array}{r}1,113 \\
1,155 \\
1,147 \\
1,115 \\
924\end{array}$ & $\begin{array}{r}1,011 \\
1,054 \\
1,011 \\
999 \\
762\end{array}$ \\
\hline
\end{tabular}




\begin{tabular}{|c|c|c|c|c|c|c|c|c|}
\hline \multirow[b]{2}{*}{ State and City } & \multicolumn{2}{|c|}{$\begin{array}{c}\text { IC Engine-Driven Heat } \\
\text { Pump }\end{array}$} & \multicolumn{2}{|c|}{$\begin{array}{l}\text { Stirling Engine-Driven Heat } \\
\text { Pump }\end{array}$} & \multicolumn{2}{|c|}{$\begin{array}{c}\text { Brayton Engine Driven Heat } \\
\text { Pump }\end{array}$} & \multicolumn{2}{|c|}{$\begin{array}{c}\text { Rankine Engine Driven } \\
\text { Heat Pump }\end{array}$} \\
\hline & $(\mathrm{kWh} / \mathrm{y})$ & (therms/y) & $(\mathrm{kWh} / \mathrm{y})$ & (therms/y) & $(\mathrm{kWh} / \mathrm{y})$ & (therms/y) & $(\mathrm{kWh} / \mathrm{y})$ & (therms/y) \\
\hline $\begin{array}{l}\text { North Carolina } \\
\text { Greensboro } \\
\text { New Bern }\end{array}$ & $\begin{array}{l}976 \\
956\end{array}$ & $\begin{array}{l}618 \\
623\end{array}$ & $\begin{array}{l}894 \\
930\end{array}$ & $\begin{array}{l}655 \\
664\end{array}$ & $\begin{array}{l}894 \\
930\end{array}$ & $\begin{array}{l}676 \\
688\end{array}$ & $\begin{array}{l}894 \\
930\end{array}$ & $\begin{array}{l}742 \\
761\end{array}$ \\
\hline $\begin{array}{l}\text { North Dakota } \\
\text { Bismarck } \\
\text { Grand Forks } \\
\text { Williston }\end{array}$ & $\begin{array}{l}1,689 \\
1,780 \\
1,594\end{array}$ & $\begin{array}{l}1,423 \\
1,616 \\
1,268\end{array}$ & $\begin{array}{l}1,462 \\
1,545 \\
1,352\end{array}$ & $\begin{array}{l}1,449 \\
1,638 \\
1,296\end{array}$ & $\begin{array}{l}1,462 \\
1,545 \\
1,352\end{array}$ & $\begin{array}{l}1,471 \\
1,659 \\
1,317\end{array}$ & $\begin{array}{l}1,462 \\
1,545 \\
1,352\end{array}$ & $\begin{array}{l}1,543 \\
1,726 \\
1,387\end{array}$ \\
\hline $\begin{array}{l}\text { Ohio } \\
\text { Akron } \\
\text { Columbus } \\
\text { Dayton } \\
\text { Toledo }\end{array}$ & $\begin{array}{l}1,246 \\
1,160 \\
1,209 \\
1,365\end{array}$ & $\begin{array}{l}811 \\
714 \\
764 \\
899\end{array}$ & $\begin{array}{l}1,075 \\
1,008 \\
1,059 \\
1,159\end{array}$ & $\begin{array}{l}832 \\
748 \\
793 \\
919\end{array}$ & $\begin{array}{l}1,075 \\
1,008 \\
1,059 \\
1,159\end{array}$ & $\begin{array}{l}854 \\
769 \\
816 \\
941\end{array}$ & $\begin{array}{l}1,075 \\
1,008 \\
1,059 \\
1,159\end{array}$ & $\begin{array}{r}922 \\
837 \\
887 \\
1,013\end{array}$ \\
\hline $\begin{array}{l}\text { Oklahoma } \\
\text { Altus } \\
\text { Oklahoma City } \\
\text { Tulsa }\end{array}$ & $\begin{array}{l}1,184 \\
1,161 \\
1,171\end{array}$ & $\begin{array}{l}782 \\
754 \\
763\end{array}$ & $\begin{array}{l}1,096 \\
1,059 \\
1,071\end{array}$ & $\begin{array}{l}832 \\
801 \\
811\end{array}$ & $\begin{array}{l}1,096 \\
1,059 \\
1,071\end{array}$ & $\begin{array}{l}859 \\
826 \\
837\end{array}$ & $\begin{array}{l}1,096 \\
1,059 \\
1,071\end{array}$ & $\begin{array}{l}949 \\
909 \\
922\end{array}$ \\
\hline $\begin{array}{l}\text { Oregon } \\
\text { Astoria } \\
\text { Medford } \\
\text { Portland }\end{array}$ & $\begin{array}{r}687 \\
1,012 \\
807\end{array}$ & $\begin{array}{l}402 \\
405 \\
509\end{array}$ & $\begin{array}{l}670 \\
929 \\
764\end{array}$ & $\begin{array}{l}416 \\
424 \\
538\end{array}$ & $\begin{array}{l}670 \\
929 \\
764\end{array}$ & $\begin{array}{l}428 \\
435 \\
554\end{array}$ & $\begin{array}{l}670 \\
929 \\
764\end{array}$ & $\begin{array}{l}464 \\
471 \\
604\end{array}$ \\
\hline $\begin{array}{l}\text { Pennsylvania } \\
\text { Philadelphia } \\
\text { Pittsburgh } \\
\text { Wilkes-Barre }\end{array}$ & $\begin{array}{l}1,069 \\
1,205 \\
1,196\end{array}$ & $\begin{array}{l}651 \\
807 \\
773\end{array}$ & $\begin{array}{r}935 \\
1,050 \\
1,029\end{array}$ & $\begin{array}{l}682 \\
830 \\
795\end{array}$ & $\begin{array}{r}935 \\
1,050 \\
1,029\end{array}$ & $\begin{array}{l}701 \\
851 \\
816\end{array}$ & $\begin{array}{r}935 \\
1,050 \\
1,029\end{array}$ & $\begin{array}{l}764 \\
918 \\
881\end{array}$ \\
\hline $\begin{array}{l}\text { South Carolina } \\
\text { Charleston } \\
\text { Greenville } \\
\text { Sumter }\end{array}$ & $\begin{array}{l}929 \\
890 \\
916\end{array}$ & $\begin{array}{l}599 \\
575 \\
594\end{array}$ & $\begin{array}{l}902 \\
840 \\
885\end{array}$ & $\begin{array}{l}639 \\
612 \\
634\end{array}$ & $\begin{array}{l}902 \\
840 \\
885\end{array}$ & $\begin{array}{l}662 \\
632 \\
656\end{array}$ & $\begin{array}{l}902 \\
840 \\
885\end{array}$ & $\begin{array}{l}733 \\
696 \\
726\end{array}$ \\
\hline $\begin{array}{l}\text { South Dakota } \\
\text { Huron } \\
\text { Rapid City }\end{array}$ & $\begin{array}{l}1,713 \\
1,405\end{array}$ & $\begin{array}{l}1,272 \\
1,007\end{array}$ & $\begin{array}{l}1,419 \\
1,207\end{array}$ & $\begin{array}{l}1,312 \\
1,015\end{array}$ & $\begin{array}{l}1,419 \\
1,207\end{array}$ & $\begin{array}{l}1,336 \\
1,037\end{array}$ & $\begin{array}{l}1,419 \\
1,207\end{array}$ & $\begin{array}{l}1,414 \\
1,107\end{array}$ \\
\hline $\begin{array}{l}\text { Teennessee } \\
\text { Bristol } \\
\text { Knoxville } \\
\text { Memphis } \\
\text { Nashville }\end{array}$ & $\begin{array}{r}976 \\
937 \\
1,072 \\
1,070\end{array}$ & $\begin{array}{l}600 \\
576 \\
697 \\
685\end{array}$ & $\begin{array}{r}880 \\
862 \\
1,002 \\
969\end{array}$ & $\begin{array}{l}632 \\
608 \\
742 \\
727\end{array}$ & $\begin{array}{r}880 \\
862 \\
1,002 \\
969\end{array}$ & $\begin{array}{l}651 \\
628 \\
766 \\
749\end{array}$ & $\begin{array}{r}880 \\
862 \\
1,002 \\
969\end{array}$ & $\begin{array}{l}712 \\
688 \\
845 \\
821\end{array}$ \\
\hline $\begin{array}{l}\text { Texas } \\
\text { El Paso } \\
\text { Fort Worth } \\
\text { Houston } \\
\text { San Antonio }\end{array}$ & $\begin{array}{l}1,038 \\
1,148 \\
1,058 \\
1,098\end{array}$ & $\begin{array}{l}689 \\
772 \\
700 \\
743\end{array}$ & $\begin{array}{r}996 \\
1,109 \\
1,050 \\
1,094\end{array}$ & $\begin{array}{l}735 \\
822 \\
749 \\
795\end{array}$ & $\begin{array}{r}996 \\
1,109 \\
1,050 \\
1,094\end{array}$ & $\begin{array}{l}760 \\
851 \\
776 \\
824\end{array}$ & $\begin{array}{r}996 \\
1,109 \\
1,050 \\
1,094\end{array}$ & $\begin{array}{l}842 \\
945 \\
864 \\
920\end{array}$ \\
\hline $\begin{array}{l}\text { Utah } \\
\text { Salt Lake City }\end{array}$ & 1,248 & 768 & 1,070 & 802 & 1,070 & 825 & 1,070 & 896 \\
\hline $\begin{array}{l}\text { Vermont } \\
\text { Burlington }\end{array}$ & 1,432 & 1,105 & 1,243 & 1,118 & 1,243 & 1,139 & 1,243 & 1,208 \\
\hline $\begin{array}{l}\text { Virginia } \\
\text { Norfolk } \\
\text { Richmond } \\
\text { Roanoke }\end{array}$ & $\begin{array}{r}969 \\
976 \\
1,003\end{array}$ & $\begin{array}{l}614 \\
600 \\
616\end{array}$ & $\begin{array}{l}899 \\
898 \\
910\end{array}$ & $\begin{array}{l}653 \\
637 \\
651\end{array}$ & $\begin{array}{l}899 \\
898 \\
910\end{array}$ & $\begin{array}{l}674 \\
657 \\
671\end{array}$ & $\begin{array}{l}899 \\
898 \\
910\end{array}$ & $\begin{array}{l}741 \\
722 \\
736\end{array}$ \\
\hline
\end{tabular}




\begin{tabular}{|l|c|c|c|c|c|c|c|c|}
\hline \multirow{2}{*}{ State and City } & \multicolumn{2}{|c|}{$\begin{array}{c}\text { IC Engine-Driven Heat } \\
\text { Pump }\end{array}$} & \multicolumn{2}{c|}{$\begin{array}{c}\text { Stirling Engine-Driven Heat } \\
\text { Pump }\end{array}$} & \multicolumn{2}{c|}{$\begin{array}{c}\text { Brayton Engine Driven Heat } \\
\text { Pump }\end{array}$} & \multicolumn{2}{c|}{$\begin{array}{c}\text { Rankine Engine Driven } \\
\text { Heat Pump }\end{array}$} \\
\cline { 2 - 9 } & $(\mathrm{kWh} / \mathrm{y})$ & (therms/y) & $(\mathrm{kWh} / \mathrm{y})$ & (therms/y) & $(\mathrm{kWh} / \mathrm{y})$ & (therms/y) & (kWh/y) & (therms/y) \\
\hline Washington & & & & & & & & \\
Moses Lake & 1,241 & 781 & 1,067 & 825 & 1,067 & 848 & 1,067 & 921 \\
Seattle & 847 & 529 & 793 & 557 & 793 & 574 & 793 & 624 \\
Spokane & 1,311 & 827 & 1,115 & 867 & 1,115 & 889 & 1,115 & 961 \\
\hline West Virginia & & & & & & & & \\
Charleston & 1,046 & 644 & 932 & 676 & 932 & 697 & 932 & 761 \\
Elkins & 1,099 & 732 & 977 & 749 & 977 & 768 & 977 & 830 \\
\hline Wisconsin & & & & & & & & \\
Green Bay & 1,473 & 1,105 & 1,270 & 1,120 & 1,270 & 1,143 & 1,270 & 1,215 \\
Madison & 1,422 & 1,037 & 1,230 & 1,057 & 1,230 & 1,080 & 1,230 & 1,153 \\
\hline Wyoming & & & & & & & & \\
Casper & 1,477 & 1,002 & 1,249 & 1,035 & 1,249 & 1,059 & 1,249 & 1,137 \\
Cheyenne & 1,378 & 961 & 1,195 & 984 & 1,195 & 1,007 & 1,195 & 1,079 \\
Lander & 1,444 & 983 & 1,190 & 1,017 & 1,190 & 1,039 & 1,190 & 1,109 \\
Sheridan & 1,472 & 1,017 & 1,246 & 1,030 & 1,246 & 1,054 & 1,246 & 1,128 \\
\hline
\end{tabular}




\begin{tabular}{|c|c|c|c|c|c|c|c|c|}
\hline \multirow[b]{2}{*}{ Stata and City } & \multicolumn{2}{|c|}{$\begin{array}{c}\text { Fuel Cell Powered Rankine } \\
\text { Heat Pump }\end{array}$} & \multicolumn{2}{|c|}{$\begin{array}{l}\text { Vuilleumier Cycle Heat } \\
\text { Pump }\end{array}$} & \multicolumn{2}{|c|}{$\begin{array}{l}\text { GAX Absorption Heat } \\
\text { Pump }\end{array}$} & \multicolumn{2}{|c|}{$\begin{array}{c}\text { Duplex Stirling Cycle Heat } \\
\text { Pump }\end{array}$} \\
\hline & $(\mathrm{kWh} / \mathrm{y})$ & (therms/y) & $(\mathrm{kWh} / \mathrm{y})$ & (therms/y) & $(\mathrm{kWh} / \mathrm{y})$ & (therms/y) & $(\mathrm{kWh} / \mathrm{y})$ & (therms/y) \\
\hline $\begin{array}{l}\text { Alabama } \\
\text { Birmingham } \\
\text { Montgomery } \\
\end{array}$ & $\begin{array}{l}0 \\
0\end{array}$ & $\begin{array}{l}527 \\
529\end{array}$ & $\begin{array}{l}1,670 \\
1,702 \\
\end{array}$ & $\begin{array}{l}932 \\
991 \\
\end{array}$ & $\begin{array}{l}757 \\
721 \\
\end{array}$ & $\begin{array}{l}890 \\
957\end{array}$ & $\begin{array}{l}1,618 \\
1,649\end{array}$ & $\begin{array}{l}719 \\
752\end{array}$ \\
\hline $\begin{array}{l}\text { Arizona } \\
\text { Phoenix } \\
\text { Tucson } \\
\text { Yuma }\end{array}$ & $\begin{array}{l}0 \\
0 \\
0\end{array}$ & $\begin{array}{l}731 \\
598 \\
752\end{array}$ & $\begin{array}{l}2,278 \\
1,909 \\
2,341\end{array}$ & $\begin{array}{l}1,390 \\
1,156 \\
1,450\end{array}$ & $\begin{array}{l}853 \\
752 \\
829\end{array}$ & $\begin{array}{l}1,352 \\
1,124 \\
1,417\end{array}$ & $\begin{array}{l}2,207 \\
1,849 \\
2,268\end{array}$ & $\begin{array}{l}975 \\
845 \\
999\end{array}$ \\
\hline $\begin{array}{l}\text { Arkansas } \\
\text { Little Rock }\end{array}$ & 0 & 576 & 1,786 & 996 & 813 & 951 & 1,730 & 763 \\
\hline $\begin{array}{l}\text { California } \\
\text { Arcata } \\
\text { Los Angeles } \\
\text { Merced } \\
\text { Oakland } \\
\text { San Diego } \\
\end{array}$ & $\begin{array}{l}0 \\
0 \\
0 \\
0 \\
0\end{array}$ & $\begin{array}{l}327 \\
242 \\
458 \\
298 \\
225\end{array}$ & $\begin{array}{r}965 \\
860 \\
1,506 \\
856 \\
687\end{array}$ & $\begin{array}{l}489 \\
507 \\
849 \\
512 \\
428 \\
\end{array}$ & $\begin{array}{l}714 \\
405 \\
706 \\
527 \\
334 \\
\end{array}$ & $\begin{array}{l}422 \\
487 \\
806 \\
470 \\
412 \\
\end{array}$ & $\begin{array}{r}935 \\
833 \\
1,459 \\
829 \\
665\end{array}$ & $\begin{array}{l}407 \\
408 \\
643 \\
418 \\
350 \\
\end{array}$ \\
\hline $\begin{array}{l}\text { Colorado } \\
\text { Colorado Springs } \\
\text { Denver } \\
\text { Grand Junction }\end{array}$ & $\begin{array}{l}0 \\
0 \\
0\end{array}$ & $\begin{array}{l}800 \\
795 \\
709\end{array}$ & $\begin{array}{l}2,176 \\
2,131 \\
2,194\end{array}$ & $\begin{array}{l}1,077 \\
1,065 \\
1,042\end{array}$ & $\begin{array}{l}1,237 \\
1,215 \\
1,122\end{array}$ & $\begin{array}{l}980 \\
971 \\
959\end{array}$ & $\begin{array}{l}2,108 \\
2,064 \\
2,125\end{array}$ & $\begin{array}{l}918 \\
906 \\
849\end{array}$ \\
\hline $\begin{array}{l}\text { Florida } \\
\text { Appalachicola } \\
\text { Jacksonville } \\
\text { Miami } \\
\text { Orlando } \\
\text { Tampa }\end{array}$ & $\begin{array}{l}0 \\
0 \\
0 \\
0 \\
0\end{array}$ & $\begin{array}{l}495 \\
497 \\
560 \\
482 \\
521\end{array}$ & $\begin{array}{l}1,691 \\
1,689 \\
2,023 \\
1,680 \\
1,839\end{array}$ & $\begin{array}{l}1,027 \\
1,020 \\
1,257 \\
1,035 \\
1,137\end{array}$ & $\begin{array}{l}634 \\
636 \\
646 \\
593 \\
624\end{array}$ & $\begin{array}{l}1,010 \\
1,001 \\
1,256 \\
1,024 \\
1,129\end{array}$ & $\begin{array}{l}1,638 \\
1,636 \\
1,959 \\
1,627 \\
1,782\end{array}$ & $\begin{array}{l}778 \\
767 \\
941 \\
780 \\
849\end{array}$ \\
\hline $\begin{array}{l}\text { Georgia } \\
\text { Atlanta } \\
\text { Augusta } \\
\text { Macon }\end{array}$ & $\begin{array}{l}0 \\
0 \\
0\end{array}$ & $\begin{array}{l}522 \\
528 \\
518\end{array}$ & $\begin{array}{l}1,613 \\
1,696 \\
1,654\end{array}$ & $\begin{array}{l}869 \\
960 \\
958\end{array}$ & $\begin{array}{l}787 \\
750 \\
713\end{array}$ & $\begin{array}{l}822 \\
921 \\
924\end{array}$ & $\begin{array}{l}1,562 \\
1,643 \\
1,603\end{array}$ & $\begin{array}{l}689 \\
734 \\
730\end{array}$ \\
\hline $\begin{array}{l}\text { Idaho } \\
\text { Boise } \\
\text { Idaho Falls } \\
\end{array}$ & $\begin{array}{l}0 \\
0\end{array}$ & $\begin{array}{l}709 \\
991\end{array}$ & $\begin{array}{l}2,126 \\
2,568\end{array}$ & $\begin{array}{l}1,001 \\
1,253\end{array}$ & $\begin{array}{l}1,168 \\
1,509\end{array}$ & $\begin{array}{r}912 \\
1,125\end{array}$ & $\begin{array}{l}2,060 \\
2,488\end{array}$ & $\begin{array}{r}825 \\
1,096\end{array}$ \\
\hline $\begin{array}{l}\text { Illinois } \\
\text { Champaigne-Urbana } \\
\text { Chicago } \\
\text { East St. Louis }\end{array}$ & $\begin{array}{l}0 \\
0 \\
0\end{array}$ & $\begin{array}{l}855 \\
846 \\
745\end{array}$ & $\begin{array}{l}2,397 \\
2,317 \\
2,170\end{array}$ & $\begin{array}{l}1,150 \\
1,108 \\
1,080\end{array}$ & $\begin{array}{l}1,297 \\
1,327 \\
1,098\end{array}$ & $\begin{array}{l}1,043 \\
1,000 \\
1,012\end{array}$ & $\begin{array}{l}2,322 \\
2,244 \\
2,102\end{array}$ & $\begin{array}{l}978 \\
951 \\
883\end{array}$ \\
\hline $\begin{array}{l}\text { Indiana } \\
\text { Fort Wayne } \\
\text { South Bend }\end{array}$ & $\begin{array}{l}0 \\
0\end{array}$ & $\begin{array}{l}776 \\
813\end{array}$ & $\begin{array}{l}2,244 \\
2,304\end{array}$ & $\begin{array}{l}1,061 \\
1,088\end{array}$ & $\begin{array}{l}1,240 \\
1,289\end{array}$ & $\begin{array}{l}962 \\
981\end{array}$ & $\begin{array}{l}2,174 \\
2,232\end{array}$ & $\begin{array}{l}895 \\
926\end{array}$ \\
\hline $\begin{array}{l}\text { Iowa } \\
\text { Des Moines } \\
\text { Sioux City }\end{array}$ & $\begin{array}{l}0 \\
0\end{array}$ & $\begin{array}{l}920 \\
997\end{array}$ & $\begin{array}{l}2,428 \\
2,661\end{array}$ & $\begin{array}{l}1,209 \\
1,291\end{array}$ & $\begin{array}{l}1,352 \\
1,428\end{array}$ & $\begin{array}{l}1,098 \\
1,167\end{array}$ & $\begin{array}{l}2,352 \\
2,578\end{array}$ & $\begin{array}{l}1,042 \\
1,111\end{array}$ \\
\hline $\begin{array}{l}\text { Kansas } \\
\text { Dodge City } \\
\text { Topeka }\end{array}$ & $\begin{array}{l}0 \\
0\end{array}$ & $\begin{array}{l}770 \\
776\end{array}$ & $\begin{array}{l}2,249 \\
2,318\end{array}$ & $\begin{array}{l}1,114 \\
1,116\end{array}$ & $\begin{array}{l}1,131 \\
1,173\end{array}$ & $\begin{array}{l}1,043 \\
1,014\end{array}$ & $\begin{array}{l}2,179 \\
2,246\end{array}$ & $\begin{array}{l}902 \\
920\end{array}$ \\
\hline $\begin{array}{l}\text { Kentucky } \\
\text { Louisville }\end{array}$ & 0 & 622 & 1,977 & 989 & 987 & 921 & 1,915 & 793 \\
\hline
\end{tabular}




\begin{tabular}{|c|c|c|c|c|c|c|c|c|}
\hline \multirow[b]{2}{*}{ Stata and City } & \multicolumn{2}{|c|}{$\begin{array}{c}\text { Fuel Cell Powered Rankine } \\
\text { Heat Pump }\end{array}$} & \multicolumn{2}{|c|}{$\begin{array}{l}\text { Vuilleumier Cycle Heat } \\
\text { Pump }\end{array}$} & \multicolumn{2}{|c|}{$\begin{array}{l}\text { GAX Absorption Heat } \\
\text { Pump }\end{array}$} & \multicolumn{2}{|c|}{$\begin{array}{c}\text { Duplex Stirling Cycle Heat } \\
\text { Pump }\end{array}$} \\
\hline & $(\mathrm{kWh} / \mathrm{y})$ & (therms/y) & $(\mathrm{kWh} / \mathrm{y})$ & (therms/y) & $(\mathrm{kWh} / \mathrm{y})$ & (therms/y) & $(\mathrm{kWh} / \mathrm{y})$ & (therms/y) \\
\hline $\begin{array}{l}\text { Louisiana } \\
\text { Lake Charles } \\
\text { New Orleans } \\
\text { Shreveport }\end{array}$ & $\begin{array}{l}0 \\
0 \\
0\end{array}$ & $\begin{array}{l}507 \\
467 \\
557\end{array}$ & $\begin{array}{l}1,703 \\
1,572 \\
1,782\end{array}$ & $\begin{array}{r}1,022 \\
953 \\
1,022\end{array}$ & $\begin{array}{l}667 \\
602 \\
768\end{array}$ & $\begin{array}{l}998 \\
934 \\
983\end{array}$ & $\begin{array}{l}1,650 \\
1,523 \\
1,726\end{array}$ & $\begin{array}{l}770 \\
719 \\
776\end{array}$ \\
\hline $\begin{array}{l}\text { Maine } \\
\text { Portland }\end{array}$ & 0 & 892 & 2,274 & 1,127 & 1,366 & 1,014 & 2,203 & 985 \\
\hline $\begin{array}{l}\text { Massachusetts } \\
\text { Falmouth }\end{array}$ & 0 & 673 & 1,834 & 909 & 1,120 & 807 & 1,777 & 779 \\
\hline $\begin{array}{l}\text { Michigan } \\
\text { Battle Creek } \\
\text { Detroit } \\
\text { Sault Ste Marie }\end{array}$ & $\begin{array}{l}0 \\
0 \\
0\end{array}$ & $\begin{array}{r}826 \\
865 \\
1,253\end{array}$ & $\begin{array}{l}2,339 \\
2,365 \\
2,577\end{array}$ & $\begin{array}{l}1,085 \\
1,123 \\
1,470\end{array}$ & $\begin{array}{l}1,302 \\
1,339 \\
1,667\end{array}$ & $\begin{array}{r}988 \\
1,021 \\
1,314\end{array}$ & $\begin{array}{l}2,266 \\
2,291 \\
2,496\end{array}$ & $\begin{array}{r}925 \\
965 \\
1,339\end{array}$ \\
\hline $\begin{array}{l}\text { Minnesota } \\
\text { Duluth } \\
\text { International Falls } \\
\text { Minneapolis }\end{array}$ & $\begin{array}{l}0 \\
0 \\
0\end{array}$ & $\begin{array}{l}1,446 \\
1,587 \\
1,139\end{array}$ & $\begin{array}{l}2,655 \\
2,686 \\
2,680\end{array}$ & $\begin{array}{l}1,655 \\
1,784 \\
1,387\end{array}$ & $\begin{array}{l}1,748 \\
1,777 \\
1,552\end{array}$ & $\begin{array}{l}1,500 \\
1,642 \\
1,282\end{array}$ & $\begin{array}{l}2,573 \\
2,602 \\
2,596\end{array}$ & $\begin{array}{l}1,529 \\
1,665 \\
1,233\end{array}$ \\
\hline $\begin{array}{l}\text { Mississippi } \\
\text { Biloxi } \\
\text { Columbus } \\
\text { Jackson }\end{array}$ & $\begin{array}{l}0 \\
0 \\
0\end{array}$ & $\begin{array}{l}495 \\
563 \\
538\end{array}$ & $\begin{array}{l}1,659 \\
1,792 \\
1,717\end{array}$ & $\begin{array}{l}994 \\
997 \\
989\end{array}$ & $\begin{array}{l}649 \\
811 \\
745\end{array}$ & $\begin{array}{l}972 \\
952 \\
951\end{array}$ & $\begin{array}{l}1,607 \\
1,736 \\
1,663\end{array}$ & $\begin{array}{l}750 \\
766 \\
752\end{array}$ \\
\hline $\begin{array}{l}\text { Missouri } \\
\text { Columbia } \\
\text { Kansas City } \\
\text { Springfield }\end{array}$ & $\begin{array}{l}0 \\
0 \\
0\end{array}$ & $\begin{array}{l}745 \\
744 \\
713\end{array}$ & $\begin{array}{l}2,169 \\
2,182 \\
2,098\end{array}$ & $\begin{array}{l}1,086 \\
1,099 \\
1,057\end{array}$ & $\begin{array}{l}1,104 \\
1,077 \\
1,064\end{array}$ & $\begin{array}{r}1,016 \\
1,033 \\
990\end{array}$ & $\begin{array}{l}2,102 \\
2,114 \\
2,033\end{array}$ & $\begin{array}{l}886 \\
885 \\
860\end{array}$ \\
\hline $\begin{array}{l}\text { Montana } \\
\text { Billings } \\
\text { Great Falls } \\
\text { Missoula }\end{array}$ & $\begin{array}{l}0 \\
0 \\
0\end{array}$ & $\begin{array}{r}904 \\
1,056 \\
928\end{array}$ & $\begin{array}{l}2,323 \\
2,355 \\
2,444\end{array}$ & $\begin{array}{l}1,172 \\
1,319 \\
1,183\end{array}$ & $\begin{array}{l}1,341 \\
1,455 \\
1,443\end{array}$ & $\begin{array}{l}1,064 \\
1,205 \\
1,071\end{array}$ & $\begin{array}{l}2,251 \\
2,281 \\
2,368\end{array}$ & $\begin{array}{l}1,012 \\
1,169 \\
1,024\end{array}$ \\
\hline $\begin{array}{l}\text { Nebraska } \\
\text { Grand Island } \\
\text { Lincoln } \\
\text { North Platte }\end{array}$ & $\begin{array}{l}0 \\
0 \\
0\end{array}$ & $\begin{array}{l}923 \\
904 \\
928\end{array}$ & $\begin{array}{l}2,544 \\
2,439 \\
2,557\end{array}$ & $\begin{array}{l}1,220 \\
1,180 \\
1,199\end{array}$ & $\begin{array}{l}1,360 \\
1,320 \\
1,381\end{array}$ & $\begin{array}{l}1,104 \\
1,064 \\
1,079\end{array}$ & $\begin{array}{l}2,465 \\
2,363 \\
2,477\end{array}$ & $\begin{array}{l}1,038 \\
1,013 \\
1,026\end{array}$ \\
\hline $\begin{array}{l}\text { Nevada } \\
\text { Ely } \\
\text { Las Vegas } \\
\text { Reno } \\
\text { Winnemucca }\end{array}$ & $\begin{array}{l}0 \\
0 \\
0 \\
0\end{array}$ & $\begin{array}{r}1,007 \\
730 \\
759 \\
835\end{array}$ & $\begin{array}{l}2,661 \\
2,219 \\
2,247 \\
2,427\end{array}$ & $\begin{array}{l}1,289 \\
1,306 \\
1,037 \\
1,156\end{array}$ & $\begin{array}{r}1,523 \\
904 \\
1,225 \\
1,301\end{array}$ & $\begin{array}{r}1,159 \\
1,258 \\
932 \\
1,048\end{array}$ & $\begin{array}{l}2,578 \\
2,149 \\
2,177 \\
2,351\end{array}$ & $\begin{array}{r}1,118 \\
932 \\
870 \\
960\end{array}$ \\
\hline $\begin{array}{l}\text { New Jersey } \\
\text { Trenton }\end{array}$ & 0 & 632 & 1,908 & 921 & 1,054 & 839 & 1,848 & 765 \\
\hline $\begin{array}{l}\text { New Mexico } \\
\text { Albuquerque } \\
\text { Farmington } \\
\text { Roswell }\end{array}$ & $\begin{array}{l}0 \\
0 \\
0\end{array}$ & $\begin{array}{l}576 \\
727 \\
623\end{array}$ & $\begin{array}{l}1,853 \\
2,215 \\
1,908\end{array}$ & $\begin{array}{r}935 \\
1,054 \\
1,031\end{array}$ & $\begin{array}{r}922 \\
1,137 \\
882\end{array}$ & $\begin{array}{l}874 \\
969 \\
981\end{array}$ & $\begin{array}{l}1,795 \\
2,146 \\
1,849\end{array}$ & $\begin{array}{l}742 \\
868 \\
794\end{array}$ \\
\hline $\begin{array}{l}\text { New York } \\
\text { Albany } \\
\text { Binghamton } \\
\text { Niagara Falls } \\
\text { Syracuse } \\
\text { Westhampton Beach }\end{array}$ & $\begin{array}{l}0 \\
0 \\
0 \\
0 \\
0\end{array}$ & $\begin{array}{l}867 \\
924 \\
862 \\
851 \\
624\end{array}$ & $\begin{array}{l}2,225 \\
2,252 \\
2,296 \\
2,227 \\
1,832\end{array}$ & $\begin{array}{r}1,109 \\
1,163 \\
1,118 \\
1,103 \\
870\end{array}$ & $\begin{array}{l}1,313 \\
1,401 \\
1,362 \\
1,307 \\
1,057\end{array}$ & $\begin{array}{r}1,002 \\
1,025 \\
999 \\
995 \\
784\end{array}$ & $\begin{array}{l}2,156 \\
2,181 \\
2,224 \\
2,158 \\
1,775\end{array}$ & $\begin{array}{r}963 \\
1,028 \\
968 \\
954 \\
737\end{array}$ \\
\hline
\end{tabular}




\begin{tabular}{|c|c|c|c|c|c|c|c|c|}
\hline \multirow[b]{2}{*}{ Stata and City } & \multicolumn{2}{|c|}{$\begin{array}{l}\text { Fuel Cell Powered Rankine } \\
\text { Heat Pump }\end{array}$} & \multicolumn{2}{|c|}{$\begin{array}{l}\text { Vuilleumier Cycle Heat } \\
\text { Pump }\end{array}$} & \multicolumn{2}{|c|}{$\begin{array}{l}\text { GAX Absorption Heat } \\
\text { Pump }\end{array}$} & \multicolumn{2}{|c|}{$\begin{array}{c}\text { Duplex Stirling Cycle Heat } \\
\text { Pump }\end{array}$} \\
\hline & $(\mathrm{kWh} / \mathrm{y})$ & (therms/y) & $(\mathrm{kWh} / \mathrm{y})$ & (therms/y) & $(\mathrm{kWh} / \mathrm{y})$ & (therms/y) & $(\mathrm{kWh} / \mathrm{y})$ & (therms/y) \\
\hline $\begin{array}{l}\text { North Carolina } \\
\text { Greensboro } \\
\text { New Bern }\end{array}$ & $\begin{array}{l}0 \\
0\end{array}$ & $\begin{array}{l}550 \\
519\end{array}$ & $\begin{array}{l}1,689 \\
1,654\end{array}$ & $\begin{array}{l}882 \\
956\end{array}$ & $\begin{array}{l}845 \\
726\end{array}$ & $\begin{array}{l}829 \\
921\end{array}$ & $\begin{array}{l}1,636 \\
1,602\end{array}$ & $\begin{array}{l}704 \\
740\end{array}$ \\
\hline $\begin{array}{l}\text { North Dakota } \\
\text { Bismarck } \\
\text { Grand Forks } \\
\text { Williston }\end{array}$ & $\begin{array}{l}0 \\
0 \\
0\end{array}$ & $\begin{array}{l}1,385 \\
1,585 \\
1,236\end{array}$ & $\begin{array}{l}2,921 \\
3,079 \\
2,758\end{array}$ & $\begin{array}{l}1,632 \\
1,805 \\
1,470\end{array}$ & $\begin{array}{l}1,745 \\
1,886 \\
1,605\end{array}$ & $\begin{array}{l}1,528 \\
1,701 \\
1,372\end{array}$ & $\begin{array}{l}2,830 \\
2,983 \\
2,672\end{array}$ & $\begin{array}{l}1,477 \\
1,667 \\
1,321\end{array}$ \\
\hline $\begin{array}{l}\text { Ohio } \\
\text { Akron } \\
\text { Columbus } \\
\text { Dayton } \\
\text { Toledo }\end{array}$ & $\begin{array}{l}0 \\
0 \\
0 \\
0\end{array}$ & $\begin{array}{l}765 \\
661 \\
697 \\
854\end{array}$ & $\begin{array}{l}2,155 \\
2,006 \\
2,091 \\
2,361\end{array}$ & $\begin{array}{r}1,028 \\
955 \\
1,017 \\
1,124\end{array}$ & $\begin{array}{l}1,244 \\
1,090 \\
1,117 \\
1,332\end{array}$ & $\begin{array}{r}923 \\
874 \\
932 \\
1,012\end{array}$ & $\begin{array}{l}2,088 \\
1,944 \\
2,025 \\
2,287\end{array}$ & $\begin{array}{l}879 \\
790 \\
843 \\
964\end{array}$ \\
\hline $\begin{array}{l}\text { Oklahoma } \\
\text { Altus } \\
\text { Oklahoma City } \\
\text { Tulsa }\end{array}$ & $\begin{array}{l}0 \\
0 \\
0\end{array}$ & $\begin{array}{l}668 \\
660 \\
664\end{array}$ & $\begin{array}{l}2,048 \\
2,009 \\
2,026\end{array}$ & $\begin{array}{l}1,107 \\
1,065 \\
1,079\end{array}$ & $\begin{array}{l}934 \\
944 \\
943\end{array}$ & $\begin{array}{l}1,054 \\
1,011 \\
1,025\end{array}$ & $\begin{array}{l}1,984 \\
1,946 \\
1,962\end{array}$ & $\begin{array}{l}844 \\
833 \\
839\end{array}$ \\
\hline $\begin{array}{l}\text { Oregon } \\
\text { Astoria } \\
\text { Medford } \\
\text { Portland }\end{array}$ & $\begin{array}{l}0 \\
0 \\
0\end{array}$ & $\begin{array}{l}380 \\
385 \\
494\end{array}$ & $\begin{array}{l}1,188 \\
1,750 \\
1,396\end{array}$ & $\begin{array}{l}558 \\
535 \\
730\end{array}$ & $\begin{array}{l}831 \\
974 \\
868\end{array}$ & $\begin{array}{l}480 \\
464 \\
659\end{array}$ & $\begin{array}{l}1,151 \\
1,696 \\
1,353\end{array}$ & $\begin{array}{l}469 \\
453 \\
602\end{array}$ \\
\hline $\begin{array}{l}\text { Pennsylvania } \\
\text { Philadelphia } \\
\text { Pittsburgh } \\
\text { Wilkes-Barre }\end{array}$ & $\begin{array}{l}0 \\
0 \\
0\end{array}$ & $\begin{array}{l}602 \\
770 \\
735\end{array}$ & $\begin{array}{l}1,849 \\
2,084 \\
2,069\end{array}$ & $\begin{array}{r}876 \\
1,025 \\
982\end{array}$ & $\begin{array}{l}1,027 \\
1,215 \\
1,192\end{array}$ & $\begin{array}{l}797 \\
925 \\
883\end{array}$ & $\begin{array}{l}1,791 \\
2,019 \\
2,005\end{array}$ & $\begin{array}{l}729 \\
878 \\
839\end{array}$ \\
\hline $\begin{array}{l}\text { South Carolina } \\
\text { Charleston } \\
\text { Greenville } \\
\text { Sumter }\end{array}$ & $\begin{array}{l}0 \\
0\end{array}$ & $\begin{array}{l}494 \\
503 \\
496\end{array}$ & $\begin{array}{l}1,608 \\
1,540 \\
1,585\end{array}$ & $\begin{array}{l}925 \\
842 \\
905\end{array}$ & $\begin{array}{l}703 \\
746 \\
707\end{array}$ & $\begin{array}{l}892 \\
798 \\
869\end{array}$ & $\begin{array}{l}1,557 \\
1,492 \\
1,535\end{array}$ & $\begin{array}{l}715 \\
660 \\
698\end{array}$ \\
\hline $\begin{array}{l}\text { South Dakota } \\
\text { Huron } \\
\text { Rapid City }\end{array}$ & $\begin{array}{l}0 \\
0\end{array}$ & $\begin{array}{c}1,234 \\
958\end{array}$ & $\begin{array}{l}2,962 \\
2,431\end{array}$ & $\begin{array}{l}1,498 \\
1,227\end{array}$ & $\begin{array}{l}1,648 \\
1,382\end{array}$ & $\begin{array}{l}1,401 \\
1,110\end{array}$ & $\begin{array}{l}2,870 \\
2,355\end{array}$ & $\begin{array}{l}1,323 \\
1,067\end{array}$ \\
\hline $\begin{array}{l}\text { Teennessee } \\
\text { Bristol } \\
\text { Knoxville } \\
\text { Memphis } \\
\text { Nashville }\end{array}$ & $\begin{array}{l}0 \\
0 \\
0 \\
0\end{array}$ & $\begin{array}{l}533 \\
503 \\
602 \\
613\end{array}$ & $\begin{array}{l}1,688 \\
1,621 \\
1,855 \\
1,850\end{array}$ & $\begin{array}{r}843 \\
830 \\
1,013 \\
965\end{array}$ & $\begin{array}{l}870 \\
824 \\
862 \\
911\end{array}$ & $\begin{array}{l}783 \\
774 \\
964 \\
910\end{array}$ & $\begin{array}{l}1,635 \\
1,570 \\
1,797 \\
1,792\end{array}$ & $\begin{array}{l}684 \\
667 \\
787 \\
770\end{array}$ \\
\hline $\begin{array}{l}\text { Texas } \\
\text { El Paso } \\
\text { Fort Worth } \\
\text { Houston } \\
\text { San Antonio }\end{array}$ & $\begin{array}{l}0 \\
0 \\
0 \\
0\end{array}$ & $\begin{array}{l}575 \\
629 \\
538 \\
562\end{array}$ & $\begin{array}{l}1,795 \\
1,987 \\
1,831 \\
1,900\end{array}$ & $\begin{array}{l}1,022 \\
1,148 \\
1,099 \\
1,149\end{array}$ & $\begin{array}{l}788 \\
838 \\
696 \\
702\end{array}$ & $\begin{array}{r}982 \\
1,105 \\
1,077 \\
1,127\end{array}$ & $\begin{array}{l}1,739 \\
1,924 \\
1,774 \\
1,841\end{array}$ & $\begin{array}{l}776 \\
856 \\
822 \\
843\end{array}$ \\
\hline $\begin{array}{l}\text { Utah } \\
\text { Salt Lake City }\end{array}$ & 0 & 719 & 2,158 & 1,012 & 1,179 & 920 & 2,091 & 840 \\
\hline $\begin{array}{l}\text { Vermont } \\
\text { Burlington }\end{array}$ & 0 & 1,076 & 2,477 & 1,302 & 1,510 & 1,180 & 2,400 & 1,163 \\
\hline $\begin{array}{l}\text { Virginia } \\
\text { Norfolk } \\
\text { Richmond } \\
\text { Roanoke }\end{array}$ & $\begin{array}{l}0 \\
0 \\
0\end{array}$ & $\begin{array}{l}548 \\
522 \\
547\end{array}$ & $\begin{array}{l}1,676 \\
1,689 \\
1,735\end{array}$ & $\begin{array}{l}894 \\
865 \\
869\end{array}$ & $\begin{array}{l}833 \\
844 \\
906\end{array}$ & $\begin{array}{l}843 \\
810 \\
805\end{array}$ & $\begin{array}{l}1,624 \\
1,636 \\
1,681\end{array}$ & $\begin{array}{l}712 \\
687 \\
700\end{array}$ \\
\hline
\end{tabular}




\begin{tabular}{|l|c|c|c|c|c|c|c|c|}
\hline & \multicolumn{2}{|c|}{$\begin{array}{c}\text { Fuel Cell Powered Rankine } \\
\text { Heat Pump }\end{array}$} & \multicolumn{2}{c|}{$\begin{array}{c}\text { Vuilleumier Cycle Heat } \\
\text { Pump }\end{array}$} & \multicolumn{2}{c|}{$\begin{array}{c}\text { GAX Absorption Heat } \\
\text { Pump }\end{array}$} & \multicolumn{2}{c|}{$\begin{array}{c}\text { Duplex Stirling Cycle Heat } \\
\text { Pump }\end{array}$} \\
\cline { 2 - 9 } Stata and City & $(\mathrm{kWh} / \mathrm{y})$ & (therms/y) & $(\mathrm{kWh} / \mathrm{y})$ & (therms/y) & $(\mathrm{kWh} / \mathrm{y})$ & (therms/y) & (kWh/y) & (therms/y) \\
\hline Washington & & & & & & & & \\
Moses Lake & 0 & 748 & 2,147 & 1,040 & 1,161 & 959 & 2,080 & 859 \\
Seattle & 0 & 514 & 1,464 & 743 & 943 & 663 & 1,419 & 618 \\
Spokane & 0 & 805 & 2,267 & 1,066 & 1,308 & 967 & 2,197 & 906 \\
\hline West Virginia & & & & & & & & \\
Charleston & 0 & 578 & 1,809 & 891 & 943 & 823 & 1,752 & 725 \\
Elkins & 0 & 685 & 1,901 & 941 & 1,122 & 843 & 1,842 & 804 \\
\hline Wisconsin & & & & & & & & \\
Green Bay & 0 & 1,072 & 2,548 & 1,312 & 1,529 & 1,188 & 2,468 & 1,165 \\
Madison & 0 & 993 & 2,460 & 1,257 & 1,440 & 1,143 & 2,383 & 1,099 \\
\hline Wyoming & & & & & & & & \\
Casper & 0 & 964 & 2,555 & 1,236 & 1,456 & 1,126 & 2,475 & 1,063 \\
Cheyenne & 0 & 926 & 2,384 & 1,188 & 1,418 & 1,071 & 2,309 & 1,032 \\
Lander & 0 & 960 & 2,498 & 1,191 & 1,407 & 1,092 & 2,420 & 1,043 \\
Sheridan & 0 & 972 & 2,546 & 1,241 & 1,447 & 1,118 & 2,466 & 1,075 \\
\hline
\end{tabular}




\section{Internal Distribution}

1. V. D. Baxter

2. J. E. Christian

3. G. E. Courville

4. T. R. Curlee

5. R. C. DeVault

6. P. D. Fairchild

7-56. S. K. Fischer

57. P. W. Garland

58-67. S. D. Labinov

68. V. C. Mei

69. C. I. Moser
70. R. W. Murphy

71. C. K. Rice

72. J. R. Sand

73. R. B. Shelton

74. J. A. Shonder

75. J. J. Tomlinson

76. A. Zaltash

77. Central Research Library

78. Document Reference Section

79. Laboratory Records

80. Laboratory Records - RC

\section{External Distribution}

81. Dr. Lilia A. Abron, President Peer Consults P.C., 1460 Gulf Boulevard Apt. 1103, Clearwater, FL 33767

82. Karim Amrane, Air Conditioning and Refrigeration Technology Institute, 4301 N. Fairfax Drive, Suite 425, Arlington, VA 22203

83. Roland Ares, Ares Corporation, 1000 Wedgewood Drive, St. Charles, MO 63303

84. Dr. Douglas Bauer, Executive Director, Commission on Engineering and Technical Systems, National Research Council, Harris 280, 2001 Wisconsin Avenue NW, Washington, DC 20007

85. Don Bennett, Director of Engineering \& Development, Outokumpu Copper Franklin, Inc., 4720 Bowling Green Road, P.O. Box 539, Franklin, KY 42135-0539

86. Don Bivens, E.I. du Pont de Nemours \& Co., Fluorochemicals Laboratory, Chestnut Run Plaza, Building 711, Room 2106, Wilmington, DL 19880-0711

87. Mort Blatt, Electric Power Research Institute, P.O. Box 10412, Palo Alto, CA 94303

88. Jim Braun, 1077 Herrick Laboratories, Purdue University, West Lafayette, IN 47907-1077

89. Clark Bullard, 124 Mechanical Engineering Building, University of Illinois, MC 244, 1206 West Green, Urbana, IL 61801

90. Charles Bullock, Carrier Corporation, Carrier Parkway, P.O. Box 4808, Syracuse, NY 13221

91. Lee Burgett, Vice President, The Trane Company, Commercial Systems Group, 3600 Pammel Creek Road, LaCrosse, WI 54601-7599

92. Jean-Luc Caillat, Vice President, Research, Copeland Corporation, 1675 West Campbell Road, Sidney, OH 45365-0669

93. Richard Cawley, Manager Unitary Technology, The Trane Company, 6200 Troup Highway, P.O. Box 9010, Tyler, TX 75711

94. James Connell, Thermo-Technology Ventures, 85 First Avenue, Waltham, MA 03154

95. James Cowie, Manager Technical Programs, CDA, 260 Madison Avenue, New York, NY 
10016

96. Titu Doctor, Crispaire, E-Tech Appl. Prod., 3285 Saturn Court, Norcross, GA 30092

97. Piotr Domanski, Group Leader Thermal Machinery Group, NIST, Building Environment Division, Building 226, Room B114, Gaithersburg, MD 20899

98. Don Erickson, President Energy Concepts Company, 627 Ridgely Avenue, Annapolis, MD 21401

99. Ron Fiskum, CE-422, 5H-048/FORS, U.S. Department of Energy, Washington, DC 20585

100. Fuel Cell Institute, P.O. Box 65481, Washington, DC 20035-5481

101. Steve Garrett, Graduate Program in Acoustics, Applied Research Laboratory, The Pennsylvania State University, P.O. Box 30, State College, PA 16804-0030

102. Paul Glamm, Engineering Manager, The Trane Company, 3600 Pammel Creek Road, Lacrosse, WI 54601-7599

103. Ken Hickman, Vice President Applied Systems Engineering, York International Corporation, 631 South Richland Avenue, P.O. Box 1592, Mail Code 191A, York, PA 17405-1592

104. Dr. Stephen G. Hildebrand, Director, Environmental Sciences Division, Oak Ridge National Laboratory, P.O. Box 2008, Oak Ridge, TN 37831-6037

105. Glen Hourahan, Air Conditioning and Refrigeration Institute, 4301 N. Fairfax Drive, Suite 425, Arlington, VA 22203

106. Michael Hughes, 195 Schultz Road, West Seneca, NY 14224

107. John Judge, Advanced Systems Engineering, York International Corporation, Heat Transfer Group, 631 South Richland Avenue, P.O. Box 1592, Mail Code 191A, York, PA 17405

108. Kwang Kim, Artificial Muscles Institute \& Mechanical Engineering Department, University of New Mexico, Albuquerque, NM 87131

109-113. Esher Kweller, U.S. Department of Energy, CE-422, 5H048/FORS, 1000 Independence Avenue, S.W., Washington, DC 20585,

114. Jim Miller, Argonne National Laboratory, Building 205, 9700 Cass Avenue, Argonne, IL 60439-4837

115. Gary Nowakowski, Gas Research Institute, 8600 West Bryn Mawr Avenue, Chicago, IL 60631

116. Darin Nutter, University of Arkansas, Mechanical Engineering Department, Fayetteville, AR 72701

117. Reinhard Radermacher, A.J. Clark School of Engineering, University of Maryland, 3137 Engineering Classroom Building, College Park, MD 20742-3035

118. Wayne Reedy, Carrier Corporation, Carrier Parkway TR4, Syracuse, NY 13221-4808

119. Edward Reid, American Gas Cooling Center, 1515 Wilson Boulevard, Arlington, VA 22209

120. Mr. P. Richard Rittelmann, FAIA Executive Vice President, Burt Hill Kosar Rittelmann Associates, 400 Morgan Center, Butler, PA 16001-5977

121. Robert Rose, Fuel Cells 2000, 1625 K Street NW, Suite 790, Washington, DC 20006

122. John Ryan, U.S. Department of Energy, CE-422, 5H048/FORS, 1000 Independence Avenue, S.W., Washington, DC 20585,

123. William Ryan, Gas Research Institute, 8600 West Bryn Mawr Avenue, Chicago, IL 60631

124. Sam Shelton, Thermax, Inc., 290 14th Street NW, Atlanta, GA 30318

125. Richard Sweetser, Exergy Parners Corporation, 12020 Meadowville Court, Herndon, VA 
20170

126. Greg Swift, Condensed Matter and Thermal Physics Group, Mail Stop K764, Los Alamos National Laboratory, Los Alamos, NM 87545

127. Dr. Susan F. Tierney, The Economic Resource Group, Inc., One Mifflin Place, Cambridge, MA 02138

128. Dr. C. Michael Walton, Ernest H. Cockrell Centennial Chair in Engineering, Department of Civil Engineering, University of Texas at Austin, Austin, TX 78712-1076

129. C. Wu, Department of Mechanical Engineering, U.S. Naval Academy, Annapolis, MD

130. Ed Wuesthoff, Americold, 2340 2nd Avenue NW, Cullman, AL 35058

131. Carl Zimm, Astronautics Corporation, Astronautics Technology Center, 5800 Cottage Grove Road, Madison, WI 53716-1387

132. OSTI, U.S. DOE, Oak Ridge, TN 37830 